\title{
Reconstructing Ecological Change, Catchment \\ Disturbance, and Anthropogenic Impact over the last 3000 years at Lake Pounui, Wairarapa, New Zealand
}

\section{Leise Rebekah Cochrane}

\author{
A thesis submitted to \\ Victoria University of Wellington in partial fulfilment of requirements \\ for the degree of Master of Physical Geography
}

School of Geography, Environment, and Earth Sciences

Victoria University of Wellington 



\section{Abstract}

Increased eutrophication of freshwater lakes has been attributed to an intensification in agriculture, with global warming projected to further compound the problem. Determining pre-human conditions of a lake has major conservation implications for water quality management, such as setting evidence-based restoration targets. New Zealand's historical monitoring records of lake water quality are short and typically only begin after the onset of deterioration. Paleolimnology offers a complementary means of evaluating historical trends that predate human impact. This thesis investigates the declining water quality of Lake Pounui. Lake Pounui possesses high ecological integrity, though the lake is experiencing an increased frequency of severe algal blooms. The primary aim of this thesis is to reconstruct the past environment of Lake Pounui using paleolimnological methods to extend the historical monitoring data beyond human arrival. The reconstruction is used to address whether algal blooms are a natural feature of the lake, and examine anthropogenic impact. This study then attempts to identify reference conditions and critical transitions within the lake environment. Using this information possible targets for lake health restoration are discussed.

Based on elevated charcoal influx, palynological evidence, and catchment disturbance indicators, such as organic content (Loss-on-Ignition (LOI)), grain size, and micro-Xray fluorescence ( $\mu$-XRF), Māori land clearance was identified at $\sim 450-350$ calendar years before present (cal yr BP) (95\% confidence interval (CI): 515.2-202.3 cal yr BP). The appearance of Pinus pollen and the diatom Asterionella formosa placed European arrival at $\sim 150$ cal yr BP (95\% CI: 243-39 cal yr BP). Pre- and post-human environments of Lake Pounui were characterised using diatom analysis, bacterial DNA analysis, and supporting evidence from $\mu$-XRF data. It appears that the lake existed in both a higher nutrient (3000-2100 cal yr BP, 95\% CI: 3210-1977 cal yr BP) and lower nutrient (1600-450 cal yr BP, 95\% CI: 1737- 389 cal yr BP) state, separated by a period of natural disturbance, which could relate to a combination of earthquakes and increased storminess. During Māori occupation (450-150 cal yr BP, 95\% CI: 515-57 cal yr BP) the quality of the lake remained relatively high; however from $150 \mathrm{cal}$ yr BP, the lake appears to become more nutrient enriched, and the cyanobacteria responsible for today's blooms (Dolichospermum and Phormidium) become abundant. Paleolimnological analysis identified that the decline in water quality seen at Lake Pounui is a trend that has occurred over the last 200 years. Dissimilarity and critical transition analysis support this finding and suggest that rapid decline began just prior to $1950 \mathrm{AD}$. Based 
on dissimilarity analysis, the period of Māori occupation provides the most realistic restoration target. Planting native vegetation, ceasing stock grazing, and removing perch should be investigated to control the phytoplankton biomass, at the owner's discretion. 


\section{Acknowledgements}

First and foremost, I would like to thank my supervisor, Andrew Rees - thank you for your guidance, your statistical prowess, and always remaining in contact no matter how many commitments you were juggling. Secondly, I would like to acknowledge and thank Margaret Harper - thank you for sharing your diatom expertise, for triple checking all my identifications, and always being willing to lend a hand. I would also like to acknowledge the numerous contributors to this work, in particular Marcus Vandergoes who played a huge role in putting this project together, collecting the cores and the modern data, carrying out pollen analysis, and putting me in touch with other experts. Thank you to Susie Wood who carried out the bacterial DNA analysis, Xun Li who carried out the pollen analysis, Brent Alloway who carried out the tephra analysis, Ainslee Brown and Sky Halford who helped with the charcoal and organic content, and Ursula Cochran for providing a second opinion on my diatom identifications. Lastly, I'd like to thank my family (Peggy, Todd, Anthea, Alex, and Max) for their support and encouragement. Thank you everyone - this would not have been possible without you. 


\section{Table of Contents}

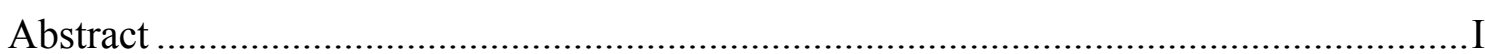

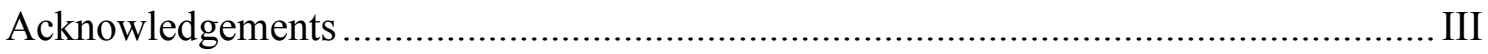

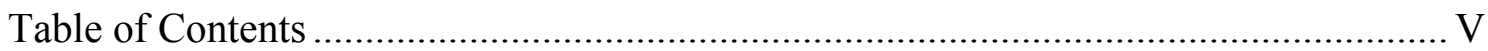

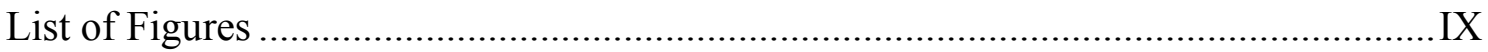

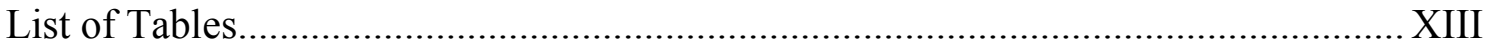

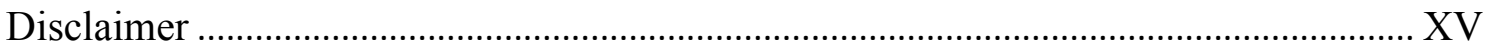

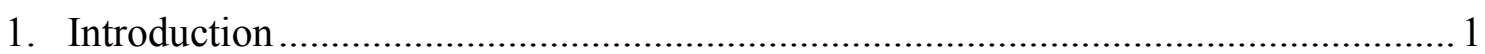

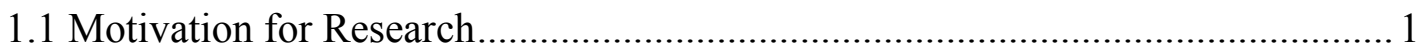

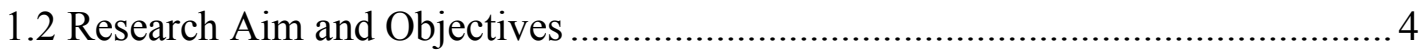

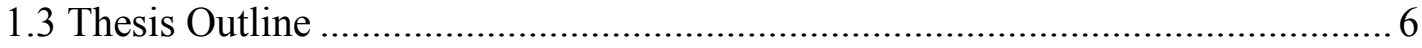

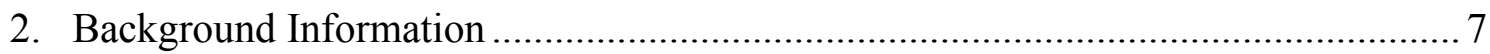

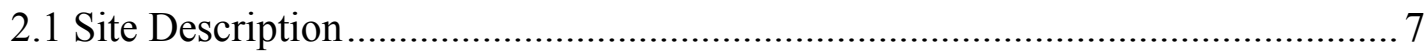

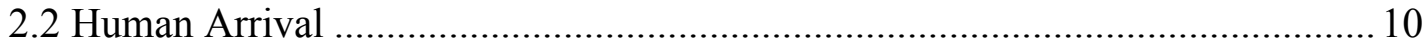

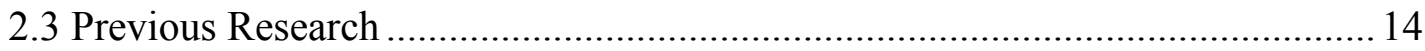

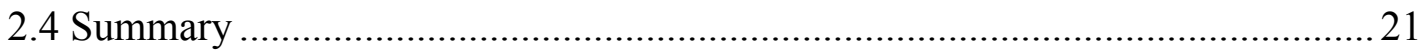

3. Are Algal Blooms a Natural Feature of Lake Pounui? .......................................... 23

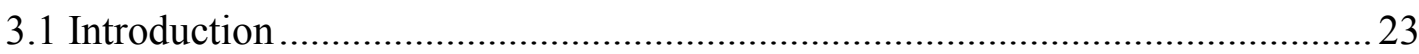

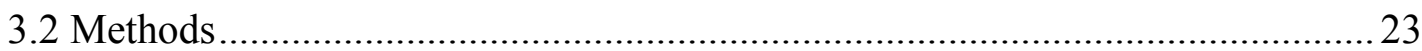

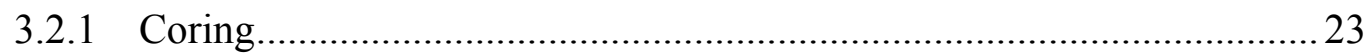

3.2.2 Age-Depth Model and Micro-X-Ray-Fluorescence Analysis................ 25

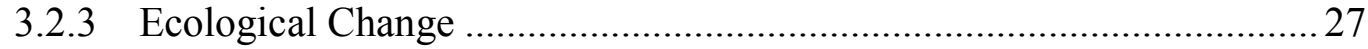

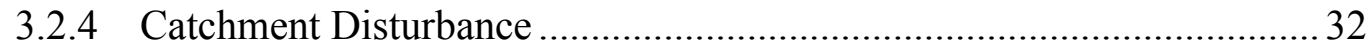

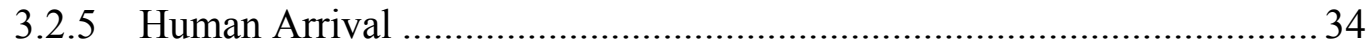

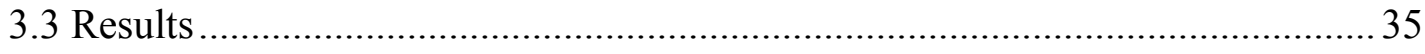

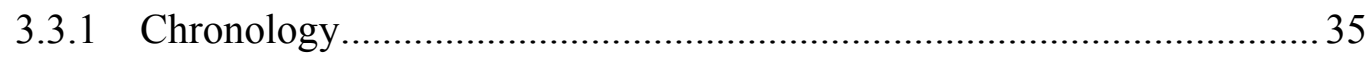

3.3.2 Lithology, Sampling Resolution, and Zonation ................................. 38

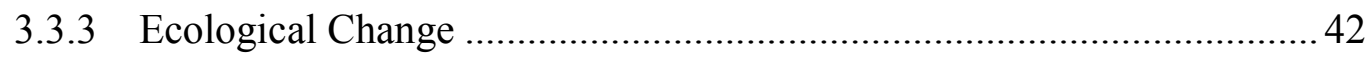




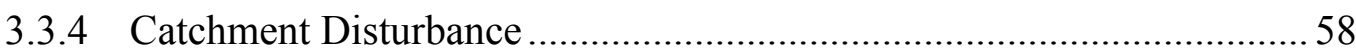

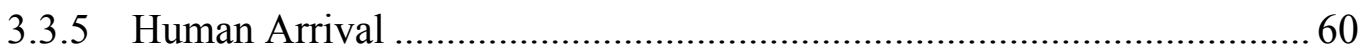

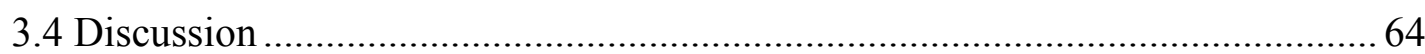

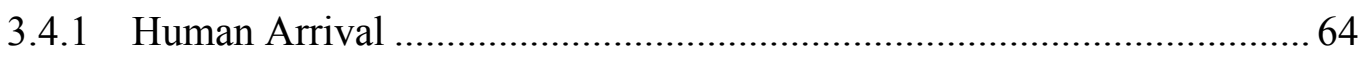

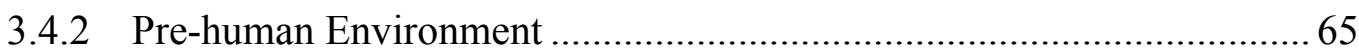

3.4.3 Post-human Environment.................................................................. 71

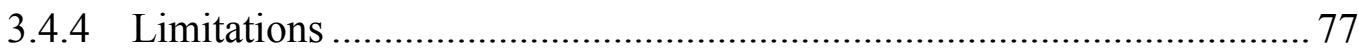

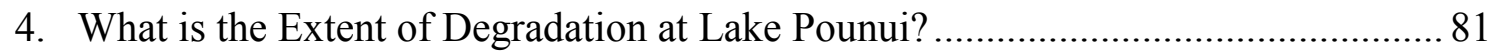

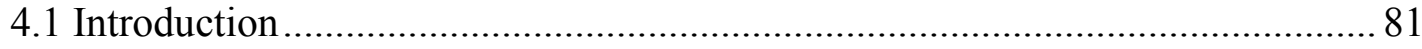

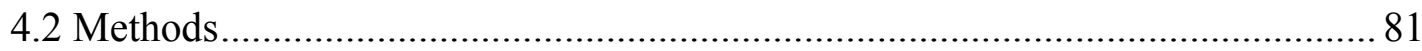

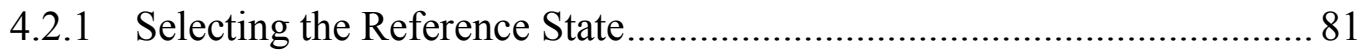

4.2.2 Squared Chord Distance Dissimilarity.............................................. 82

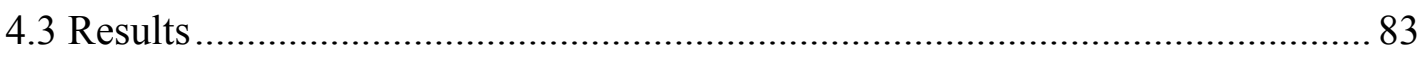

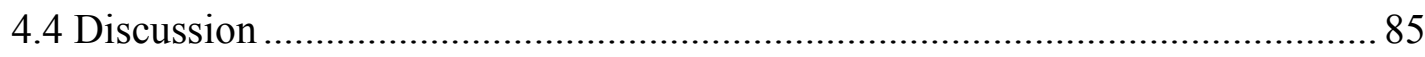

4.4.1 Application of Squared Chord Distance Dissimilarity Scores............... 85

4.4.2 Criticisms of References Conditions Framework ............................... 86

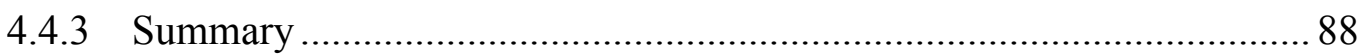

5. Can Generic Early Warning Signals Prior to Critical Transitions be identified at

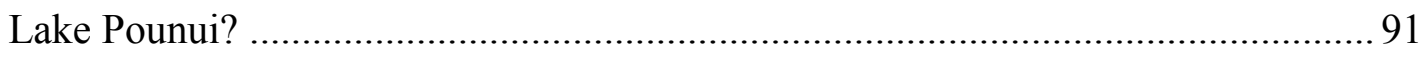

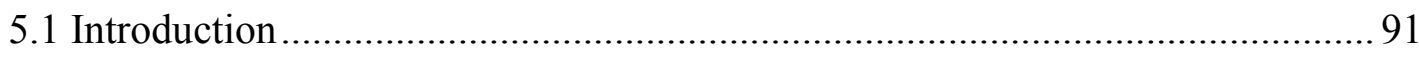

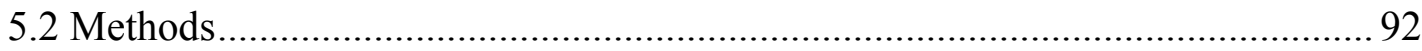

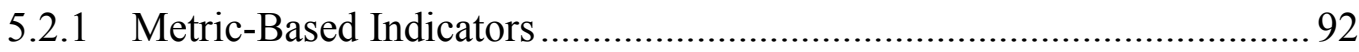

5.2.2 Principal Component Analysis (PCA) .............................................. 93

5.2.3 Early Warning Signals Analysis .................................................... 93

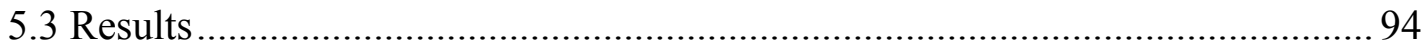

5.3.1 Principal Component Analysis (PCA) …............................................ 94

5.3.2 Early Warning Signals Analysis ................................................... 100

5.3.3 Generalised Additive Model (GAM) ................................................ 101 
5.4 Discussion

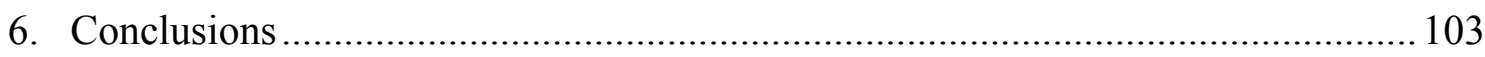

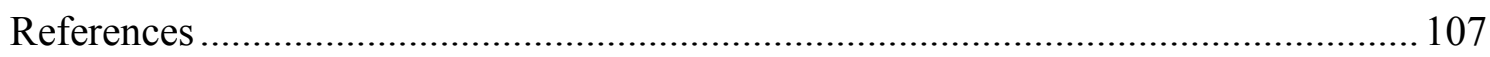

Appendix A: List of submerged macrophytes recorded in Lake Pounui ..................... 123

Appendix B: Procedure for radiocarbon dating used by the Rafter Radiocarbon

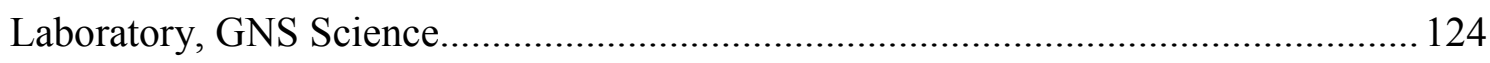

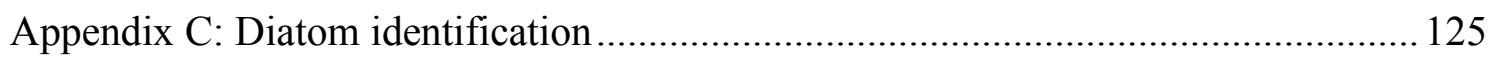

Appendix D: Diatom ecological and habitat preferences ....................................... 170

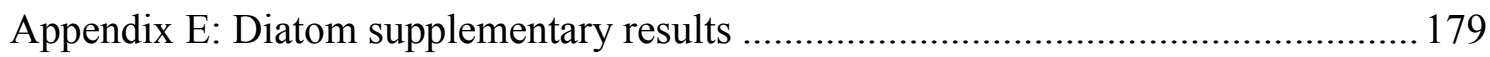

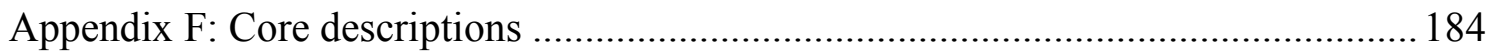




\section{List of Figures}

Figure 1.1: Lake Pounui with reference to location in New Zealand 3

Figure 2.1: Lake Pounui catchment 8

Figure 2.2: Lake Pounui bathymetry and coring site 9

Figure 2.3: Archaeological sites in the Wairarapa area 12

Figure 2.4: Dissolved oxygen and temperature measurements at Lake Pounui from $12 / 2012$ to $10 / 2014$ 18

Figure 2.5: Phytoplankton, turbidity, chlorophyll $\alpha$, and dissolved oxygen measurements at Lake Pounui from 12/2012 to 01/2016 19

Figure 2.6: Summary of previous research of the ecological condition of Lake Pounui, $1977-2016$

Figure 3.1: Coring method 24

Figure 3.2: Frustule structure of a raphid diatom. 29

Figure 3.3: Lake Pounui age-depth model and tephra marker.... 37

Figure 3.4: Alignment of core P3 with core P2.1 39

Figure 3.5: Alignment of core P2.2 with master depth. 39

Figure 3.6: Master core 40

Figure 3.7: Alignment of core and sampling intervals for proxies 41

Figure 3.8: Diatom counts presented as percentage abundance. 44

Figure 3.9: Diatoms grouped by trophic status preference 46

Figure 3.10: Diatoms grouped by salinity preference 47

Figure 3.11: Diatoms grouped by $\mathrm{pH}$ preference. 48

Figure 3.12: Diatoms grouped by oxygen preference 49

Figure 3.13: Oxygen concentration estimated using the iron/manganese (Fe/Mn) ratio calculated from the $\mu$-XRF data, compared with oxygen concentration estimated from diatom data 
Figure 3.14: Diatoms grouped by habitat preference.

Figure 3.15: Summary of ecological change. Left to right: lithology, diatom ecological preferences, diatom diversity, and zones

Figure 3.16: Pollen data presented as percentage abundance. Pollen data collected and prepared by Marcus Vandergoes and Xun Li (GNS Science)

Figure 3.17: Bacterial DNA data. Figure adapted from original by Susie Wood (Cawthron Institute) 56

Figure 3.18: Cyanobacteria DNA data. Figure adapted from original by Susie Wood (Cawthron Institute)

Figure 3.19: Mean grain size, sorting, skewness, kurtosis, and sediment accumulation rate from Lake Pounui

Figure 3.20: Minerogenic and organic proxies for Lake Pounui. From left to right: titanium (x100), potassium (x100), aluminium (x100), incoherent/coherent scattering, organic content $(\%)$

Figure 3.21: Lake Pounui pollen data, charcoal less than $100 \mu \mathrm{m}$ provided by Marcus Vandergoes and Xun Li (GNS Science) and charcoal influx 150-250 $\mu \mathrm{m}$

Figure 3.22: Minerogenic and organic proxies for Lake Pounui indicating land clearance. From left to right: titanium (x100), potassium (x100), aluminium (x100), mean grain size $(\mu \mathrm{m})$, grain sorting, incoherent/coherent scattering, organic content $(\%)$, and charcoal influx (particles $/ \mathrm{cm}^{-2} / \mathrm{yr}$ )

Figure 3.23: Summary of catchment disturbance indicators. Left to right: lithology, incoherent/coherent scattering as a proxy for organic content, titanium as a proxy for minerogenic content, mean grain size, accumulation rate, magnetic susceptibility, soil diatoms, and charcoal influx

Figure 3.24: Correlation of inferred periods of change and minerogenic input in Lake Pounui and periods of increased storminess (Page et al, 2010), and uplift on the Wairarapa fault (McSaveney et al, 2006; Little et al, 2009) ....................................... 70

Figure 3.25: Basic Four Level Food Chain in Lakes. .................................................. 74

Figure 3.26: Timeline of major events in Lake Pounui’s history ................................ 77

Figure 4.1: Dissimilarity from $\mathrm{REF}_{200}$ (200 cal yr BP; 95\% CI: 319-83 cal yr BP)....... 83 
Figure 4.2: Dissimilarity from $\mathrm{REF}_{3000}$ (3000 cal yr BP; 95\% CI: 3210-2696 cal yr BP)

Figure 4.3: GAM of dissimilarity from $\mathrm{REF}_{3000}$ (3000 cal yr BP; 95\% CI: 3210-2696 cal yr BP) 84

Figure 4.4: Cluster dendrogram of the GAM modelled dissimilarity from $\mathrm{REF}_{3000}(3000$ cal yr BP; 95\% CI: 3210-2696 cal yr BP).

Figure 5.1: Systems with low resilience undergo critical slow down and/or flickering prior to critical transition into an alternative stable state 92

Figure 5.2: Species that contribute to $>1 \%$ of the variance explained by PCA Axis 1 .. 95 Figure 5.3: Species that contribute to $>1 \%$ of the variance explained by PCA Axis 3 .. 95 Figure 5.4: Principal component axes 1 to 5 and relation to diatom-inferred zones ..... 96 Figure 5.5: PCA biplots of diatom data axis 2 and 3, divisions between zones and major drivers. 97

Figure 5.6: PCA biplots of diatom data axis 4 and 5, divisions between zones and major drivers. .98

Figure 5.7: PCA time track plots of diatom data, showing how the assemblage changed over time and divisions between zones..... 99

Figure 5.8: Metric-based indicators for early warning signals of critical transitions. Top to bottom: autocorrelation, standard deviation, skewness, and kurtosis 100

Figure 5.9: GAM model of variance in PCA axis 1 of the diatom data....... 101 


\section{List of Tables}

Table 1: Acknowledgement of data sources XV

Table 2: Average climate at Wairongomai Station ( $\sim 9 \mathrm{~km}$ from Lake Pounui) 10

Table 3: Records of fish species present in Lake Pounui.... 15

Table 4: Water quality variables recorded at Lake Pounui compared to national median values for catchments dominated by indigenous forest

Table 5: Conventional radiocarbon ages (CRA) produced by the Rafter Radiocarbon Laboratory, GNS Science, and calibrated radiocarbon dates (cal yr BP) 36

Table 6: van Dam et al. (1994) diatom ecological indicators and how they relate to the summary groups 45

Table 7: Summary statistics of diatoms making up $>5 \%$ of the population in $>2$ samples

Table 8: PCA summary values for the full diatom dataset 94

Table 9: PCA summary values for the diatom dataset $>2 \%$ in $>2$ samples 94 


\section{Disclaimer}

This thesis is part of a wider study being led by Andrew Rees (Victoria University of Wellington (VUW)) and Marcus Vandergoes (GNS Science). For this reason, data have been collected from a range of sources that are acknowledged below:

\begin{tabular}{|l|l|}
\hline \multicolumn{2}{|c|}{ Table 1: Acknowledgement of data sources } \\
\hline Data & Collector \\
\hline $\begin{array}{l}\text { Monitoring data of phytoplankton, } \\
\text { turbidity, chlorophyll } \alpha \text {, temperature, and } \\
\text { oxygen saturation }\end{array}$ & $\begin{array}{l}\text { Marcus Vandergoes (GNS Science), } \\
\text { Andrew Rees (VUW) }\end{array}$ \\
\hline Collection of sediment cores & $\begin{array}{l}\text { Marcus Vandergoes (GNS Science), } \\
\text { Andrew Rees (VUW) }\end{array}$ \\
\hline Radiocarbon dating & $\begin{array}{l}\text { Pre-processing of samples Leise Cochrane } \\
\text { (Author), processing by Rafter } \\
\text { Radiocarbon Laboratory, GNS Science }\end{array}$ \\
\hline Mirco-X-ray-fluorescence & $\begin{array}{l}\text { Australian Nuclear Science and } \\
\text { Technology Organisation (ANSTO) }\end{array}$ \\
\hline Tephra analysis & Brent Alloway (VUW) \\
\hline Diatom analysis & Leise Cochrane (Author) \\
\hline Pollen analysis & $\begin{array}{l}\text { Xun Li (GNS Science), Marcus Vandergoes } \\
\text { (GNS Science) }\end{array}$ \\
\hline Bacterial DNA & Susie Wood (Cawthron Institute) \\
\hline Grain size analysis & Leise Cochrane (Author) \\
\hline Organic content via loss-on-ignition & $\begin{array}{l}\text { Ainslee Brown (Environmental Science } \\
\text { (ENSC) 302 student), Sky Halford (ENSC } \\
\text { 302 student), Leise Cochrane (Author) }\end{array}$ \\
\hline Charcoal analysis & $\begin{array}{l}\text { Ainslee Brown (ENSC 302 student), Sky } \\
\text { Halford (ENSC 302 student), Leise } \\
\text { Cochrane (Author) }\end{array}$ \\
\hline
\end{tabular}




\section{Chapter One: Introduction}

There is now evidence that human impacts have caused fundamental shifts in Earth's systems, such as lakes, which exceed the natural variability experienced in the Holocene (Wolfe et al., 2013; Barnosky et al., 2012). This has prompted scientists to propose a new geological epoch defined by anthropogenic influence - the Anthropocene (Bostock et al., 2015; Crutzen \& Stoemer, 2000). Degradation of freshwater quality throughout this period is of increasing concern leading to extensive research on its management and restoration. In particular, the importance of establishing the pre-human condition of these environments has been recognised, so that realistic restoration targets can be determined. For example lake sediments preserve numerous proxies that can provide a local- to regional-scale record of environmental change and catchment disturbance over time. This thesis presents an environmental reconstruction from Lake Pounui, Wairarapa, New Zealand, using paleolimnological methods to examine anthropogenic impact in relation to reference conditions and critical transitions. The following sections will detail the motivation for this research, the aims and objectives, and conclude with a brief explanation of the research chapters.

\subsection{Motivation for Research}

New Zealand's freshwater bodies have important cultural, and economic value for our society. They provide power generation, drinking water, recreation, and "mahinga kai" (freshwater food source) for our communities. Their ecological health also has intrinsic value, and degradation at one site may have large flow on effects. Of the 3820 lakes ( $>1$ ha) in New Zealand, 32\% are classified as eutrophic or worse (Verburg, Hamill, Unwin, \& Abell, 2010). Eutrophication is a process whereby excessive nutrient enrichment (namely nitrogen and phosphorous) within a water body causes an increase in biological productively, often resulting in algal blooms. This can cause oligotrophic waters (low productivity) to become either mesotrophic (moderately productive) or eutrophic (highly productive). Eutrophication can have several negative impacts, such as: increased phytoplankton growth, oxygen depletion, and increased turbidity, which can cause a decline in suitable habitat for many species. Increased eutrophication of freshwater has been attributed to an intensification in agriculture, with global warming projected to further compound the problem (Lowe \& Walker, 2014; Smith, 2003). To deal with this problem, there has been increased research on freshwater restoration and protection (Bennion, Battarbee, Sayer, Simpson, \& Davidson, 2011). However, not all 
restoration programmes achieve their goals, and there is still much uncertainty as to what constitutes an achievable restoration target (Bennion et al., 2015). To do this effectively, many believe we need to assess the extent of degradation against some nondegraded natural baseline, often referred to as the reference condition (Bennion et al., 2015; Bennion \& Simposon, 2011; Bennion et al., 2011a; Battarbee et al., 2005). This is done using paleolimnological methods, which offer a complementary means of evaluating historical trends - where modern monitoring schemes are highly resolved over short periods, paleolimnology produces coarser records of much longer duration often encompassing pre-human impact (Schallenberg et al., 2011). Paleolimnology allows the difference from natural conditions to be considered when allocating conservation resources and setting restoration targets. For example, resources will not be wasted trying to restore a lake that is, and always has been, naturally eutrophic. Paleolimnological methods are now routinely used in other parts of the world, such as Europe, to reconstruct chemical and biological reference conditions for lakes (Bennion et al., 2015; Bennion, Simpson, et al., 2011; Kelly et al., 2005). However, this application seems to be lacking in New Zealand and should be developed further.

Another means of characterising anthropogenic impact includes critical transitions. A critical transition occurs when conditions change over time and reduces the ability of a system to recover from perturbations. At this point, even minor disturbances can cause a system to shift to an alternative state - thus undergoing a critical transition (Dakos et al., 2012). It is now well known that when perturbations occur, a freshwater ecosystem can abruptly switch into a contrasting state (Scheffer et al., 2012). For instance, an increased input of limiting nutrients, like nitrogen and phosphorus, into a nutrient poor lake can cause a critical transition to a eutrophic state, where nutrients and organic productivity are high (Lowe \& Walker, 2014; Hall \& Smol, 2010). Often transition to an alternative stable state is difficult to reverse, or in some cases irreversible due to large changes in the physical or ecological properties of the system (Scheffer et al., 2012; Dakos et al., 2012). Modelling suggests that, prior to these transitions, there are generic markers such as critical slow down (when the rate at which a system recovers from perturbation slows prior to a critical transition) and flickering (when a system repeatedly moves between two alternative states prior to a critical transition) that, if identified, could be used as early warning signals of transition (Dakos et al., 2012; Wang et al., 2012). Real world examples are scarce, although early research shows that these generic markers may be archived in paleolimnological records from lake systems (Wang et al., 2012). Early 
warning signals could allow lakes to be prioritised according to risk of transition, again permitting better resource allocation.

As discussed, paleolimnological methods can be used to establish reference conditions and identify critical transitions. These methods offer an opportunity to investigate anthropogenic impact on an important ecosystem in New Zealand (NZ) - Lake Pounui. Lake Pounui is a 50-ha, moderately shallow (9.6 m) (Verburg et al., 2010), lowland lake, located in the southern end of the Wairarapa valley (Perrie \& Milne, 2012; de Winton et al., 2011; Jellyman, 1990). The Lake possesses high ecological integrity and is home to a number of native aquatic plant and fish species (Jellyman, 1990). Lake Pounui is protected under a Queen Elizabeth II Open Space Covenant (Perrie \& Milne, 2012), and has been used as a reference lake to assess water quality (Schallenberg et al., 2011; Drake, Kelly, \& Schallenberg, 2011). However, modern monitoring spanning the last 40 years suggests that the lake may be experiencing an increased frequency and duration of algal blooms (de Winton, 2016; Perrie \& Milne, 2012; de Winton et al., 2011). In comparison to other lakes in the area (e.g., Lake Wairarapa and Lake Onoke), Lake Pounui's depth and position away from faults and tidal influence provides a stable environment to record environmental change for paleolimnological analysis. This thesis will identify human arrival in the region, along with the extent of anthropogenic disturbance, and help develop evidence-based restoration targets for Lake Pounui.

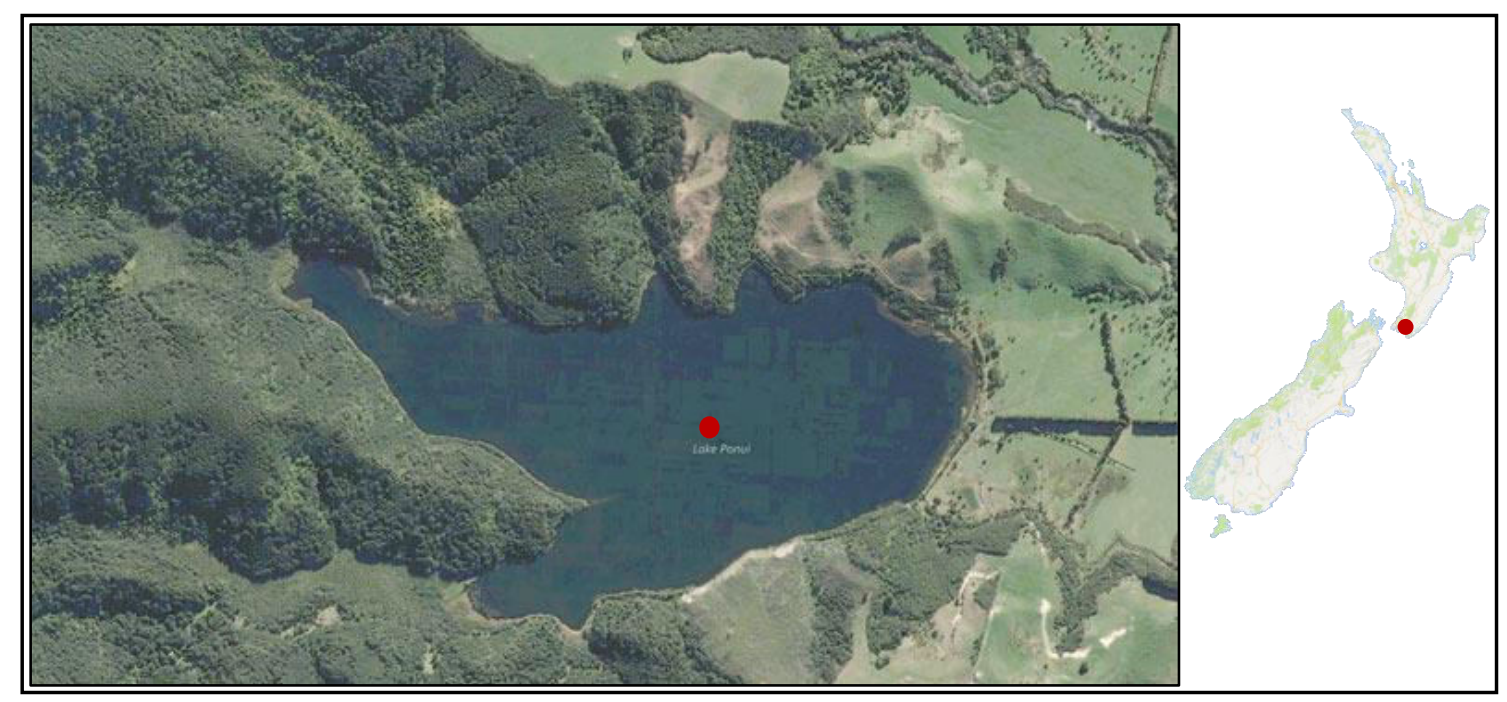

Figure 1.1: Lake Pounui with reference to location in New Zealand (red dot). Satellite image taken from Google Maps (2016), map from LINZ data service (2016). 


\subsection{Research Aim and Objectives}

This thesis aims to reconstruct environmental change at Lake Pounui using paleolimnological methods and examine anthropogenic impact in relation to reference conditions and critical transitions. To achieve this aim, sediment cores from Lake Pounui were studied to address the following research questions:

1) Research question one: are algal blooms a natural feature of Lake Pounui, or do they coincide with human arrival?

Although Lake Pounui is a site of high ecological heritage, it is now at risk due to increasingly frequent algal blooms. This raises the question: are algal blooms a natural feature of the lake system, or do they coincide with human arrival to the area? The null hypothesis is that algal blooms are a natural feature of Lake Pounui. To investigate, the following objectives were carried out:

a) Construct an age-depth model - radiocarbon dates were determined from plant and freshwater mussel fragments and calibrated with SHCal13 (Hogg et al., 2013). The age-depth model was then constructed with the Bacon package using Bayesian statistics (Blaauw \& Christen, 2011) in R (R Core Development Team, 2015).

b) Reconstruct ecological change - to investigate whether algal blooms occurred prior to human arrival, ecological change was reconstructed to show periods of increased productivity. To reconstruct ecological change diatoms were used as a proxy for trophic status, oxygen concentration, salinity, and $\mathrm{pH}$. The reconstruction of oxygen concentration was also supported by changes in the iron (Fe (II) to manganese (Mn (II)) ratio, two elements sensitive to redox conditions which were estimated using micro-X-ray-fluorescence analysis. Bacterial DNA and pollen data were also used as supporting evidence.

c) Reconstruct catchment disturbance - to investigate what may have caused ecological changes within the lake, catchment disturbance was reconstructed based on grain size, organic matter, and micro-X-ray-fluorescence analysis.

d) Identify human arrival - to investigate whether algal blooms coincided with human arrival, charcoal, pollen, and catchment disturbance indicators were used to identify periods of anthropogenic land clearance via fire. The arrival of Pinus 
pollen and the diatom Asterionella formosa were also used as indicators of European settlement.

2) Research question two: what is the extent of degradation at Lake Pounui?

Lake Pounui has been used as a reference lake in several studies; however, research shows that the water quality has declined over the last 40 years. This raises the question - what is the extent of degradation at Lake Pounui? To investigate this, the following objectives were carried out:

a) Define reference conditions - based on data collected from research question one, reference conditions were selected prior to human arrival.

b) Determine deviation from reference conditions - to determine the extent of change from reference conditions, squared chord distance dissimilarity analysis was conducted on the diatom assemblage data. This compares the chosen reference state to all other assemblages and assigns a score ranging from zero (identical) to two (entirely different). It was hypothesised that dissimilarity would increase as human impact occurred.

c) Discuss realistic restoration targets and possible mitigation techniques

3) Research question three: can generic warning signals prior to critical transitions be identified at Lake Pounui?

Changes identified in Lake Pounui may represent critical transitions. If so, Lake Pounui may offer the opportunity to test for generic warning signals in a real ecosystem. To investigate this research question the following objectives were carried out:

a) Identify possible critical transitions - to identify possible critical transitions principal component analysis was conducted on the diatom assemblage data to show where the greatest variance occurred.

b) Test for generic early warning signals - to test for generic early warning signals the diatom Principal Component (PC) axes were analysed using the Early 
Warning Signals package (Dakos et al., 2012) in R (R Core Development Team, 2015).

\subsection{Thesis Outline}

This thesis contains six chapters. Chapter two provides background information on Lake Pounui: geology, climate, and previous research. The following chapters are split into individual research questions and contain the associated background information, methods, results, and discussion. Chapter three contains the bulk of the research in which the diatom analysis is the main contribution by the Author. Chapter three provides the foundation for chapters four and five, in which quantitative analysis is attempted. Chapter six summarises this study with a general conclusion of all results. References and appendices follow. 


\section{Chapter Two: Background Information}

This chapter provides important background information pertaining to Lake Pounui and human arrival in the New Zealand context. The following sections will give a site description, a discussion of previous research conducted at Lake Pounui, and define the markers of human occupation in the region.

\subsection{Site description}

\section{Physical Characteristics and Geology}

Lake Pounui is a shallow (Verburg et al., 2010), lowland lake (9.6 m deep, $20 \mathrm{~m}$ above sea level). Water enters Lake Pounui via three major streams that drain the Rimutaka Range (Fig. 2.1). The streams originate in the north-western side of the catchment, which is largely forested by native bush, and flow through $500 \mathrm{~m}$ of swamp before entering the lake (Perrie \& Milne, 2012; Jellyman, 1990; Lawless, 1983). Water exits the lake on the eastern shore into farm pasture via Pounui Stream (Perrie \& Milne, 2012; Jellyman, 1990). Pounui Stream then flows into Pounui Lagoon, and eventually Lake Onoke (Fig. 2.1) (Perrie \& Milne, 2012). The bathymetry of the lake has been described by Jellyman (1990) and Lawless (1983), who characterise a single basin with an east-west orientation and two arms extending westwards, separated by a submerged ridge (Fig. 2.2). Lawless (1983) and Turner and Lillis (1994) theorise that lake formation was associated with the end of the last glaciation. As sea level rose, the base level of the Ruamahanga River and tributaries rose, causing increased sediment deposition. The valley that contains Lake Pounui may have been damned by this sediment deposition some 6000 years ago during the highest Holocene shoreline. Jellyman (1980), however, states that it is also possible that the lake was formed due to tectonics.

Lake Pounui's catchment is $\sim 627$ ha and situated in the southern end of the Wairarapa Valley (Fig. 2.1). The Wairarapa Valley exists within New Zealand's active tectonic belt running north-east along the country (Palmer, Vucetich, McGlone, \& Harper, 1989). The basement rock is comprised of faulted and folded Mesozoic greywacke and argillite, which also forms the Rimutakas and Aorangi Ranges (McFadgen, 2003; Palmer et al., 1989). There are numerous active faults that strike north-east in the wider area such as the Wairarapa fault, the Wellington Fault, and the Palliser-Kaiwhata Fault. A series of marine benches exist within the catchment and are covered in up to $20 \mathrm{~m}$ of 
beach sediment and loess (Turner \& Lillis, 1994). These benches overlay Castlecliffian (Late Pleistocene) marine sediments. Material eroded from these sources enters Lake Pounui (McFadgen, 2003; Turner \& Lillis, 1994; Palmer et al., 1989).

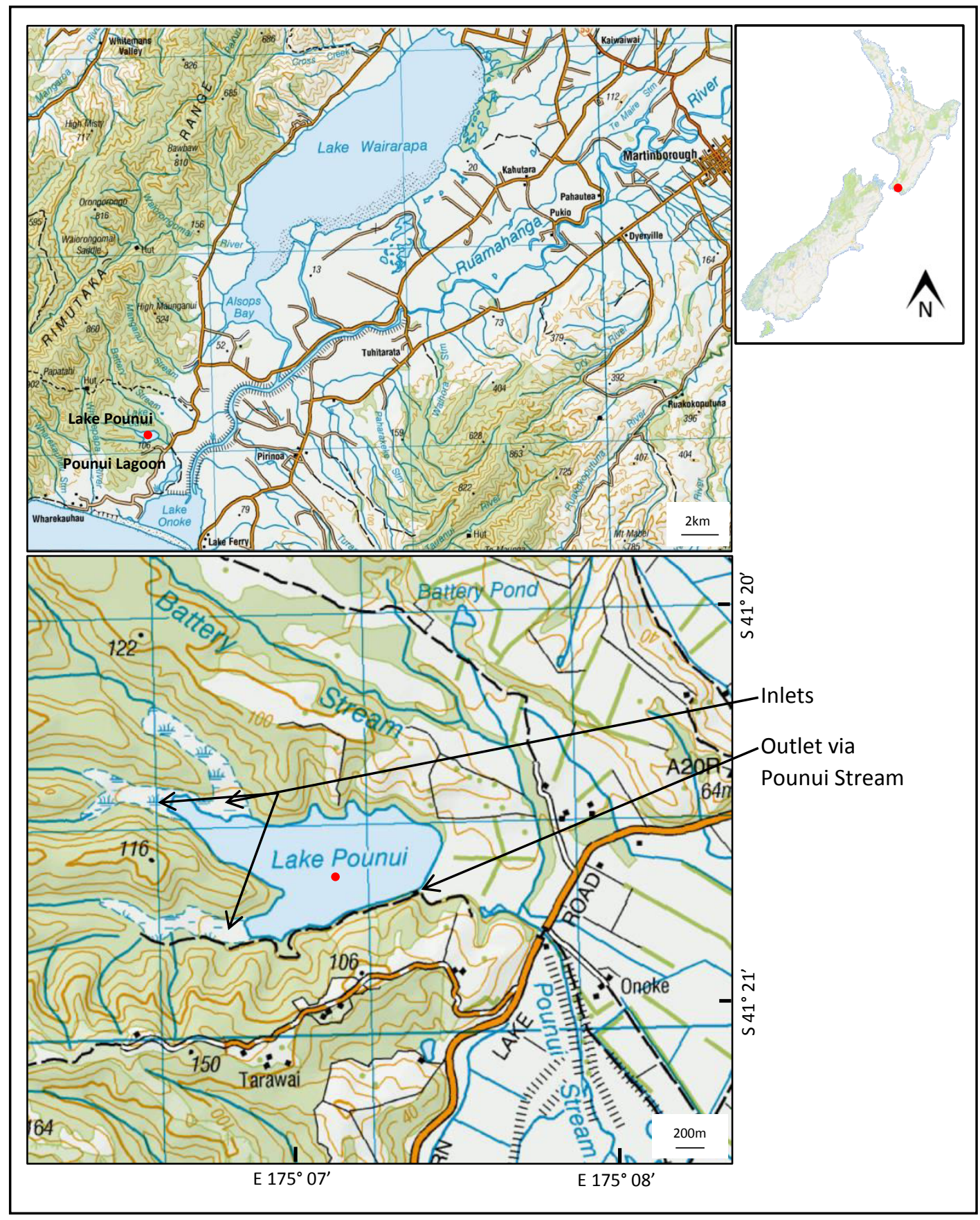

Figure 2.1: Lake Pounui catchment. Red dots show position of Lake Pounui. Contours $=20 \mathrm{~m}$ intervals. Map adapted from LINZ data service, 2016. 


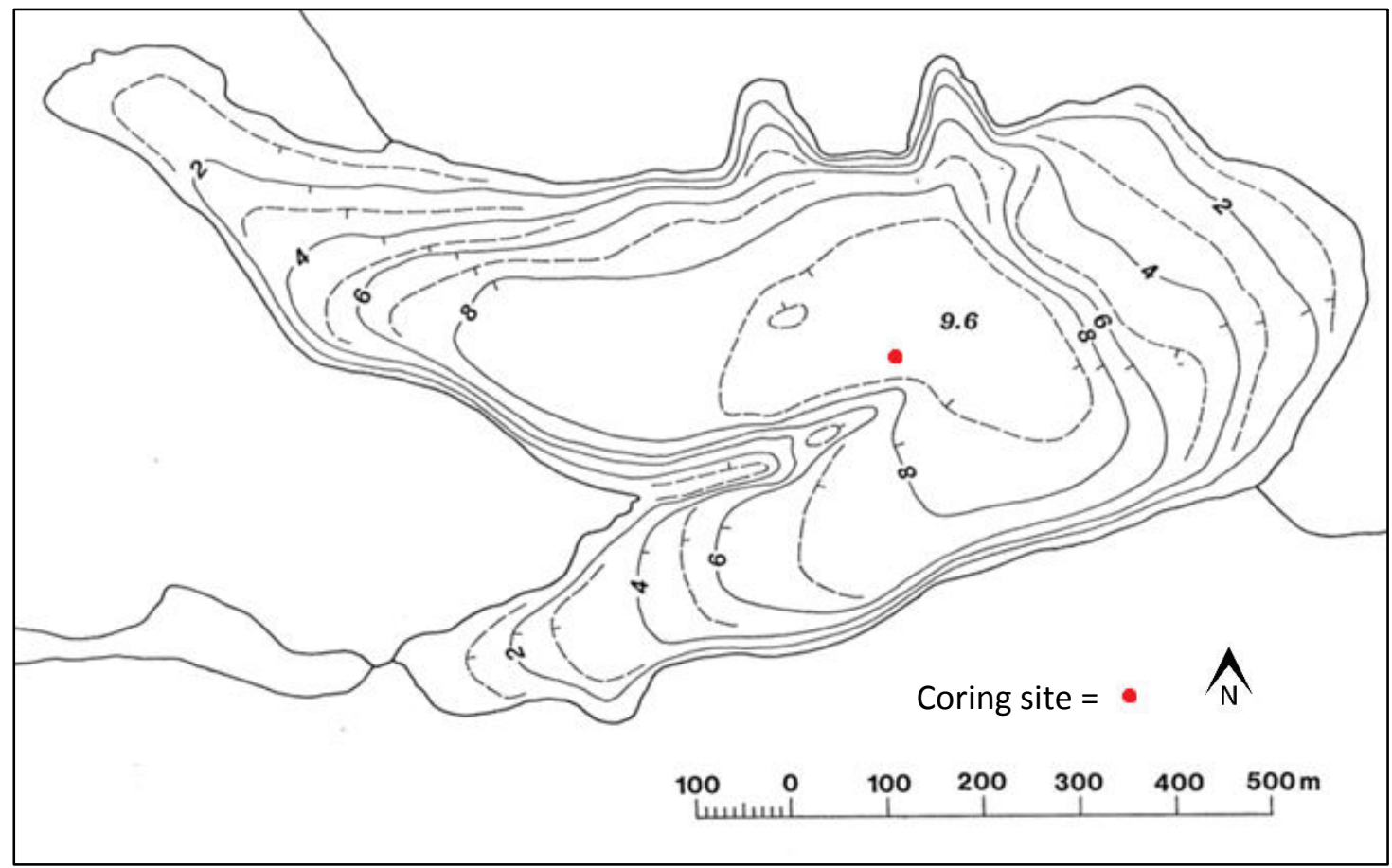

Figure 2.2: Lake Pounui bathymetry adapted from Jellyman (1990) and coring site. Contours $=1$ metre.

\section{$\underline{\text { Vegetation }}$}

There is extensive forest to the north and west of Lake Pounui (McQueen, 1991). Black beech (Fuscospora solandri) dominates at higher elevations, hard beech (Fuscospora truncata) becomes dominant at lower elevations, and matai (Prumnopitys taxifolia) and rimu (Dacrydium cupressinum) are scattered in the foot hills (McQueen, 1991). On the valley floor, swamp forest persists and is dominated by swamp maire (Syzygium maire) and few Kahikatea (Dacrydium dacrydioides) (McQueen, 1969). During early farming attempts $(\sim 1844)$, the land to the north and east of Lake Pounui was burnt (McQueen, 1991). Fire associated with pig hunting has since been repeated in the area, creating sections of older and younger vegetation (McQueen, 1991). In the younger stands, the dominant vegetation is manuka (Leptospermum scoparium), with hard beech (Fuscospora solandri) becoming dominant in older stands (McQueen, 1991). Some manuka scrubland was also converted to pasture in 1976 on the hill faces in the north and upper south-western side of the lake (Perrie \& Milne, 2012; Jellyman, 1990).

\section{Climate}

The area experiences cool, wet winters and warm, dry summers (McQueen, 1991; Lawless, 1983). The closest climate station is located at Waiorongomai, $\sim 9 \mathrm{~km}$ from Lake Pounui (-41.261 175.148). The average summer temperature is $16.6^{\circ} \mathrm{C}$, with 101.6 $\mathrm{mm}$ of rain, and the average winter temperature is $8.7^{\circ} \mathrm{C}$, with $163.9 \mathrm{~mm}$ of rain, 
although the reliability of this information is limited as it was only collected until 1993 (Table 2). The Rimutaka Mountains on the north-western side of Lake Pounui are approximately $300 \mathrm{~m}$ higher than at Waiorongomai, therefore, the foehn wind effect may cause lower rainfall at Lake Pounui (McQueen, 1991). The area experiences relatively strong wind year round. The proximity to the cook strait $(<5 \mathrm{~km})$ and the north-west orientation of the Pounui valley is thought to intensify the prevailing northwesterly winds (Jellyman, 1990; Lawless, 1983), with hills to the south providing protection from southerlies and the Rimutaka Range sheltering from westerlies (Jellyman, 1990). Lawless (1983) states that sea spray has been noted $700 \mathrm{~m}$ from the lake. This is thought to give Lake Pounui a slightly higher alkalinity than average freshwater.

\begin{tabular}{|l|l|l|l|l|l|}
\hline \multicolumn{6}{|c|}{$\begin{array}{c}\text { Table 2: Average climate at Wairongomai Station ( 9 km from Lake Pounui). Data } \\
\text { retrieved from New Zealand's National Climate Database, NIWA, 2016 }\end{array}$} \\
\hline Variable & Summer & Autumn & Winter & Spring & Annual \\
\hline $\begin{array}{l}\text { Mean Daily Wind Run 1971- } \\
\text { 1993 (km) }\end{array}$ & 414.0 & 353.1 & 336.9 & 430.7 & 383.6 \\
\hline $\begin{array}{l}\text { Mean Daily Temperature } \\
\text { 1970-1993 }\left({ }^{\circ} \mathrm{C}\right)\end{array}$ & 16.6 & 13.2 & 8.7 & 12.1 & 12.6 \\
\hline $\begin{array}{l}\text { Total Rainfall 1929-1993 } \\
(\mathrm{mm})\end{array}$ & 101.6 & 126.8 & 163.9 & 127.9 & 1560.5 \\
\hline
\end{tabular}

\subsection{Human Arrival}

The arrival of humans to New Zealand has been studied extensively. It has been established that initial Polynesian settlement occurred c. 700-800 calibrated years before present (cal yr BP) with Europeans arriving c. 150 cal yr BP (McWethy, Whitlock, Wilmshurst, Wood, \& McGlone, 2014; McWethy et al., 2010; Wilmshurst, Anderson, Higham, \& Worthy, 2008; McFadgen, 2003). However, there is evidence that settlement of the Wairarapa Valley may not have occurred until later (McFadgen, 2003; Leach, 1981). Archaeological and paleolimnological evidence has been used to establish this timeline.

\section{Archaeological evidence of human arrival}

McFadgen (2003) states that the earliest evidence of Polynesians in the Wairarapa area consists of angular charcoal, found just below the Loisels Pumice, in wave-cut coastal sections at three locations: Ta Kaukau Point, Te Oroi, and Te Awaiti. Loisels Pumice is sea rafted and sourced from multiple eruptions and/or volcanoes located in the Tonga- 
Kermadec arc (Shane, Froggatt, Smith, \& Gregory, 1998). Based on radiocarbon dates from coastal sections, the Loisels Pumice found in Wairarapa has been dated to $600 \mathrm{cal}$ yr BP(McFadgen, 2003). McFadgen (2003) concluded that the charcoal found just below the Loisels Pumice likely represents the first forest clearance during Polynesian settlement c.700 years ago. Another piece of evidence for first settlement and forest clearance is a burnt totara tree root buried in growth position beneath a garden at Okoropunga (McFadgen, 1980). This was also radiocarbon dated to approximately 600 cal yr BP (McFadgen, 2003). Leach (1981) estimated, based on evidence of agriculture and economic system, that there was a maximum population of 300 people located in villages at the mouths of rivers and valleys in Palliser Bay at this time.

Palliser Bay was likely abandoned in the late $15^{\text {th }}$ century following catastrophic events such as tectonic uplift and possibly a tsunami (Clark et al., 2015). The Wellington fault (Langridge et al., 2011), Alpine fault (Howarth et al., 2014), and the Hikurangi subduction margin (Clark et al., 2015) are known to have ruptured at approximately 500 cal yr BP, corroborating with archaeological evidence of migration. McFadgen (2003) suggested that people moved inland from the Wairarapa coast to the main Valley, where Lake Pounui is located. Leach (1981) stated that the Ngati Kahungunu iwi also migrated to Wairarapa from Poverty Bay in 300 cal yr BP (1650 AD) and suggested that this is when settlement of the main Wairarapa Valley occurred.

There are numerous archaeological sites in the Wairarapa Region recorded by the New Zealand Archaeological Association's Archaeological Site Recording Scheme (NZAA ArchSite) (Fig. 2.3). The closest site to Lake Pounui (NZAA Site Number R27/121, E $1777475 \mathrm{~N} 5420984$ ) exists $\sim 130 \mathrm{~m}$ from the eastern edge of the lake. It was identified as a midden (oven) and classified as Indigenous Maori pre-1769 by B.F. Leach and M. Leach in 1971; however, on recent inspection the site was not found. B.F. Leach and M. Leach also identified a pa site located $\sim 1.7 \mathrm{~km}$ north-east of the lake (NZAA Site Number R27/122, E 1779002 N 5421311) which was also classified as Maori Indigenous pre-1769. The site was inspected in 2007 and was still in good condition. 


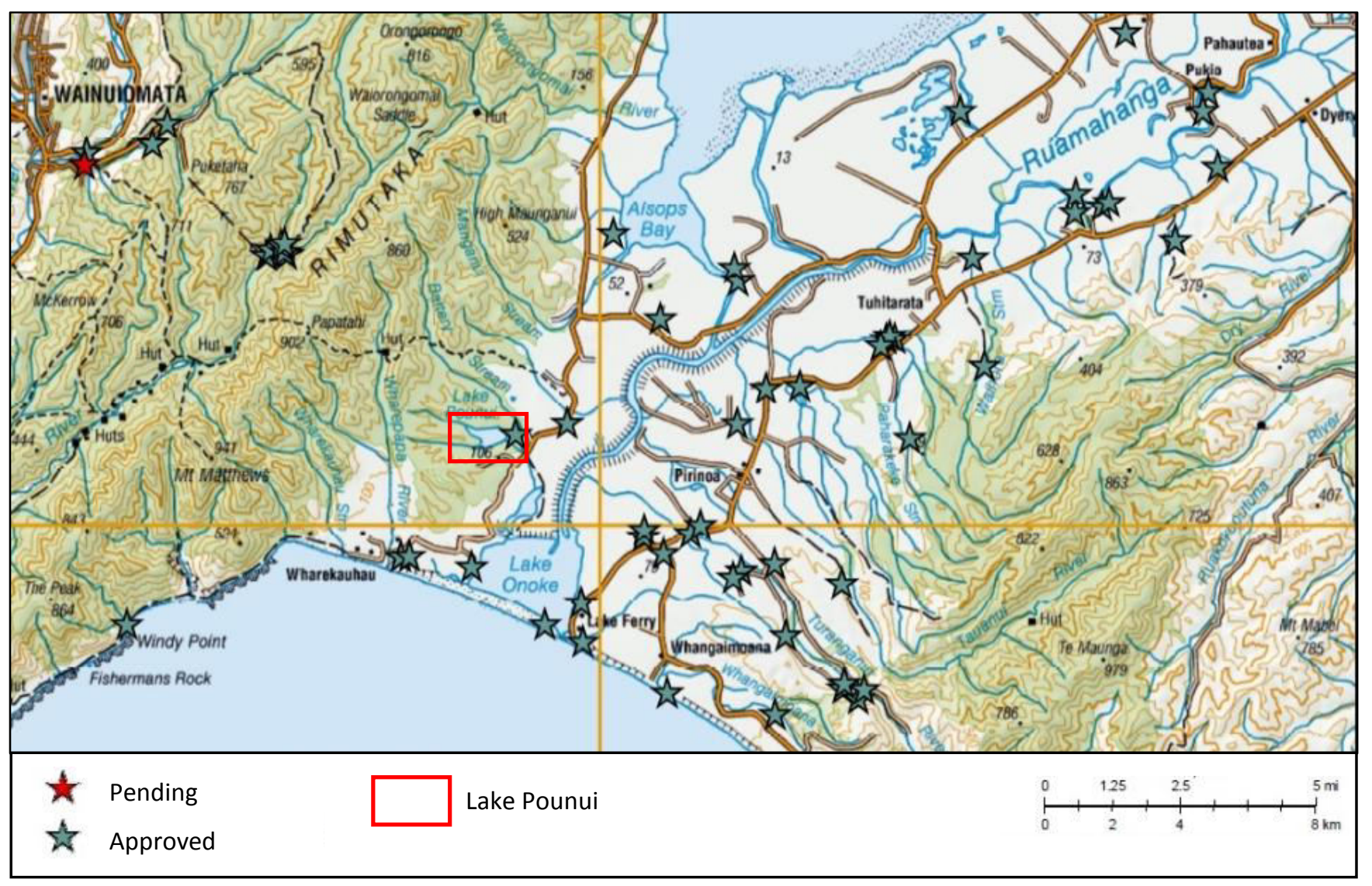

Figure 2.3: Archaeological sites in the Wairarapa area. Adapted from Archsite (2016). 
Land clearance for agriculture would have been carried out in the main Wairarapa Valley as was done on the coast; however, no solid evidence can be found in the literature. Beadel, Perfect, Rebergen, and Sawyer (2000) suggested that forest in the Valley was cleared by widespread fires in the mid-1 $7^{\text {th }}$ century. McFadgen (2003) estimated that, by $\sim 200$ cal yr BP (1750 AD), the forest was largely cleared from the area. Captain Cook arrived in Palliser Bay on $9^{\text {th }}$ February 1770 (Leach, 1981). At the time of European arrival, there were large areas of scrub, fern, and grassland (Hill, 1963). Conflict between Europeans and Maori is thought to have decreased the population in the Wairarapa region to less than 100 indigenous individuals (Leach, 1981). After the Treaty of Waitangi was signed, the area was resettled with a Maori population of 604 recorded in the Kemp's 1848-1849 census (Leach, 1981). The region was not formally settled by Europeans until 1853, when a government scheme was approved (Leach, 1981).

\section{Paleolimnological evidence of human arrival}

Fire is often used during early settlement to modify the landscape. Before Polynesian arrival, 85-90\% of New Zealand was forested (McWethy et al., 2014). McGlone (1989) argued that Polynesian settlers used fire to clear land for dwellings, food cultivation, tracks, and to encourage the growth of bracken (Pteridium esculentum), which was an important food source. The deliberate burning associated with Polynesian arrival in New Zealand has been dubbed the 'Initial Burning Period' (IBP) (McWethy et al., 2010; McGlone \& Wilmshurst, 1999). It is estimated that this lead to the loss of up to $50 \%$ of New Zealand's forest (McWethy et al., 2010; McGlone \& Wilmshurst, 1999).

There is abundant fuel in New Zealand, but the high level of moisture makes naturally occurring fires rare (McWethy et al., 2013). Therefore, an increase in magnitude and frequency of charcoal, an abrupt decline in forest pollen and shift to seral species, and changes in lithology due to catchment disturbance are generally strong pieces of evidence for anthropogenic influence (McGlone \& Wilmshurst, 1999). Accordingly, these proxies have been used by numerous authors to identify Polynesian arrival in various parts of New Zealand (Abrahim, Parker, \& Horrocks, 2013; McWethy et al., 2010; Augustinus, Reid, Anderson, Deng, \& Horrocks, 2006; McGlone \& Wilmshurst, 1999; Newnham, Lowe, McGlone, Wilmshurst, \& Higham, 1998).

In the Wairarapa region, there is only one study that has employed these methods to determine Polynesian arrival. Trodahl, Rees, Newnham, and Vandergoes (2016) used 
paleolimnological methods to reconstruct the geomorphic history of Lake Wairarapa. A notable increase in charcoal was found at c.720 cal yr BP, which coincides with the generally accepted date for Polynesian arrival c.750 cal yr BP (McWethy et al., 2014; Wilmshurst et al., 2008). There was also an increase in median grain size at this time, which suggests a reduced residence time of particles in the catchment, and therefore increased erosion, as expected with vegetation clearance.

When Europeans arrived in New Zealand, they introduced a number of exotic plants. The appearance of pine pollen (Pinus spp.) has been used to identify the arrival of Europeans in lake and estuarine sediment records by many studies (Abrahim et al., 2013; McWethy et al., 2010; Augustinus et al., 2006; Page, Trustrum, \& DeRose, 1994). Trodahl et al. (2016) found a low abundance of pollen in the stratigraphic record of Lake Wairarapa, therefore palynological analysis could not be completed. The diatom Asterionella formosa is also an indicator of European arrival to New Zealand (Harper, 1994). The increase in abundance of Asterionella formosa is thought to have been stimulated by mammals or exotic fish and the associated nutrient increase (Harper, 1994). Lake Pounui, which is a more stable environment than Lake Wairarapa for proxy preservation, should provide complementary evidence on the timing and magnitude of anthropogenic modification in this region (Trodahl et al., 2016).

\subsection{Previous Research}

\section{$\underline{E \operatorname{colog} y}$}

There have been a number of studies on the ecology of Lake Pounui. A thesis by Lawless (1983) carried out an ecological study on the zooplankton of Lake Pounui. Lawless (1983) observed seasonal succession of the major zooplankton population. Bosmina meridionalis dominated in spring followed by a succession from Ceriodaphnia dubia, to Calamoecia lucasi, to Conochilus spp. in late autumn. The breeding of the cladocerans (Bosmina meridionalis and Ceriodaphnia dubia) was seasonal with high production in spring to summer, whereas, breeding of copepods (Calamoecia lucasi and Boeckella hamata) was continuous throughout the year (Lawless, 1983). Lawless (1983) also observed that the mite Piona uncata exigua was an important predator of the cladocerans.

Jellyman $(1989,1980)$ and (Jellyman \& Ryan, 1983) conducted studies on the fish and eel populations in Lake Pounui. The European perch (Perca fluviatilis) was introduced 
to New Zealand in 1868, and there is now a large population in Lake Pounui (1052 adult fish caught from July 1974 to December 1975), with the largest population occurring during spawning in late-September/early-October (Jellyman, 1980). Jellyman (1989) and Jellyman and Ryan (1983) conducted surveys on the migration and diet of eels Anguilla australis (shortfin) and Auguilla dieffenbachii (longfin) in Lake Pounui. The number of eels caught each season from November 1974 to July 1978 ranged from 6754 to 190,009 , with the largest migrations occurring when there was greatest seasonal rainfall during the months of November to April (Jellyman \& Ryan, 1983). Most recently, fish surveys for the Greater Wellington Regional Council have been conducted (Table 3). Over the course of the survey, ten species have been found: eight natives and two exotics. Over recent years, it appears that the numbers of native fish species present have declined. Fresh water mussels (Echyridella menziesi) (de Winton, Champion, \& Wells, 2011) and snails (Potamopyrgus antipodarum) (de Winton, 2016) have also been found, however, there is no data on population change.

Table 3: Records of fish species present in Lake Pounui. Data retrieved from New
Zealand Freshwater Fish Database, Joy (2003), and McEwan (2010). *denotes exotic
species

There is also a large population of submerged macrophytes that have been surveyed by the Greater Wellington Regional Council (GWRC) using the Lake Submerged Plant Index (LakeSPI) (Appendix A). Over the last five years, there have been declines in the LakeSPI and Native Condition Index and an increase in the Invasive Impact Index (de Winton, 2016). This change is due to an increase in the depth range colonised by the invasive species Elodea canadensis, and a reduction in the endemic quillwort Isoetes kirkii (included in the New Zealand threat classification list) due to shading in shallow zones by filamentous algae (de Winton, 2016). 


\section{$\underline{\text { Water Quality }}$}

The water quality of Lake Pounui has been sporadically monitored (Table 4). Jellyman (1990) conducted monitoring for 10 months from 1975-1978, Lawless (1983) carried out infrequent monitoring from 1980-1982, Drake et al. (2011) took spot measurements in 2007, and NIWA took spot measurements for the GWRC on 17/03/2011 published by Perrie and Milne (2012). Based on the data presented in these studies, Lake Pounui has elevated levels of nitrogen, phosphorous, and chlorophyll $\alpha$ compared to the national median values for catchments dominated by indigenous forest cover (Perrie \& Milne, 2012; Verburg et al., 2010). In terms of the New Zealand National Policy Statement for Freshwater Management (NPS-FM) both phosphorous and chlorophyll $\alpha$ levels (if taken as the annual maxima) are representative of a state where "lake ecological communities are moderately impacted by additional algal and plant growth arising from nutrient levels that are elevated well above natural reference conditions" (NPS-FM, 2014, pp. 24, 26).

Previous research shows that Lake Pounui experiences periods of thermal stratification and reduced dissolved oxygen in summer months. Lawless (1983) and (Jellyman, 1990) found slight thermal and oxygen stratification in summer months; however, an increase in wind speed from $3.4 \mathrm{~m} \mathrm{~s}^{-1}$ to $9.7 \mathrm{~m} \mathrm{~s}^{-1}$ induced mixing within a 24 hour period (Jellyman, 1990). Perrie and Milne (2012) also observed oxygen stratification with $<0.5$ $\mathrm{mg} \mathrm{L}^{-1}$ at depths $>7.5 \mathrm{~m}$, although temperatures remained homogenous. Monitoring of dissolved oxygen and temperature carried out by Marcus Vangergoes (GNS Science) and Andrew Rees (VUW) from 2012-2014 showed periods of slight thermal stratification coinciding with reduced dissolved oxygen concentrations in summer months (Fig. 2.4).

Previous research also shows that Lake Pounui has experienced periodic algal blooms during summer months. Jellyman (1990) observed cyanobacteria blooms (Diolichospermum spp.) which occurred from mid-January to early-February and lasted up to 10 days during each year of the study. Monitoring of phytoplankton, turbidity, and chlorophyll $\alpha$ by Vandergoes (GNS Science) and Rees (VUW) from 2012-2016 shows periods of increased nutrient enriched phytoplankton species, turbidity, and chlorophyll $\alpha$ occurring in summer months following periods of reduced dissolved oxygen (Fig. 2.5). The latest LakeSPI survey published by de Winton (2016) was conducted during 
an algal bloom. De Winton (2016) stated that other evidence such as shoreline filamentous algae, masses of small sponges, and abundant snails (Potamopyrgus antipodarum), are all indicative of a highly productive lake.

\begin{tabular}{|c|c|c|c|c|c|}
\hline $\begin{array}{l}\text { Monitoring } \\
\text { Study }\end{array}$ & $\begin{array}{c}\text { Jellyman, } \\
1990\end{array}$ & Lawless, 1986 & $\begin{array}{l}\text { Drake et } \\
\text { al., } 2011\end{array}$ & $\begin{array}{l}\text { de Winton et } \\
\text { al., } 2011\end{array}$ & $\begin{array}{l}\text { National } \\
\text { Median } \\
\text { (Verburg et } \\
\text { al., 2010) }\end{array}$ \\
\hline Dates & $\begin{array}{c}\text { 19/08/1977 - } \\
\text { 28/06/1978 }\end{array}$ & $\begin{array}{c}\text { 05/1980 - } \\
\text { 11/1981; } \\
08 / 04 / 1982\end{array}$ & 2007 & $17 / 03 / 2011$ & $2005-2009$ \\
\hline $\begin{array}{l}\text { Temperature } \\
\left({ }^{\circ} \mathrm{C}\right)\end{array}$ & 14.4 & 12.9 & & 19.1 & \\
\hline pH & 7.6 & & 7.5 & 8 & 7.5 \\
\hline $\begin{array}{l}\text { Conductivity } \\
(\mu \mathrm{S} / \mathrm{m})\end{array}$ & 186 & & & 189 & 228 \\
\hline $\begin{array}{l}\text { Chlorophyll } \alpha \\
\left(\mathrm{mg} / \mathrm{m}^{3}\right)\end{array}$ & & 1.49 & 3.2 & 29 & 1.6 \\
\hline $\begin{array}{l}\text { Nitrate } \\
\text { Nitrogen } \\
\text { (mg/L) } \\
\end{array}$ & & $<0.01$ & 0.0022 & $<0.002$ & \\
\hline $\begin{array}{l}\text { Ammoniacal } \\
\text { Nitrogen } \\
\text { (mg/L) }\end{array}$ & & 0.28 & 0.0116 & 0.012 & 0.006 \\
\hline $\begin{array}{l}\text { Total Kjeidahl } \\
\text { Nitrogen } \\
\text { (mg/L) } \\
\end{array}$ & & & & 0.012 & \\
\hline $\begin{array}{l}\text { Dissolved } \\
\text { Reactive } \\
\text { Phosphorous } \\
\text { (mg/L) }\end{array}$ & & 0.005 & 0.0031 & 0.005 & 0.002 \\
\hline $\begin{array}{l}\text { Total } \\
\text { Phosphorous } \\
\text { (mg/L) }\end{array}$ & & 0.022 & 0.0117 & 0.026 & 0.007 \\
\hline $\begin{array}{l}\text { Surface Oxygen } \\
\text { (mg/L) }\end{array}$ & & 10.6 & & 9.28 & \\
\hline $\begin{array}{l}\text { Secchi Depth } \\
\text { (m) }\end{array}$ & & & & 3.1 & 6.5 \\
\hline Turbidity (NTU) & & & & 1.37 & 0.8 \\
\hline $\begin{array}{l}\text { Total } \\
\text { Suspended } \\
\text { Solids (mg/L) }\end{array}$ & & & & $<2$ & \\
\hline $\begin{array}{l}\text { Total Organic } \\
\text { Carbon (mg/L) }\end{array}$ & & & 5.1 & 6.8 & \\
\hline $\begin{array}{l}\text { E.coli } \\
\text { (cfu/100mL) }\end{array}$ & & & & 3 & \\
\hline
\end{tabular}




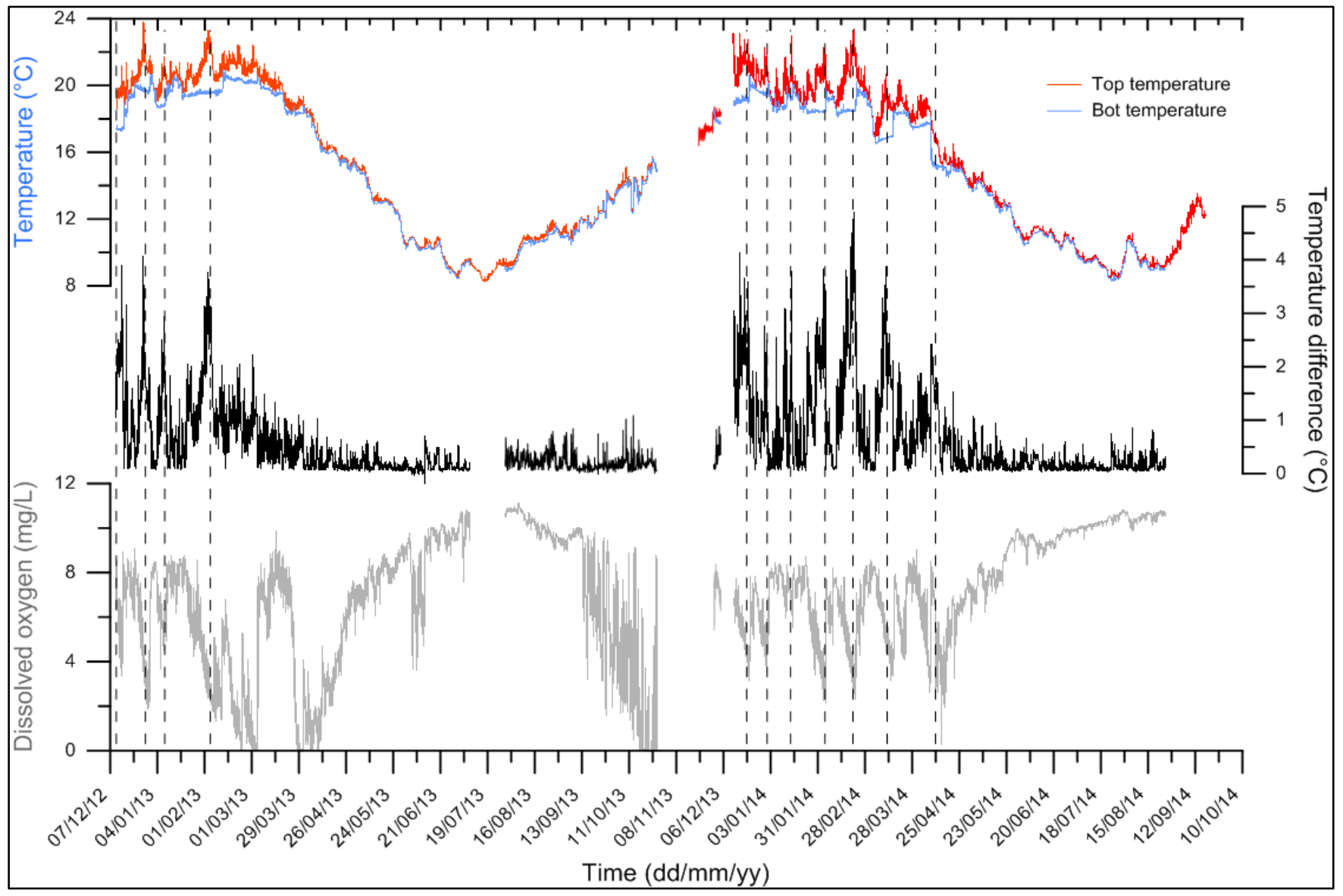

Figure 2.4: Dissolved oxygen and temperature measurements at Lake Pounui from 12/2012 to 10/2014 conducted by Vandergoes (GNS Science) and Rees (VUW) shows periods of thermal stratification and dissolved oxygen depletion in summer months. Figure produced by Rees (VUW). 


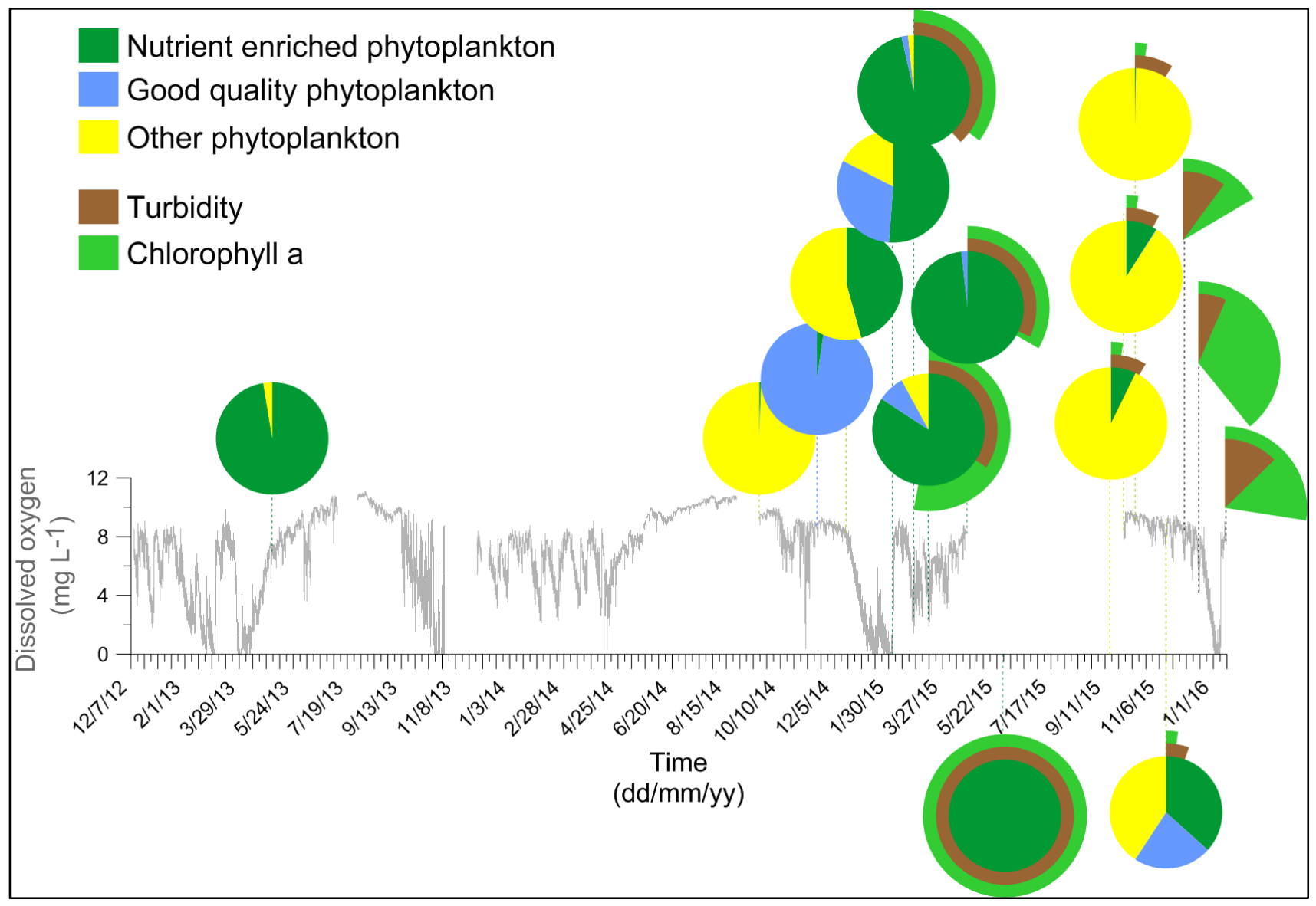

Figure 2.5: Phytoplankton, turbidity, chlorophyll $\alpha$, and dissolved oxygen measurements at Lake Pounui from 12/2012 to 01/2016 conducted by Vandergoes (GNS Science) and Rees (VUW) shows periods of increased nutrient enriched phytoplankton (dark green inner circles), turbidity (outer brown circles), and chlorophyll a (outer green circles) following periods of reduced dissolved oxygen concentration (grey) in summer months. Figure produced by Rees (VUW). 
de Winton (2016) described Lake Pounui's condition as moderate, but declining. Previously, the lake had been classified as oligotrophic to mesotrophic (Drake et al., 2011; Jellyman, 1990; Lawless, 1983); however, Perrie and Milne (2012) later classified the lake as eutrophic, suggesting that the water quality of Lake Pounui may have declined over recent years (Fig. 2.6) (Bunny, Perrie, Milne, \& Keenan, 2014). The algal blooms in this catchment are unexpected and may be due to a number of factors including: external nutrient loading via the clearance of manuka scrubland and development of pasture (Lawless, 1983); internal nutrient cycling via thermal stratification, bottom water anoxic, and breakdown of dissolved organic matter (Perrie \& Milne, 2012; Lawless, 1983); or trophic interactions by the perch population (de Winton et al., 2011; Smith \& Lester, 2007).

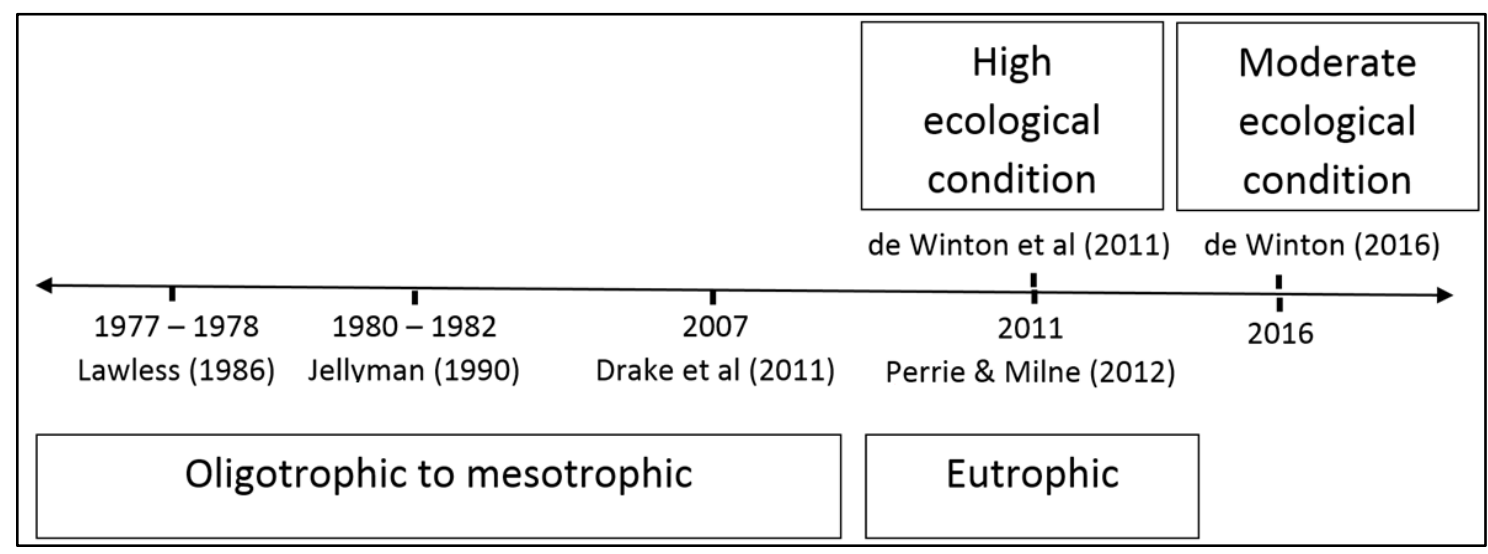

Figure 2.6: Summary of previous research of the ecological condition of Lake Pounui, 1977-2016.

\section{$\underline{\text { Paleolimnology }}$}

Previously at Lake Pounui, paleolimnological methods have been used to study palaeomagnetic secular variation (Turner \& Lillis, 1994). An age-depth model was also created based on four radiocarbon dates from organic fractions extracted from sediment sections (Turner \& Lillis, 1994). Turner and Lillis (1994) estimated that the 3-m of sediment sampled covered the past 2500 years. Further paleolimnological research on the past environmental conditions of Lake Pounui would prove useful in determining whether algal blooms are a natural feature of the lake, and the degree of degradation since human arrival. 


\subsection{Summary}

In summary, evidence suggests that the water quality of Lake Pounui is declining due to an increased duration and frequency of algal blooms. However, this monitoring only spans five periods over the last 40 years. To investigate the cause of the declining water quality and assess departure from baseline conditions, we must expand the record of monitoring. Paleolimnology offers a means of evaluating trends prior to human impact, and Lake Pounui provides a stable environment for preserving numerous proxies. 


\subsection{Introduction}

If algal blooms occurred before human arrival in Lake Pounui, the current algal blooms may be a natural feature, rather than a symptom of anthropogenic eutrophication. Determining whether algal blooms are a natural feature of Lake Pounui has important implications for how the lake is managed going forward. Reconstructing the past environment of Lake Pounui will allow anthropogenic impact to be assessed with respect to natural conditions (i.e., reference conditions). This provides a natural baseline against which to assess degradation and produces information that can be used to set targets for restoration. Paleolimnological methods are becoming recognised as an essential tool for evaluating lake health (Birks, 1996; Battarbee, 1999; Smol, 2008; Bennion \& Battarbee, 2007; Battarbee et al, 2010b), and in New Zealand numerous studies have used these methods (Abrahim et al., 2013; McWethy et al., 2010; Augustinus et al., 2006; McGlone \& Wilmshurst, 1999; Newnham et al., 1998). To investigate research question one - are algal blooms a natural feature of Lake Pounui - I will measure indicators of ecological change, catchment disturbance, and human arrival. The following section will discuss the rationale and methods for the chosen proxies.

\subsection{Methods}

\subsubsection{Coring}

Cores were collected by Andrew Rees, Marcus Vandergoes, and Randall McDonnell using a modified Livingstone corer (Livingstone, 1955) (Fig. 3.1) operated from a cataraft with a flat wooden deck. The cataraft was towed by boat to the central part of the lake's basin ( $~ 9.6 \mathrm{~m}$ deep), where accumulation of sediment should be highest. P1 was collected on 08/08/14 from S41.34486 , E175.11345 . Three 1-m drives were made: P1.1 (0.40-1.23 m), P1.2 (1.40-2.28 m), and P1.3, which was aborted due to high wind, but a recovery of 2.40-2.71 m was made. Cores P2 and P3 were collected with continuous barrels, which were subsequently sectioned, on 09/09/14. P2 was collected from $\mathrm{S} 41.34493^{\circ}, \mathrm{E} 175.11345^{\circ}$. This core contained the sediment-water interface and was split into P2.1 $(0.0-1.0 \mathrm{~m})$ and P2.2 $(1.0-2.02 \mathrm{~m})$. P3 was collected from 
$\mathrm{S} 41.34492^{\circ}, \mathrm{E} 175.11342^{\circ}$. This core started $0.30 \mathrm{~m}$ into the sediment and was split into P3.1 (0.30-1.30 m), P3.2 (1.30-2.30 m), and P3.3 (2.30-3.03 m). P5 was collected on 17/08/16 from S41.20694 ${ }^{\circ}$, E175.06821 ${ }^{\circ}$. This core was a single drive of 0-1.315 m. Cores were split in half; one half was kept as an archive and used for lithologic description, the other half was subsampled at $0.5 \mathrm{~cm}$ or $1.0 \mathrm{~cm}$ intervals. Cores were correlated based on lithologic transitions, LOI, and $\mu$-XRF data.

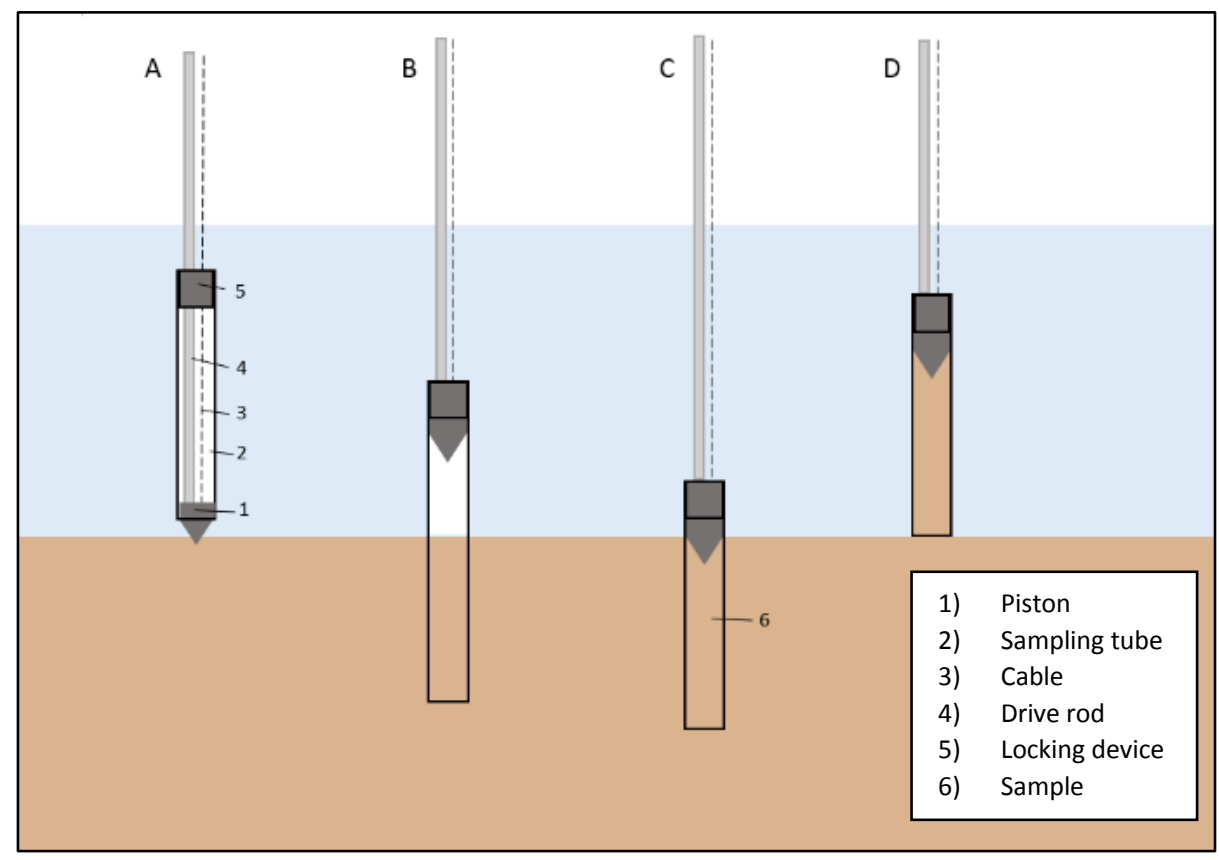

Figure 3.1: Coring Method A) Corer is lowered to sediment-water interface B) Corer is pushed into sediment C) Piston creates suction holding sample in place D) Corer is removed from sediment. 


\subsubsection{Age-Depth Model and Micro-X-Ray Fluorescence Analysis}

\section{$\underline{\text { Radiocarbon }\left({ }^{14} \mathrm{C}\right) \text { dating }}$}

Radiocarbon $\left({ }^{14} \mathrm{C}\right)$ dating is the most widely used dating technique for samples younger than c.50,000 years containing sufficient organic matter (Howarth, Fitzsimons, Jacobsen, Vandergoes, \& Norris, 2013; Blaauw \& Christen, 2011). Accelerator mass spectrometry (AMS) radiocarbon dating was carried out at the Rafter Radiocarbon Laboratory, GNS Science, on seven terrestrial plant macrofossils, one fresh water mussel macrofossil, and two sediment samples with small plant fragments collected from the Lake Pounui cores

\section{$\underline{\text { Procedure }}$}

Samples were rinsed in a $90-\mu \mathrm{m}$ and $150-\mu \mathrm{m}$ sieve stack using distilled water, before being inspected under a microscope to identify the sample and remove contaminants. Samples were then placed in an ultrasonic bath to remove any stubborn contaminants, dried in a $50^{\circ} \mathrm{C}$ oven overnight, and weighed. Acid/Alkali/Acid pretreatment, using 0.5 $\mathrm{M} \mathrm{HCl}$ and $1.0 \mathrm{M} \mathrm{NaOH}$, was carried out on plant material to isolate the humin fraction. An acid etch, using $0.5 \mathrm{M} \mathrm{HCl}$, was carried out on fresh water mussels to remove foreign carbonates. Combustion, graphitisation, and AMS measurement were then carried out by lab technicians at the Rafter National Isotope Centre, GNS Science (detailed methods can be found in Appendix B).

\section{Data Analysis}

Radiocarbon dates were calibrated with SHCal13 (Hogg et al., 2013). An age-depth model was constructed with the Bacon package using Bayesian statistics (Blaauw \& Christen, 2011) in R (R Core Development Team, 2015) which is known to produce reasonable interpolations in low-density dated cores (Blaauw \& Christen, 2011).

\section{Micro-X-ray-fluorescence analysis}

Micro-X-ray-fluorescence analysis ( $\mu$-XRF) is a rapid and non-destructive method to analyse high-resolution geochemistry of sediment cores (Rothwell \& Croudace, 2015a). $\mu$-XRF sediment core scanners use $\mathrm{x}$-ray fluorescence spectrometry to rapidly measure element variations ( $<50$ seconds per increment) at high resolution (one measurement every $500 \mu \mathrm{m}$ on the Lake Pounui cores) (Rothwell \& Croudace, 2015a). There are numerous elemental proxies that have been used to indicate changes in climate, erosion, redox conditions, and organic productivity. 
The archived halves of P2.1 (0.0-1.0 m) and P3 $(0.30-3.03 \mathrm{~m})$ were submitted to the Australian Nuclear Science and Technology Organisation (ANSTO) for $\mu$-XRF analysis using an ITRAX scanner. To account for closed sum effects, such as changes in water and organic content affecting detection of lighter elements, and to avoid relationships between elements (Davies, Lamb, \& Roberts, 2015) data were normalised by the kilocounts per second (kcps).

\section{$\underline{\mu-X R F \text { proxy for tephra }}$}

Magnetic susceptibility describes the degree of magnetization when a magnetic field is applied (Rothwell \& Croudace, 2015b). This generally reflects the presence of ferromagnetic minerals, such as iron-titanium oxides, which are attracted to magnetic fields and retain magnetism when the field is removed (Rothwell \& Croudace, 2015b). Hence magnetic susceptibility reflects iron (Fe) and titanium (Ti) mineral concentrations. Magnetic susceptibility peaks can also be used to identify tephra layers (Davies et al., 2015).

\section{$\underline{\text { Procedure }}$}

$\mu$-XRF identified a magnetic susceptibility spike, corresponding to a 1-mm tephra layer at $291.1 \mathrm{~cm}$ down core. Tephras have been used in numerous studies as independent isochronous markers (Abrahim et al., 2013; Augustinus, Bleakley, Deng, Shane, \& Cochran, 2008; Augustinus et al., 2006).

The tephra was extracted by sieving the sample at $63 \mu \mathrm{m}$ and $30 \mu \mathrm{m}$, rinsing with acetone, and drying in an oven set to $50^{\circ} \mathrm{C}$. The tephra was processed and identified by Brent Alloway at Victoria University, Wellington, using a JEOL Superprobe (JXA8230).

\section{$\mu-X R F$ proxy for oxygen concentration}

The oxidised form of most elements is stable in oxygen rich conditions; however, when oxygen becomes depleted, an element may be reduced to a lower oxidation state (Davidson, 1993). Iron (Fe) and manganese (Mn) profiles can be used to identify changes in redox conditions. When Fe (III) and Mn (IV) are reduced to Fe (II) and Mn (II), their solubility increases and they can be released from the sediment (dissolution occurs), although, Mn (IV) is more readily affected (Haberzettl et al., 2007). Because of the higher solubility of $\mathrm{Mn}$ versus $\mathrm{Fe}$, a rising $\mathrm{Fe} / \mathrm{Mn}$ ratio can indicate the start of anoxic conditions (Stephens et al., 2012; Haberzettl et al., 2007). Haberzettl et al. 
(2007) interpreted lower Fe/Mn ratios as enhanced lake mixing/oxygenation as a result of either increased wind speed or decreased lake level. Corella et al. (2012) found a statistical correlation between phosphorous and Fe/Mn ratios. This is likely to be related to eutrophication events enhancing the stratification of the lake and promoting anoxic bottom water conditions (Corella et al., 2012). The Fe/Mn ratio will be calculated to support the reconstruction of oxygen concentration via diatom analysis (Section 3.3.3).

\section{$\mu-X R F$ proxy for organic content}

The ratio of incoherent to coherent scattering relates to the atomic number of the average matrix of the sediment at that point. Because organic carbon has, on average, a lower atomic number than most clastic material, higher incoherent to coherent scattering ratios can be used to indicate increased organic content (Davies et al., 2015). The incoherent/coherent scattering ratio will be using to support the reconstruction of organic content via loss-on-ignition (Section3.3.4)

\section{$\mu-X R F$ proxy for erosion}

Davies et al. (2015) stated that geochemically stable lithogenic elements, such as aluminium $(\mathrm{Al})$, silica $(\mathrm{Si})$, potassium $(\mathrm{K})$, titanium $(\mathrm{Ti})$, iron $(\mathrm{Fe})$, rubidium $(\mathrm{Rb})$, and (zircon) Zr, can be used as indicators of allochthonous input and increased erosion. Al, $\mathrm{Si}, \mathrm{K}$, and $\mathrm{Fe}$ are the main elements within the argillite and greywacke basement rocks of the main axial ranges in New Zealand; these elements are well measured by $\mu$-XRF. Diatoms are abundant throughout the core, so without correcting Si for biogenic input, that element is not an accurate indicator of detrital input. Fe is also affected by redox conditions, therefore, Al, K, and Ti should provide evidence of increased erosion via natural disturbances such as storms or earthquakes, and anthropogenic disturbances such as land clearance (McWethy et al., 2010) (Section 3.3.4, 3.3.5).

\subsubsection{Ecological Change}

Ecological change can be reconstructed using fossilised diatoms and pollen, and bacterial DNA, which are all well preserved in lake sediment. Different taxa have different affinities along environmental gradients, permitting inferences about past environments. 


\section{$\underline{\text { Diatoms }}$}

Diatoms (class Bacillariophyceae) are microscopic, unicellular, eukaryotic algae (Lowe \& Walker, 2014; Battarbee et al., 2001; Round, Crawford \& Mann, 1990). All diatoms have unique silicified cell walls called frustules (Sims, 2006; Round et al., 1990) (Fig. 3.2). A frustule consists of two overlapping thecae: the epitheca and hypotheca (Sims, 2006; Round et al., 1990). The hypotheca consists of the younger, smaller valve created after the last cell division and the epitheca consists of the older, larger valve, which is inherited from the parent cell (Round et al., 1990). Each theca also contains a number of linking structures called girdle bands or cingulum, which hold the valves together (Sims, 2006; Round et al., 1990). Frustules are both highly differentiated between taxa and well preserved in depositional environments making them a useful proxy (Round et al., 1990). Frustules have two basic morphologies: centric (cylindrical) and pennate (elongated) (Round et al., 1990). Taxa can then be differentiated based on numerous features such as: number of striae in $10 \mu \mathrm{m}$, and the presence, absence, and position of a raphe on pennate diatoms (Fig. 3.2) (Round et al., 1990).

Diatoms are a useful proxy because they quickly respond to environmental change, and exist in a wide variety of water quality gradients (Ruhland, Paterson, \& Smol, 2015). Diatoms can be described by life strategy: planktonic, tychoplanktonic, epipelic, epiphytic or terrestrial (Ruhland et al., 2015; Round et al., 1990). The growth and behaviour of planktonic and tychoplanktic diatoms is mainly influenced by the amount of silicate and the tendency of diatoms to sink due to the density of siliceous walls (Round et al., 1990). Planktonic diatoms are adapted to remain in suspension with little turbulence (Round et al., 1990). Planktonic diatoms are generally lightly silicified, have high surface area to volume ratios, and have small diffusion boundaries for efficient nutrient uptake (Ruhland et al., 2015). Tychoplanktonic species, however, are more heavily silicified, and require turbulence for suspension and nutrient recycling (Ruhland et al., 2015). Epipelic (or benthic) diatoms live attached to the substratum or freely on and in sediment, epiphytic diatoms live attached to plants, and terrestrial diatoms live amongst the soil on land (Round et al., 1990).

There are multiple controls on diatom populations that can cause assemblage change (Smol \& Cumming, 2000); these can be split into physical and chemical variables. Physical variables include temperature, ice cover, wind, and solar radiation, which affect processes such as lake mixing/stratification, depth of limnetic zone, and nutrient availability (Ruhland et al., 2015). Chemical variables include acidity, salinity, oxygen 
concentration, and nutrient availability (Lowe \& Walker, 2014). Modern diatoms have been studied to determine their ecological preferences, so fossil diatoms can be used to infer past environments and assess nutrient status (Battarbee et al., 2001). Diatoms have been used as proxies for past environments in a number of studies in New Zealand (Augustinus, Cochran, Kattel, D’Costa, \& Shane, 2012; Stephens et al., 2012; Young, 2010; Augustinus et al., 2008; Cochran et al., 2007; Augustinus et al., 2006). van Dam, Merterns, and Sinkeldam (1994) created a checklist which assigns values to 984 diatom taxa based on affinity for $\mathrm{pH}$, salinity, nitrogen uptake, oxygen requirement, saprobity, moisture, and trophic status. This checklist has been used by a number of studies in New Zealand to reconstruct environment and nutrient status based on diatom assemblages (Augustinus et al., 2012; Young, 2010; Augustinus et al., 2008).

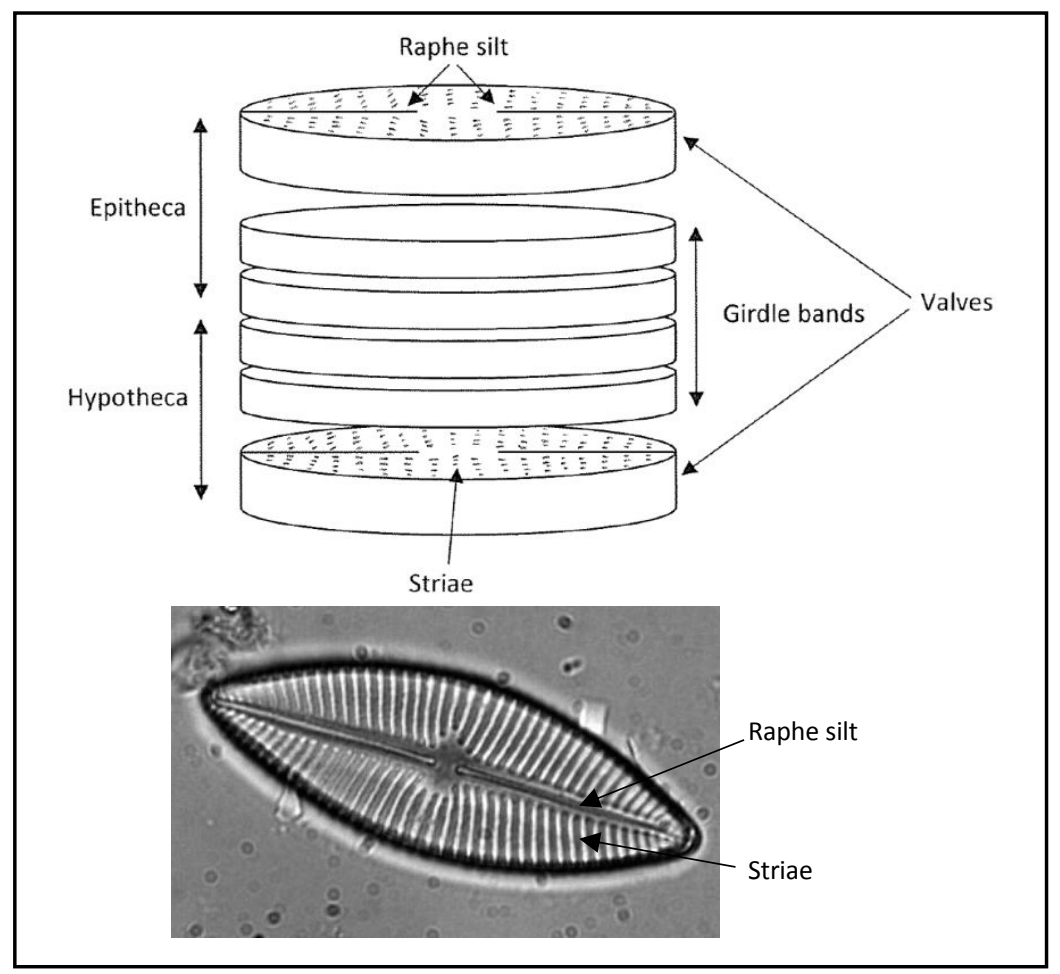

Figure 3.2: Frustule structure of a raphid diatom. Each frustule contains an older epitheca and younger hypotheca. Each thecae contains a valve and numerous girdle bands. Striae are rows of pores on the valve surface. Raphid diatoms have raphe silts through the valve allowing movement over surfaces. 


\section{Procedure}

Diatom analysis was carried out using standard methods presented in Battarbee (1986) with adaptations suggested by Harper (2015, pers. comm.). Samples were taken at 0.5$\mathrm{cm}$ intervals in the top $12 \mathrm{~cm}$ of P2.1 to examine modern human impact, 2 to $5-\mathrm{cm}$ intervals in the top $60 \mathrm{~cm}$ to examine human arrival, 1 to $5-\mathrm{cm}$ intervals between 160 $\mathrm{cm}$ to $190 \mathrm{~cm}$ to examine an identified pre-human environmental shift, and $10-\mathrm{cm}$ intervals throughout the rest of the core; totalling 79 samples. Only $1 \mathrm{~g}$ of sediment per sample interval was needed for diatom analysis. Organic matter was oxidised using 10 $\mathrm{ml}$ of hydrogen peroxide (27\%), left overnight, and heated for $2 \mathrm{hr}$ to ensure the reaction was complete. Samples were then rinsed until neutral. Samples were sieved through a $5-\mu \mathrm{m}$ mesh with luke-warm water to remove clay. Diatom frustules were then settled onto coverslips and mounted on slides using Naphrax (refractive index 1.74). A minimum of 300 valves were counted at 1,000x magnification using a Leica DMC light microscope. Diatoms were identified to species level when appropriate using Krammer and Lange-Bertalot (1991) as the main text and assigned to currently accepted names from AlgalBase (Guiry \& Guiry, 2016). Diatom identification and associated references can be found in Appendix C.

\section{$\underline{\text { Data analysis }}$}

\section{Stratigraphy}

The diatom stratigraphy was plotted in C2 (Juggins, 2003) and Tilia Version 2.0.41 (Grimm, 2015). Diatom ecological preferences were identified using van Dam et al. (1994) as the main text and via literature review; these preferences were used as groupings in the stratigraphic plots. Diatom ecological and habitat preferences and associated references can be found in Appendix D.

\section{Summary Statistics}

Summary statistics such as Hill's N2 effective number of occurrences, mean, median, maximum, minimum, and standard deviation were calculated in C2 (Juggins, 2003). The Shannon diversity index (H') was also produced using the Vegan package (Oksanen et al., 2016) in R (R Core Development Team, 2015) to measure diversity within the assemblage (Xhulaj, 2012).

\section{Zonation}

Zonation of the diatom data was used to visualise where significant changes in 
assemblages occurred. Zonation of a stratigraphical dataset can be implemented using either clustering or divisive methods that are stratigraphically constrained, meaning that similar samples are only grouped if they are stratigraphically adjacent (Birks, 2010). As suggested by Bennett (2005) and Birks (2010), the diatom percentage data were squareroot transformed and zoned with Psimpoll using the optimal-splitting by information content criterion. Optimal splitting is a stratigraphically constrained divisive technique. Division is based on minimising the sum of variance at each stage based on the information content criterion (Bennet, 2005). The optimal technique 'starts afresh' for each split, so zones are not necessarily related (Bennett, 2005). Pseudo statistical significance can be determined by comparing zones to a broken stick model (Birks, 2010; Bennett, 2005). Each zone accounts for part of the total variance in the dataset, and zones that explained more variance than those randomly generated by the broken stick model were considered significant (Bennett, 2005).

\section{$\underline{\text { Pollen }}$}

Pollen is produced by angiosperms and gymnosperms, while spores are the equivalent in ferns and mosses (Bennett \& Willis, 2001). Pollen and spores are dispersed by wind or insects, and the surplus that is not used in reproduction accumulates in environments such as lake sediments (Bennett \& Willis, 2001). The walls of pollen contain sporopollenin, which is resistant to most chemical and physical degradation except oxidation, therefore pollen grains preserve well in anaerobic environments (Bennett \& Willis, 2001). The walls of pollen grains have specific morphologies allowing identification of different taxa, which can be used to infer different environmental conditions (Bennett \& Willis, 2001; McGlone \& Wilmshurst, 1999). Changes in pollen taxa can also be used to identify both Polynesian land clearance, via a decline in forest pollen and a shift to seral species, and European arrival, via the introduction of exotic taxa like Pinus spp.

Pollen stratigraphy will be used to identify changes in catchment and lake vegetation and thus environmental change, as well as to support the charcoal analysis in the identification of human arrival (Section 3.3.5). Pollen data from 11 samples was provided by Xun Li and Marcus Vandergoes (GNS), who followed standard preparation methods outlined in Faegri and Iverson (1989). 


\section{$\underline{\text { Bacterial DNA }}$}

Bacteria make up a significant part of the freshwater phytoplankton in lakes and are used as indicators of water quality in New Zealand. Cyanobacteria and E. coli are measured attributes in the NPS-FM for human health for recreation (NPS-FM, 2014, pg. 31-32). Cyanobacteria often form blooms that are aesthetically unpleasant, can limit habitat for other organisms, and can produce dangerous toxins (Wood et al., 2013), whereas E. coli are used as an indicator of faecal contamination, although they are usually not pathogenic themselves (Wood et al., 2013). Different bacteria have different life strategies, and environmental preferences. Identification of remnant bacterial DNA from sediment cores can provide information on the environment in which they lived, along with water quality data over lengthy time scales. Traditionally, bacteria have been identified using time consuming microscope techniques (Wood et al., 2013) and rarely have they been used in lake sediment studies. However, molecular genetic tools have been developed - these are much more efficient and enable a wide array of novel hypotheses.

The 16S ribosomal RNA (16S rRNA) gene is a widely used genetic marker for bacterial identification. Bacterial 16S rRNA High Throughput Sequencing (HTS) data from 39 samples was provided by Susie Wood (Cawthron Institute), who followed methods outlined in Webster-Brown, Hawes, Jungblut, Wood, and Christenson (2015).

\subsubsection{Catchment disturbance}

Catchment disturbance provides information on past events that may have affected the lake system. Changes in grain size, organic matter, and element concentrations (Section 3.2.2) often record catchment disturbance (Trodahl et al., 2016; Lowe \& Walker, 2014; Augustinus et al., 2012; McWethy et al., 2010; Augustinus et al., 2008).

\section{$\underline{\text { Grain size }}$}

Disturbance of catchments, for instance by anthropogenic land clearance, earthquakes, or increased storminess, may promote the deposition of coarse grains due to reduced residence time on the landscape (Trodahl et al., 2016). Grain size can also indicate change in lake level as coarse grains are often found on lake margins, while finer grains accumulate in deeper water (Lowe \& Walker, 2014). 


\section{Procedure}

Grain size analysis was carried out using methods adapted from Francus et al. (2013). Pre-treatment of grain size samples was carried out on $3 \mathrm{~g}$ samples taken at $10-\mathrm{cm}$ intervals. Samples were heated for several hours in a $65^{\circ} \mathrm{C}$ water bath while $\mathrm{H}_{2} \mathrm{O}_{2}(30 \%)$ was added continuously, then left at room temperature for 1 week to remove organic matter. Samples were then centrifuged, decanted, and freeze-dried. Samples were not treated with $\mathrm{HCl}$ as no calcium carbonate was present throughout the cores, nor were they treated with $\mathrm{NaCO}_{3}$ to remove biogenic silica as this would potentially damage any minerogenic silica present.

Grain size distributions were determined using the LS13320 laser diffraction particle size analyser at Victoria University of Wellington. Samples were sonicated for 15 minutes before being introduced to the LPS analyser.

\section{$\underline{\text { Data Analysis }}$}

A number of descriptive statistics were used to visualise grain size data. The median describes the middle of the population. Sorting describes the standard deviation of the samples (well sorted=low standard deviation; poorly sorted=high standard deviation). The skewness describes the asymmetry of the distribution, where positive or fineskewed samples have an excess of fine particles, and negative or coarse-skewed samples have an excess of coarse particles. Kurtosis measures the ratio between sorting in the tails and sorting in the centre of the distribution, where samples that are leptokurtic have better sorting in the centre than in the tails, and samples that are platykurtic have better sorting in the tails than in the centre (Blott \& Pye, 2001). These statistics were calculated with GRADISTAT version 8.0 (Blott, 2010), using Folk and Ward graphical methods as suggested by Blott and Pye (2001).

\section{Organic content via loss-on-ignition}

Loss-on-ignition (LOI) measures the organic content of sediment. Organic content may vary due to a change in autochthonous or allocthonous productivity. For example, increased productivity within a lake, increased catchment vegetation, or the development of humic soils may result in increased organic matter within lake sediments (Lowe \& Walker, 2014). However, periods of increased erosion or disturbance may promote greater input of allocthonous minerogenic material, which can 
be identified as a relative decrease in organic content (Lowe \& Walker, 2014; McWethy et al., 2010). Land clearance via fire reduces the vegetation in the catchment and may reduce the organic content within the lake. Therefore, organic content via LOI was also used to assess evidence for human arrival (Section 3.3.5).

\section{Procedure}

Organic matter was determined using loss-on-ignition methods adapted from Dean (1974). To measure LOI, $1 \mathrm{~cm}^{3}$ of sediment was taken every $5 \mathrm{~cm}$, dried overnight at $110^{\circ} \mathrm{C}$, and ashed in a muffle furnace for $4 \mathrm{hr}$ at $550^{\circ} \mathrm{C}$. Samples were processed at 5cm intervals with help from Ainslee Brown and Sky Halford (ENSC 302 students).

\section{$\underline{\text { Data Analysis }}$}

LOI was calculated as the percentage of dry weight lost after the ashing phase.

\subsubsection{Human arrival}

Lake sediment can be used to identify human arrival in NZ based on fire history and appearance of exotic species. Fire history can be reconstructed using three lines of evidence: increase in particulate charcoal, change in pollen indicating a disturbance to the vegetation, and lithological evidence indicating a disturbance to the catchment (Whitlock \& Larsen, 2001).

\section{Charcoal analysis}

As previously stated, an increase in magnitude and frequency of charcoal in stratigraphic records in New Zealand is generally strong evidence for anthropogenic influence (McGlone \& Wilmshurst, 1999). Charcoal analysis can focus on microscopic $(<100 \mu \mathrm{m})$ and/or macroscopic $(>100 \mu \mathrm{m})$ charcoal (Whitlock \& Larsen, 2001). Microscopic charcoal travels further due to its smaller size, and therefore is used as a proxy for regional fires (Whitlock \& Larsen, 2001; McGlone \& Wilmshurst, 1999). Macroscopic charcoal travels shorter distances due to its larger size, and therefore is used as a proxy for local fires (Whitlock \& Larsen, 2001). There is some variation in the lower limit of macroscopic charcoal size; however, most studies use the 125-250 $\mu \mathrm{m}$ fraction as it is the most practical for analysis (Rees, Cwynar, \& Fletcher, 2015; McWethy et al., 2010; Enache \& Cumming, 2007; Whitlock \& Larsen, 2001). Sample volume also ranges from 1 to $5 \mathrm{~cm}^{3}$ depending on charcoal concentration (Rees et al., 2015; Enache \& Cumming, 2007). Whitlock and Larsen (2001) state that a fire event is 
typically represented by $>50$ particles $\mathrm{cm}^{-3}$. In this study, macroscopic charcoal analysis was conducted using methods adapted from Rees et al. (2015), Enache and Cumming (2007) and Whitlock \& Larsen (2001).

\section{Procedure}

60 sediment samples of $2 \mathrm{~cm}^{3}$ were taken at 5 -cm intervals. Samples were disaggregated in $40 \mathrm{~mL}$ of $10 \% \mathrm{KOH}$ for 1 week. Samples were then washed through $125-\mu \mathrm{m}$ and $250-\mu \mathrm{m}$ sieves. The 125 to $250-\mu \mathrm{m}$ fraction was placed in a gridded Petri dish, and charcoal fragments were counted using a microscope at 17x magnification. Samples were processed at 5-cm intervals with help from Ainslee Brown and Sky Halford (ENSC 302 students). Micro-charcoal less than $100 \mu \mathrm{m}$ was counted from pollen slides by Xun Li (GNS).

\section{$\underline{\text { Data Analysis }}$}

Charcoal counts were converted to concentration (charcoal particles $\mathrm{cm}^{-3}$ ) by dividing counts by volume of sediment sieved (McWethy et al., 2010). Deposition time ( $\left.\mathrm{yr} \mathrm{cm}^{-3}\right)$ was calculated from the Bayesian age-depth model and converted into influx (particles $\mathrm{cm}^{-2} \mathrm{yr}^{-1}$ ) by dividing the concentration by the deposition time.

\subsection{Results}

The following chapter presents the chronology and lithology of the sediment cores, describes changes in the ecological and catchment disturbance proxies, and identifies human arrival.

\subsubsection{Chronology}

\section{Age-depth model}

The ten samples submitted to the GNS Rafter Radiocarbon Laboratory yielded the conventional radiocarbon ages (CRA) presented in Table 5. These were then calibrated with SHCal13 using the Bacon package (Blaauw \& Christen, 2011) in R (R Core Development Team, 2015) to produce the age-depth model shown in Figure 3.3. 


\section{Tephra marker}

The tephra layer found at $291.1 \mathrm{~cm}$, using the magnetic susceptibility profile, was identified by Brent Alloway (VUW) as an Egmont tephra. Egmont has erupted numerous times with the tephra grading between rhyolitic and andesitic. The tephra found in Lake Pounui is intermediate between rhyolitic and andesitic. Its chemical composition best matches the Kaupokonui and Manganui tephra. The Kaupokonui tephra, dated at $\sim 1400$ cal yr BP (Whitehead, 1976) based on radiocarbon dates, is too young to be deposited at $291.1 \mathrm{~cm}$ (95\% CI: 2647-3151 cal yr BP). The Manganui tephra is estimated to be deposited at $\sim 3200 \mathrm{cal}$ yr BP, based on its position between a lahar deposit dated to $4030+/-110 \mathrm{cal}$ yr BP and an unnamed tephra deposit dated to 1990+/-70 cal yr BP (Whitehead, 1976), and therefore is more likely to be the tephra found in Lake Pounui.

\begin{tabular}{|c|c|c|c|c|c|c|c|c|}
\hline & & & \multicolumn{6}{|c|}{$\begin{array}{l}\text { Table 5: Conventional radiocarbon ages (CRA) and error produced by the Rafter Radiocarbon } \\
\text { Laboratory, GNS Science. Calibrated radiocarbon dates (cal yr BP), minimum } 95 \% \text { (CI), } \\
\text { maximum } 95 \% \mathrm{Cl} \text {, mean, and median calibrated with SHCal13 (Hogg et al., 2013) using the } \\
\text { Bacon package (Blaauw \& Christen, 2003) in R (R Core Development Team, 2015). }\end{array}$} \\
\hline \multicolumn{5}{|c|}{ Conventional radiocarbon ages (CRA) } & \multicolumn{4}{|c|}{ Calibrated radiocarbon dates (cal yr BP) } \\
\hline Lab ID & Description & $\begin{array}{l}\text { Master } \\
\text { Depth (m) }\end{array}$ & CRA & Error & $\begin{array}{l}\text { Min } \\
95 \% \mathrm{Cl}\end{array}$ & $\begin{array}{l}\text { Max } \\
95 \% \mathrm{Cl}\end{array}$ & Mean & Median \\
\hline Surface & Shell & 0 & 230 & 26 & -87.2 & -26.6 & -59.8 & -61 \\
\hline P2.1-6 & Plant & 0.060 & 161 & 20 & -2.4 & 139.5 & 44.3 & 29.2 \\
\hline P3.1-22.5a & Plant & 0.325 & 398 & 20 & 328.8 & 485.3 & 410.2 & 411.2 \\
\hline P2.1-41a & Plant & 0.410 & 513 & 20 & 476.6 & 544.5 & 516 & 515.9 \\
\hline P3.1-41 & Plant & 0.510 & 643 & 20 & 556.7 & 649 & 610.6 & 613.1 \\
\hline P3.1-81 & Wood & 0.910 & 1348 & 21 & 987.9 & 1173.3 & 1098.4 & 1102.2 \\
\hline P2.1-94 & Wood & 0.940 & 1214 & 21 & 1013.1 & 1188.5 & 1124.9 & 1131.4 \\
\hline P3.2-28.5 & Wood & 1.385 & 1617 & 22 & 1379.5 & 1530.3 & 1453.8 & 1450.9 \\
\hline P1.2-33-35 & Plant & 2.000 & 1821 & 18 & 1717 & 2030.7 & 1840.4 & 1819.5 \\
\hline P1.2-83-85 & Plant & 2.500 & 2492 & 18 & 2307.4 & 2649.2 & 2440.9 & 2425.8 \\
\hline
\end{tabular}




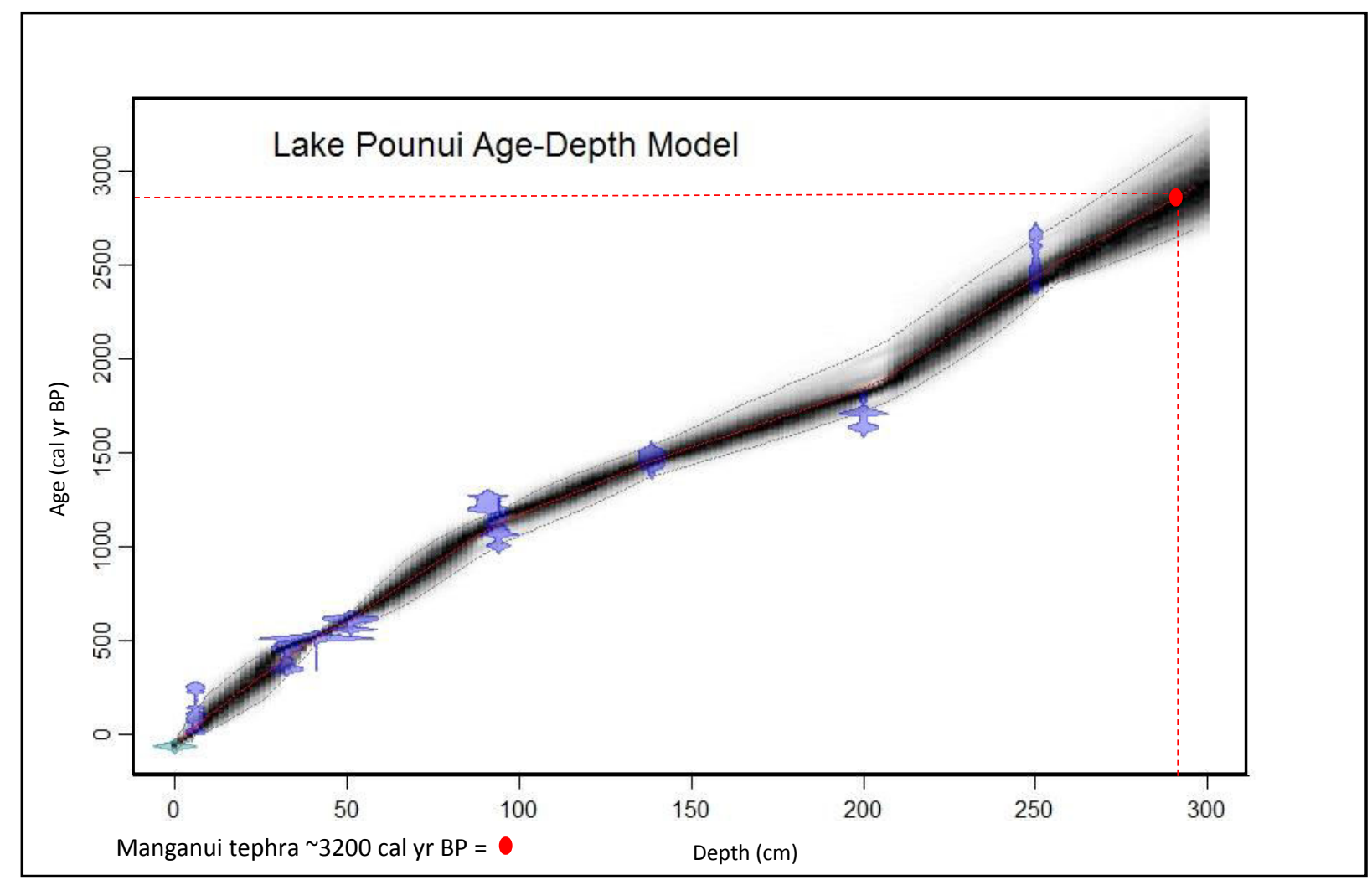

Figure 3.3: Lake Pounui age-depth model produced using the Bacon package (Blaaw \& Christen, $2003)$ in $R$ ( $R$ Core Development Team, 2015). Calibrated radiocarbon dates shown in blue, red curve shows the best model based on the weighted mean, and grey shaded area shows $95 \%$ confidence intervals with darker grey indicating more likely calendar ages. The magnetic susceptibility spike (red dashed line) was identified as the Manganui tephra sourced from Mount Egmont (Brent Alloway) and dated to 3200 cal yr BP (Whitehead, 1976). 


\subsubsection{Lithology, Sampling Resolution, and Zonation}

The lithology of the cores was described based on the Limnological Reasearch Center (LRC) sediment classification scheme (Schnurrenberger, Russell, \& Kelts, 2003) and the Munsell Soil Colour Chart (1994 revised edition). Description of cores can be found in Appendix F. We were not able to carry out all analyses on all the Pounui sediment cores (Fig. 3.7), so cores were correlated based on available information such as lithologic transitions, $\mu-\mathrm{XRF}$, and LOI analysis. P2.1 was used as the master depth scale, putting P3 at an offset of $11 \mathrm{~cm}$ (Fig. 3.4). Therefore, P2.1 was used as the top $11.75 \mathrm{~cm}$ of the master core in proxy analysis (Fig. 3.6, 3.7). Based on LOI, P2.2 was offset from the master scale by $16.75 \mathrm{~cm}$ (Fig. 3.5). Core P3.2 was disturbed between $160.75 \mathrm{~cm}$ and $175.75 \mathrm{~cm}$ due to the core catcher coming loose and becoming lodged within this part of the core, therefore, P2.2 was used for diatom samples within this interval (Fig. 3.6, 3.7). P1, used to supplement the radiocarbon dates, was offset by 22.9 $\mathrm{cm}$ and P5, used for Bacterial DNA analysis, was offset by $-4.9 \mathrm{~cm}$, according to a comparison of lithologic units (Fig. 3.7). The offset between cores may be due to compression/expansion when the cores were taken or slight differences in sedimentation rates.

Zoning trials were conducted using all of the diatom species, diatom species making up more than $2 \%$ of more than 2 samples, and diatom species making up more than $5 \%$ of

more than 2 samples. Using the information from those zoning trials, 5 zones were determined to be the most useful for describing floral-changes. These were:

Zone $1-296.25-216.25 \mathrm{~cm}, 3000$ to $2100 \mathrm{cal}$ yr BP (95\% CI: 3210-1977 cal yr BP)

Zone $2-216.25-162.75 \mathrm{~cm}, 2100$ to $1600 \mathrm{cal} \mathrm{yr} \mathrm{BP} \mathrm{(95 \%} \mathrm{CI:} \mathrm{2361-1507} \mathrm{cal} \mathrm{yr} \mathrm{BP)}$

Zone 3 - $162.75-36.25 \mathrm{~cm}, 1600$ to 450 cal yr BP (95\% CI: $1737-389$ cal yr BP)

Zone $4-36.35-14.25 \mathrm{~cm}, 450$ to $150 \mathrm{cal}$ yr BP (95\% CI: $515-57 \mathrm{cal}$ yr BP)

Zone 5 - 14.25-0.25 cm, 150 cal yr BP (95\% CI: 290-57 cal yr BP) to present. 


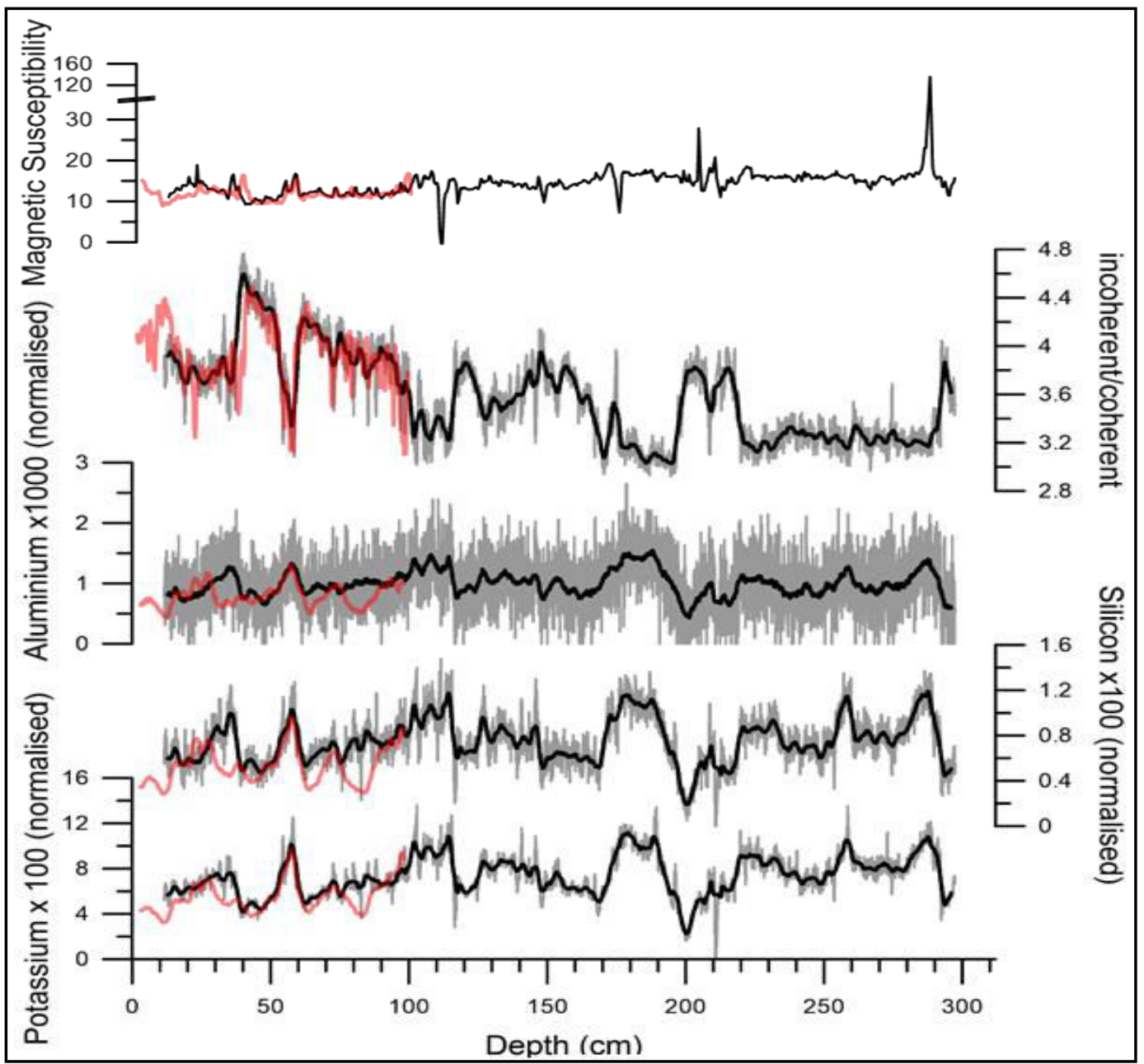

Figure 3.4: Alignment of core P3 (grey line, black line weighted average) with core P2.1 (red line), based on magnetic susceptibility, incoherent/coherent scattering, aluminium, silicon, and potassium data from $\mu-X R F$ analysis. When core P3 is offset by $11 \mathrm{~cm}$ the proxies align relatively well.

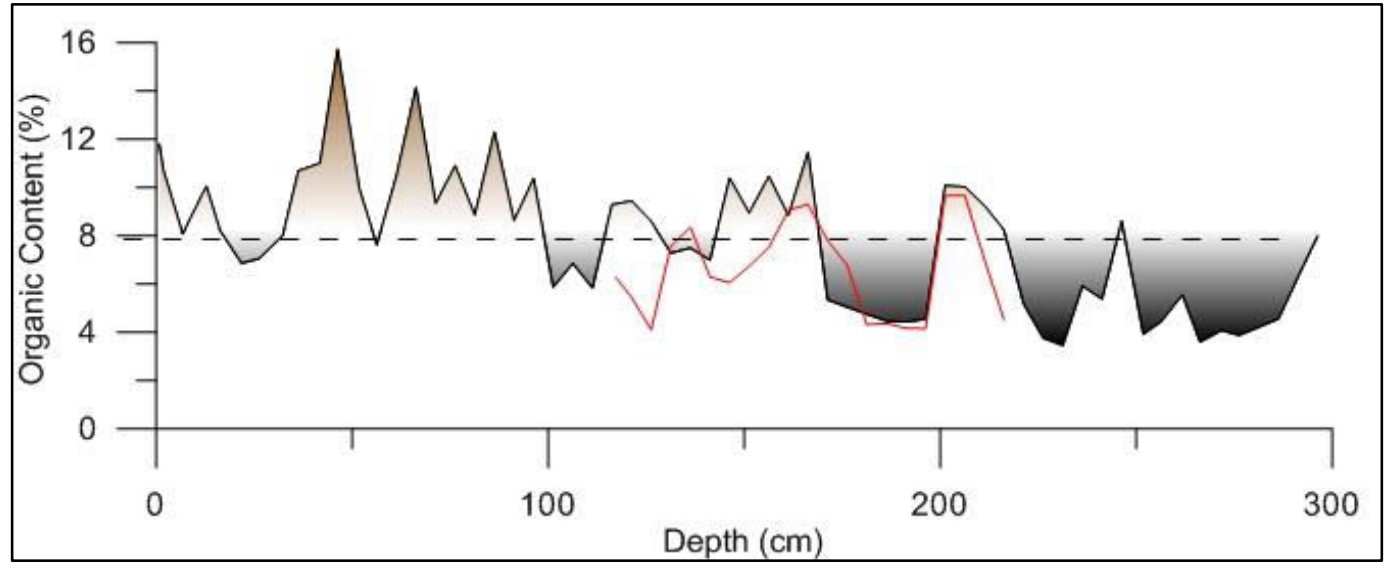

Figure 3.5: Alignment of core P2.2 (red line) with master core based on organic content from loss-on-ignition analysis. When core P2.2 is offset by $16.75 \mathrm{~cm}$ the proxies align relatively well. 


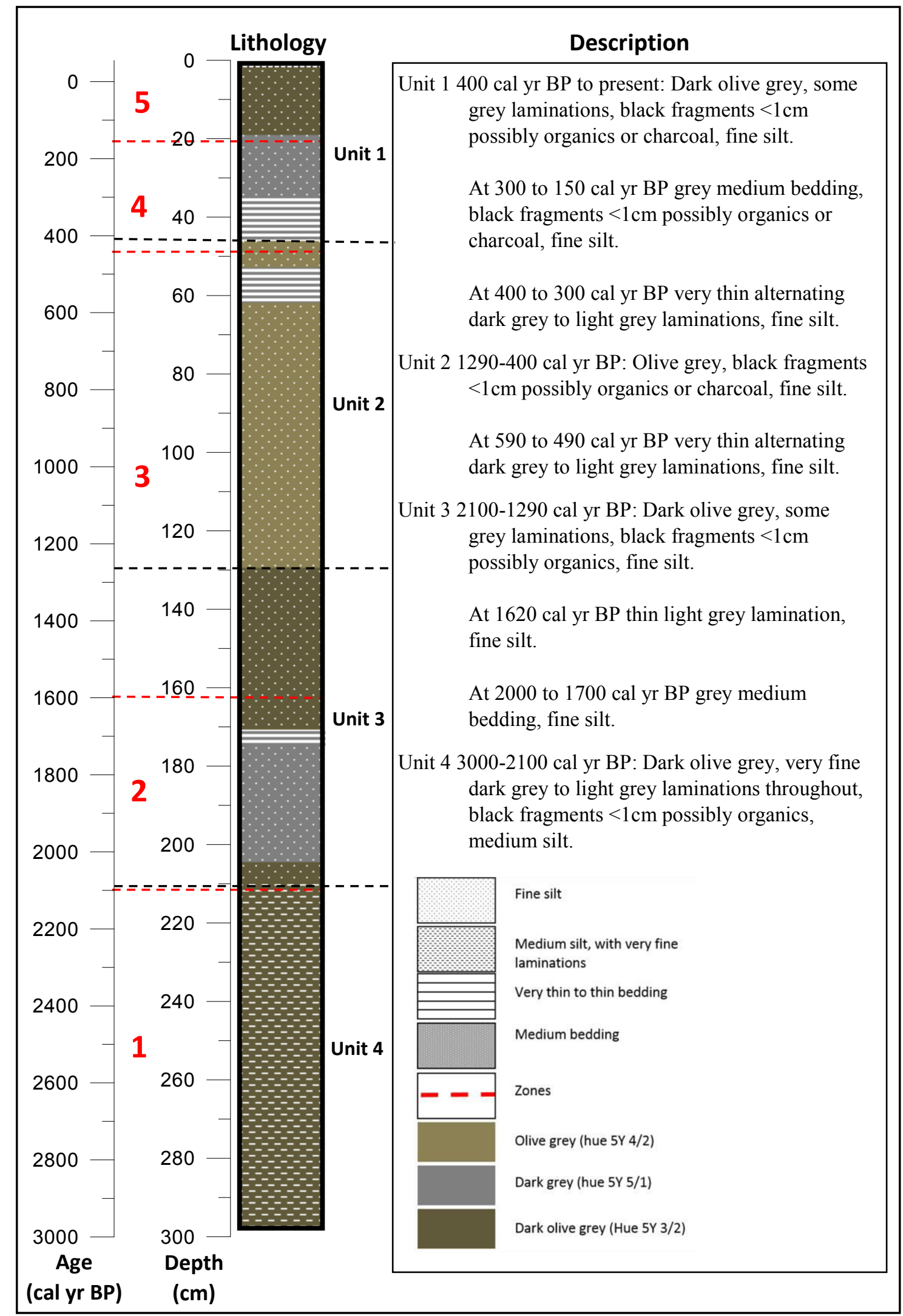

Figure 3.6: Master core. Lithological descriptions shown on right, lithological units shown by black dashed lines, zones identified using the diatom assemblage shown by red dashed lines and red numbers. 


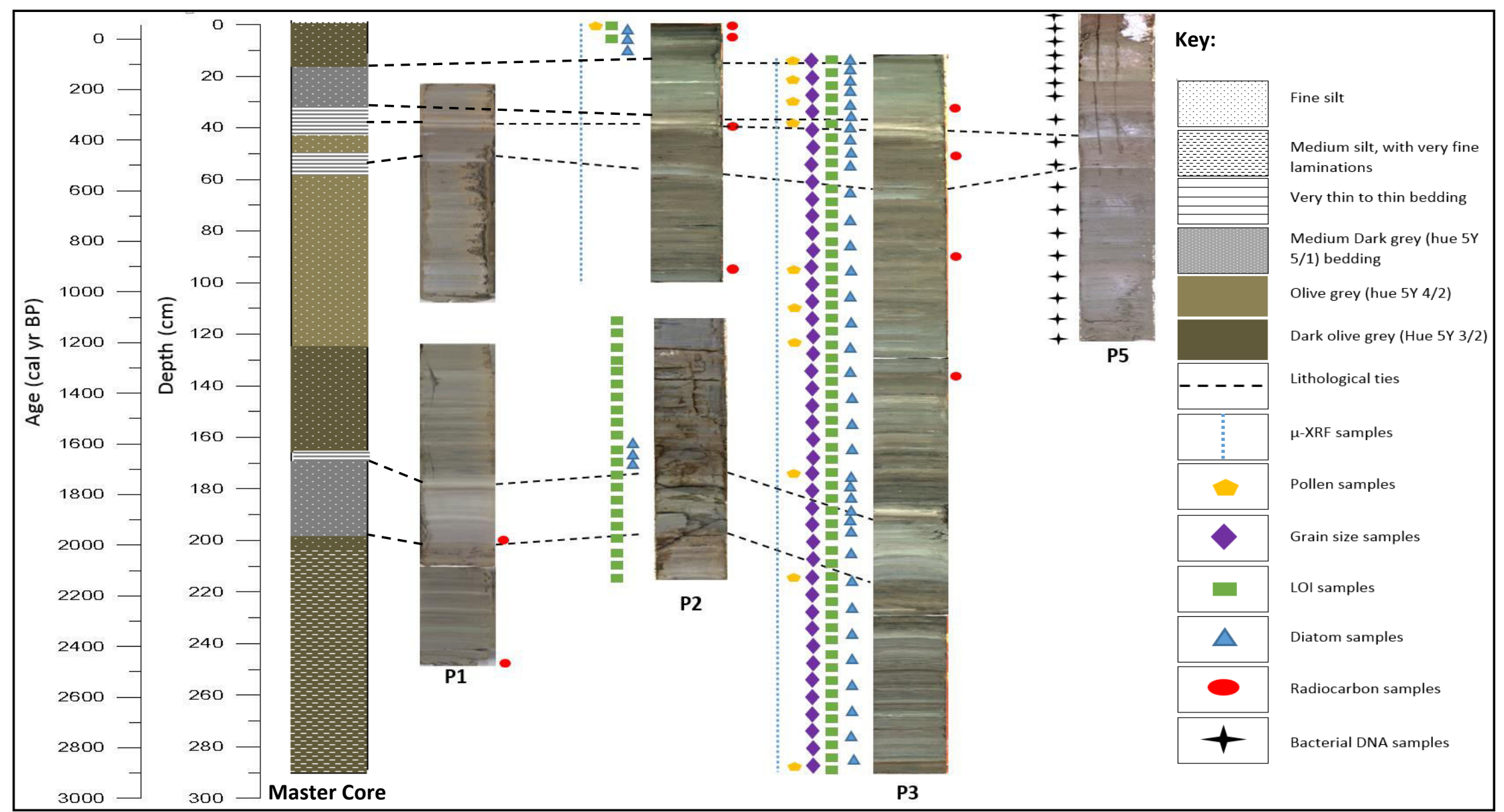

Figure 3.7: Alignment of core and sampling for proxies. Radiocarbon samples (red ovals) were taken where there were visible organics. $\mu$-XRF was performed at $0.05 \mathrm{~cm}$ resolution on $P 2.1$ and P3. Pollen samples were taken at $10 \mathrm{~cm}$ resolution in the top $40 \mathrm{~cm}$ of P3, and sporadically down core. Grain size samples were taken at $5 \mathrm{~cm}$ resolution from P3. LOI samples were taken at $5 \mathrm{~cm}$ resolution from $P 3$ and $P 2.2$. Diatom samples were taken at $0.5 \mathrm{~cm}$ resolution in the top $12 \mathrm{~cm}$ of P2.1, and 1-3 cm resolution from 160-175 cm of P2.2, 2-5 cm resolution in the top $56 \mathrm{~cm}$ of $P 3.1$ and $178-296 \mathrm{~cm}$ of $P 3.2$, and $10 \mathrm{~cm}$ resolution throughout the rest of P3. Bacterial DNA samples were taken from P5 at $1 \mathrm{~cm}$ resolution in the top $10 \mathrm{~cm}, 2 \mathrm{~cm}$ resolution from 10-30 $\mathrm{cm}$, and $5 \mathrm{~cm}$ resolution throughout the rest of the core. 


\subsubsection{Ecological change}

\section{$\underline{\text { Diatoms }}$}

A total of 90 diatom taxa were identified from 79 samples throughout the Lake Pounui core. After removing rare taxa (i.e., those with less than 5\% abundance occurring in fewer than 2 samples), 18 taxa remained (Fig. 3.8) (a more detailed diagram can be found in Appendix E). The diatom assemblage defined 5 zones, which are described below.

Zone 1: 3000 to 2100 cal yr BP - Discostella stelligera, Aulacoseira ambigua, Epithemia spp., and Ulnaria ulna

Discostella stelligera (23\%) and Aulacoseira ambigua (20\%) are dominant in this zone. Epiphytic diatoms, Epithemia spp. (15\%) and Ulnaria ulna (5\%) increase toward the top of the zone. Melosira varians, Cyclostephanos dubius, Navicula spp., Rhopalodia novae-zelandiae and Cocconeis placentula are constant throughout this zone at low levels $(<6 \%)$.

Zone 2: 2100 to 1600 cal yr BP - Discostella stelligera, Aulacoseira spp., and Melosira varians

On average Aulacoseira spp. (34\%) and Discostella stelligera (30\%) dominate, with eutrophic species Aulacoseira granulata var. angustissima showing a large increase. However, at $\sim 1700$ cal yr BP the riverine diatom species Melosira varians spikes, after which small fragilarioid species Staurosira construens, Staurosirella pinnata, Staurosira venter, and Pseudostaurosira brevistriata increase.

Zone 3: 1600 to 450 cal yr BP - Discostella stelligera, Aulacoseira ambigua, and small fragilarioids.

Discostella stelligera (40\%) and Aulacoseira ambigua (15\%) remain dominant, however Aulacoseria granulata var. angustissima and Epithemia spp. decline. Small fragilarioids, Staurosira construens, Staurosirella pinnata, Staurosira venter and Pseudostaurosira brevistriata, further increase, making up $20 \%$ on average.

Zone 4: 450 to 150 cal yr BP - Discostella stelligera, Epithemia spp., and Melosira varians

Discostella stelligera (50\%) remains dominant, whereas Aulacoseira spp. decline. The epiphytic species Epithemia increases (18\%), and small fragilarioids slightly decrease 
$(8 \%)$. The riverine species Melosira varians increases at the start of this zone and the marine species Actinocyclus octonarius also increases.

Zone 5: 150 cal yr BP to present Discostella stelligera, Aulacoseira granulata var angustissima, and small fragilariods.

Discostella stelligera (35\%) remains dominant; however, eutrophic species Aulacoseira granulata var. angustissima and Cyclostephanous dubius increase towards the top of this zone. Small fragilarioids and Ulnaria ulna show a slight increase. Epithemia spp. and Actinocyclus octonarius maintain constant abundance from zone 4.

\section{$\underline{\text { Ecological variables }}$}

Diatoms were grouped according to their ecological preferences using van Dam et al. (1994)'s ecological indicators. These indicators were simplified into summary groups (Table 6) that were used for Figure 3.15. Of the 90 identified diatom taxa, 81 were listed in van Dam et al (1994). On average $18 \%$ of the assemblage was unknown for trophic status, $4 \%$ for salinity, $5 \%$ for $\mathrm{pH}$, and $44 \%$ was unknown for oxygen, nitrogen, and saprobity. Because of the high proportion of unknowns for nitrogen and saprobity, these groups were removed from analysis; however, the oxygen group was compared to concentrations reconstructed using $\mathrm{Fe} / \mathrm{Mn}$ ratios from the $\mu$-XRF data and was thus retained. 


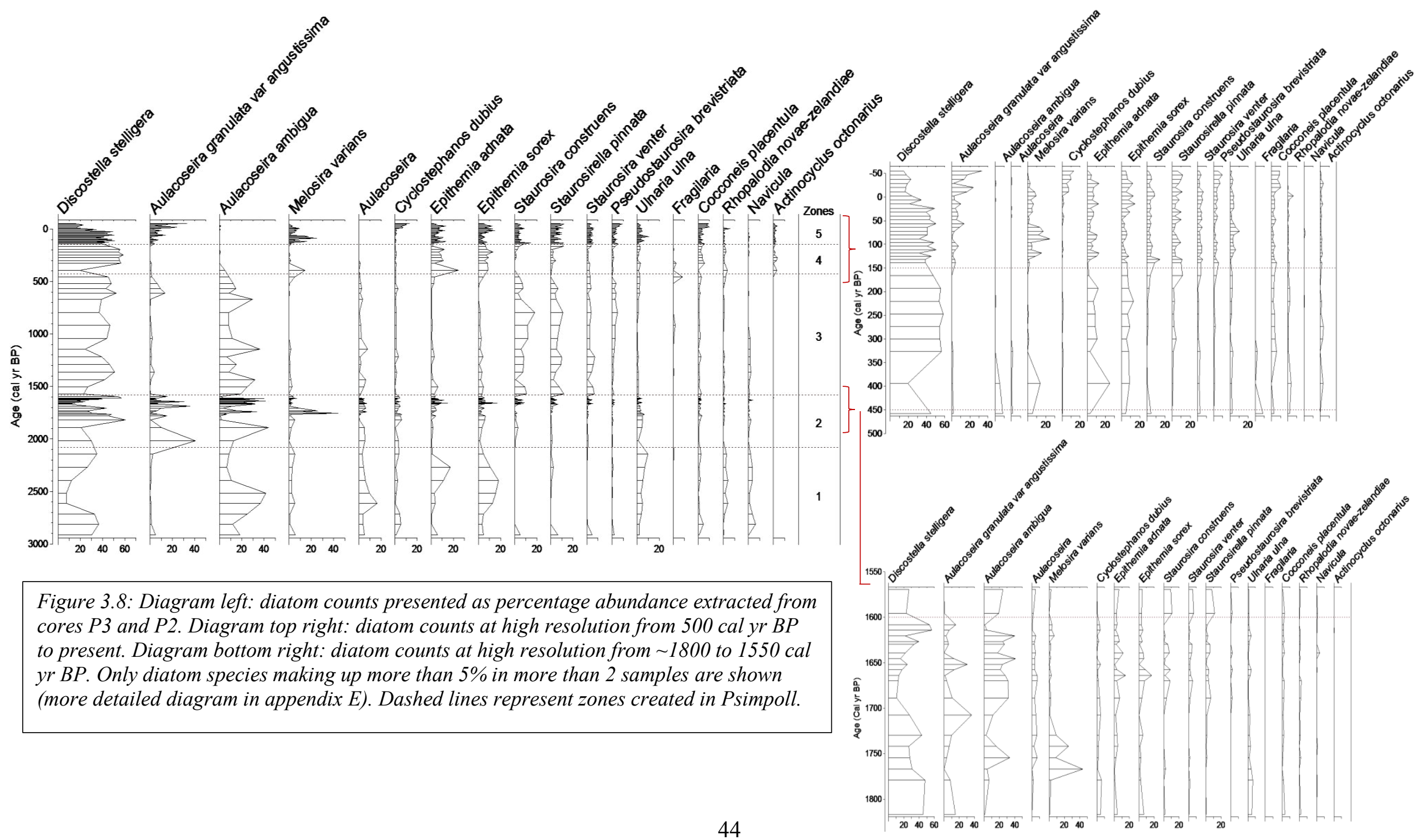




\begin{tabular}{|c|c|c|c|}
\hline \multirow{2}{*}{\multicolumn{3}{|c|}{$\mathrm{pH}$}} & \multirow{4}{*}{$\begin{array}{l}\text { Summary Groups } \\
\mathrm{pH}<7\end{array}$} \\
\hline & & & \\
\hline Acidobionitic & \multicolumn{2}{|c|}{ Optimal occurrence at $\mathrm{pH}<5.5$} & \\
\hline Acidophilous & \multicolumn{2}{|c|}{ Mainly occurring at $\mathrm{pH}<7$} & \\
\hline Circumneutral & \multicolumn{2}{|c|}{ Mainly occurring at pH-values about 7} & $\mathrm{pH} \sim 7$ \\
\hline Alkaliphilious & \multicolumn{2}{|c|}{ Mainly occurring at $\mathrm{pH}>7$} & \multirow{2}{*}{$\mathrm{pH}>7$} \\
\hline Alkalibiontic & \multicolumn{2}{|c|}{ Exclusively occurring at $\mathrm{pH}>7$} & \\
\hline Indifferent & \multicolumn{2}{|l|}{ No apparent optimum } & \multirow{2}{*}{ Unknown or indifferent } \\
\hline Unknown & & & \\
\hline \multicolumn{3}{|l|}{ Salinity } & Summary Groups \\
\hline & $\mathrm{Cl}^{-}\left(\mathrm{mg} \mathrm{l}^{-1}\right)$ & Salinity $(\% \circ)$ & \\
\hline Fresh & $<100$ & $<0.2$ & \multirow{2}{*}{ Fresh } \\
\hline Fresh brackish & $<500$ & $<0.9$ & \\
\hline Brackish fresh & $500-1000$ & $0.9-1.8$ & \multirow{2}{*}{ Brackish } \\
\hline Brackish fresh & $1000-5000$ & $1.8-9.0$ & \\
\hline Unknown & & & Unknown \\
\hline \multicolumn{3}{|c|}{ Oxygen Requirements } & Summary Groups \\
\hline \multicolumn{3}{|c|}{ Continuously high (about 100\% saturation) } & $\sim 100 \%$ \\
\hline \multicolumn{3}{|c|}{ Fairly high (above 75\% saturation) } & $>75 \%$ \\
\hline \multicolumn{3}{|c|}{ Moderate (above $50 \%$ saturation) } & $>50 \%$ \\
\hline \multicolumn{3}{|c|}{ Low (above $30 \%$ saturation) } & $>30 \%$ \\
\hline \multicolumn{3}{|c|}{ Very low (about $10 \%$ saturation) } & $\mathrm{n} / \mathrm{a}$ \\
\hline \multicolumn{3}{|l|}{ Unknown } & Unknown \\
\hline \multicolumn{3}{|l|}{ Trophic State } & Summary Groups \\
\hline \multicolumn{3}{|l|}{ Oligotraphentic } & Oliantronhir \\
\hline \multicolumn{3}{|c|}{ Oligo-mesotraphentic } & Uigotropnic \\
\hline \multicolumn{3}{|c|}{ Mesotraphentic } & Mesotronhir \\
\hline \multicolumn{3}{|c|}{ Meso-eutraphentic } & iviesotropmic \\
\hline \multicolumn{3}{|l|}{ Eutraphentic } & Eutrophic \\
\hline \multicolumn{3}{|c|}{ Hypereutraphentic } & \\
\hline \multicolumn{3}{|c|}{ Oligo- to eutraphentic (hypereutraphentic) } & Unknown or indifferent \\
\hline
\end{tabular}




\section{Trophic Status}

Diatoms were grouped based on trophic status preference (Fig. 3.9). Oligotraphentic diatoms indicate low nutrient conditions, mesotraphentic diatoms indicate moderate nutrient conditions, and eutraphenic diatoms indicate high nutrient conditions. On average zones 1,2, and 5 have a higher proportion of eutraphentic diatoms, whilst zones 3 and 4 have a higher proportion of oligotraphenic diatoms.

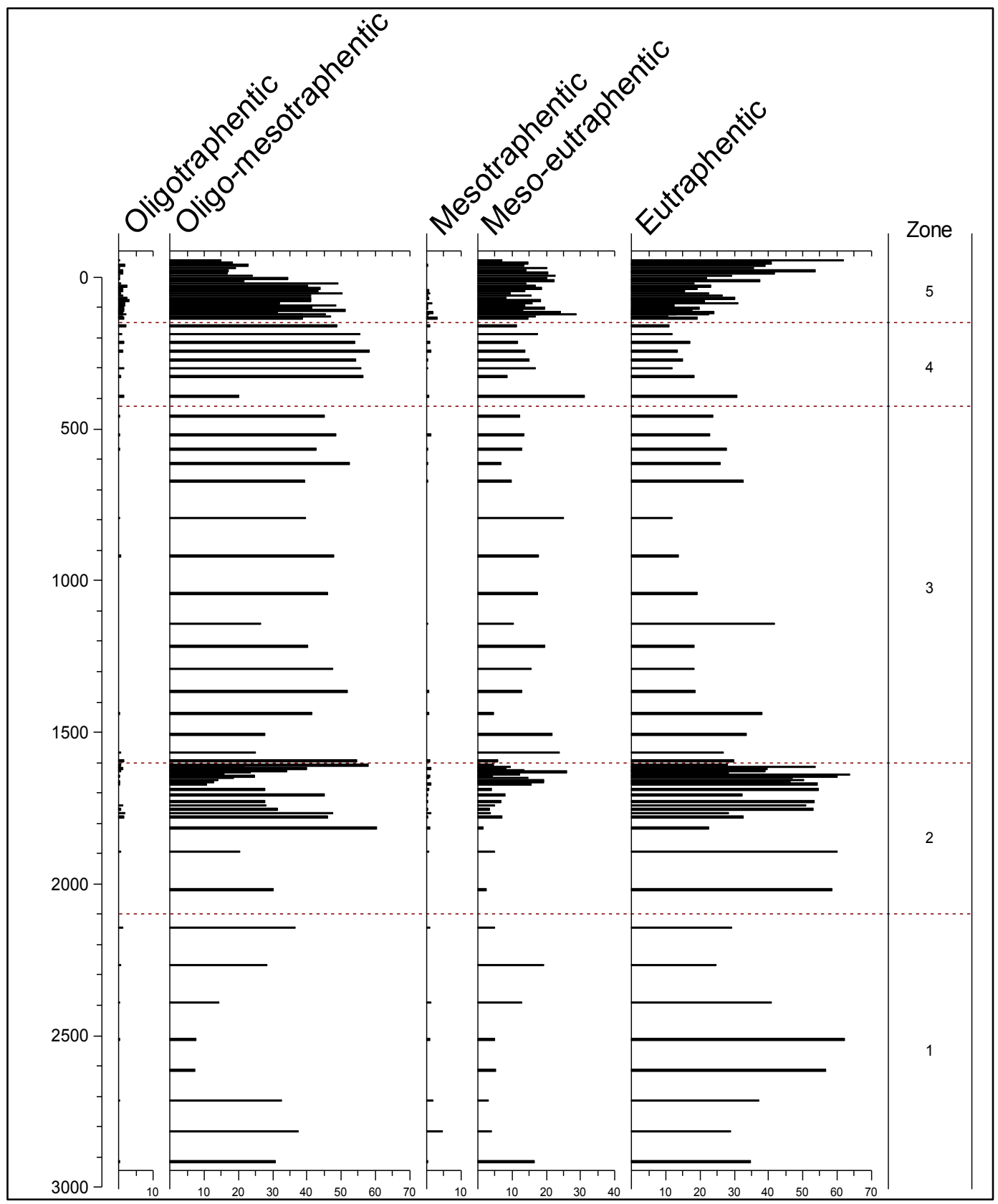

Figure 3.9: Diatoms grouped by trophic status preference (van Dam et al., 1994). 


\section{Salinity}

Diatoms were grouped based on salinity preference (Fig. 3.10). Fresh-brackish diatoms dominate the assemblage, although brackish-fresh and brackish diatoms are present in zones 1 and 2. In zone 3, brackish-fresh and brackish diatoms decline, though brackishfresh and brackish diatoms increase in zones 4 and 5, with a spike of brackish-fresh diatoms in the most recent sediments.

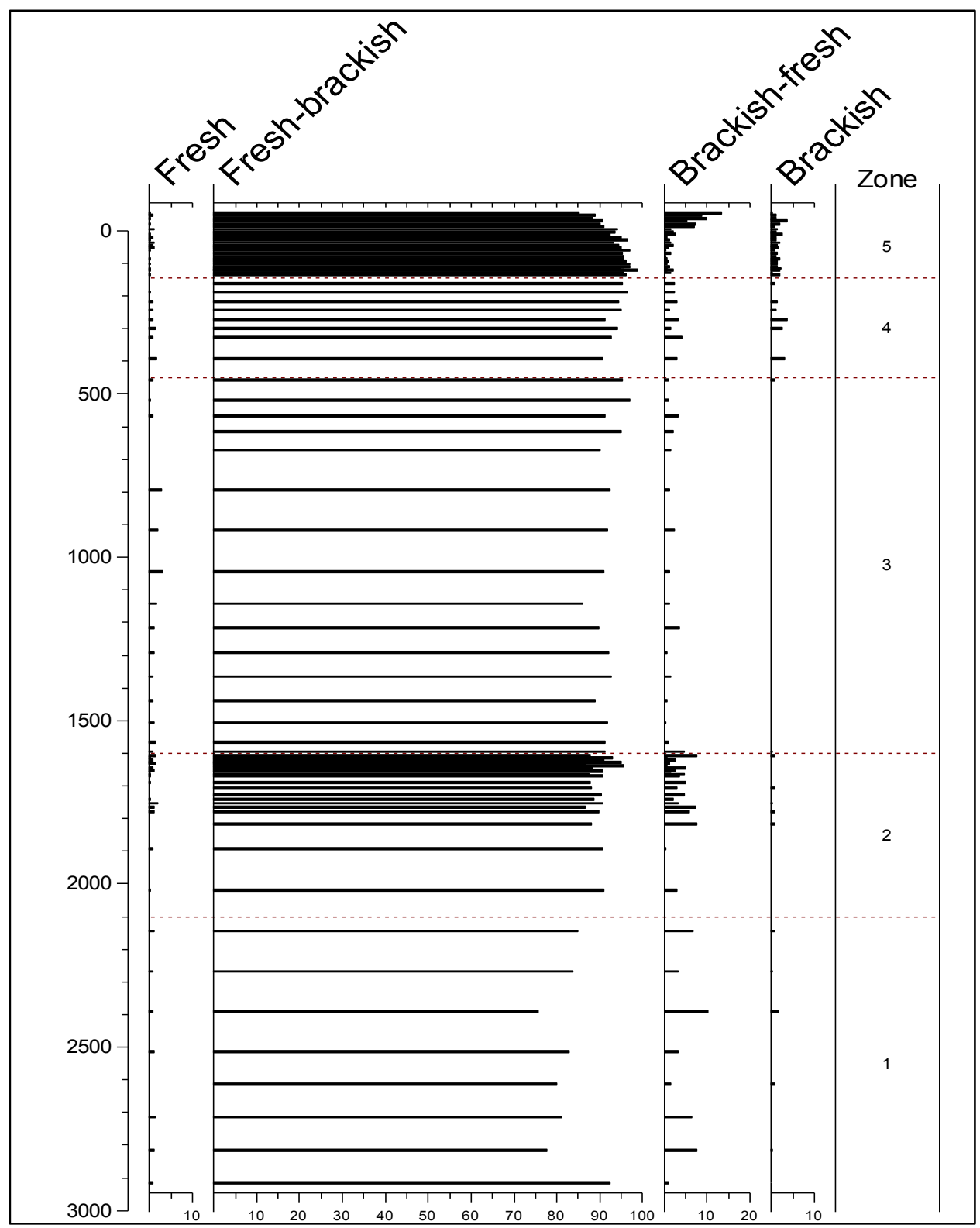

Figure 3.10: Diatoms grouped by salinity preference (van Dam et al., 1994). 
$p H$

Diatoms were grouped based on $\mathrm{pH}$ preference (Fig. 3.11). The assemblage is dominated by alkaliphilous diatoms; however, circumneutral diatoms appear in relatively high abundance in zone 1, and acidophilous diatoms occur in zones 4 and 5.

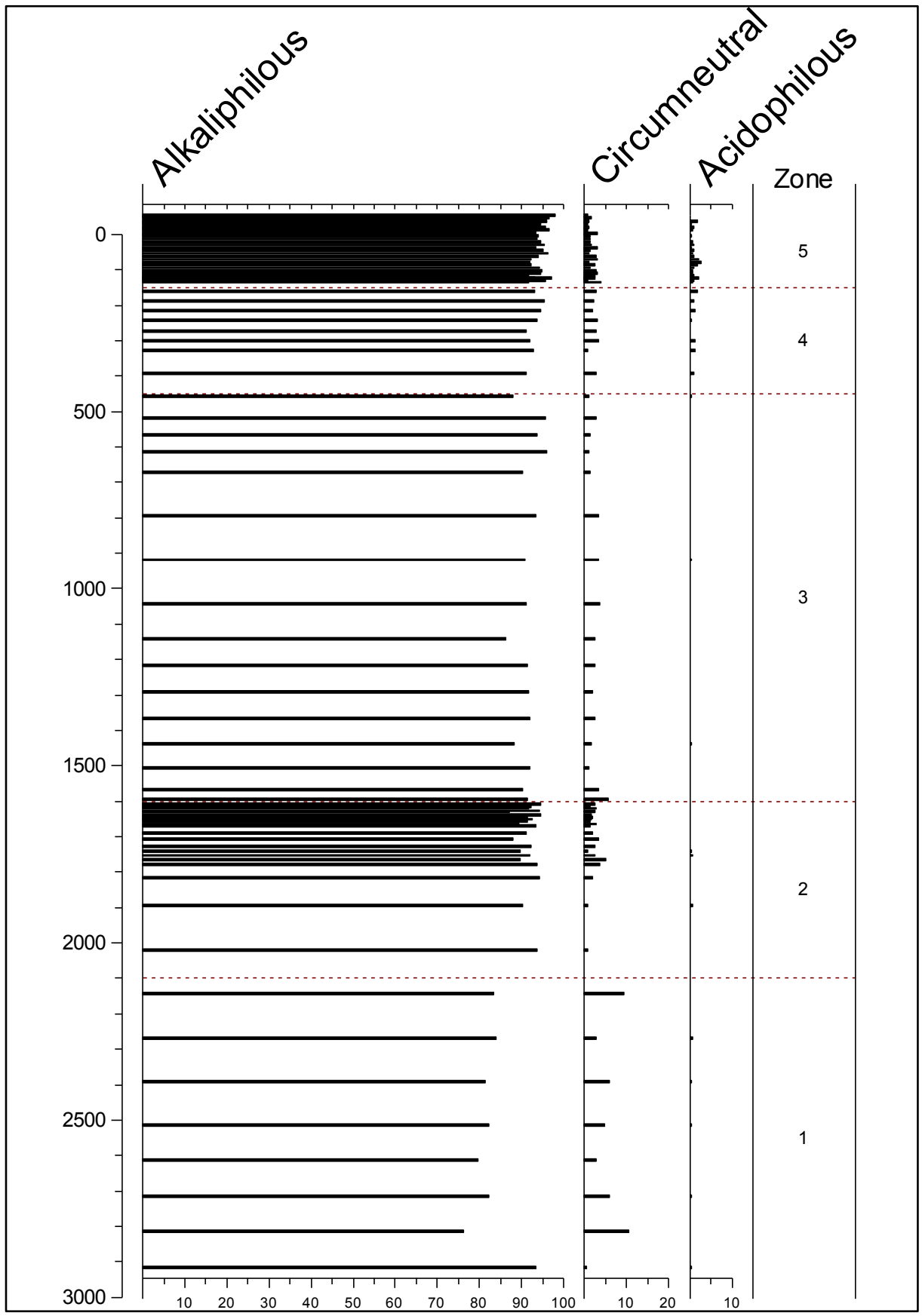

Figure 3.11: Diatoms grouped by pH preference (van Dam et al., 1994). 


\section{Oxygen}

Diatoms were grouped based on oxygen saturation (Fig. 3.12). On average diatoms with moderate oxygen requirements dominate in zones 1 and 2 . Diatoms needing continuously high oxygen saturation increase in zone 3. Diatoms needing fairly high saturation increase in zone 4 , with moderate saturation diatoms increasing again in zone 5.

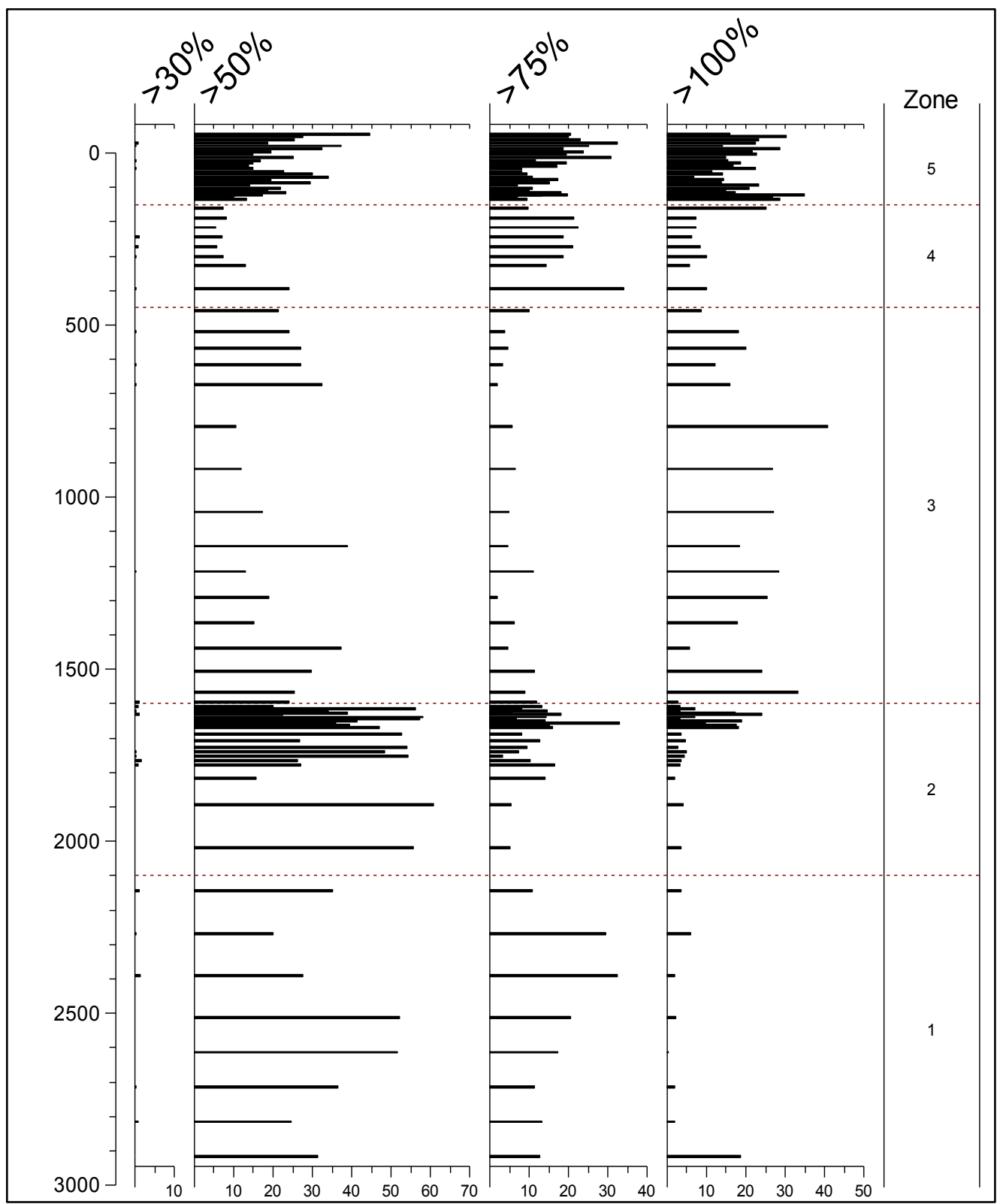

Figure 3.12: Diatoms grouped by oxygen preference (van Dam et al., 1994).

Oxygen concentration was also estimated using the Fe/Mn ratio calculated from the $\mu$ XRF data (Fig. 3.13). The Fe/Mn ratio appears to agree with diatom estimates with lower concentrations in zones 1 and 2, and higher concentrations in zone 3 and 4 . 
However, the diatom data appears to show a decrease in oxygenation in zone 5, whereas the $\mathrm{Fe} / \mathrm{Mn}$ ratio shows an increase.

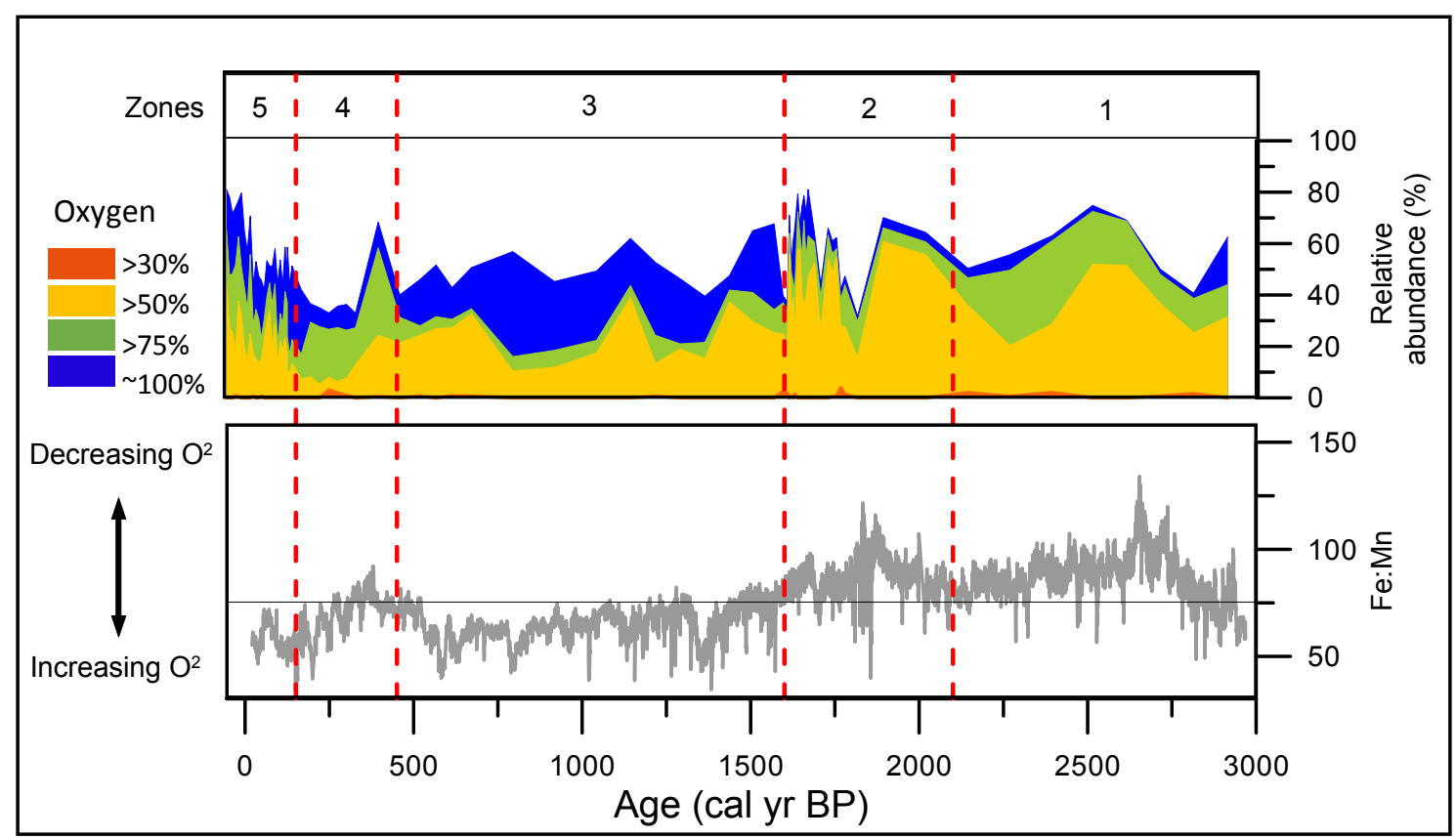

Figure 3.13: Oxygen concentration estimated using the Fe:Mn ratio calculated from the $\mu$ $X R F$ data, compared with oxygen concentration estimated from diatom data.

\section{Habitat}

Diatoms were grouped by habitat using Guiry and Guiry (2016); Li, Liao, Chen, and Shen (2015); Johansen (2010); van Dam et al. (1994); Round et al. (1990); Vos and de Wolf (1988); S.S. Kilham and Kilham (1975); Lund (1946) (full list of diatom species, habitats, and references in appendix D) (Fig. 3.14). Terrestrial taxa are those that have been recorded in terrestrial habitats, epipelic taxa are those found in sedimentary environments, epiphytic taxa are those living attached to plants, planktonic taxa are free-floating, and tychoplanktic taxa are dependent on turbulence to remain in suspension. Epiphytic and epipelic diatoms are relatively high in zone 1, however, these groups decrease in zones 2 and 3. In zone 4 epiphytic diatoms increase and tychoplanktic diatoms decrease. In zone 5 epiphytic diatoms remain relatively high, planktic diatoms decrease, and tychoplanktic diatoms increase. 


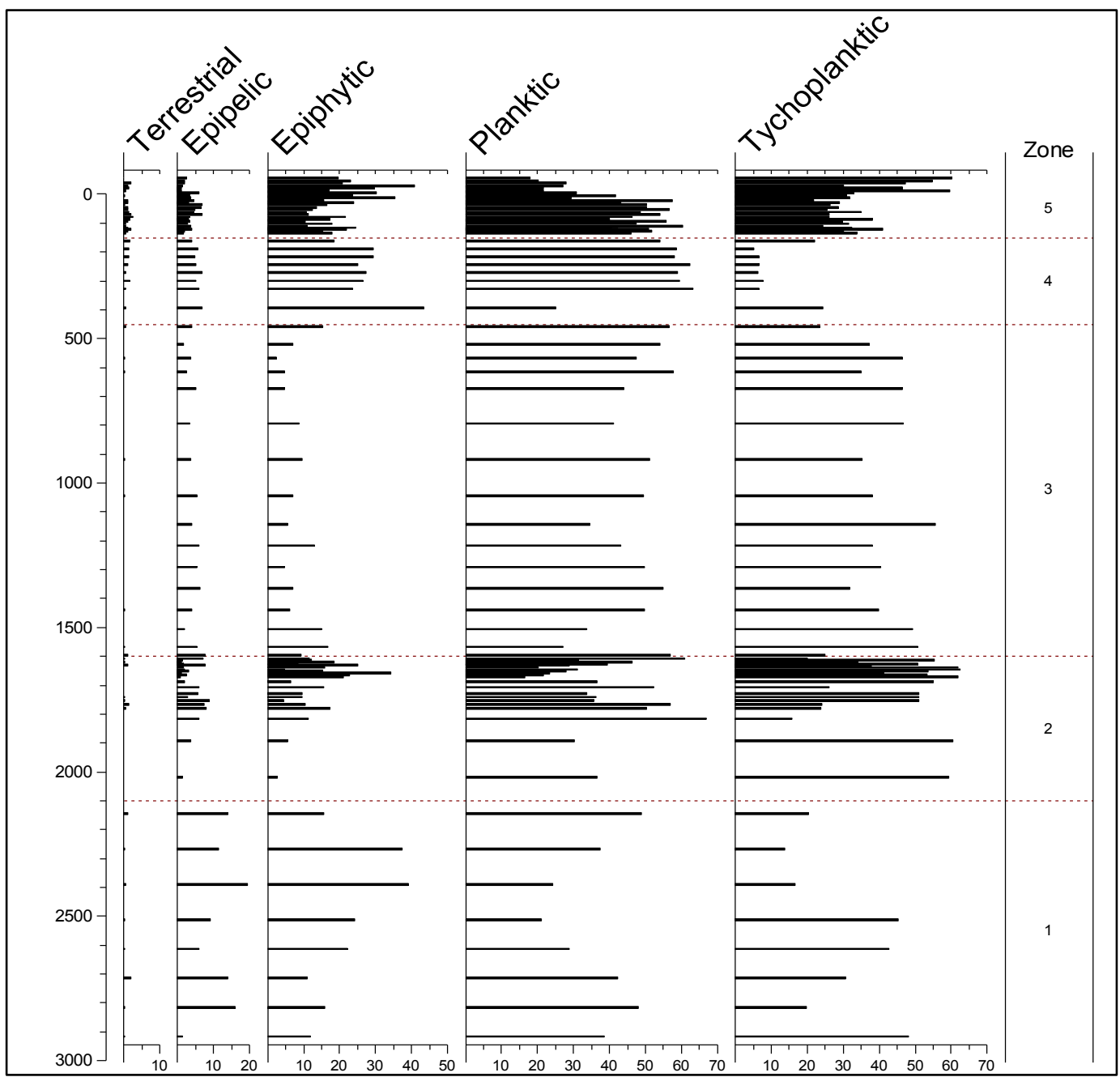

Figure 3.14: Diatoms grouped by habitat preference (van Dam et al., 1994).

\section{$\underline{\text { Statistical analysis }}$}

Summary statistics were calculated using C2 (Juggins, 2003) to examine the structure of the dataset. Minimum (min), maximum ( $\max$ ), mean, median, and standard deviation (st.dev) presented in Table 7, all relate to the number of occurrences of each diatom taxa. Hill's N2 shows the effective number of occurrences of taxon, by measuring the number of taxa in the assemblage but weighting each taxon by abundance (Birks, 2012). Discostella stelligera was the most common species throughout the assemblage, and only Discostella stelligera and Epithemia adnata were present in every sample.

The Shannon diversity index was used to compare diversity within the assemblage (Fig. 3.15). Diatom diversity is relatively high in zone 1, it drops abruptly at the start of zone 2 and remains relatively low throughout zone 3 . Diversity spikes at the start of zone 4 and then declines throughout zone 5 . 


\begin{tabular}{|l|l|l|l|l|l|l|}
\hline $\begin{array}{l}\text { Table 7: Summary statistics of diatoms making up }>5 \% \text { of the population in }>2 \text { samples. Full list } \\
\text { of species and summary statistics can be found in Appendix E. }\end{array}$ \\
\hline Species & Hills N2 & Min & Max & Mean & Median & St.dev \\
\hline Actinocyclus octonarius & 20.97 & 0 & 11 & 1.69 & 0 & 2.72 \\
\hline Aulacoseira ambigua & 31.27 & 0 & 132 & 33.19 & 19 & 39.25 \\
\hline $\begin{array}{l}\text { Aulacoseira granulata var } \\
\text { angustissima }\end{array}$ & 26.45 & 0 & 123 & 19.16 & 9 & 25.96 \\
\hline Aulacoseira spp. & 28.68 & 0 & 50 & 6.97 & 4 & 8.86 \\
\hline Cocconeis placentula & 40.75 & 0 & 30 & 7.08 & 5 & 6.49 \\
\hline Cyclostephanos dubius & 31.86 & 0 & 39 & 6.44 & 3 & 7.49 \\
\hline Discostella stelligera & 64.38 & 22 & 181 & 105.11 & 113 & 42.68 \\
\hline Epithemia adnata & 40.02 & 1 & 74 & 14.63 & 11 & 13.67 \\
\hline Epithemia sorex & 47.07 & 0 & 55 & 15.97 & 13 & 12.30 \\
\hline Fragilaria spp. & 2.61 & 0 & 25 & 0.57 & 0 & 3.02 \\
\hline Melosira varians & 19.98 & 0 & 132 & 12.40 & 5 & 20.57 \\
\hline Navicula spp. & 20.42 & 0 & 19 & 2.09 & 1 & 3.42 \\
\hline Pseudostaurosira brevistriata & 33.97 & 0 & 28 & 5.15 & 3 & 5.66 \\
\hline Rhopalodia novae-zelandiae & 30.59 & 0 & 18 & 2.69 & 2 & 3.25 \\
\hline Staurosira construens & 38.66 & 0 & 56 & 11.16 & 9 & 10.82 \\
\hline Staurosira venter & 46.32 & 0 & 21 & 7.15 & 6 & 5.62 \\
\hline Staurosirella pinnata & 43.32 & 0 & 35 & 12.23 & 10 & 10.45 \\
\hline Ulnaria ulna & 48.34 & 0 & 31 & 8.21 & 7 & 6.10 \\
\hline
\end{tabular}




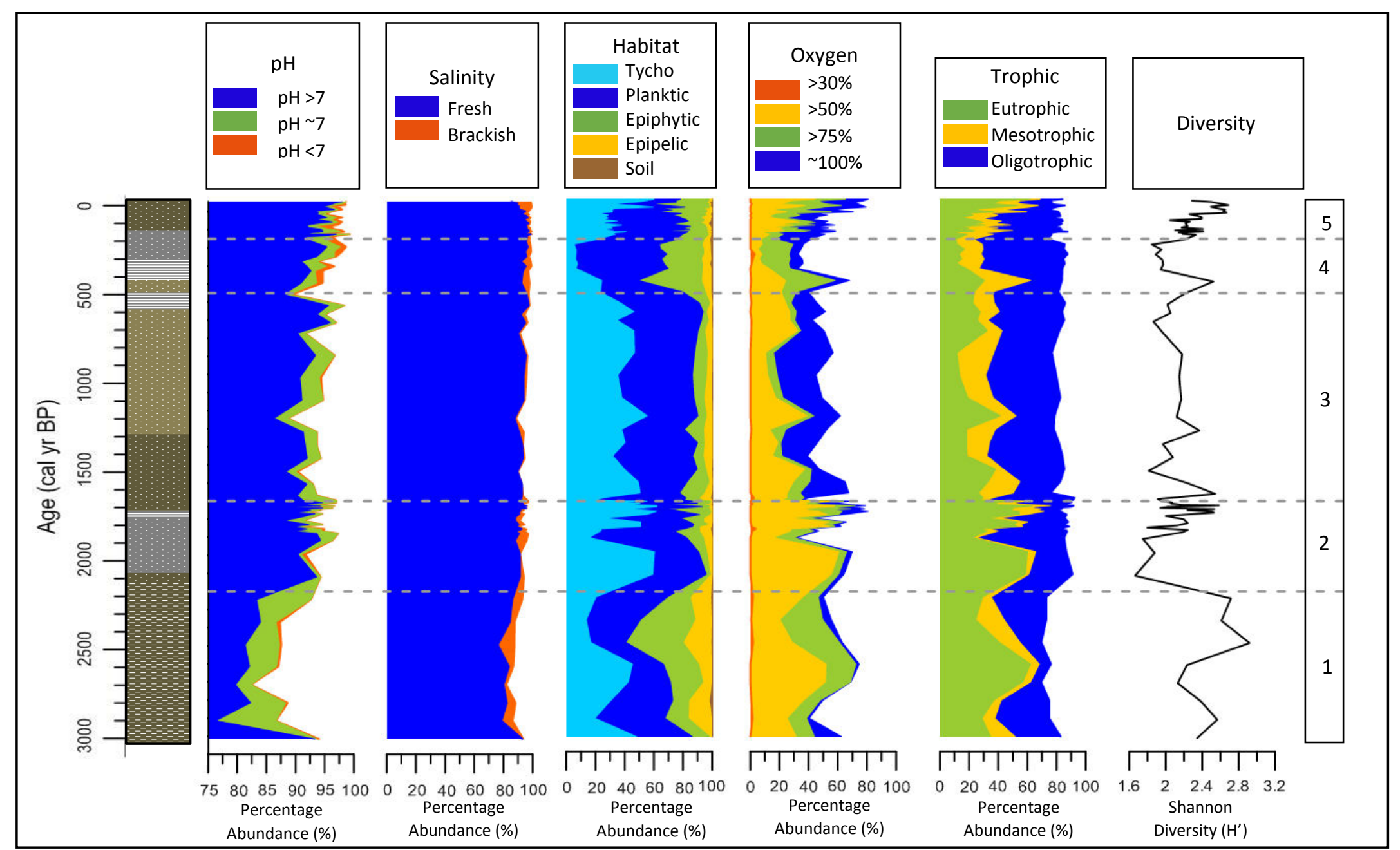

Figure 3.15: Summary of diatom based ecological change. Left to right: lithology, diatom ecological preferences, diatom diversity, and zones. 


\section{Pollen}

In zone one the catchment is dominated by tall trees, and submerged macrophytes are also present within the lake, mainly Potamogeton, which is common in mesotrophic waters (Fig. 3.16). In zone 2 tall trees slightly decline, being replaced by tree ferns. Submerged macrophytes also decline. In zone 3, tall trees and tree ferns fluctuate, submerged macrophytes remain low; however, Isoetes (now on the NZ threat classification list), which is common in oligotrophic waters, makes its first appearance at very low levels. In zone 4, tall trees decline and are replaced by ferns, shrubs, and grasses, and the submerged macrophyte Isoetes spikes in this zone. In zone 5, tall trees continue to decline and are replaced by shrubs and grasses. Ferns also decrease. Isoetes declines while Potamogeton increases.

\section{Bacterial DNA}

Bacterial DNA was extracted from P5 by Susie Wood (Cawthron institute). Figure 3.17 shows four main taxa increasing after $500 \mathrm{cal} \mathrm{yr}$ BP (95\% CI: 480-547 cal yr BP): Bacteroidetes (kahki top), Nitrospirae (teal top), Atribacteria (kahki middle), and Fusobacteria (green middle). Bacteroidetes and Fusobacteria are found in the gastrointestinal tract of animals and humans (Gupta \& Sethi, 2014; S. A. Wood et al., 2013). Nitrospirae has nitrate oxidising and sulphate reducing members (Schneider, Arp, Reimer, Reitner, \& Daniel, 2013). Atribacteria live in anaerobic environments and may play a role in nutrient recycling (Nobu et al., 2016).

Cyanobacteria (black) also increase after 500 cal yr BP. Cyanobacteria are photosynthetic, nitrogen fixing bacteria, some of which are toxic. Two cyanobacteria taxa that now form blooms at Lake Pounui, Dolichospermum and Phormidium, were absent before 500 cal yr BP (Fig. 3.18). 


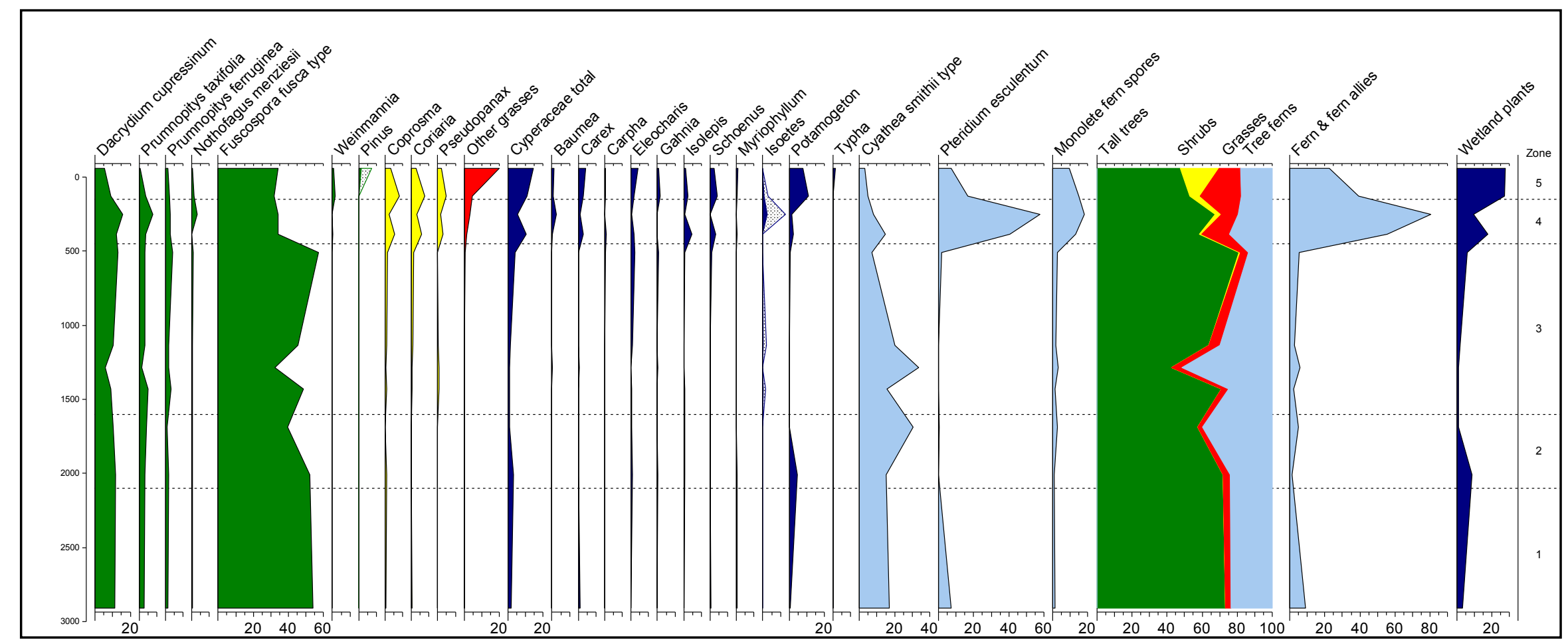

Figure 3.16: Pollen data presented as percentage abundance through time extracted from cores P3 and P2. Pollen data collected and prepared by Marcus Vandergoes and Xun Li (GNS Science). Black dashed lines indicate diatom-inferred zones. Scale expanded on Pinus and Isoetes by a factor of 5 . 


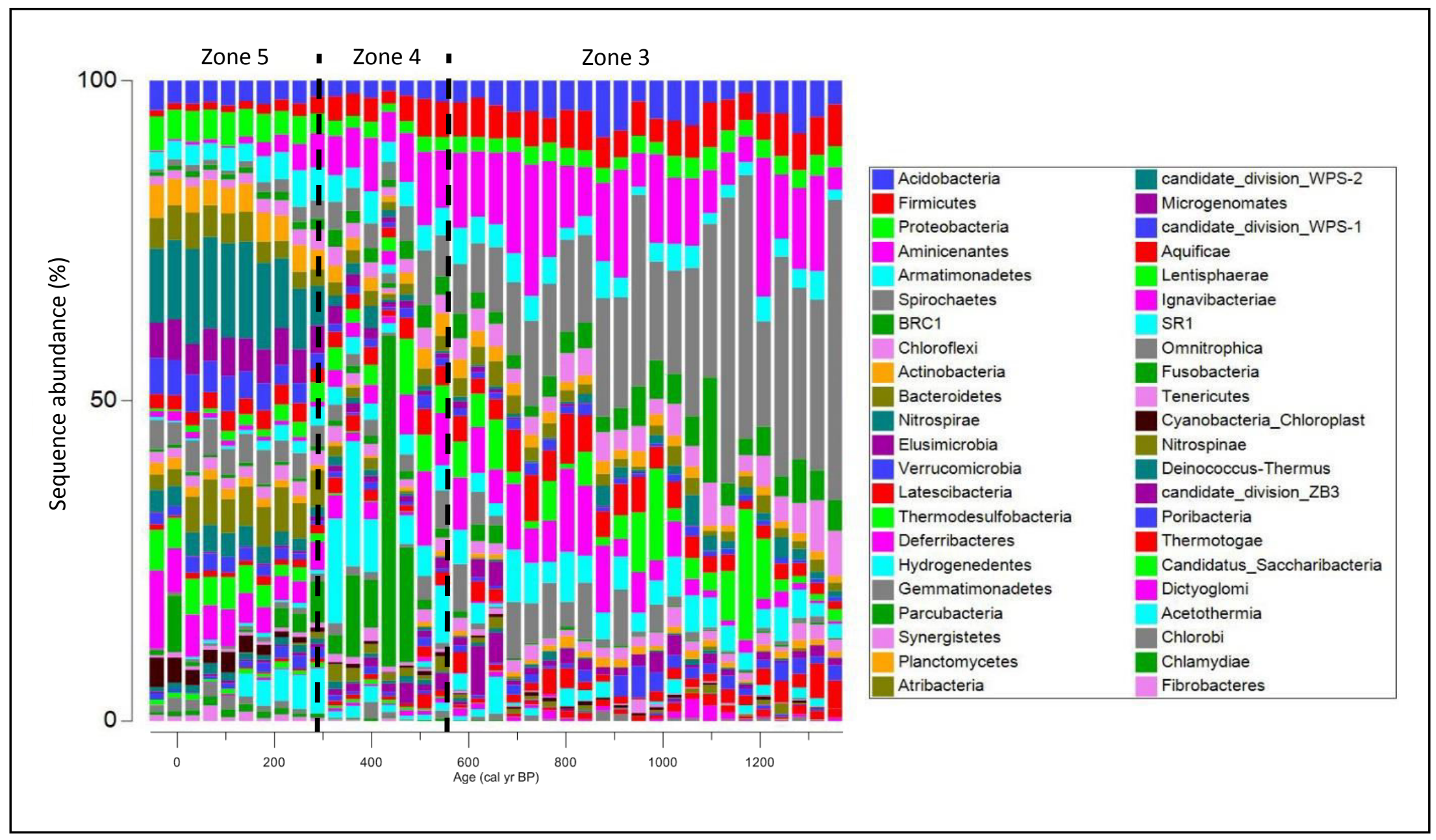

Figure 3.17: Bacterial DNA data through time extracted from core P5, each colour represents a different phylum of bacteria. Black dashed lines indicate diatom inferred zones. Figure adapted from original by Susie Wood (Cawthron Institute). 


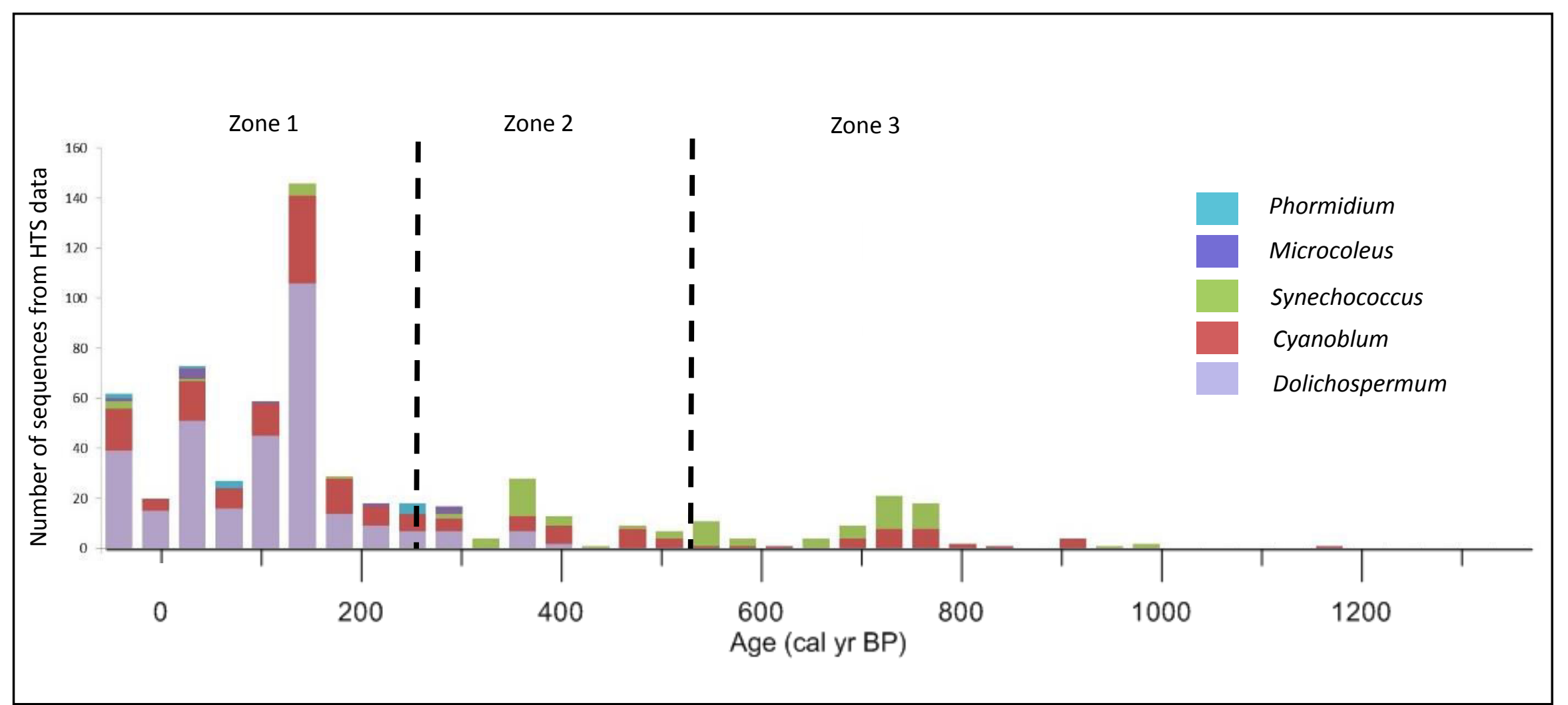

Figure 3.18: Cyanobacteria DNA data through time extracted from core P5.Black dashed lines indicate diatom-inferred zones. Figure adapted from original by Susie Wood (Cawthron Institute). 


\subsubsection{Catchment Disturbance}

\section{Grain size}

Throughout the core, median grain size varies from $3.6 \mu \mathrm{m}$ to $8.1 \mu \mathrm{m}$, which is classified as very fine silt to medium silt (Blott, 2010) (Fig. 3.19). In zone 1 grain size is on average $>5 \mu \mathrm{m}$, with poor sorting, fine skew, platykurtic distribution, and a low accumulation rate. Grain size decreases in zones 2 and 3, before increasing again in zones 4 and 5. Sorting of grains fluctuates, becoming poorly sorted in zones 4 and 5 . The distribution remains coarsely skewed from zone 2 onwards and kurtosis fluctuates between mesokurtic and platykurtic. A period of increased sediment accumulation occurs in zones 2 and 3 from 1800 - 1100 cal yr BP (95\% CI: 2011989 cal yr BP).

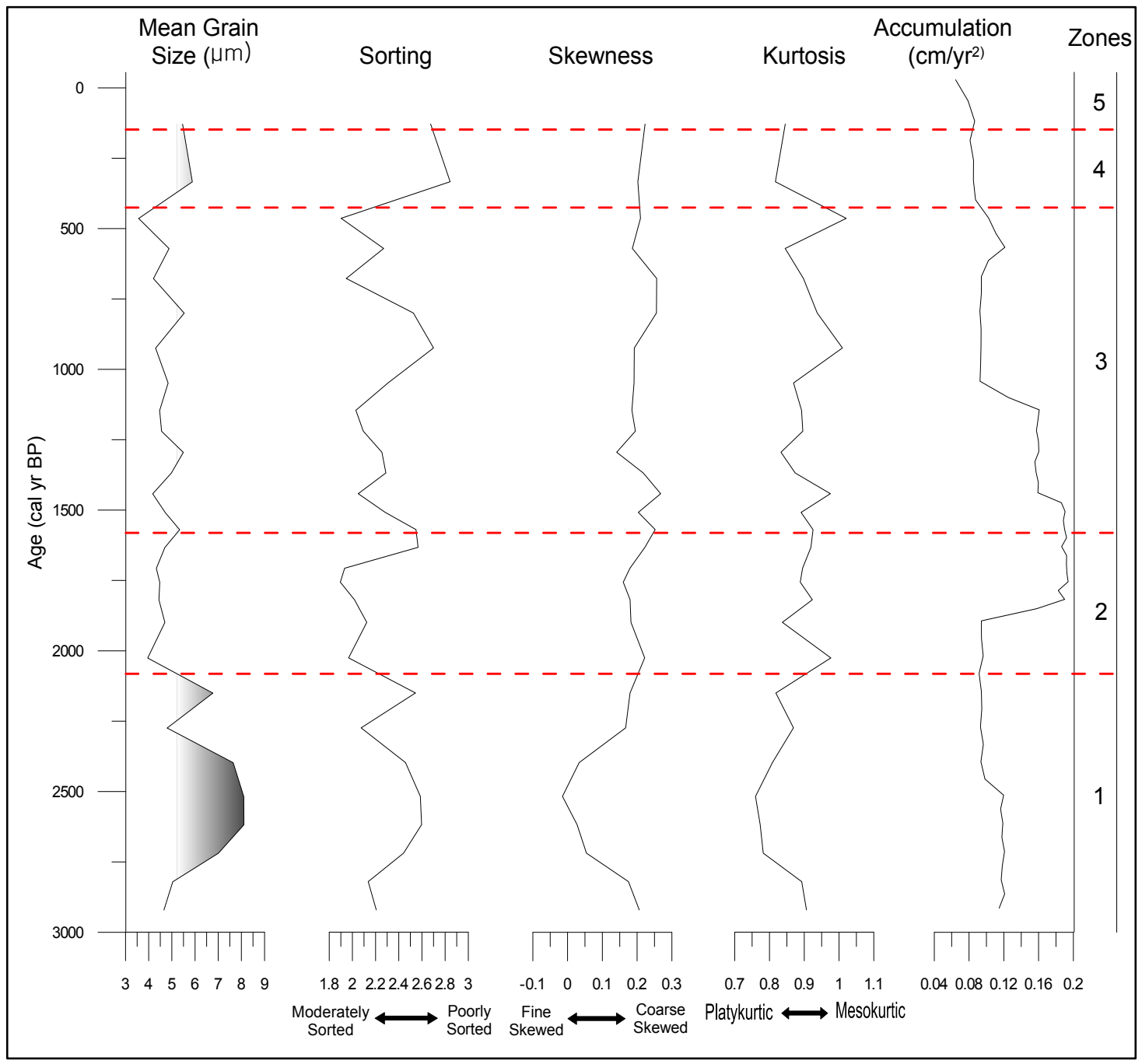

Figure 3.19: Mean grain size, sorting, skewness, kurtosis, and sediment accumulation rate from Lake Pounui, red dashed lines indicate diatom-inferred zones. 


\section{$L O I$ and $\mu-X R F$ proxies}

Incoherent/coherent scattering agrees well with the organic matter record produced via loss-on-ignition (Fig. 3.20). Al, K, and Ti also agree well with each other and show periods of increased input when organic matter is low (Fig. 3.21).

In zone 1 there is relatively high minerogenic and low organic content (5\% on average). There is fluctuation in zone 2; organic content increases to $>10 \%$ and minerogenics decrease, then organic content abruptly drops to $<4 \%$ and minerogenics increase coinciding with the increase in accumulation rate (Fig. 3.19). Organic matter increases to $9.5 \%$ on average in zone 3 . Organic matter then drops in zone 4 and begins to increase again in zone 5 (10\% on average).

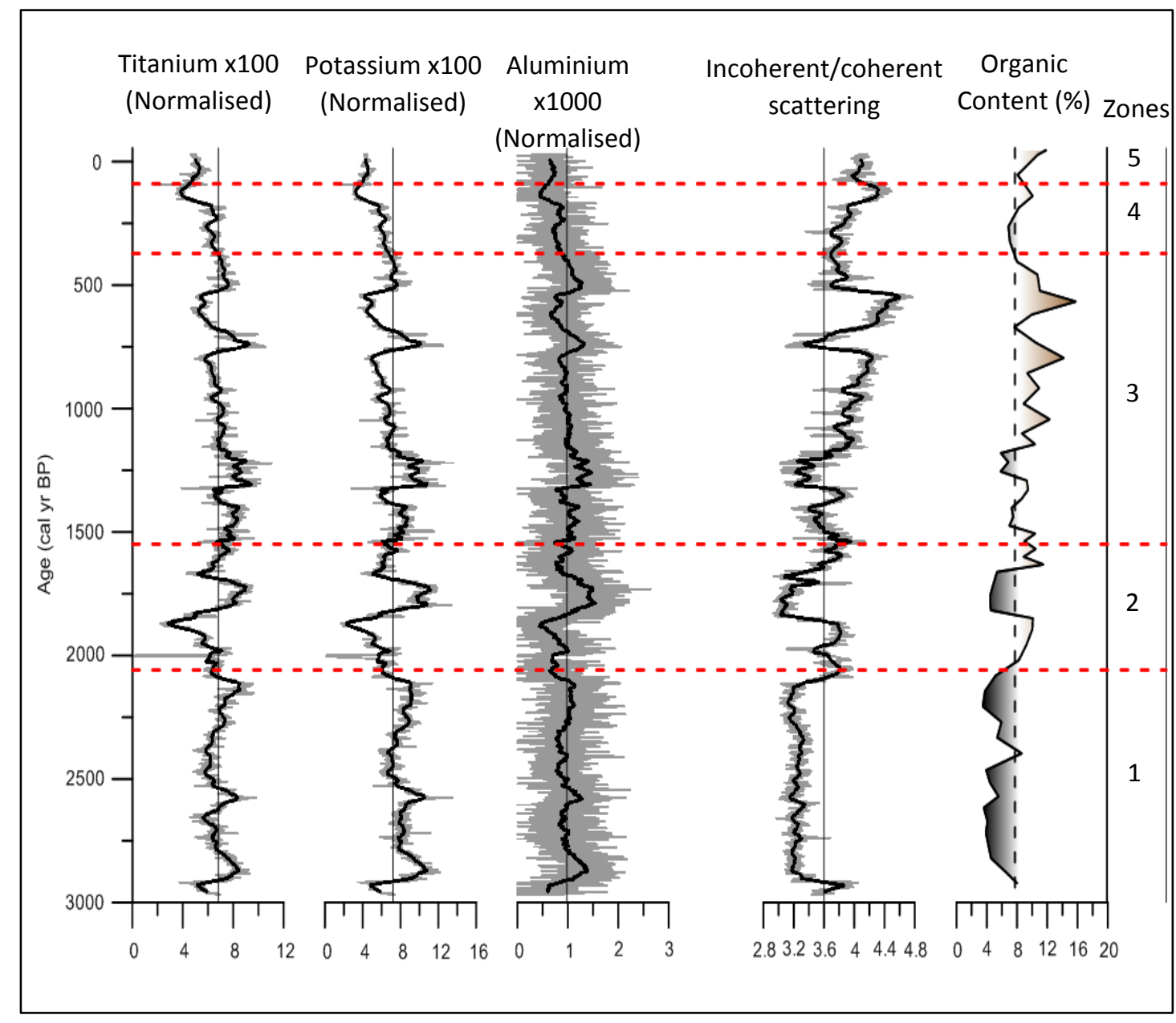

Figure 3.20: Minerogenic and organic proxies for Lake Pounui. From left to right: titanium (x100), potassium (x100), aluminium (x100), incoherent/coherent scattering, organic content $(\%)$, red dashed lines indicate diatom-inferred zones. 


\subsubsection{Human Arrival}

\section{Charcoal}

Charcoal persists at low levels throughout most of the core. In zone 4 at 450 cal yr BP, (95\% CI: $515-393$ cal $\mathrm{yr}$ BP) the influx increases to 107.4 particles $/ \mathrm{cm}^{-2} / \mathrm{yr}^{-1}$, with a peak of 2207.4 particles $/ \mathrm{cm}^{-2} / \mathrm{yr}^{-1}$ occurring at $\sim 350 \mathrm{cal}$ yr BP (95\% CI: 441-202 cal yr BP). From these results we can infer that Māori land clearance began between $\sim 450-350$ cal yr BP (95\% CI: 515-202 cal yr BP). Charcoal then decreases, however remains higher than before human arrival (Fig. 3.22, 3.23).

\section{$\underline{\text { Pollen }}$}

In zone 4 between $\sim 500$ and $\sim 400$ cal yr BP (95\% CI: 543-275 cal yr BP) the percentage of tall trees declines from $81 \%$ to $58 \%$ and herbs and shrubs increase from $5 \%$ to $18 \%$ (Fig. 3.21). This correlates with an increase in charcoal, and is likely due to Māori land clearance. Further corroborating this detail, bracken fern, a traditional staple of Māori diet, was most abundant in zone 4. Tall trees recover slightly after the initial burning, but they decline again in zone 5 at $\sim 150$ cal yr BP (95\% CI: 39-243 cal yr BP), when grasses and shrubs increases to a maximum of $34 \%$. This is most likely related to European arrival and land clearance, although Pinus spp. is only recorded in the most recent sample, therefore its introduction occurred at some point after $130 \mathrm{cal} \mathrm{yr} \mathrm{BP}$ (95\% CI: 243-29 cal yr BP).

\section{LOI, $\mu-X R F$ Proxies, and Grain Size}

When charcoal increases in zone 4, organic matter decreases, likely due to burning of vegetation. Grain size also increases slightly, and sorting decreases, indicating increased erosion likely due to decreased stability of the catchment. 


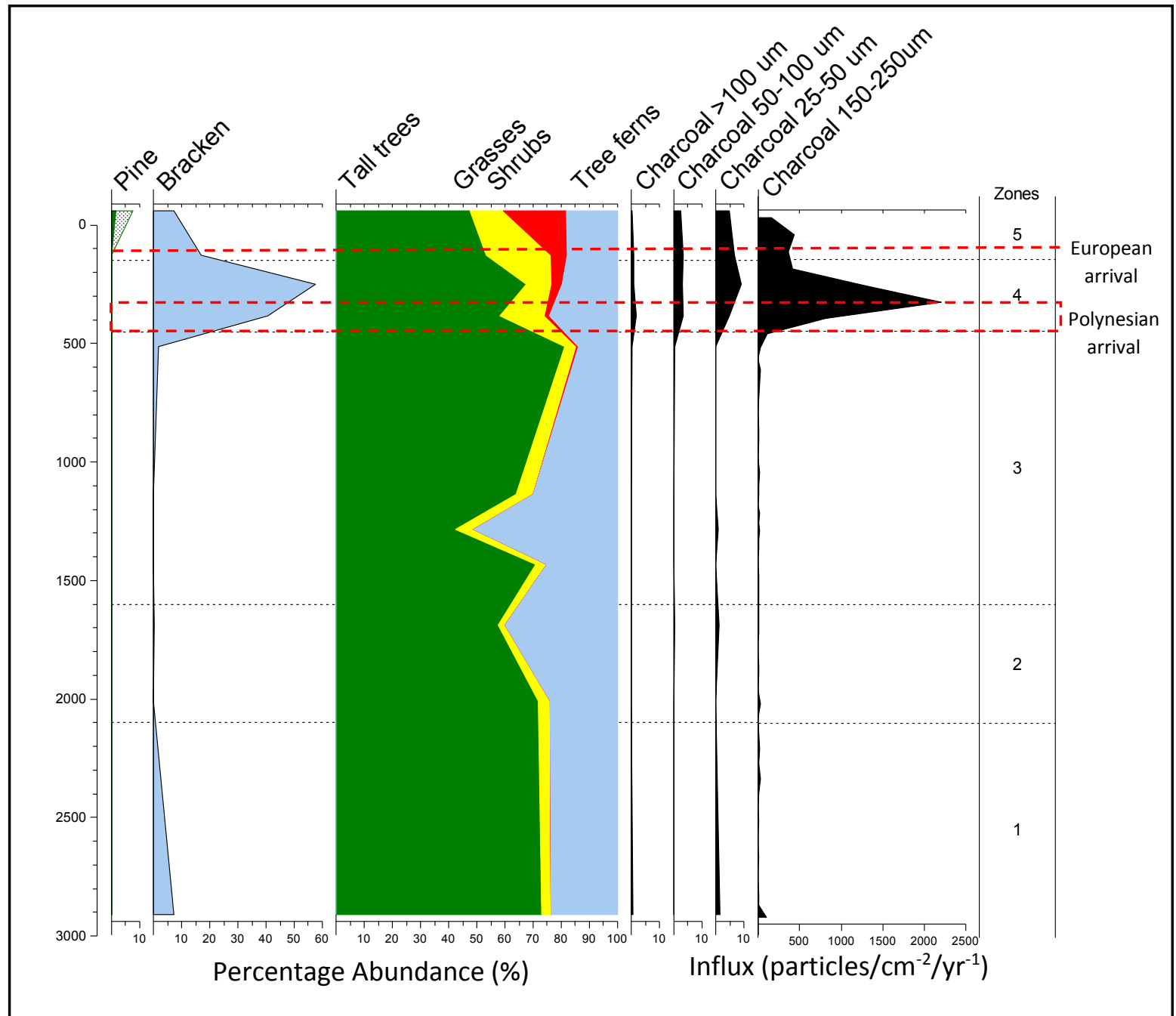

Figure 3.21: Lake Pounui pollen data and charcoal data, Pinus exaggerated x5. Pollen and charcoal $<100 \mu m$ was provided by Marcus Vandergoes (GNS) and Xun Li (GNS). Black dashed lines indicate diatom-inferred zones. Red dashed lines indicate inferred arrival times for Europeans ( 130 cal yr BP, 95\% CI: 243-29 cal yr BP), and Polynesians ( 450-350 cal yr BP, 95\% CI: 515-202 cal yr BP). 


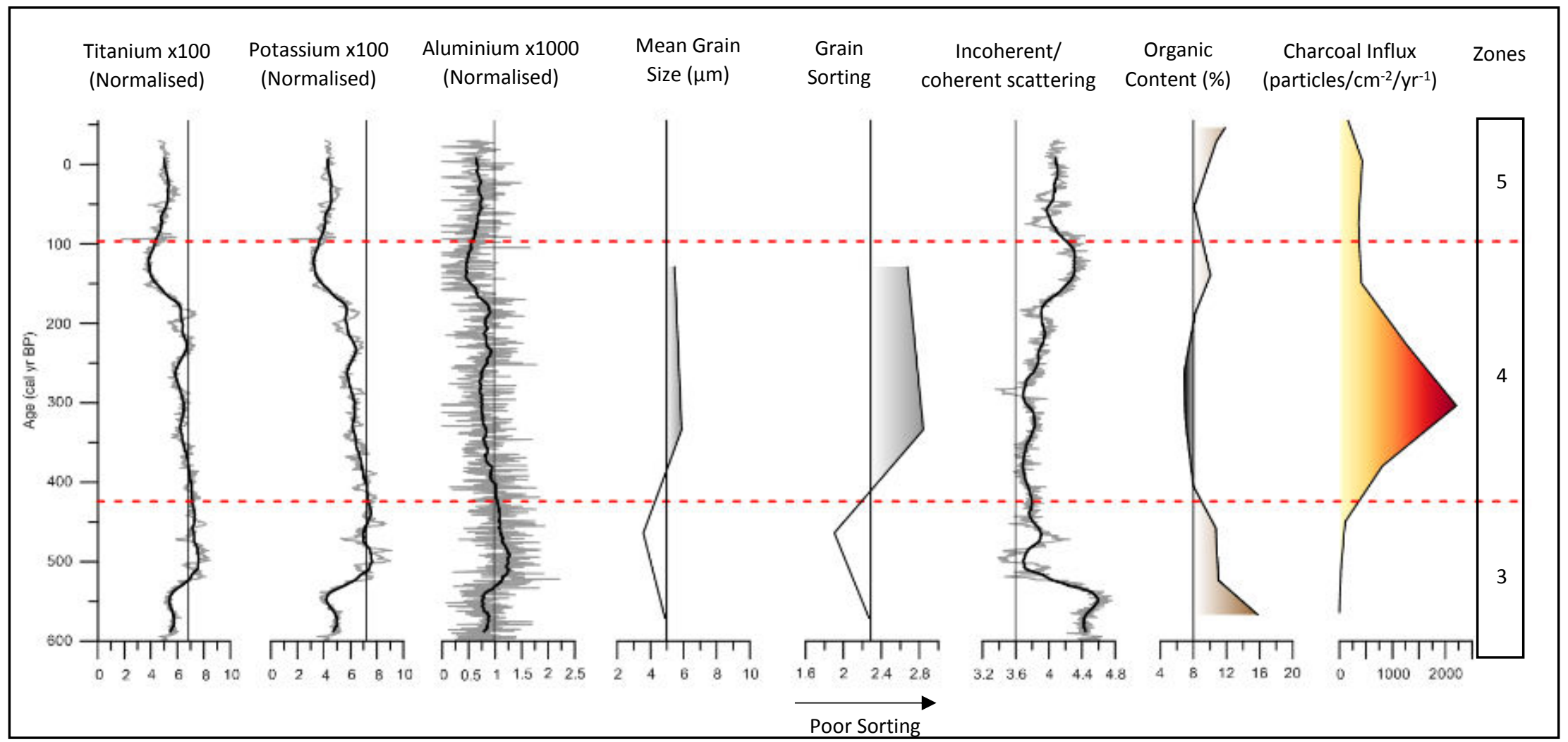

Figure 3.22: Minerogenic and organic proxies for Lake Pounui indicating land clearance. From left to right: titanium (x100), potassium (x100), aluminium (x100), mean grain size ( $\mu \mathrm{m})$, grain sorting, incoherent/coherent scattering, organic content $(\%)$, and charcoal influx (particles $\left./ \mathrm{cm}^{-2} / y r^{-1}\right)$ Red dashed lines indicate diatom-inferred zones. 


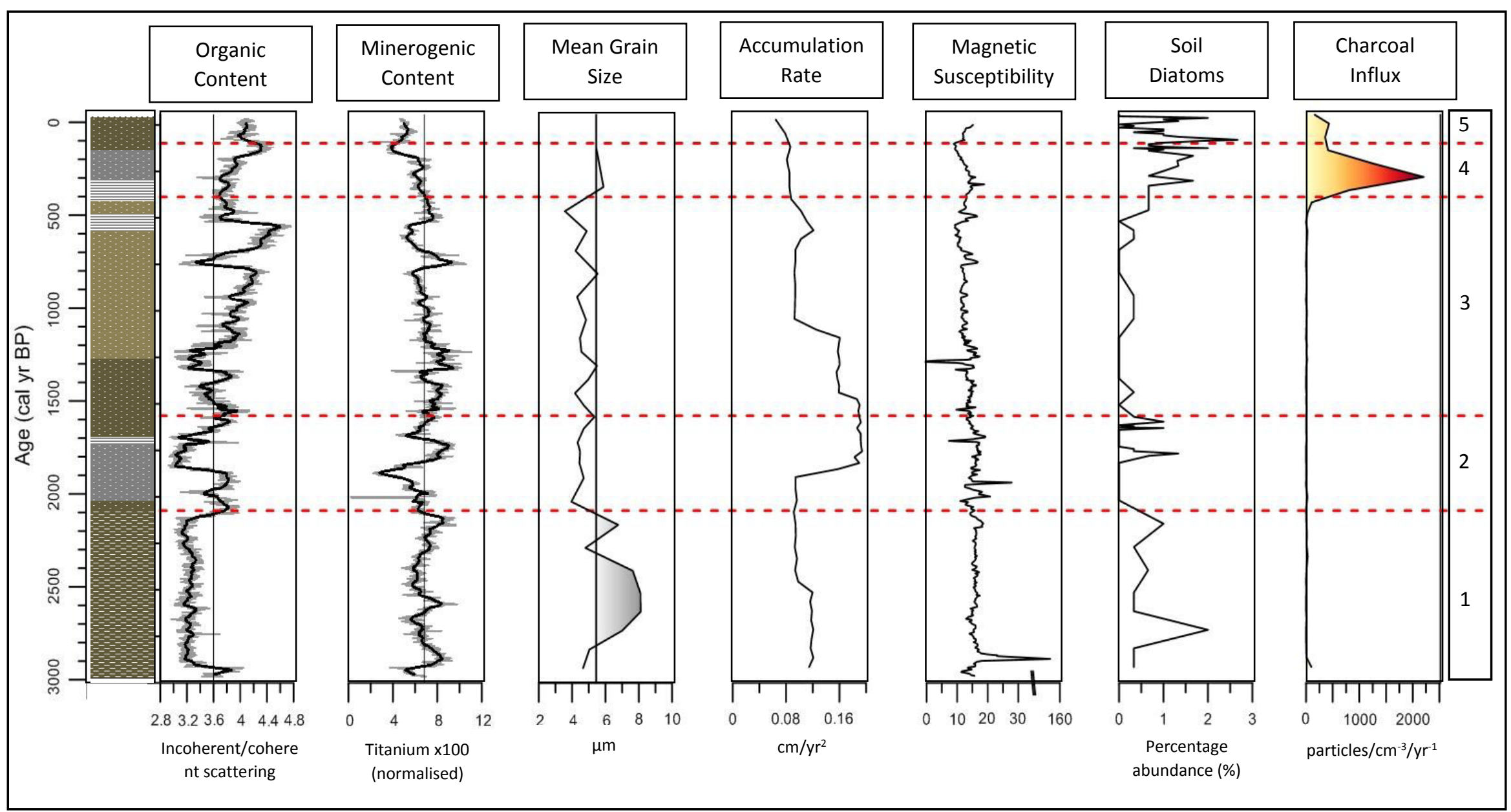

Figure 3.23: Summary of catchment disturbance indicators. Left to right: lithology, incoherent/coherent scattering as a proxy for organic content, titanium as a proxy for minerogenic content, mean grain size, accumulation rate, magnetic susceptibility, soil diatoms, and charcoal influx. Red dashed lines indicate diatom-inferred zones. 


\subsection{Discussion}

The following section will discuss human arrival to Lake Pounui's catchment and describe the pre- and post-human environments in relation to ecological change and catchment disturbance. This discussion will relate to summary Figures 3.15 and 3.23 presented on pages 52 and 62.

\subsubsection{Human Arrival}

\section{$\underline{\text { Māori arrival }}$}

Evidence suggests that Māori arrival occurred between 450-350 cal yr BP. During this period there is a large increase in the influx of charcoal, a decline in tall trees, and an increase in grasses, shrubs, and bracken fern. The lack of natural fires in this region prior to $\sim 450$ cal yr BP and the establishment of bracken fern is strong evidence of repeated anthropogenic burning for land clearance. LOI and incoherent/coherent ratio (from $\mu$-XRF) both show a drop in organic content during this period, likely due to burning of vegetation, while a slight increase in mean grain size, and a decrease in sorting indicates increased erosion.

Although this is younger than the established date for Polynesian settlement in New Zealand (c. 700-800 cal yr BP) (McWethy et al., 2014; McWethy et al., 2010; Wilmshurst et al., 2008; McFadgen, 2003), it agrees with archaeological evidence from the Wairarapa region. There is evidence of tectonic uplift and an associated tsunami approximately $500 \mathrm{cal}$ yr BP in the Wairarapa region (Clark et al., 2015; Howarth et al., 2014; Langridge et al., 2011). This may have caused a migration of the Māori population from Palliser Bay inland to the Wairarapa Valley (McFadgen, 2003). There is also evidence of the Ngati-Kahungunu iwi settling in the main Wairarapa Valley approximately 300 cal yr BP (Leach, 1981).

However, Trodahl et al. (2016) identified an increase in charcoal, and an increase in median grain size in Lake Wairarapa at c.720 cal yr BP which was not seen in Lake Pounui. This may indicate that Māori settled around Lake Wairarapa prior to the area surrounding Lake Pounui. Lake Wairarapa (at its most southern point) is $\sim 7 \mathrm{~km}$ away from Lake Pounui, therefore, it is possible that local fires around each lake may not have caused charcoal deposition in the other as charcoal $>125 \mu \mathrm{m}$ usually travels no more than $2 \mathrm{~km}$ (Whitlock \& Larsen, 2001), and the prevailing north-easterly wind may have blown charcoal westward. Lake Wairarapa also has a much larger depositional 
area and catchment than Lake Pounui; therefore it is more likely to represent a regional signal while Lake Pounui is more likely to record local signals

\section{European arrival}

Pinus spp. pollen is considered a strong indicator of European arrival; however, the low resolution of pollen sampling means the introduction of the taxon cannot be constrained further than post $130 \mathrm{cal}$ yr BP. The diatom Asterionella formosa which was introduced by Europeans, first appears at 125 cal yr BP (95\% CI: 36-240 cal yr BP), and a slight decline in forest pollen and a shift to grasses and shrubs occurs at $\sim 150 \mathrm{cal}$ yr BP $(95 \%$ CI: 39-243 cal yr BP). Therefore, it is estimated that European arrival occurred at approximately 150 cal $\mathrm{yr}$ BP, which fits with historical evidence of first arrival at Palliser Bay in $1770 \mathrm{AD}$ and formal settlement of the Wairarapa Valley in $1853 \mathrm{AD}$ (Leach, 1981; Hill, 1963).

\section{Summary}

In summary, Māori arrival at Lake Pounui occurred between $1500 \mathrm{AD}$ and $1600 \mathrm{AD}$ ( 450-350 cal yr BP, 95\% CI: 515.2-202.3 cal yr BP), which fits with archaeological evidence presented by McFadgen (2003) and Leach (1981), but is later than the estimated arrival time to the Wairarapa Valley of c.720 cal yr BP (Trodahl et al., 2016). European arrival occurred at $1800 \mathrm{AD}$ ( 150 cal yr BP, 95\% CI: 243-39 cal yr BP). This information will be used in the following chapters to compare pre- and post-human environments of Lake Pounui.

\subsubsection{Pre-human environment}

\section{Zone 1: 3000 to 2100 cal yr BP}

The relatively coarse grain size, low organic content, moderate minerogenic content, and relatively high proportion of terrestrial diatom species $(0.7 \%)$, all indicate moderately high terrigenous input during zone 1, compared to the rest of the record. Not surprisingly, the diatom assemblage in this period has high species diversity and significant proportions of tychoplanktic (30\%), and benthic species $(34 \%)$ which is indicative of terrigenous influx and the introduction of littoral and soil diatom species to the centre of the lake (Orpin et al., 2009). There is a relatively high proportion of brackish-fresh and circumneutral diatoms compared to the rest of the record. This may be due to the terrigenous input of soil derived bicarbonate (Augustinus et al., 2006), humic acids or the effect of the tephra layer at the base of this zone (Reid, 2005). 
This period is dominated by diatom species that have been identified by van Dam et al. (1994) as eutrophic (42\%). The proportion of eutrophic taxa is higher than present; although, $25 \%$ of the assemblage is made up of oligotrophic species, mainly Discostella stelligera (Augustinus et al., 2006; van Dam et al., 1994). Discostella stelligera have thin diffusion boundaries for efficient nutrient absorption so they thrive in oligotrophic waters (Ruhaland et al., 2015; Wang et al., 2008). However, Discostella stelligera has been identified by Reid et al (2005) as a wide-spread diatom found in many lakes in New Zealand, and so likely tolerates a range of ecological conditions. Therefore, this period is likely one of eutrophic-mesotrophic condition. A number of the main species Aulacoseira ambigua, Melosira varians, and Ulnaria ulna also have low to moderate oxygen requirements (van Dam et al., 1994), which would be expected in a productive system.

The pollen record shows a high proportion of tall trees, mainly Fuscospora fusca, indicating that the catchment was forested. Fuscospora fusca are a light demanding canopy tree that prefer deep, fertile, well drained soils at low elevations (Stewart \& Rose, 1990). There are also low levels of submerged marcophyte Potamogeton, which has been found in eutrophic-mesotrophic waters (de Winton, 2016; de Winton et al., 2011). The submerged marcophyte population would support the high proportion of epiphytic diatoms.

In summary, during this period moderately high minerogenic input and high proportions of soil, benthic, and tychoplanktic diatoms indicate terrigenous flux to the lake. This likely increased the catchment input of nutrients, creating a productive lake environment where eutrophic diatoms existed at a higher proportion than currently. Due to the nature of the reconstructed environment it is inferred that algal blooms likely occurred during this period. However, they would have been composed of different phytoplankton than at present, as the cyanobacteria of concern today (Dolichospermum and Phormidium) did not appear until human arrival (Fig. 3.19).

\section{Zone 2: 2100 to 1600 cal yr BP}

At 2000 cal yr BP (95\% CI: 1847-2212 cal yr BP) there appears to be a disturbance that causes a large decrease in diatom diversity, an increase in Aulacoseira granulata var. angustissima, a decrease in grain size, and an increase in organic content. Aulacoseira granulata var. angustissima has high nutrient requirements (van Dam et al., 1994; Kilham \& Kilham, 1975), are more heavily silicified than Discostella stelligera, and 
form chain-like colonies, so they rely on turbulent environments for recycling of nutrients and to remain in suspension (i.e they are tychoplanktic) (Ruhland et al., 2015; Wang et al., 2008; Kilham, Theriot, \& Fritz, 1996). Therefore, there may have been increased turbulence, shallowing, or an increase in nutrients from 2000-1800 cal yr BP (95\% CI: 1678-2212 cal yr BP).

At 1800 cal yr BP (95\% CI: 1678-1984 cal yr BP) organic content decreases, and minerogenics abruptly increase, along with the accumulation rate. There is a dark grey clay bed at this point in the core which may correspond to the increased minerogenic input. There is also a spike in Discostella stelligera, Melosira varians, and soil diatoms at this point. Discostella stelligera, are lightly silicified, and have high surface area to volume ratios, so they thrive in deep, often still waters (Ruhland et al., 2015; Wang et al., 2008). Melosira varians is often found in riverine environments where it forms long filaments in ponded areas that can be scoured away during floods (Kelly et al., 2005). As such, Melosira varians have also been found in the basal units of flood deposits (Matsumoto et al., 2016). This may indicate a period of flooding or raising of the water table.

At 1650 cal yr BP (95\% CI: 1542-1795 cal yr BP) organic content and minerogenics return to levels similar to the start of the zone and small fragilarioid diatoms increase. These small fragilarioids are tychoplanktic diatoms that live attached to sediment grains but often end up suspended in turbulent conditions (Vos \& de Wolf, 1988). They have been found in lakes across a wide range of water chemistry gradients in New Zealand, however, they seem to be more common in lakes with relatively good water clarity (Reid, 2005). Small fragilarioid diatoms have been called pioneer species and have been associated with rapid environmental change (Cochran et al., 2007) Events throughout this zone likely caused a period of environmental change allowing small fragilarioid diatoms to thrive.

Pollen shows a slight decrease in forest taxa, and an increase in ferns linked to a decline in Fuscospora fusca and an increase in Cyathea smithii from 2000-1650 cal yr BP (95\% CI: 2212-1542 cal yr BP). Cyathea smithii thrives in wetter areas, and is often abundant in indigenous forest that has been damaged and thus can be an important indicator of vegetation disturbance (Wilmshurst \& McGlone, 2005).This fits well with the disturbance indicators from the other proxies. However, tree ferns spores are often produced abundantly and are poorly dispersed which can cause over-representation, 
they can also be washed into lakes in large amounts during rainstorms and floods (Wilmshurst \& McGlone, 2005).

\section{Natural drivers of change}

There are a number of events that are thought to have occurred during this time period. Cochran et al. (2007) found environmental transitions at 2600 to 2000 cal yr BP recorded in the diatom assemblage of three lakes in the Wellington region, Okupe Lagoon, Taupo Swamp, and Lake Kohangapiripiri. Okupe Lagoon and Taupo Swamp show a shift to more open waters, and Lake Kohangapiripiri shows shallowing (Cochran et al., 2007). Trodahl et al. (2016) also identified a period of change in the sedimentary record of Lake Wairarapa at 2500 cal yr BP (95\% CI: 2740.6-2290.5 cal yr BP). These changes coincided with inferred ruptures on the Ohariu and Wairarapa faults. Based on dating the uplift of four beach ridges McSaveney et al. (2006) suggested that the Wairarapa fault ruptured between 2380 and 2060 cal yr BP and resulted in a 9.1-m uplift at Turakirae head, approximately $20 \mathrm{~km}$ from Lake Pounui. Little, Van Dissen, Schermer, and Carne (2009) suggested, based on trench dates, there may have been two ruptures on the Wairarapa fault between 2340 and $2110 \mathrm{cal}$ yr BP, resulting in the 9.1-m uplift. The rupture on the northern Ohariu fault was dated to between 2310 and $1070 \mathrm{cal}$ yr BP via trench dates by Heron, Van Dissen, and Sawa (1998).

There is also evidence of increased storm frequency and magnitude on the eastern side of the North Island of New Zealand during this period, which lines up well with the period of inferred flooding or water table rise in Lake Pounui (Fig 3.24). A study by Page et al. (2010) tracked storm frequency and magnitude in the sediment record of Lake Tutira, Hawkes Bay. The authors found that large storms were related to two of the major controls on New Zealand's climate: the El Niño Southern Oscillation (ENSO) (Mullan, 1989) and the Southern Annular Mode (SAM) (Renwick \& Thompson, 2006). El Niño events cause stronger south-westerlies, cooler temperatures, increased rainfall in the south-west, and drier conditions in the north-east (Mullan, 1989), whereas La Niña events cause stronger north-easterly winds and rainfall, and warmer, milder conditions across the country (Mullan, 1989). During a positive SAM westerlies and storm activity increase over the southern ocean and decrease over New Zealand (Renwick \& Thompson, 2006). In general this leads to drier, and warmer conditions in the west (Renwick \& Thompson, 2006). During a negative SAM the storm track moves equatorward causing increased westerlies, and storminess in New Zealand (Renwick, 2011). Page et al. (2010) found that large storms occurred most frequently when a La 
Niña and/or positive SAM occurred, which produce greater north-easterly wind flow and rain; Lake Pounui is particularly susceptible to weather systems from this direction which could cause flooding or turbulence (Jellyman, 1990; Lawless, 1983). Between 2030 and 1830, and 2120 and $2090 \mathrm{cal}$ yr BP the highest frequency and magnitude of storms were recorded in Lake Tutira (Orpin et al., 2009). This also coincides with periods of enhanced erosion recorded at Round Lake, Hawkes Bay at approximately $2050 \mathrm{cal} \mathrm{yr} \mathrm{BP}$, the enhanced erosion was thought to be due to earthquakes or severe storms (Chester \& Prior, 2004). Higher precipitation associated with more northwesterly airflow after 2500 cal yr BP was also recorded at Lake Poukawa (McGlone, 2002).

The timing of uplift identified by McSaveney et al. (2006) and Little et al. (2009) does not line up well with the inferred changes seen in Lake Pounui (Fig 3.24); however this may reflect uncertainty of the age-depth model. Therefore, it is possible that a combination of earthquakes and storms caused major change in Lake Pounui throughout this period, and more robust age-depth modelling may highlight possible drivers of this change more accurately.

\section{Zone 3: 1600 to 450 cal yr BP}

Grain size and minerogenic material remain low, organic content increases throughout the period, and the accumulation rate drops abruptly at 1100 cal yr BP (95\% CI: 9861178 cal yr BP).

Diatom diversity makes a recovery at the start of zone 3 and then remains relatively low. Oligotrophic diatoms dominate $(40 \%)$ and oxygen saturation increases. Planktic $(45 \%)$ and tychoplanktic (40\%) diatoms dominate, salinity decreases, and water remains relatively alkaline. The abundance of Discostella stelligera (41\%) indicates that the water depth may have increased and/or turbulence may have decreased creating a more thermally stratified lake (Ruhland et al., 2015). However, the abundance of tycoplanktic Aulacoseira ambigua (15\%) indicates that the lake experienced some degree of turbulence (Kilham \& Kilham, 1975), and small fragilarioids (20\%) indicate that the lake was still relatively shallow, and possessed good light penetration (Reid, 2005).

Pollen shows an increase in tall tree taxa indicating forest made a recovery. The submerged macrophyte Potamogeton declines and appears to be replaced by Isoetes at very low levels which is often found in oligotrophic conditions (de Winton, 2016; de Winton et al., 2011). 
This period likely represents a deeper, more stratified lake, with lower nutrient concentration, and less terrigenous input compared with previous periods.

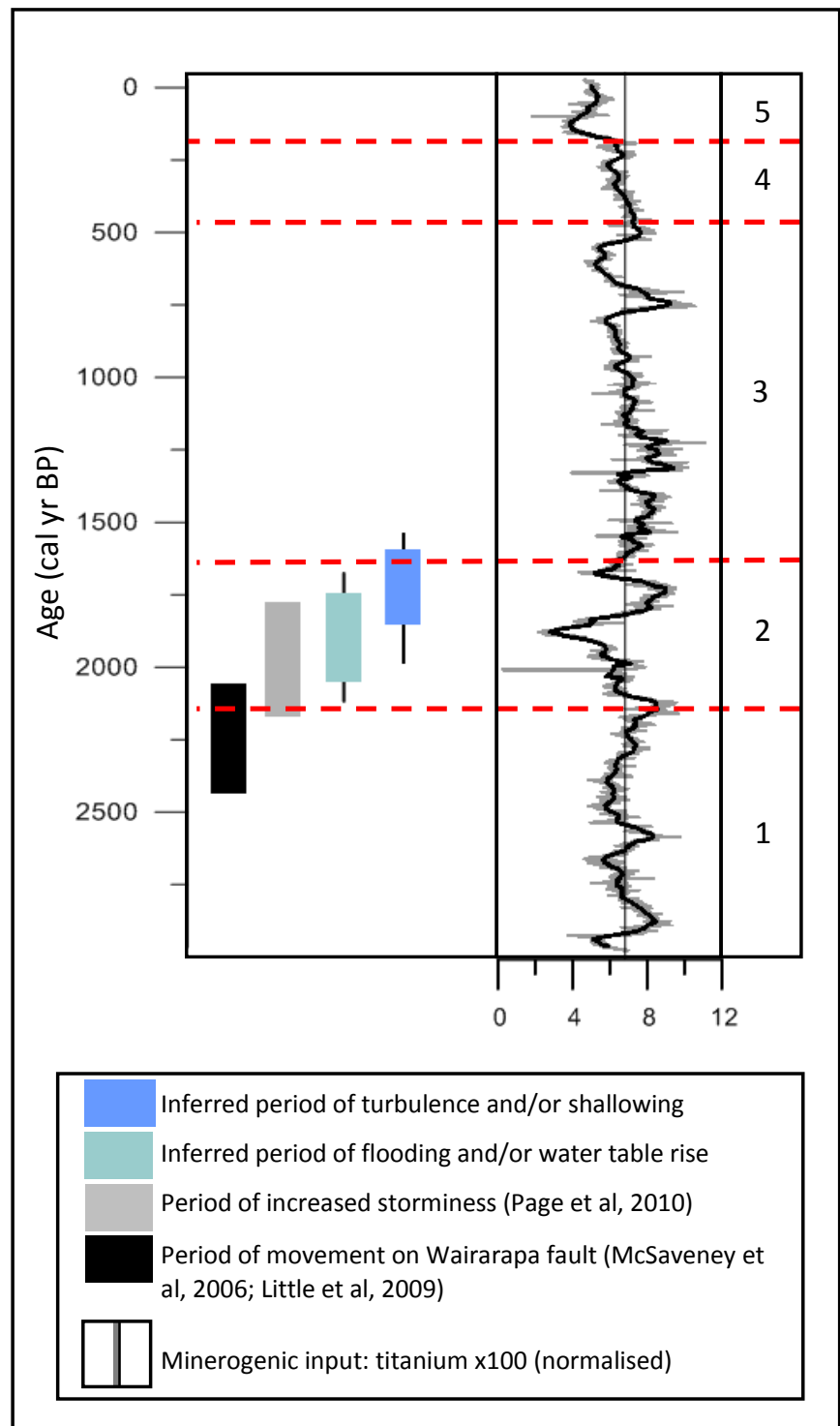

Figure 3.24: Correlation of inferred periods of change and minerogenic input (titanium x100) in Lake Pounui and periods of increased storminess (Page et al, 2010), and movement on the Wairarapa fault (McSaveney et al, 2006; Little et al, 2009). Red dashed lines depict diatom-inferred zones. 


\section{Zone 4: 450 to 150 cal yr BP}

As stated previously, zone 4 is characterised by features inferred to be related to Māori arrival such as increase in charcoal influx, decline in tall trees, and increase in grasses, shrubs, and bracken. There is also an increase in grain size, drop in organic content, and an increase in soil diatoms, likely due to increased erosion from the land clearance. This causes an ecological change within the lake.

The major change in the bacterial assemblage during this period is an increase in Fusobacteria which are found in the gastrointestinal track of animals and humans (Gupta \& Sethi, 2014; S. A. Wood et al., 2013) and the appearance of the cyanobacteria Dolichospermum at low levels.

In terms of diatoms, epiphytic species, with moderate nutrient requirements such as Epithemia spp. and riverine species Melosira varians spike at 400 cal yr BP (95\% CI: 309-481 cal yr BP) and then decline. This may be a response to the initial burning and associated increased nutrient input into the lake. From 350 to $150 \mathrm{cal}$ yr BP $(95 \% \mathrm{CI}$ : 450-50 cal yr BP) the diatom assemblage appears to recover, similar to the assemblage in zone 3. Discostella stelligera (50\%) dominates although epiphytic diatoms remain high which may relate to the increase of submerged macrophytes Isoetes and Potamogeton during this period. Interestingly, the marine diatom Actinocyclus octonarius makes its first appearance during this period and could have been introduced by either Māori fishing practises or natural events. For example there is evidence of tectonic uplift and an associated tsunami at approximately 500 cal yr BP in the Wairarapa region (Clark et al., 2015; Howarth et al., 2014; Langridge et al., 2011) which may have introduced Actinocyclus octonarius to the lake. The effect of tectonic uplift and an associated tsunami may have also played a role in the ecological change.

In summary Māori occupation is associated with catchment disturbance from land clearance, though it is also associated with high water quality. After the initial impact the ecological conditions of the lake appear to recover, similar to conditions in zone 3, which could indicate good management practises.

\section{Zone 5: 150 cal yr BP to present}

As stated previously, zone 1 is characterised by features inferred to be related to European arrival. This is identified by the appearance of Pine (Pinus) pollen, the diatom 
Asterionella formosa, and the elevated levels of charcoal. During this period there is an increase in eutrophic and mesotrophic diatoms (from $29 \%$ to $45 \%$ ) specifically Aulacoseira granulata var. angustissima and a decline in oligotrophic diatoms (from $54 \%$ to $36 \%$ ) like Discostella stelligera which indicates declining water quality. A similar transition in relation to human impact was also observed by Augustinus et al (2006) at Lake Pupuke, Auckland. However, at this point the lake does not appear to be as dominated by eutrophic and mesotrophic diatoms as in zone 1 (51\%). Tychoplanktic diatoms increase from $13 \%$ to $34 \%$ which may relate to an increase in turbulence or shallowing.

The bacterial DNA also shows a major change with the increase in Bacteroidetes, Nitrospirae, and Atribacteria. Bacteroidetes are found in the gastrointestinal track of animals and humans (Gupta \& Sethi, 2014; S. A. Wood et al., 2013) and could reflect the increased population in the area and introduction of farming during this period. Nitrospirae has nitrate oxidising members (Schneider et al., 2013) and may have provided a nursery effect for other nitrogen-limited bacteria. Atribacteria live in anaerobic environments (Nobu et al., 2016) and therefore may indicate increased stratification of the lake or reduced oxygen via increasing productivity. Critically, the cyanobacteria Phormidium appears and Dolichospermum increases in abundance during this period - these are the taxa that comprise the main bloom-forming species today. Dolichospermum and Phormidium both have the ability to produce cyanotoxins (Heath, 2015; Weller, 2011). Blooms of Phormidium have been linked to elevated dissolved inorganic nitrogen, although have occurred in very low concentrations of dissolved reactive phosphorous $\left(<0.01 \mathrm{mg} \mathrm{L}^{-1}\right)$ (Heath, 2015), whereas, Dolichospermum is a nitrogen fixing cyanobacteria and is more reliant on dissolved reactive phosphorous (Smith et al., 2016).

In summary, European arrival coincides with a degradation in water quality, specifically an increase in eutrophic diatom species, and an increases in bloom forming cyanobacteria Dolichospermum and Phormidium.

\section{Human induced change}

The decrease in water quality at the beginning of zone 5 is likely driven by a range of factors related to European settlement such as land use change and the introduction of exotics. Anthropogenic climate change may further compound the problem. 


\section{Land use change}

The major issue associated with anthropogenic land use change is the increase in nutrient input from the catchment to the associated water body. Land clearance creates more available nutrients in catchment soils as they are not taken up by vegetation (Fahey \& Jackson, 1997). The lack of vegetation also destabilises the catchment, increasing erosion (Fahey \& Jackson, 1997). Therefore, more nutrients end up in the water body. The effect is even greater when extra nutrients are added to the soil via cattle effluent and fertiliser additions (Harper, 1992). The excess nutrients in the water body can cause eutrophication and internal nutrient loading. In terms of Lake Pounui, land clearance by Māori and conversion to pasture and farming by Europeans may have increased the external nutrient load to the lake during this period causing an increase in productivity.

\section{Introduction of exotic fish}

Humans have altered trophic interactions by introducing exotic species to water bodies. It is common to see four level food chains where additions of piscivorous fish, reduce planktivorous fish, allowing large zooplankton, which feed on phytoplankton, to dominate, thus lowering phytoplankton biomass (Duggan et al., 2015). Additions of planktivorous fish, however, can cause a shift from larger to smaller zooplankton species which are not as efficient feeders on phytoplankton (Duggan et al., 2015).

The native fish population currently present in Lake Pounui is made up of giant and banded kokopu (Galaxia argenteus and Galaxia fasciatus), the common bully (Gobiomosphus contidianus), brown mudfish, (Neochanna apoda), and common smelt (Retropinna retropinna) (Joy, 2003; McEwan, 2010), which all feed to some degree on zooplankton and invertebrates. In Lake Pounui, there is a population of large zooplankton (Ceriodaphina dubia and calanoid copepods such as Boeckella hamata and Calamoecia lucasi) and smaller zooplankton (such as Bosmina meridionalis and many rotifer species) (Lawless, 1983). Two exotic species, brown trout (Salmo trutta) and perch (Perca fluviatilis) were introduced to New Zealand in the late 1860's (Jellyman, 1990) and are now present in Lake Pounui. Both perch and brown trout are known to feed on other fish, and reduce native species populations (Rowe, 2007; Smith \& Lester, 2007). Due to large population size and competition for resources, the perch population is made up of small individuals (Jellyman, 1980) which have also been shown to feed on large zooplankton such as Ceriodaphina dubia and calanoid copepods (Smith \& 
Lester, 2007). It is likely that the introduction of perch decreased the population of large-bodied zooplankton, resulting in an increase in phytoplankton due to reduce predation. However, if perch and brown trout are able to grow to sizes large enough to consume other fish, they may reduce the native population of fish feeding on large zooplankton, which would reduce phytoplankton. There are likely many complex trophic interactions occurring within Lake Pounui (which are beyond the scope of this thesis) that may have led to the changes seen during this period.

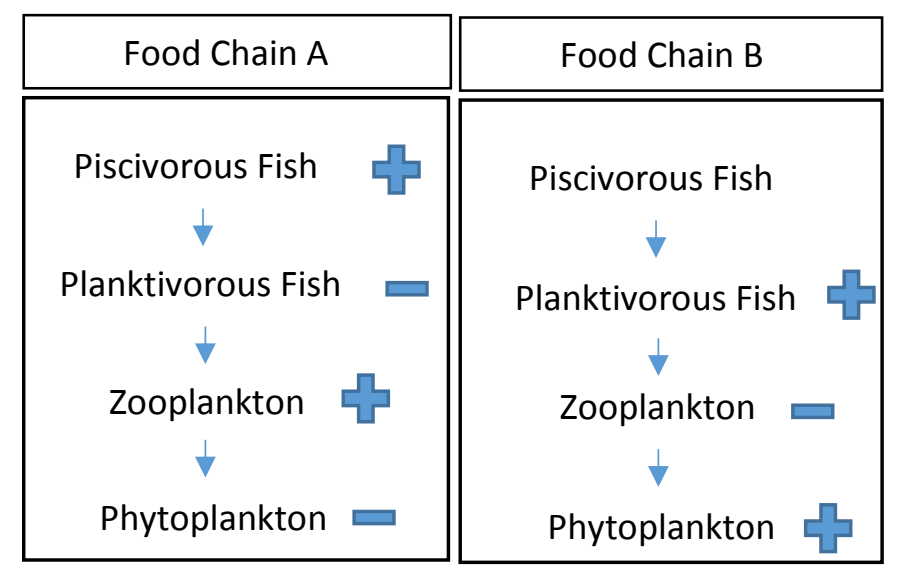

Figure 3.25: Basic Four Level Food Chain in Lakes. In food chain $A$ the introduction of piscivorous fish, such as large bodied perch and brown trout, causes a reduction in planktivorous fish; this increases zooplankton and reduces phytoplankton. In food chain B the introduction of planktivorous fish, such as small perch, causes a reduction in zooplankton and increase in phytoplankton.

\section{Anthropogenic climate change}

Another factor that needs to be considered during this time period is anthropogenic climate change. Anthropogenic climate change is thought to further compound the issue of eutrophication. However, it is difficult to separate the effect of anthropogenic climate change from other impacts, such as land use change and the introduction of exotics. For example, anthropogenic climate change may increase the nutrient concentrations via a number of mechanisms: increased temperatures can cause release of nutrients from lake sediments (Sondergaard, Jensen, \& Jeppesen, 2003); weather extremes, such as storms, may cause increased nutrient input via erosion, and droughts may cause concentration of nutrients (Moss et al., 2011); and higher temperatures often favour small omnivorous fish which, as discussed above, can increase phytoplankton biomass via trophic cascades (Moss et al., 2011; Duggan et al., 2015).

In terms of evidence from diatom assemblages, the most wide spread response to climate change appears to be a rise in abundance of small Cyclotelloid taxa and a decline in heavily silicified Aulacoseira taxa and small benthic fragilarioids (Ruhland \& 
Smol, 2008). This is linked to an increase in thermal stratification due to increased temperatures and longer ice free periods (Ruhland et al., 2015). This is often accompanied by a reduction in trophic status, contrary to the arguments above (Ruhland et al., 2015). Lakes that experience low seasonality may be less sensitive to warming, and larger increases in temperature may be needed before changes are seen (Ruhland et al., 2015). In the case of Lake Pounui, the area experiences low seasonality and the lake has always had a large proportion of small Cyclotelloid taxa, in particular, the dominant Discostella stelligera. In most recent times, the proportion of Discostella stelligera appears to have declined, and the proportion of tychoplanktic Aulacoseira granulata var. angustissima has increased. The effect of anthropogenic climate change will differ between lakes, based on their original setting, ecological condition, and regional climate differences.

To understand the effect that anthropogenic climate change may have on Lake Pounui, we first need to understand what is likely to happen in New Zealand. In New Zealand, temperatures have warmed by just under a degree over the last 100 years (Christensen et al., 2013), but temperature has been modulated by an upward trend in southerly wind flow since 1950 (Dean \& Scott, 2009). Temperatures are expected to rise at $70 \%$ of the global rate due to buffering from the Southern Ocean (Christensen et al., 2013).

The effect of climate change on ENSO and SAM also need to be considered. Throughout the $20^{\text {th }}$ century, there has been a trend of 'La Niña-like' events (An, Kim, Im, Kim, \& Park, 2011), though there may be a weak upward trend in El Niño events with climate warming (Tokinaga et al., 2012; An et al., 2011). However, there is low confidence in changes to the ENSO pattern in a warmer climate (Christensen et al., 2013). There has also been a trend of positive SAM events from $\sim 1957$ in austral summer and autumn that is unprecedented in the last 150 years (Fogt, Bromwich, \& Hines, 2011). This positive trend has been linked to stratospheric ozone depletion and increased greenhouse gas emissions (Fogt et al., 2011; Thompson et al., 2011) The latest IPCC AR5 CMIP5 models show a slight weakening in the positive SAM trend; however, this is strongly dependent on the emission scenario due to the competing effects of greenhouse gases and ozone recovery (Christensen et al., 2013).

Based on the above information, there has not been a strong trend in increasing temperature over the period of eutrophication seen in Lake Pounui. The trend of increased La Niña events over the $20^{\text {th }}$ century may have caused increased wind and storms to the Lake Pounui region due to enhanced north-easterlies. Increased windiness 
and turbulence could explain the increase in tychoplanktic diatoms in most recent times, namely Aulacoseira granulata var. angustissima; however, the record of measured wind speed since 1970 shows no significant trend (NIWA, 2016). It is possible that throughout the $21^{\text {st }}$ century there may be an increase in El Niño and negative SAM events, which may cause a reduction in windiness and storms to the Pounui region. This may cause increased stratification, as seen in other regions (Ruhland et al., 2008). However, the latest IPCC report states that there is low confidence in changes to ENSO and SAM patterns (Christensen et al., 2013).

It appears that the role of climate change is still a large unknown but is likely to have played some role in the changes seen in Lake PounuiA more extensive literature review is beyond the scope of this thesis, but should be considered as more data becomes available.

\section{$\underline{\text { Summary }}$}

Prior to human arrival, natural change occurred at Lake Pounui. From 3000 to $2100 \mathrm{cal}$ yr BP, the lake appears to have been relatively productive, with a higher percentage of eutrophic and mesotrophic diatoms than at present. This may have been driven by a relatively shallow, turbulent environment with high catchment input of nutrients. A period of disturbance, which could relate to a combination of earthquakes (McSaveney et al., 2006; Little et al., 2009) and increased storminess (Page et al., 2010), occurs from 2100 to $1600 \mathrm{cal} \mathrm{yr}$ BP. It is possible that this natural disturbance caused the shift to a lower nutrient, deeper, more stratified state from 1600 to 450 cal yr BP. Māori arrival then occurs at $\sim 450 \mathrm{cal}$ yr BP. This causes disturbance in both the physical and ecological condition of the lake; however, Lake Pounui appears to recover to natural, baseline conditions, with perhaps even higher water quality. This indicates that, apart from the initial impact of land clearance, Māori "managed" the lake relatively well. From $150 \mathrm{cal}$ yr BP to present, the lake appears to become more nutrient enriched, indicating that European settlement and associated activities, such as farming and the introduction of exotic fish, may have initiated the decline in water quality that has been seen over the last 40 years. The effect of anthropogenic climate change can also not be ruled out. Interestingly, it appears that prior to human arrival, Lake Pounui persisted as both a higher nutrient and lower nutrient state over millennial timescales. This raises questions of what qualifies as reference conditions and what defines restoration targets. These questions will be explored further in the following chapters. 


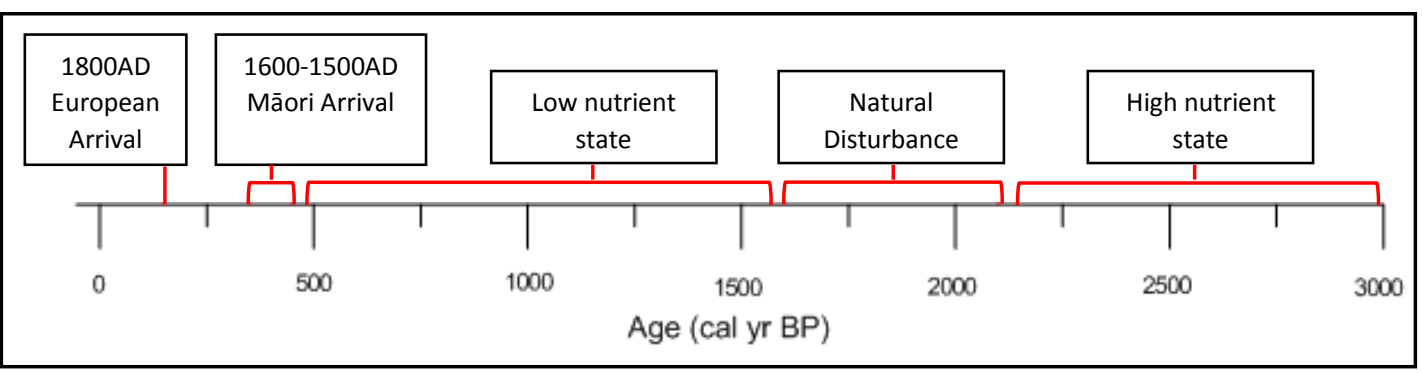

Figure 3.26: Timeline of events in Lake Pounui's history.

To answer research question one: are algal blooms a natural feature of Lake Pounui? - it is likely that algal blooms did occur during the high nutrient state from 3000 to $2100 \mathrm{cal}$ yr BP; however they were probably comprised of different phytoplankton than at present. The cyanobacteria of concern in today's algal blooms (Dolichospermum and Phormidium) did not appear until human arrival. Therefore, algal blooms are a natural feature of Lake Pounui, although, the species responsible for the current algal blooms are a consequence of anthropogenic impact.

\subsubsection{Limitations}

\section{Age-depth model}

There are always large uncertainties when creating an age-depth model. The main errors stem from variable sediment accumulation rate, contamination with young and/or old carbon, low frequency sampling, and the modelling framework.

The age-depth model produced for this study is based on 10 samples. The age of the base of the core has been extrapolated to approximately 3000 cal yr BP (weighted mean=2915.3, 95\% CI=3210-2696 cal yr BP). The only other age-depth modelling carried out at Lake Pounui estimated that $3 \mathrm{~m}$ of sediment spanned only the last 2500 cal yr BP (Turner \& Lillis, 1994). The age-depth model produced by Turner and Lillis (1994) was based on only 4 radiocarbon dates, one of which was identified as an outlier because it estimated an age that was 200 years older than expected. It is possible that the samples used for the age-depth model in this study were affected by contamination with old carbon. Contamination by old carbon is common and causes a larger amount of error than contamination by young carbon. It is often caused by re-deposition of old organics during periods of catchment disturbance (McGlone \& Wilmshurst, 1999). Although, more confidence is placed in the age-depth model produced by this study as no age reversals were seen and more radiocarbon dates were used. 
The Manganui tephra identified at $291.96 \mathrm{~cm}$ is estimated to have been deposited at approximately 3200 cal yr BP, based on its position between a lahar deposit dated at $4030+/-110$ cal yr BP and an unnamed tephra deposit dated at 1990+/-70 cal yr BP (Whitehead, 1976). The age-depth model dates the position of this tephra to approximately $2870 \mathrm{cal}$ yr BP (95\% CI: 3156-2649 cal yr BP). The upper most limit for the tephra (3156 cal yr BP) is 50 years younger than estimate made by Whitehead (1976). This may indicate that the age-depth model underestimates the age of the core. Contamination by young carbon is often caused by reworking of younger sediments down core via bioturbation or by humic-rich ground water contaminating inorganic sediments (McGlone \& Wilmhurst, 1999), although, there is no evidence of bioturbation or large groundwater influence within Lake Pounui. Variable sediment accumulation rates can also cause errors in interpolation between dates. The Bacon package models accumulation rates in an attempt to deal with this variability (Blaauw \& Christen, 2011). It is most likely, however, that any of the error associated with the agedepth model is related to the poor distribution of ages. To be more confident in the ages presented in this study more radiocarbon dates should be analysed from the bottom of the cores, and lead and caesium dating could be used to better constrain the most modern sediments.

\section{Paleolimnological methods}

Paleolimnological methods are criticised as being time consuming and costly (Schallenberg et al., 2011). It is true that paleolimnological methods require time and resources, but they provide a depth of knowledge that cannot be inferred from modelling, eco-typing, or expert assessment. With this in mind, there are a number of limitations that should be discussed.

\section{Sampling resolution}

Generally higher sampling resolution creates a more robust reconstruction; however, time and funding constraints often imposes limitations. Higher resolution of radiocarbon dating would create a more robust age-depth model. Higher resolution analysis may provide a better understanding of the catchment scale effect of some of the natural disturbances and allow European impact to be better pin-pointed. Extension of the bacterial DNA record may also provide more information on the effect of natural disturbances within the catchment. Higher resolution sampling of the diatom record 
throughout the whole core would provide a more robust reconstruction of ecological conditions within the lake.

\section{New Zealand specific ecological preferences}

One of the major issues in diatom analysis is the lack of data on New Zealand specific ecological preferences. Therefore, diatom ecological preferences from the Netherlands presented in van Dam et al (1994) were used, as has been done in a number of studies in New Zealand (Augustinus et al., 2012; Young, 2010; Augustinus et al., 2008). However, on average $18 \%$ of the assemblage was unknown for trophic status, $4 \%$ for salinity, $5 \%$ for $\mathrm{pH}$, and $44 \%$ for oxygen concentration. The larger the amount of unknowns, the lower the accuracy of results. Oxygen for example was only included in the analysis because it could be compared to independent estimates from the Fe/Mn ratio. To further compound this, there is no guarantee that diatoms from the Netherlands have the same ecological preferences as diatoms in New Zealand. However, when making inferences about ecological changes throughout the core, preferences from van Dam et al (1994) were supported with other evidence, highlighting the importance of a multiproxy approach.

To provide quantitative estimates of the aforementioned environmental variables, the diatom data presented in this study could be analysed using transfer functions presented by Reid (2005) and Cochran et al (2007). This would involve gaining access to the transfer function and harmonising the taxonomy to their specific training set, although it is likely there would be unknowns in this analysis. There is a need for more New Zealand specific diatom-water chemistry transfer functions. They have proved incredibly useful in Europe for reconstructing trends in water quality problems (Battarbbe et al., 2000) and assessing the impact of acid rain. The European Diatom Database (EDDI) has now been created, which harmonised many regional training sets to create robust transfer functions for $\mathrm{pH}, \mathrm{TP}$, and salinity to cover most of the geographic regions of Europe (Battarbee et al. ,2000). A database such as the EDDI would be useful in analysing paleoecological data in New Zealand and would offer more robust reconstructions.

\section{More proxies $=$ more robust evidence}

Time constraints and funding often limit the number of proxies that can be incorporated into any one study; however, the more lines of evidence that are given, the more robust the reconstruction. For example, the reconstruction of oxygen saturation from diatom 
preferences was verified using the $\mathrm{Fe} / \mathrm{Mn}$ ratio (attained via $\mu-\mathrm{XRF}$ ). As stated, there are limitations when using ecological preferences of diatoms from other parts of the world. Diatoms also respond to a number of stimuli at once, therefore, what may look like a trend in one variable, may be driven by another. Fe/Mn was able to confirm the changes in oxygen concentration suggested by the diatom data, providing robust evidence for this proxy.

There are a number of other proxies that could be collected from Lake Pounui. Diatom concentration was not measured in this study, as the method of mounting diatom samples on to slides meant that the diatoms were not evenly distributed across the surface. Diatom concentration should be analysed, as it can give indication of changes in productivity, and would have been re-done if there was sufficient time available. Possible methods for determining diatom concentration include alkaline extraction of biogenic silica (Conley \& Schelske, 2001; Mortlock \& Froelich, 1989), calculation from the addition of a known concentration of microspheres (Battarbee \& Kneen, 1982), or the use of evaporation trays to get a randomly distributed spread of diatoms from which concentration can then be calculated (Battarbee, 1986).

Chironomid head capsules were found during charcoal analysis and would provide supporting evidence of ecological changes. Photosynthetic pigments can be preserved in lake sediment, with different pigments associated with different phytoplankton, and changes in pigment abundances can reveal changes in community structure (e.g., switch from diatom to cyanobacterial dominance) (Kpodonu, Hamilton, Hartland, Laughlin, \& Lusk, 2016), which would complement the bacterial DNA analysis. Carbon to nitrogen isotope ratios would establish the contribution of allochthonous and autochthonous organic matter to the total organic matter content identified by LOI. This would give a better understanding of internal productivity versus external inputs

\section{$\underline{\text { Summary }}$}

Although there are limitations, paleolimnological analysis of past environments provides a better understanding of the natural lake environment and provides answers to questions that cannot be answered by modern ecological studies. Paleolimnolgical analysis permits more informed management decisions, for instance the results from this thesis will help establish realistic restoration targets for Lake Pounui. 


\section{Chapter Four: What is the Extent of Degradation at Lake Pounui?}

\subsection{Introduction}

Reference conditions have been defined as those expected in the absence of significant anthropogenic impact (European Union, 2000). Legislation, such as the European Council Water Framework Directive (WFD), now mandates assessments to measure the ecological quality of water bodies (European Union, 2000). This has created a wealth of studies that have used diatoms to reconstruct both chemical and biological reference conditions for lakes in Europe (Bennion et al., 2015; Bennion, Simpson, et al., 2011; Kelly et al., 2005). However, this application seems to be lacking in New Zealand. As established in the previous chapters, the water quality of Lake Pounui appears to have declined since 150 cal yr BP. Defining reference conditions for Lake Pounui may provide a restoration target to strive towards and a baseline against which to assess degradation. Therefore, the diatom data from Chapter three will be used to quantify the extent of change from reference conditions.

\subsection{Methods}

\subsubsection{Selecting the Reference State}

In theory, any sediment prior to human arrival fits the definition of 'conditions expected in the absence of significant anthropogenic impact'. However, the natural condition of a lake is not static, namely it varies throughout time due to internal and external processes (Bennion, Battarbee, et al., 2011; Schallenberg et al., 2011). Often, paleolimnological analysis identifies a range of conditions prior to human impact that could be used as the reference state. In choosing a reference condition, Bennion, Battarbee, et al. (2011) suggested that reference conditions should provide an achievable restoration target in relation to cost and the reversibility of the system, for example a condition where soils, climate, or lake depth are significantly different is not realistic. Most studies choose reference conditions just prior to significant human impact as it is thought that the catchment is most similar physically and climatically to present conditions, thus making restoration to these conditions the most realistic (Bennion et al., 2015; Bennion, Simpson, et al., 2011; Kelly et al., 2005). With this in mind, conditions just prior to European settlement should be chosen as reference conditions. In the case of Lake 
Pounui, however, paleolimnological methods identified a period prior to human arrival (zone one: 3000-2100 cal yr BP), with similar conditions to modern, which could be used as a reference state. To explore the effect of choosing different reference conditions two reference states will be considered: (1) the diatom assemblage at the base of the core (3000 cal yr BP; 95\% CI: 3210-2696 cal yr BP), and (2) the diatom assemblage just prior to European arrival (200 cal yr BP; 95\% CI: 319-83 cal yr BP). These will be referred to as $\mathrm{REF}_{3000}$ and $\mathrm{REF}_{200}$ respectively.

\subsubsection{Squared Chord Distance Dissimilarity}

To quantify the degree of change from reference conditions, a number of studies use the squared chord distance (SCD) dissimilarity measure (Bennion, Battarbee, et al., 2011). Dissimilarity coefficients are measures of difference between multivariate samples (Overpeck, Webb, \& Prentice, 1985). The squared chord distance was dubbed a 'signalto-noise' coefficient by Overpeck et al. (1985) as it emphasizes the signal or pattern in the species assemblage data at the expense of the random variation (noise). Gavin, Oswald, Wahl, and Williams (2003) and Overpeck et al. (1985) found that the squared chord distance coefficient performed best at distinguishing similar vs. non-similar ecological assemblages. Therefore, squared chord distance coefficients were calculated in R (R Core Development Team, 2015) using the analogue package (Simpson, 2007) as suggested by (Bennion, Simpson, et al., 2011).

Using the SCD dissimilarity measure the diatom assemblage at $\mathrm{REF}_{200}$ (200 cal yr BP; 95\% CI: 319-83 cal yr BP) was compared to all samples younger than $200 \mathrm{cal}$ yr BP (Fig. 4.1), and the diatom assemblage at $\mathrm{REF}_{3000}$ (3000 cal yr BP; 95\% CI: 3210-2696 cal yr BP) was compared to all samples younger than 3000 cal yr BP (Fig. 4.2). SCD scores range from 0 to 2 , where 0 indicates that the samples are identical and 2 indicates that the samples are completely different (Bennion et al., 2015). It was expected that samples would become more dissimilar (SCD scores would increase) to reference conditions as time progressed and human impact occurred. SCD scores were analysed using a linear regression in Excel to identify trends. Because the SCD data for REF 3000 did not fit a linear model, a Generalised Additive Model (GAM) was used fit the trend using the mgcv package (Wood, 2011) in R (R Core Development Team, 2015). GAMs locally fit data with a set of smooth functions that are penalised for overfitting, thus not forcing data into unnatural forms (Guisan, Edwards, \& Hastie, 2002). Therefore, GAMs can deal with non-linear data in a balanced way. A cluster dendogram was then used to show which zones were statistically the most similar. 


\subsection{Results}

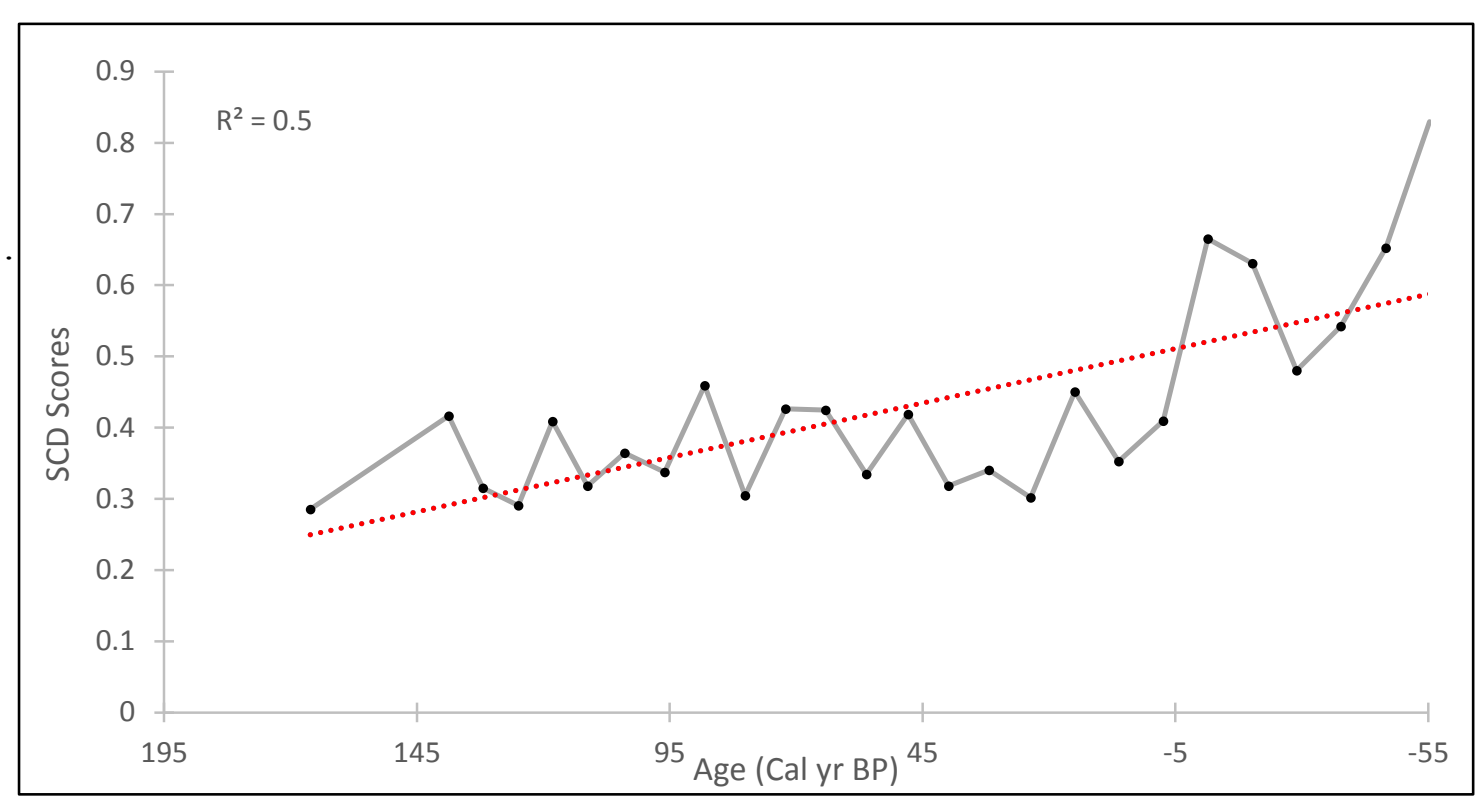

Figure 4.1: Dissimilarity from REF 200 (200 cal yr BP; 95\% CI: 319-83 cal yr BP). Using the Squared-Chord Distance (SCD) dissimilarity measure the diatom assemblage at $R E F_{200}$ was compared to all samples younger than 200 cal yr BP to create SCD scores over time (Cal yr BP. 0=1950 AD). A SCD score of 0 indicates that samples are identical, and a SCD score of 2 indicates that the samples are completely different (Bennion et al., 2015). This shows that the diatom assemblage has become increasingly dissimilar since $200 \mathrm{Cal}$ yr BP $\left(R^{2}=0.5\right.$, $P$-Value $\left.=0.00\right)$

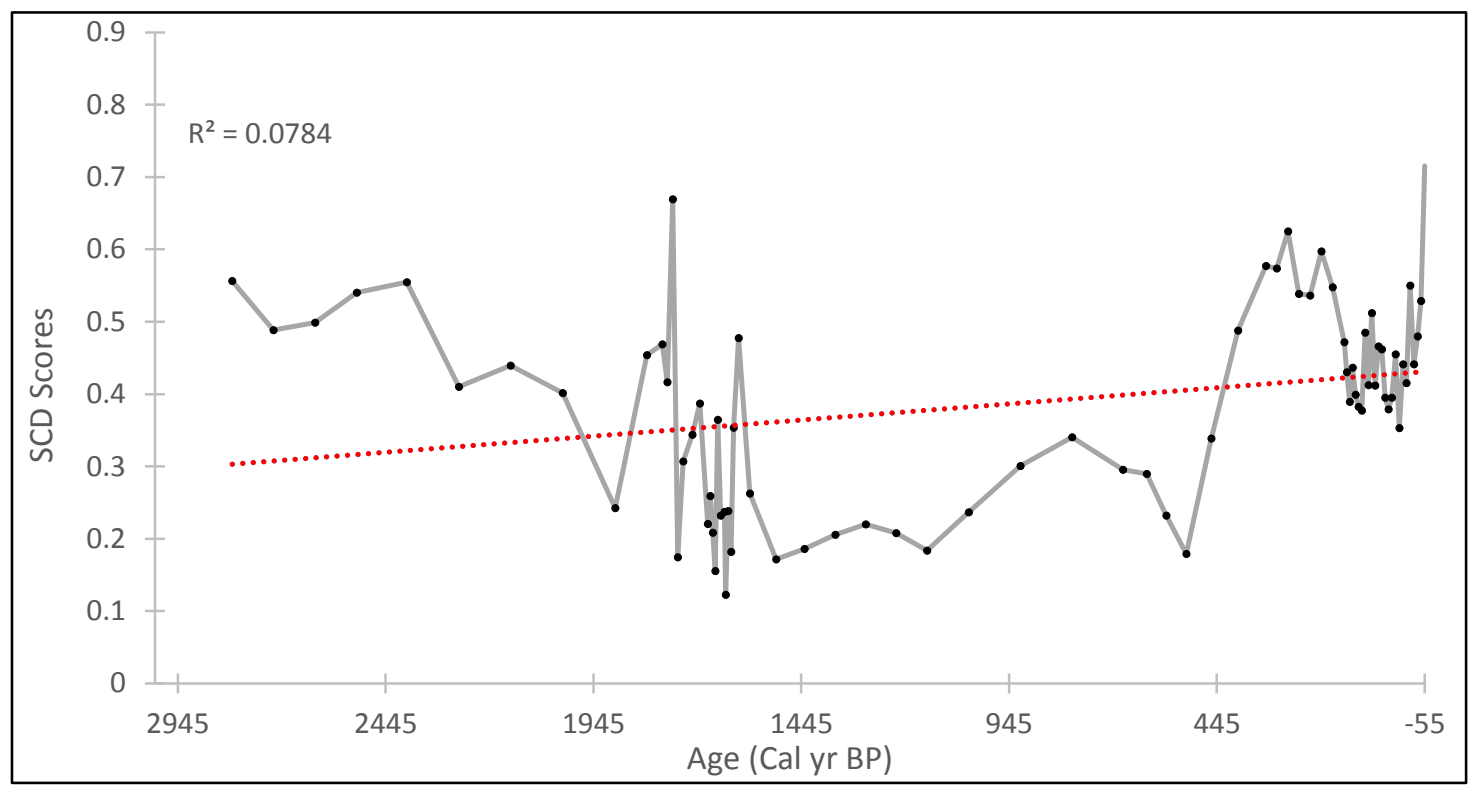

Figure 4.2: Dissimilarity from $R E F_{3000}$ (3000 cal yr BP; 95\% CI: 3210-2696 cal yr BP). Using the Squared-Chord Distance (SCD) dissimilarity measure the diatom assemblage at $R E F_{3000}$ was compared to all samples younger than 3000 cal yr BP to create SCD scores over time (Cal yr BP. $0=1950$ AD). A SCD score of 0 indicates that samples are identical, and a SCD score of 2 indicates that the samples are completely different (Bennion, Simpson, \& Goldsmith, 2015). This shows that there is no significant linear trend in dissimilarity between diatom assemblages from $3000 \mathrm{cal}$ yr BP to present $\left(R^{2}=0.08, P\right.$ Value $=0.01$ ). 
When the $\mathrm{REF}_{200}$ is used as the reference state we see a significant increase in dissimilarity as human impact occurs, as expected (Fig. 4.1). Although the data fits a linear regression model, the SCD scores do fluctuate throughout time. The SCD scores appear to increase most substantially around $1950 \mathrm{AD}$ (0 cal yr BP). When $\mathrm{REF}_{3000}$ is used as the reference state we see no significant linear trend (Fig. 4.2); it is clear that the data is non-linear. To better analyse the non-linear SCD data from $\mathrm{REF}_{3000}$, a GAM was used to model the trend (Fig. 4.3) with references to the diatom-inferred zones (Section 3.3.2). The GAM preformed relatively well and explained $67.2 \%$ of the deviance in the data; however zone 3 may be over-fitted. The GAM model shows that dissimilarity values (from $\mathrm{REF}_{3000)}$ are greatest in zones 1,4 , and in the most recent period of zone 5 . The cluster dendrogram (Fig. 4.4) confirms that zones 1 and 4 are most similar to each other, and that they are also similar to zone 5 . These zones are completely distinct from zones 2 and 3 .

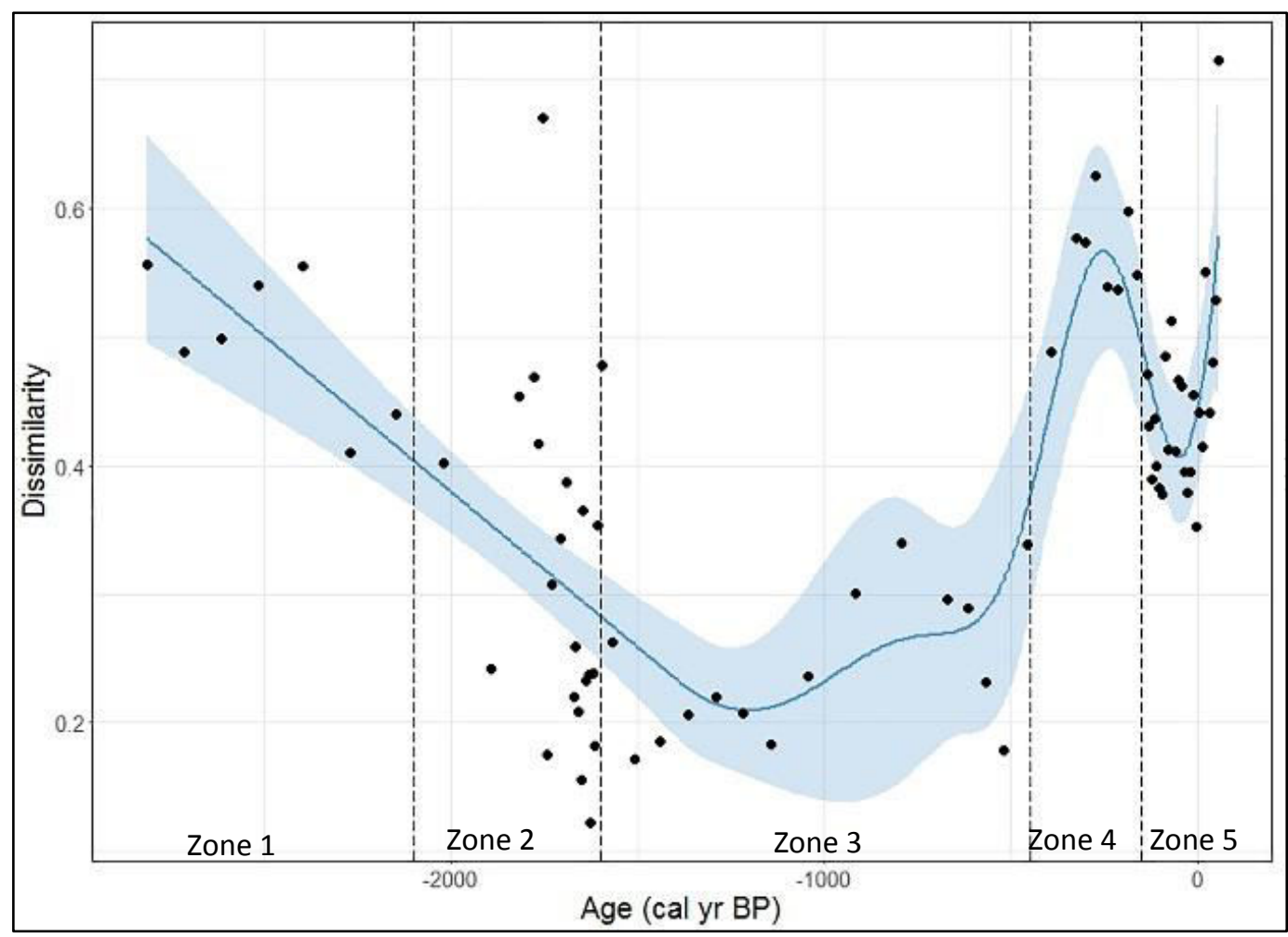

Figure 4.3: Generalised additive model of dissimilarity from $R_{3} F_{3000}(3000$ cal yr BP; 95\% CI: 3210-2696 cal yr BP) with reference to diatom-inferred zones. The model explains $67.2 \%$ of the deviance, however, may over fit zone 3 at the expense of fitting zone 4 and 5. This shows that the diatom assemblages in zones 1, 4, and the most recent samples of zone 5 are the most dissimilar to the diatom assemblage at $R E F_{3000,}$ whereas the diatom assemblages in zones 2 and 3 are the most similar to the diatom assemblage at $R E F_{3000}$. 


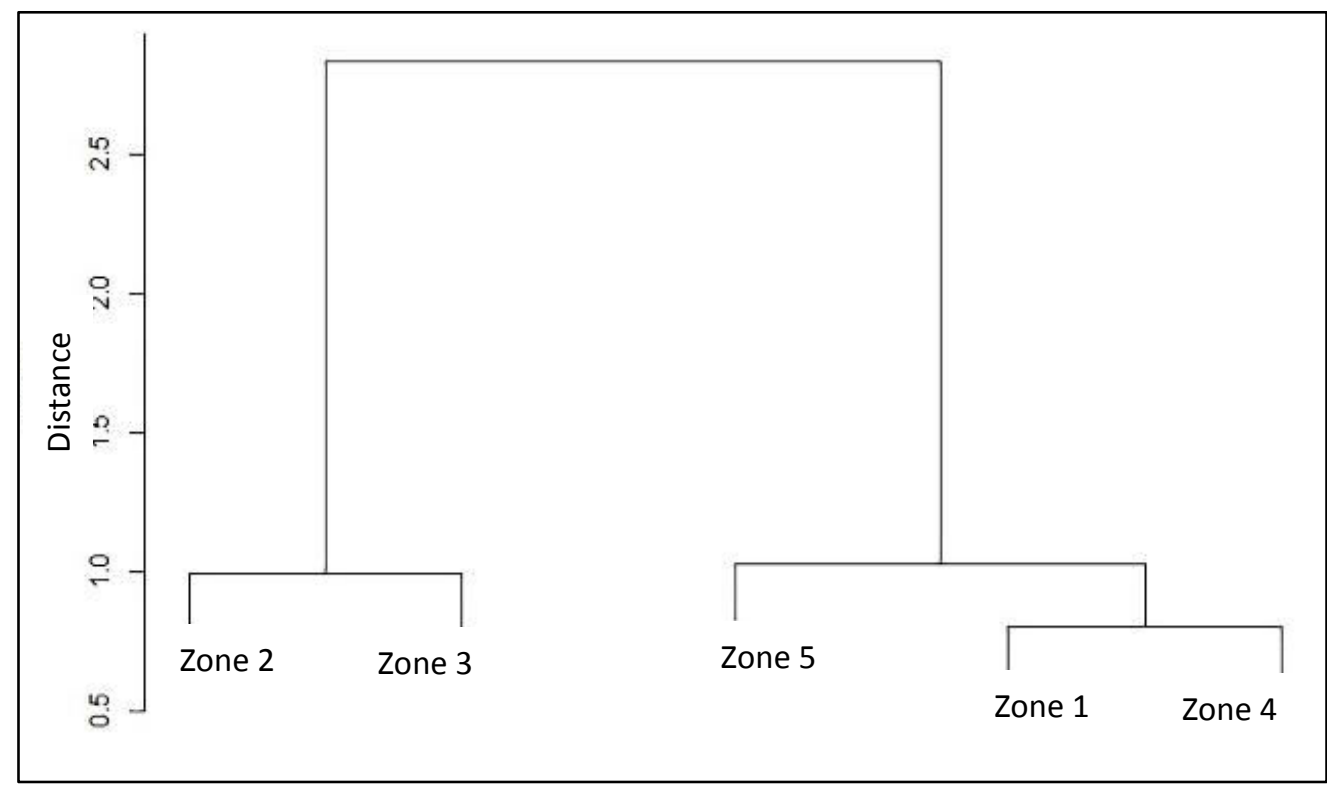

Figure 4.4: Cluster dendrogram of the GAM modelled dissimilarity from $R E F_{3000}$ (3000 cal yr BP; 95\% CI: 3210-2696 cal yr BP) with reference to diatom-inferred zones. This shows that the diatom assemblages in zones 1 and 4 are most similar to each other, and they are also similar to zone 5, and that the diatom assemblages in these zones are completely distinct to those in zones 2 and 3.

\subsection{Discussion}

\subsubsection{Application of Squared Chord Distance Dissimilarity Scores}

Dissimilarity analysis produced some interesting results. Large changes in trends were seen depending on which assemblage was chosen as the reference state.

When $\mathrm{REF}_{200}$ was used as the reference state a significant trend of increasing SCD scores was seen, as expected (Fig. 4.1). $\mathrm{REF}_{200}$ represents the period after Māori arrival when the initial disturbance from land clearance had subsided and the system was beginning to recover. This period offers the most realistic restoration target as the lake still has relatively low productivity (oligotrophic-mesotrophic), although, much of the natural forest is thought to have been cleared. This would be the point in time where the climate and physical conditions of the lake were most similar to present. The substantial increase in SCD scores from approximately 1950AD (95\% CI: 1888-1995AD) relates to a decline in water quality, coincident with modern human impacts. These results are similar to those produced by Bennion et al. (2015); Bennion, Simpson, et al. (2011); and 
Kelly et al. (2005) who used assemblages just prior to substantial human impact as their reference state in dissimilarity analysis.

When $\mathrm{REF}_{3000}$ was used as the reference state the complex nature of Lake Pounui's ecological history was exposed (Fig 4.3). Zones 2 and 3 were most similar to REF 3000 (i.e., $\mathrm{REF}_{3000}$ dissimilarity=0). These periods likely represent lower nutrient states in Lake Pounui's history, although they do not provide realistic restoration targets as climate and physical conditions may been substantially different. Zones 1 and 4 were most similar to each other (Fig. 4.4). Zone 4 represents the period of Māori settlement, where the lake was more productive than zones 2 and 3, but water quality still remained relatively high. As stated above, zone 4 probably offers the most realistic restoration target. Zone 1 represents a period of high productivity before human impact. Climate and physical conditions were probably quite different 3000-2000 cal yr BP; however, this zone provides information on what could be expected in a naturally productive state of Lake Pounui.

\subsubsection{Criticisms of reference conditions framework}

Although using reference conditions to assess degradation and set restoration targets appears to be useful for Lake Pounui there are a number of criticisms that need to be considered.

\section{Reference conditions are static}

Static reference conditions, as a restoration target, do not take into account that conditions may have naturally changed during the period of human impact, in other words, not all the change can be attributed to humans (Schallenberg et al, 2011; Bennion et al, 2015). This was shown when using $\mathrm{REF}_{3000}$ as the reference state. In terms of using $\mathrm{REF}_{200}$, there have been a number of fault ruptures in the lower North Island that may have affected the physical properties of the lake in the last 200 years, the last of which occurred in 1855 AD. The 1855 AD Wairarapa fault rupture caused an 8-8.3 magnitude earthquake and a 6-m uplift at Turakirae Head ( $20 \mathrm{~km}$ from Lake Pounui) (McSaveney et al., 2006). However, based on the catchment disturbance indicators, there is no evidence of major change within Lake Pounui associated with the $1855 \mathrm{AD}$ earthquake, and there is little evidence for large natural climate change. Therefore, it seems logical to use $\mathrm{REF}_{200}$ as the reference condition. 


\section{Not all human influence can be removed}

Secondly, because human influence cannot be completely removed during restoration, reference conditions prior to human impact might not be realistic restoration targets (Schallenberg et al, 2011). This is true for a number of anthropogenic impacts, such as land use change and introduction of exotic species. These impacts are difficult, costly, and would take a significant amount of time to reverse. Others are, on the scale of catchment management, irreversible, such as anthropogenic climate change.

\section{Land use change}

At Lake Pounui, land use may be reverted to conditions similar to Māori inhabitation by planting native vegetation and removal of sheep, at the owner's digression. This may reduce the effect of eutrophication by reducing the external nutrient load to the lake; however, if internal nutrient loading has occurred, recovery is often delayed as sediment high in phosphorous often accumulates at the lake bottom (Sondergaard et al, 2003). This phosphorous can then be released via a number of processes, including resuspension, increase in temperature and $\mathrm{pH}$, and onset of anoxic conditions (Sondergaard et al, 2003). This therefore reduces the effectiveness of external nutrient reduction until the internal load has been used up. There are a number of restoration methods that have been used to address internal nutrient loads, such as biomanipulation, chemical flocculants and adsorbents, and sediment dredging (Sondergaard et al, 2003). Therefore, if little effect was seen in Lake Pounui's state after external nutrient reduction, within lake manipulation should be investigated.

\section{Introduction of exotics}

Studies on the removal of perch and brown trout have been carried out at the Lower Karori Reservoir, Wellington. Smith \& Lester (2006) found that perch abundance was related to increased cyanobacteria, lower populations of large zooplankton, and higher populations of small rotifer species (Smith \& Lester, 2006). They concluded that removal of perch could reduce phytoplankton abundance, either by reduced pressure on zooplankton grazers or by direct reduction of nutrients excreted by large perch populations (Smith \& Lester, 2006). Shortly after perch removal by electrofishing, there was a reduction in cyanobacteria and an increase in zooplankton (Hicks et al, 2007). The removal of brown trout has also been conducted in the Lower Karori Reservoir by rotenone treatment (Duggan et al, 2015). The removal of brown trout caused an increase in the number of galaxiids during the next spawning and a delayed shift from large 
zooplankton dominance to small rotifer dominance (Duggan et al, 2015). However, there was also a reduction of phytoplankton, which occurred immediately after trout removal before the changes in zooplankton occurred (Duggan et al, 2015). This may have been due to reduction in the fish population and therefore a reduction of excreted nutrients. However, as the galaxiid population recovers, they are likely to reduce the grazing pressure of zooplankton on phytoplankton, which may ultimately enhance algal blooms (Duggan et al, 2015). This would cause a contrasting effect to the removal of perch. The removal of exotic fish from Lake Pounui is possible, but before it is considered, further study of these interactions should be conducted, possibly employing the mesocolumn technique used by Smith \& Lester (2006) to examine the effects of removal.

\section{Anthropogenic climate change}

It appears that the role of climate change on changes in lake ecosystems is still a large unknown; however, global warming will likely cause changes that cannot be as easily reversed or minimised. It seems that anthropogenic climate change has not had a large effect on Lake Pounui as yet, but its influence cannot be ruled out. This needs to be considered when assessing restoration based on a reference state where climate may have been quite different. It has been shown that large changes such as anthropogenic impact and climate change can result in novel ecosystems without past analogues (Bennion et al, 2015). When large scale changes like this occur, even if environmental conditions are restored, it may not result in the original assemblage. In this case, SCD scores may not correctly identify degradation and recovery.

\subsubsection{Summary}

In summary, SCD scores produce different results depending on the reference state chosen. Choosing the reference state just prior to significant human impact $\left(\mathrm{REF}_{200}\right)$ provides information on the extent of change during the following period. Choosing a reference state from a more distant time $\left(\mathrm{REF}_{3000}\right)$ may help identify periods in the lake's history that could be useful for determining restoration targets. For example, zone 4 provides the most realistic restoration target for Lake Pounui because it has relatively high water quality and similar physical and climatic conditions to at present. 
Based on above, conditions could be reversed by planting native vegetation, and removing sheep, perch, and brown trout. However, these options have to be tempered by the landowner's needs and desires. For instance, the farmers at Lake Pounui may not wish to cease sheep grazing, so this clearly may not be a viable option. Recovery to conditions similar to zones 4 and 1 would see a reduction in Aulacoseira granulata var. angustissima, and Cyclostephanos dubius, the return of Aulacoseira ambigua, and an increase in Discostella stelligera. If restoration resulted in recovery of diatom assemblages this could be modelled by a decrease in SCD scores as done by Bennion et al. (2015); however, restoration of environmental conditions does not guarantee recovery of the original diatom assemblage. This needs to be considered if SCD scores were to be used to model recovery. 


\section{Chapter Five: Can Generic Early Warning Signals Prior to Critical Transitions be identified at Lake Pounui?}

\subsection{Introduction}

Shallow lakes can shift between two alternative equilibriums: one dominated by submerged macrophytes and one dominated by phytoplankton (Scheffer \& Nes, 2007; Scheffer, Hosper, Meijer, Moss, \& Jeppesen, 1993). Submerged macrophytes can maintain a clear water, low nutrient state by reducing resuspension of sediment, increasing habitat for grazing zooplankton, and reducing nutrient availability (Scheffer $\&$ Nes, 2007; Scheffer et al., 1993). Turbid environments, however, prevent growth of submerged macrophytes due to light limitation (Scheffer \& Nes, 2007; Scheffer et al., 1993). In this state, waves and fish may increase nutrient recycling, as sediment is more easily re-suspended, thus encouraging algal growth (Scheffer \& Nes, 2007; Scheffer et al., 1993). At different nutrient states, the stability of these two equilibria change. In the clear water equilibrium, a small increase in nutrients may result in the development of the alternative turbid counterpart (Scheffer et al., 1993). If nutrient enrichment continues, the clear state will gradually become more unstable, making it more vulnerable to perturbations that may cause it to tip into the contrasting state (Fig. 5.1) (Scheffer et al., 1993).

There is a possibility of generic markers that precede these transitions, such as critical slow down and flickering. Critical slow down occurs when the rate at which a system recovers from perturbation slows when close to a tipping point (Fig. 5.1) (Scheffer et al., 2012). When alternative states arise in stochastic systems, flickering between the two states may occur (Fig. 5.1) (Scheffer et al., 2012). These generic markers have now been modelled by numerous authors (Scheffer et al., 2012; Wang et al., 2012; Dakos et al., 2008) but, real world data are scarce. Predicting these changes is challenging in complex networks such as ecosystems (Dakos et al., 2008), though the ability to identify critical transitions holds important conservation implications, for example: determining which ecosystems have high or low resilience will allow better allocation of conservation resources. Therefore, the diatom data collected to reconstruct ecological change will be analysed for tipping points and generic markers using the Early Warning Signals package (Dakos et al., 2012) in R (R Core Development Team, 2015). 
A

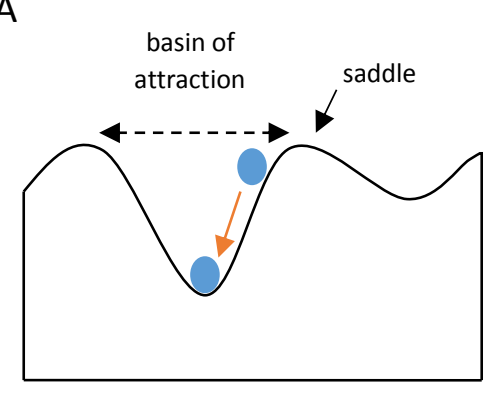

B basin of

attraction

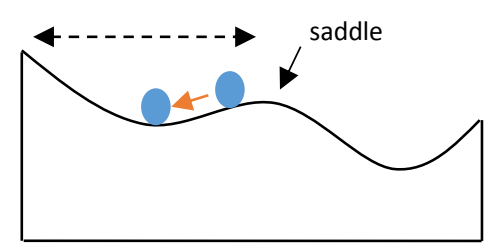

A) High resilience

A system (blue circle) far from a tipping point has a deep basin of attraction and quickly recovers from perturbations (red arrow); disturbances do not easily shift the system to an alternative state.

B) Low resilience

The basin of attraction becomes shallow as conditions change and no longer favour this state. Recovery rate from disturbances is slower (red arrow); and fluctuations become larger and more correlated in time.

Figure 5.1: Systems with low resilience undergo critical slow down and/or flickering prior to critical transition into an alternative stable state.

\subsection{Methods}

\subsubsection{Metric-Based Indicators}

Generic markers of critical transitions such as slow down and flickering can be identified based on statistical properties of the time series (Dakos et al., 2012). Statistical properties that were calculated for this analysis are:

(1) Autocorrelation - autocorrelation is a measure of similarity between the assemblage at different points in time. An increase in autocorrelation indicates that the consecutive observations of the assemblage have become more similar (Dakos et al., 2012). An increase in autocorrelation is expected during both slow down and flickering (Dakos et al., 2012).

(2) Variance - variance is a measure of spread between numbers in a dataset and the mean, which is represented here by the standard deviation (square-root of variance) (Dakos et al., 2012). An increase in standard deviation is expected during both slow down and flickering (Dakos et al., 2012)

(3) Skewness - skewness describes the asymmetry of a distribution. As a system approaches a transition fluctuation around the mean can become more asymmetric 
because there are more fluctuations towards the new alternative state, and recovery to the current equilibrium begins to take longer (Kefi et al., 2014). Therefore, a change in skewness can be seen prior to a transition.

(4) Kurtosis - kurtosis is a measure of the weight of the tails of the distribution. Flickering or perturbations that occur prior to a critical transition make it more likely that a system will reach extreme values, which fall at the tails of the distribution. This causes a rise is kurtosis, or a shift to leptokurtic distribution where the tails become thicker due to an increase in rare values in the dataset (Dakos et al., 2012).

\subsubsection{Principal Component Analysis (PCA)}

To calculate the metric-based indicators in the Early Warning Signals package (Dakos et al., 2012) the diatom assemblage data was first transformed into a univariate time series.

Detrended Correspondance Analysis of the diatom data was carried out (using the Decorana function in $\mathrm{R}$ (R Core Development Team, 2015)) to determine whether linear or unimodal statistical methods were more appropriate for converting the assemblage data to a univariate time series. All axis gradients were less than two standard deviations, therefore, linear methods (i.e., Principal Component Analysis (PCA)) were more appropriate (Birks, 1995).

PCA simplifies multivariate data into principal components that are arranged by the most variance explained. This allows multivariate correlations between the data to be visualised in two dimensional plots. PCA was conducted in R (R Core Development team, 2015), using the Vegan package (Oksanen et al., 2016). Species data was first hellinger transformed as suggested by Legendre and Gallagher (2001). PCA axes were compared to a broken stick model to determine which axes would be retained (Jackson, 1993). PCA axis data was separated into the five zones identified using Psimpoll and presented as simple line graphs (Fig 5.4), biplots (Fig 5.5, 5.6), and time track plots (Fig 5.7) using Grapher.

\subsubsection{Early Warning Signals Analysis}

To use the Early Warning Signals package Dakos et al. (2012) suggest detrending the univariate time series, and using interpolation to create equally spaced data points. 
Therefore, the Early Warning Signals analysis was run using a rolling window size of 40, on interpolated data, which was detrended using a Gaussian filter (Dakos et al., 2012; Wang et al., 2012). The Early Warning Signals package then tests the strength of the trend in the metric-based indicators using Kendall's $\tau$ rank correlation, where 0 is no relationship, an 1 is a perfect relationship (Dakos et al., 2012)

It has been argued, however, that in some instances the data transformations can change the underlying structure of the data producing artefacts that can be interpreted as signal (Carstensen, Telford, \& Birks, 2013). For example, Carstensen et al (2013) proposed that evidence of flickering prior to a transition in Lake Erhari, China, published by Wang et al (2012), may have resulted from data processing. Linear interpolation to coerce evenly spaced samples in a time series can reduce variance and increase autocorrelation in data with lower resolution sampling (Carstensen et al, 2013). A Generalised Additive Model (GAM) was used to avoid this problem. As stated previously, GAMs can handle irregularly spaced, non-linear data, as they locally fit data with a set of smooth functions that are penalised for overfitting, thus better modelling the underlying structure (Guisan et al., 2002). The GAM was run with the mgcv package (S. Wood, 2011) in R (R Core Development Team, 2015) with the age and variance set as predictors.

\subsection{Results}

\subsubsection{Principal Component Analysis (PCA)}

PCA was carried out on both the full diatom dataset and the dataset with only the diatoms that make up $>2 \%$ in $>2$ samples to ensure that the structure of the data was not notably changed when rare taxa were removed. Tables 8 and 9 shows that the difference

\begin{tabular}{|c|c|c|c|c|c|}
\hline & PCA1 & PCA2 & PCA3 & PCA4 & PCA5 \\
\hline Standard deviation & 2.772 & 1.8698 & 1.7054 & 1.55564 & 0.30199 \\
\hline Proportion of variance & 0.295 & 0.1342 & 0.1117 & 0.09291 & 0.06508 \\
\hline Cumulative proportion & 0.295 & 0.4292 & 0.5409 & 0.63376 & 0.69884 \\
\hline \multicolumn{6}{|c|}{$\begin{array}{l}\text { Table 9: PCA summary values for the diatom dataset }>2 \% \text { in }>2 \text { samples produced using the } \\
\text { Vegan package (Oksanen et al., 2016) in R ( } R \text { core development team, 2015). }\end{array}$} \\
\hline & PCA1 & PCA2 & PCA3 & PCA4 & PCA5 \\
\hline Standard deviation & 2.5694 & 1.8314 & 1.6894 & 1.5167 & 1.25490 \\
\hline Proportion of variance & 0.3076 & 0.1563 & 0.1330 & 0.1072 & 0.07338 \\
\hline Cumulative proportion & 0.3076 & 0.4639 & 0.5969 & 0.7041 & 0.77747 \\
\hline
\end{tabular}


between the two datasets was minimal, therefore the diatom dataset with rare taxa removed was used for analysis

Five PCA axes were identified by the broken-stick model (Fig. 5.4). This indicates that there is a lot of structure in the data. PCA axis 1 explains most of the variance (33.4\%) and was the focus of the critical transitions analysis. PCA axis 1 clearly identifies the pre- and post-human diatom assemblages with pre-human assemblages plotting on the left hand side of Figures 5.5 and 5.6, and post-human assemblages plotting on the right. The variance shown by PCA axis 1 is mainly related to Aulacoseira ambigua (Fig. 5.2), and is likely driven by its reduction in post-human assemblages. The remaining axes do a better job at identifying differences between zones 4 and 5 (Fig. 5.6). In particular, axis 3 appears to correspond to changes in trophic status with oligotrophic/mesotrophic assemblages plotting above zero in Figure 5.4, and eutrophic assemblages plotting below. The variance shown by PCA axis 3 is mainly related to Aulacoseira granulata var. angustissima (Fig. 5.3).

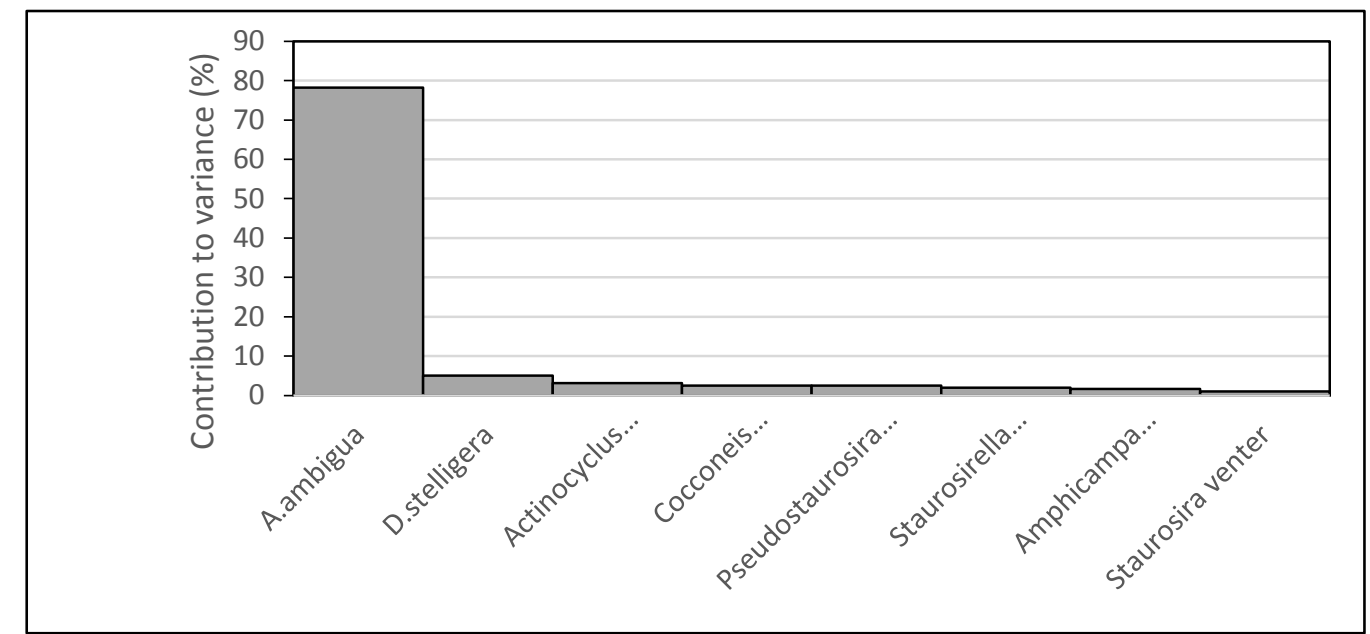

Figure 5.2: Species that contribute to more than 1\% of the variance explained by PC Axis 1.

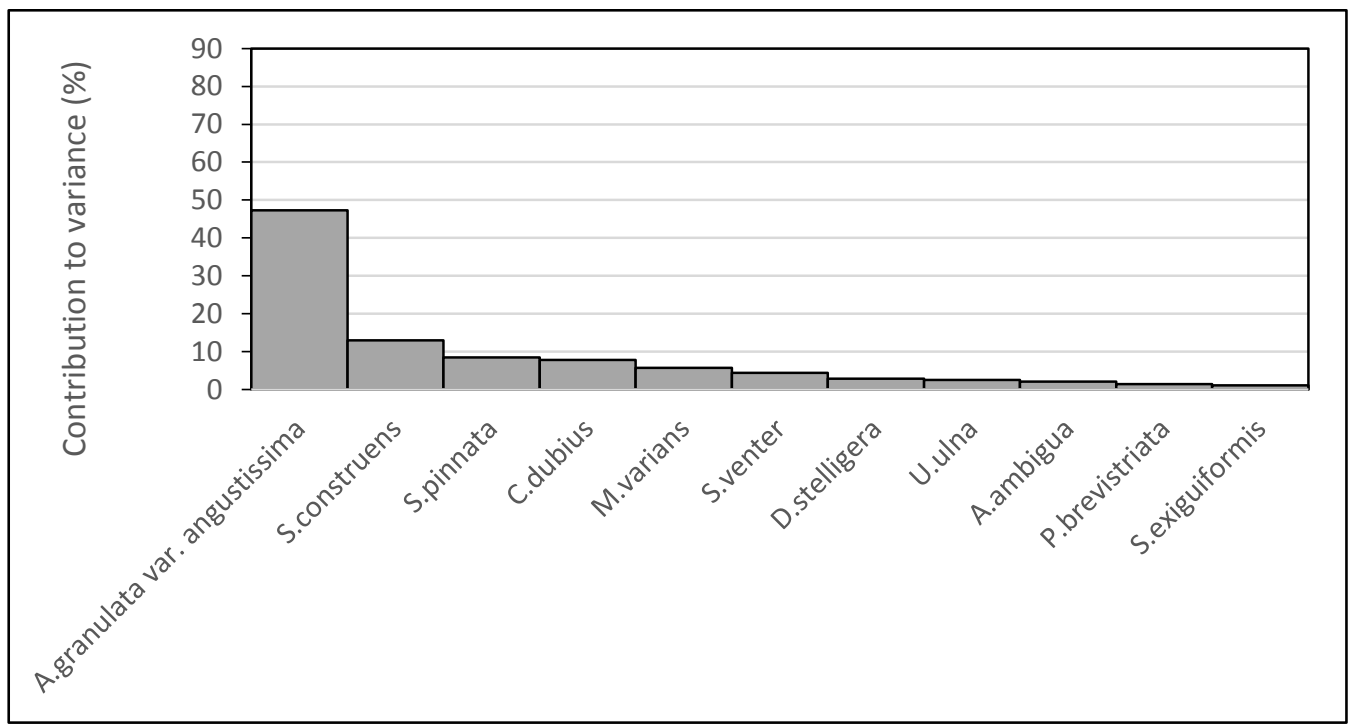

Figure 5.3: Species that contribute to more than 1\% of the variance explained by PC Axis 3. 


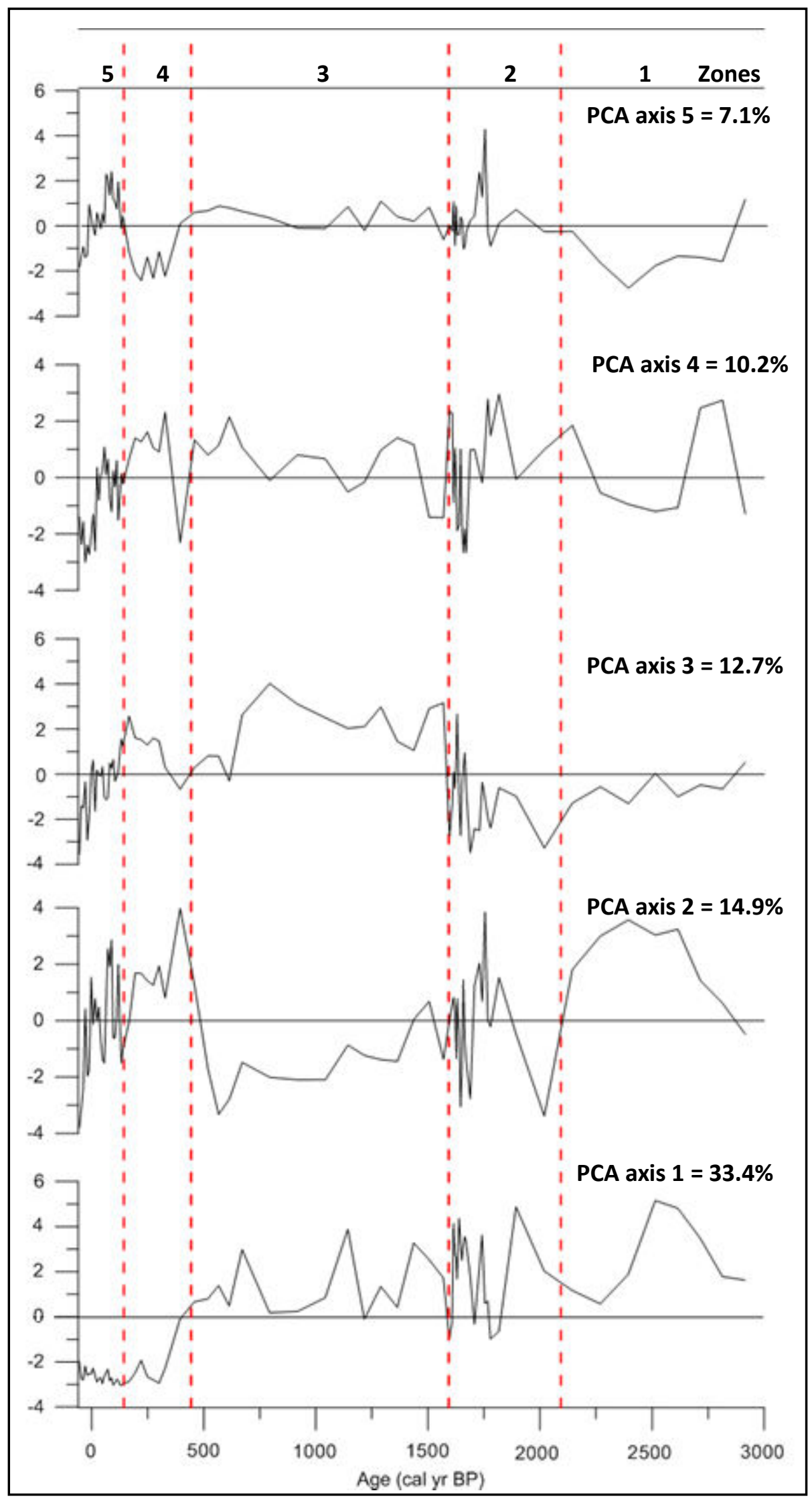

Figure 5.4: Principal component axes 1 to 5 and relation to diatominferred zones. 


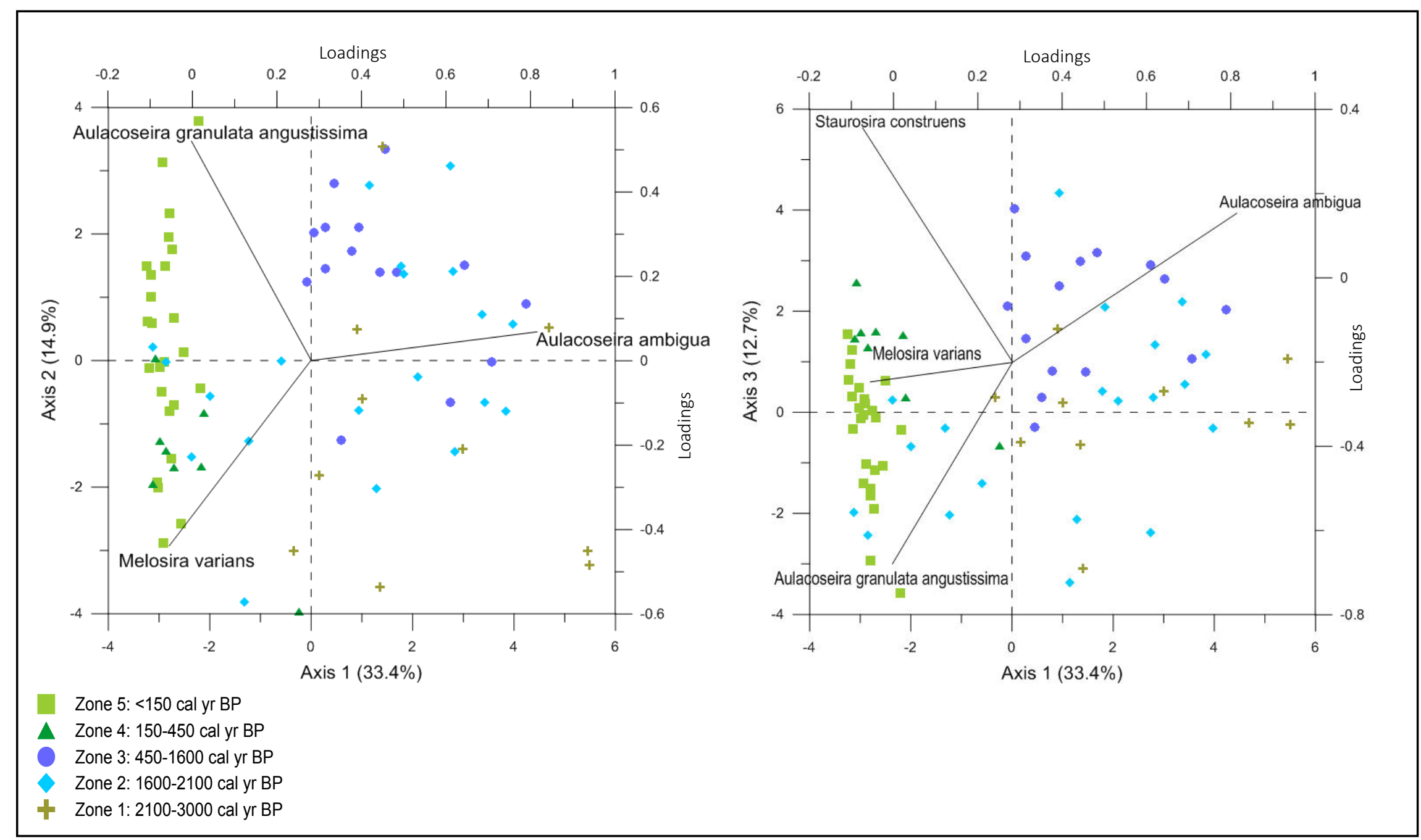

Figure 5.5: Principal component analysis biplots of diatom data axis 2 and 3, showing divisions between diatom-inferred zones and major drivers. Left and bottom axes relate to PCA axes, top and right axes relate to loadings (amount of variance diatom species contribute to the sample). 


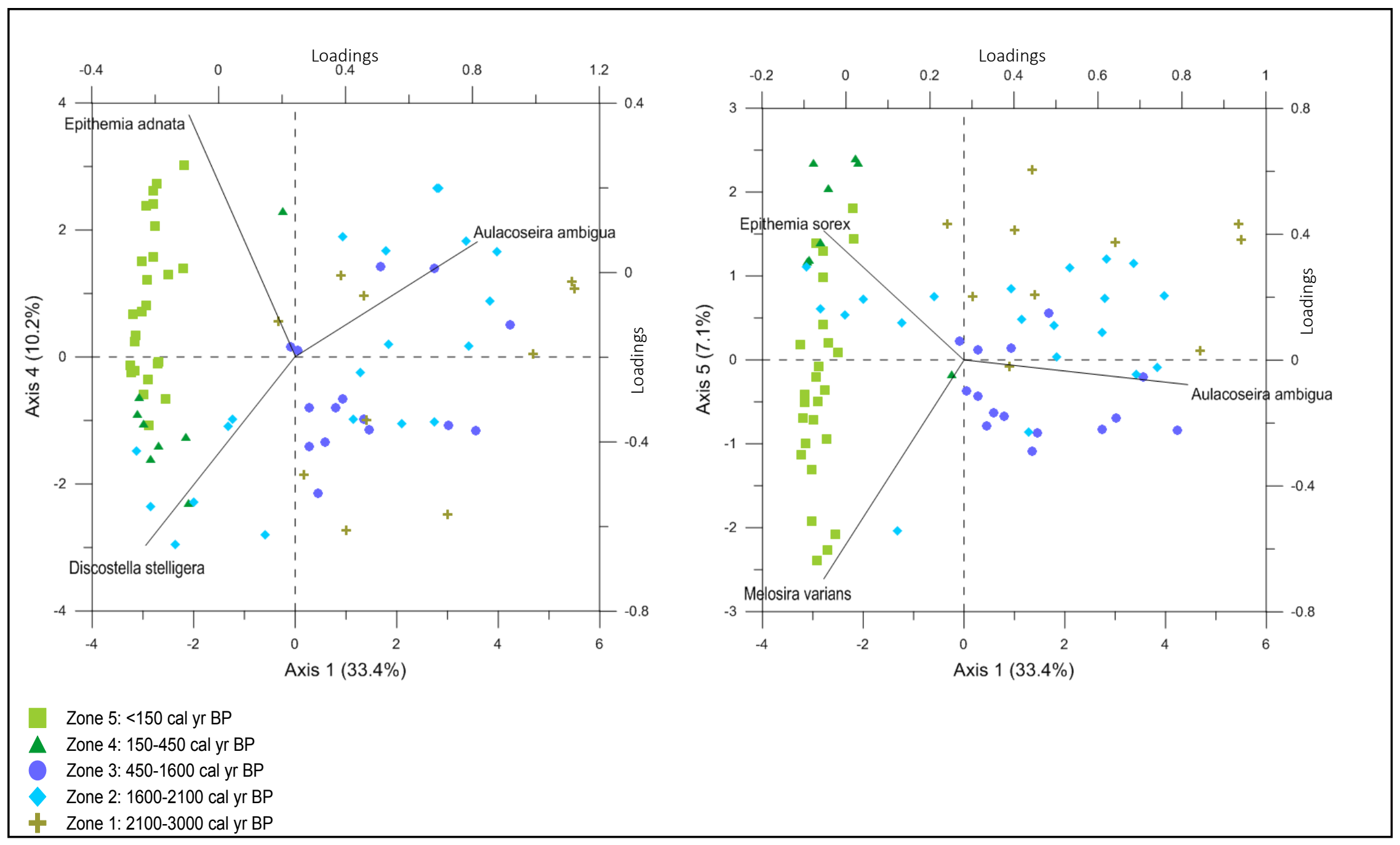

Figure 5.6: Principal component analysis biplots of diatom data axis 4 and 5, showing divisions between diatom-inferred zones and major drivers. Left and bottom axes relate to PCA axes, top and right axes relate to loadings (amount of variance diatom species contribute to the sample). 


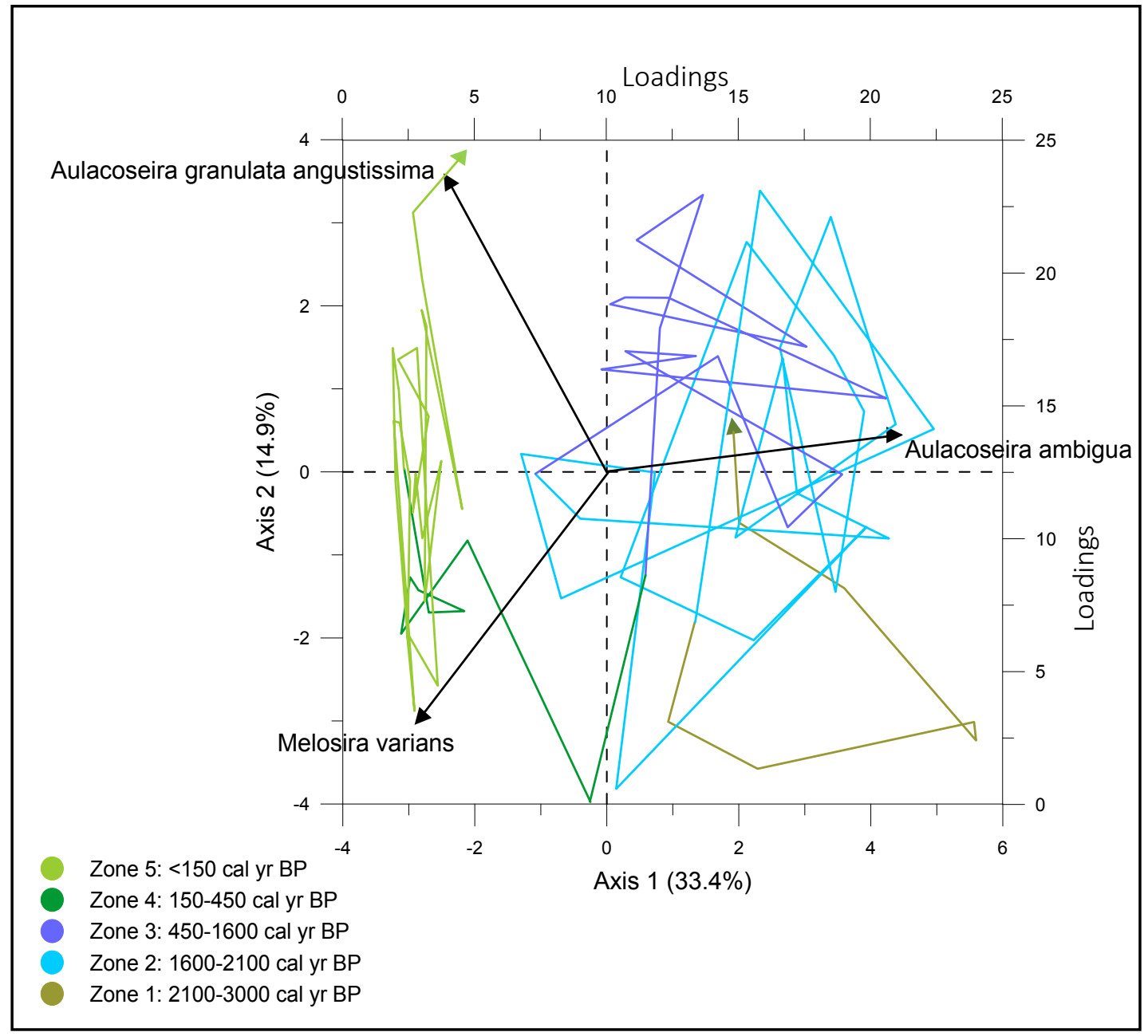

Figure 5.7: Principal component analysis time track plot of diatom data, showing how the assemblage changed over time and divisions between diatom-inferred zones. Left and bottom axes relate to PCA axes, top and right axes relate to loadings (amount of variance diatom species contribute to the sample). 


\subsubsection{Early Warning Signals Analysis}

There were no significant trends in the metric-based indicators, as shown by the low Kendall $\tau$ scores; although, large changes occurred at approximately 1900 AD (50 cal yr BP) (Fig. 5.8). Autocorrelation, skewness and kurtosis abruptly increase, and variance abruptly decreases, and then increases.

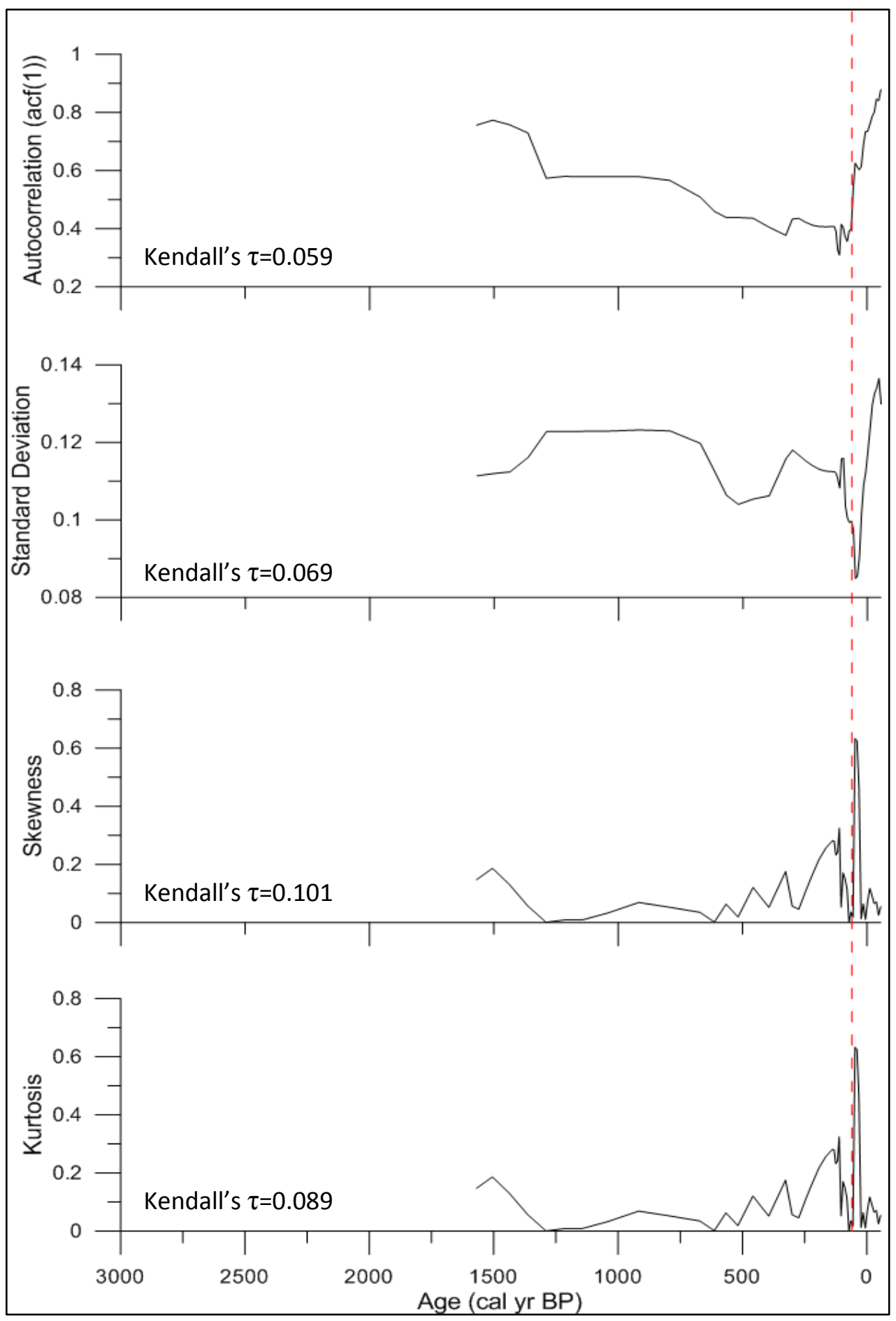

Figure 5.8: Metric-based indicators for early warning signals of critical transitions. Top to bottom: autocorrelation, standard deviation, skewness, and kurtosis. 


\subsubsection{Generalised Additive Model}

A GAM was used to model the variance of PCA axis 1. The GAM model showed a large amount of variance in the oldest part of the core, with a decrease towards present (spread in left panel of Figure 9, decreasing trend in right panel).

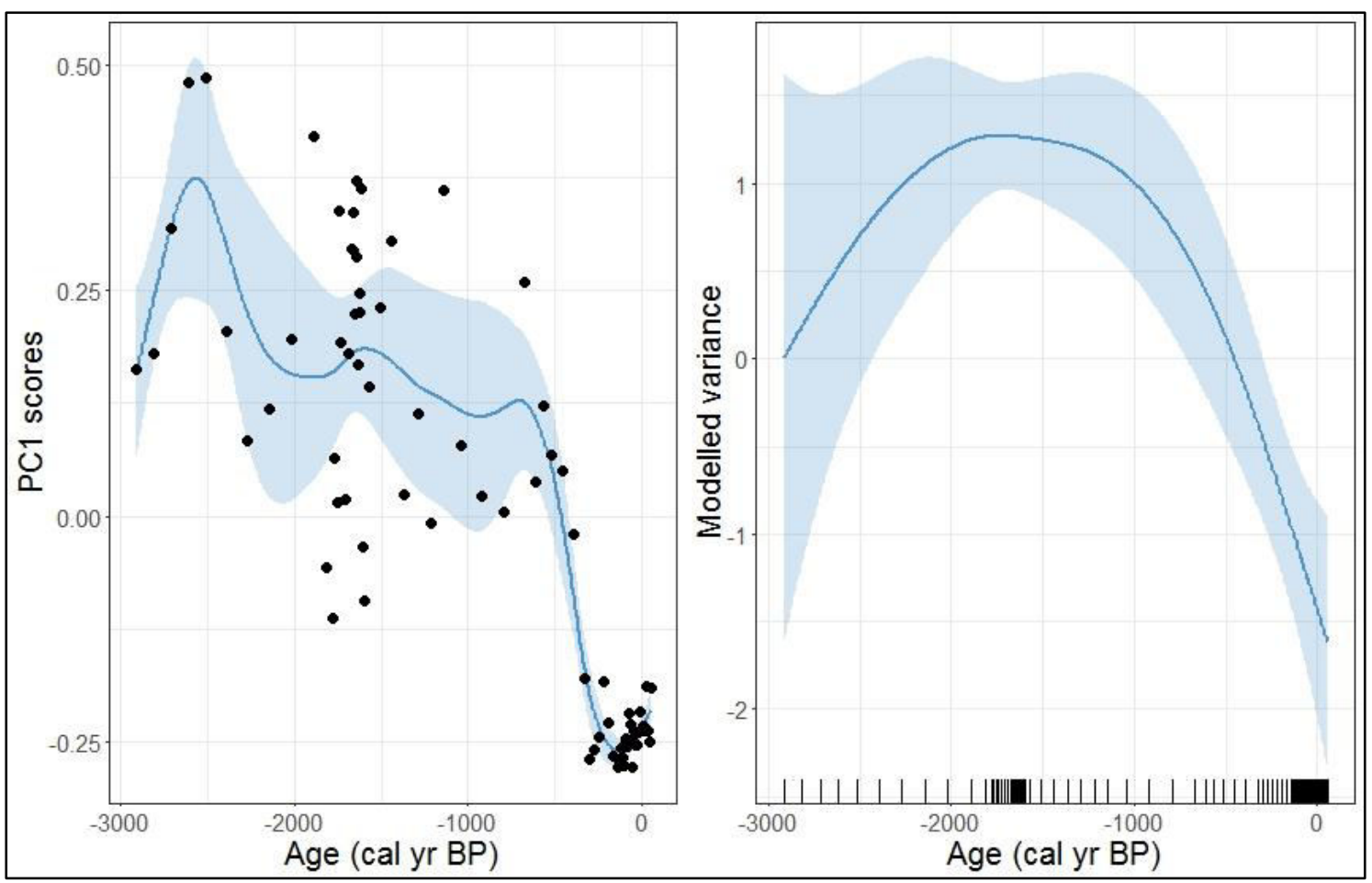

Figure 5.9: GAM model of variance in PCA axis 1 of the diatom data. Left panel shows spread of variance, right panel shows the trend.

\subsection{Discussion}

Although there were no significant trends in the metric-based indicators produced by the Early Warning Signals Analysis, there were interesting changes at 1900 AD (50 cal yr BP), which suggest a transition. The increase in autocorrelation indicates that the assemblages became increasingly similar. This is a symptom of critical slow down prior to a transition, where the system starts to recover more slowly from perturbations (Dakos et al., 2012). The increase in skewness may also indicate critical slow down, whereby the assemblage becomes more asymmetric as it moves to a different state (Dakos et al., 2012). The increase in kurtosis, however, may indicate flickering whereby the system starts to reach more extreme values prior to transition (Dakos et al., 2012). An increase in variance has been linked to both critical slow down (Dakos et al., 2012) and flickering (Wang et al., 2012). 
However, the increase in variance was not expected, as PCA axis 1 shows a sharp decline and uniform trough towards present, where variance remains relatively constant (Fig. 5.4). The increase in variance from the Early Warning Signals analysis could result from interpolation. The top $12 \mathrm{~cm}$ of the lake sediment was analysed at higher resolution for diatoms in an attempt to identify anthropogenic impacts. Therefore, interpolation was carried out on the bottom section of the data to create an equally spaced time series with matching resolution. This interpolation may have decreased the variance prior to the high resolution sampling, making it appear that standard deviation increased abruptly in the top of the core. Indeed, the GAM model highlights decreasing variance towards present (Fig. 5.9). Therefore, it is likely that the increase in variance shown by the Early Warning Signals analysis is a symptom of data processing (Carstensen et al., 2013).

In summary, data processing within the Early Warning Signal analysis likely changes the underlying structure of the data, as suggested by Carstensen et al (2013). GAMs provide a way to verify changes in variance that may be introduced by data processing; however, further checks are needed to verify the other metrics. Another way to avoid data processing artefacts would be to collect diatom samples at high resolution throughout the core, though this would be very time consuming and would not account for changing accumulation rates, and hence how much time is represented per centimetre. The Early Warning Signals analysis does indicate a transition at approximately 1900 AD (50 cal yr BP), which coincides with modern human impacts. However, the changes in the metric-based indicators do not fit within the classic critical slow down or flickering framework. Furthermore, this critical transition analysis was only preformed on PCA axis 1 - other PCA axes may provide additional insight. To properly resolve this issue, we need a model akin to a GAM that can handle multivariate response variables (i.e., multiple species). 


\section{Conclusions}

Modern monitoring suggests that the water quality of Lake Pounui has declined due to an increase in duration and frequency of algal blooms. However, this monitoring only spans the last 40 years, and earlier than 2012, that monitoring is very patchy. To investigate the cause of declining water quality, this study aimed to reconstruct the past environment of Lake Pounui, using paleolimnological methods to specifically address whether algal blooms had occurred in the past, and to examine anthropogenic impact in relation to reference conditions and critical transitions.

To reconstruct the past environment, an age-depth model was created. The model placed the base of the sediment cores at $3000 \mathrm{cal}$ yr BP. Human arrival was documented using charcoal, pollen, diatom assemblages, and catchment disturbance proxies like organic content (LOI), grain size, and using $\mu$-XRF. Based on these proxies, Polynesian arrival occurred between $450-350$ cal yr BP (95\% CI: 515.2-202.3 cal yr BP), and European arrival occurred at $\sim 150$ cal yr BP (95\% CI: 39-243 cal yr BP).

Diatom analysis was the main contribution by the author. Diatom analysis was used to reconstruct change throughout the Lake Pounui record. Based on the diatom assemblage, five zones were inferred: Zone $1-3000$ to $2100 \mathrm{cal}$ yr BP, Zone $2-2100$ to $1600 \mathrm{cal} \mathrm{yr} \mathrm{BP}$, Zone $3-1600$ to $450 \mathrm{cal} \mathrm{yr} \mathrm{BP}$, Zone $4-450$ to $150 \mathrm{cal} \mathrm{yr} \mathrm{BP}$, and Zone 5 -150 cal yr BP to present. All other proxy data were analysed based on these zones.

With the addition of bacterial DNA analysis, and supporting evidence from $\mu$-XRF data, the pre- and post-human environments of Lake Pounui were characterised. Prior to human arrival, natural change occurred within the lake. From 3000-2100 cal yr BP, the lake was relatively productive, with a high proportion of eutrophic and mesotrophic diatoms. From 2100 to $1600 \mathrm{cal}$ yr BP, there was a period of disturbance that could relate to a combination of earthquakes and increased storminess identified at other locations in New Zealand. It appears that this disturbance caused a shift to a lower, deeper, more stratified lake environment from 1600-450 cal yr BP. When Polynesians arrived $\sim 450$ cal yr BP, there was an initial disturbance in the lake; however, Lake Pounui appears to have recovered to previous oligotrophic conditions, indicating good "management" by early settlers. From 150 cal yr BP to present, the lake appears to become more nutrient enriched, and the cyanobacteria responsible for today's algal blooms (Dolichospermum and Phormidium) become abundant. This indicates that 
modern activities, such as farming and the introduction of exotic fish, may have caused the decline in water quality seen over the last 40 years, although anthropogenic climate change cannot be ruled out as a driver. It is likely that algal blooms did occur naturally during the high nutrient state from 3000-2100 cal yr BP; however, the species responsible for the current algal blooms are a consequence of anthropogenic impact.

The reconstruction presented here could be made more robust by increasing sampling resolution of the age-depth model, pollen, bacterial DNA, and diatom data, and by adding other proxies such as diatom transfer functions, biogenic silica, chironomids, photosynthetic pigments, and $\mathrm{TOC} / \mathrm{TN}$ ratios. However, due to time and funding constrains, these could not be including in this study. Regardless, the information gained through paleolimnological analysis of Lake Pounui's sediment has provided a better understanding of the natural lake environment, which will enable more informed decisions on restoration targets.

In an attempt to quantify the extent of degradation at Lake Pounui dissimilarity analysis was carried out on the diatom data. Dissimilarity analysis also identified decreasing water quality over the last 150 years, in particular since approximately 1950 AD. The period from 2100 to $450 \mathrm{cal}$ yr BP (zones 2 and 3) was identified as having conditions most similar to the very base of the core $(\sim 3000$ cal yr BP). However, because of climatic and physical changes in the environment since that time, it is not a suitable restoration target. The period from 450 to $150 \mathrm{cal}$ yr BP (zone 4) was identified as the most realistic restoration target as the lake still has relatively good water quality (for example a large population of submerged macrophytes, and oligotrophic-mesotrophic diatoms) and has similar climatic and physical environmental conditions. The most viable option for creating conditions similar to this period would be the removal of perch, which could reduce the internal nutrient load of the lake and increase the population of large zooplankton, thus increasing predation on the phytoplankton biomass. Recovery of the lake in the future may be identified by the reduction of Aulacoseira granulata var. angustissima, and Cyclostephanos dubius, and the return of Aulacoseira ambigua, and an increase in Discostella stelligera; however recovery of the environmental conditions does not guarantee recovery of the original diatom assemblage. 
Critical transition analysis did not show convincing evidence of warning signals prior to transition. It was shown that data processing, in particular interpolation, caused changes in the underlying structure of the data. To overcome this GAMs can be used to verify changes in variance, however further checks are needed to verify the other metrics. A model akin to a GAM that can handle multivariate data may resolve this issue. Early Warning Signal analysis did, however, identify a transition just prior to 1950 AD which fits with the other evidence of significant anthropogenic impact.

In conclusion paleolimnological analysis identified that the declining water quality of Lake Pounui is a trend that has been occurring since 150 cal yr BP. Dissimilarity and critical transition analysis support this finding, and suggest that rapid decline began just prior to $1950 \mathrm{AD}$. The most realistic restoration target for Lake Pounui is just prior to European settlement. To restore Lake Pounui to these conditions it is suggested that the removal of perch be investigated. This may reduce the phytoplankton biomass, thus controlling the algal blooms. Restoration of the lake may result in recovery of the original diatom assemblage, if this is the case then recovery could be modelled using dissimilarity analysis. 


\section{References}

Abrahim, G. M. S., Parker, R. J., \& Horrocks, M. (2013). Pollen core assemblages as indicator of Polynesian and European impact on the vegetation cover of Auckland Isthmus catchment, New Zealand. Estuarine, Coastal and Shelf Science, 131, 162-170. doi: 10.1016/j.ecss.2013.06.028

An, S. I., Kim, J. W., Im, S. H., Kim, B. M., \& Park, J. H. (2011). Recent and future sea surface temperature trends in the tropical pacific warm pool and cold tounge regions. Climate Dynamics, 39, 1373-1383.

Augustinus, P., Bleakley, N., Deng, Y., Shane, P., \& Cochran, U. (2008). Rapid change in early Holocene environments inferred from Lake Pupuke, Auckland City, New Zealand. Journal of Quaternary Science, 23(5), 435-447. doi: $10.1002 /$ jqs. 1153

Augustinus, P., Cochran, U., Kattel, G., D’Costa, D., \& Shane, P. (2012). Late Quaternary paleolimnology of Onepoto maar, Auckland, New Zealand: Implications for the drivers of regional paleoclimate. Quaternary International, 253, 18-31. doi: 10.1016/j.quaint.2011.02.028

Augustinus, P., Reid, M., Anderson, S., Deng, Y., \& Horrocks, M. (2006). Biological and geochemical record of anthropogenic impacts in recent sediments from Lake Pupuke, Auckland City, New Zealand. Journal of Paleolimnology, 35(4), 789805. doi: 10.1007/s10933-005-5306-8

Barnosky, A.D., Hadly, E.A., Bascompte, J., Berlow, E.L., Brown, J.H., Fortelius, M., . . Smith, A.B. (2012). Approaching a state shift in Earth's biosphere. Nature, 52(486), 52-58. doi:10.1038/nature11018

Battarbee, R. (1986). Diatom analysis. In B. E. Berglund (Ed.), Handbook of Holocene paleoecology and paleohydrology (pp. 527-570): John Wiley \& Sons.

Battarbee, R., Jones, V. J., Flower, R. J., Cameron, N. G., Bennion, H., Carvalho, L., \& Juggins, J. (2001). Diatoms, Chapter 8. In J. P. Smol, H. J. B. Birks \& W. M. Last (Eds.), Tracking environmental change using lake sediments: terrestrial, algal, and siliceous indicators. (Volume 3, pp. 155-202): Kluwer Academic Publishers.

Battarbee, R., Juggins, J., Gasse, F., Anderson, N. J., Bennion, H., \& Cameron, N. G. (2000). European Diatom Database (EDDI). An information system for paleoenvironmental reconstruction. Paper presented at the European Climate Science Conference. 
Battarbee, R., \& Kneen, M. J. (1982). The use of electronically counted microspheres in absolute diatom analysis. Limnology and Oceanography, 27(1), 184-188.

Beadel, S., Perfect, A., Rebergen, A., \& Sawyer, J. (2000). Wairarapa plains ecological district survey report for the protected natural areas programme. (pp. 203). Wellington Conservancy: Department of Conservation.

Bennett, K., \& Willis, K. J. (2001). Pollen, Chapter 2. In H. J. B. Birks \& W. M. Last (Eds.), Tracking environmental change using lake sediments: terrestrial, algal, and siliceous indicators (Volume 3, pp. 5-32). Dordrecht: Springer.

Bennett, K. D. (2005). Documentation for psimpoll 4.25 and pscomb 1.03: C programs for plotting pollen diagrams and analysis pollen data.

Bennion, H., Battarbee, R., Sayer, C., Simpson, G., \& Davidson, T. (2011). Defining reference conditions and restoration targets for lake ecosystems using paleolimnology: a synthesis. Journal of Paleolimnology, 45(4), 533-544. doi: 10.1007/s10933-010-9419-3

Bennion, H., Simpson, G., \& Goldsmith, B. (2015). Assessing degradation and recovery pathways in lakes impacted by eutrophication using the sediment record. Frontiers in Ecology and Evolution, 3(94). doi: 10.3389/fevo.2015.00094 Bennion, H., Simpson, G. L., Anderson, N. J., Clarke, G., Dong, X., Hobaєk, A., . . . Tolotti, M. (2011). Defining ecological and chemical reference conditions and restoration targets for nine European lakes. Journal of Paleolimnology, 45, 415431.

Birks, H. J. B. (1995). Quantitative paleoenvironmental reconstructions. In D. Maddy \& J. S. Brew (Eds.), Statistical modelling of Quaternary science data (pp. 161254). Cambridge: Quaternary Research Association.

Birks, H. J. B. (2010). Numerical methods for the analysis of diatom assemblage data, Chapter 3. In J. P. Smol \& E. F. Stoemer (Eds.), The Diatoms: applications for the environmental and earth sciences (2nd edition, pp. 23-54): Cambridge University Press.

Birks, H. J. B. (2012). Introduction and overview of part II, Chapter 4. In H. J. B. Birks, A. F. Lotter, J. Juggins \& J. P. Smol (Eds.), Tracking environmental change using lake sediments: data handling and numerical techniques (Voloume 5, pp. 101-121). Dordrecht: Springer.

Blaauw, M., \& Christen, J. A. (2011). Flexible paleoclimate age-depth models using a autoregressive gamma process. Bayesian Analysis, 6, 457-474.

Blott, S. J. (2010). GRADISTAT Version 8.0. 
Blott, S. J., \& Pye, K. (2001). GRADISTAT: A grainsize distribution and statistics package for the analysis of unconsolidated sediments. Earth Surface Processes and Landforms, 26, 1237-1248.

Bostock, H. C., Lowe, D. J., Gillespie, R., Priestley, R., Newnham, R. M., \& Mooney, S. D. (2015). The advent of the Anthropocene in Australasia. Quaternary Australasia, 32(1), 7-16.

Bunny, T., Perrie, A., Milne, J. R., \& Keenan, L. (2014). Lake water quality in the Ruamahanga Whaitua. (pp. 1-15). New Zealand: Greater Wellington Regional Council.

Carstensen, J., Telford, R. J., \& Birks, H. J. B. (2013). Diatom flickering prior to regime shift. Nature, 498(7455), E11-E12. doi: 10.1038/nature12272

Cassie, V. (1989). A contribution to the study of New Zealand diatoms. Bibliotheca Diatomologica, 17, 1-266.

Chester, P. I., \& Prior, C. A. (2004). An AMS ${ }^{14}$ C pollen-dated sediment and pollen sequence from the late Holocene, southern coastal Hawke's Bay, New Zealand. Radiocarbon, 46, 721-731.

Christensen, J. H., Kumar, K., Aldrian, E., An, S. I., Cavalcanti, I., F.A., de Castro, M., ... Zhou, T. (2013). Climate phenomena and their relevance for future regional climate change, Chapter 14. In T. F. Stocker, D. Qin, G. K. Plattner, M. Tignor, S. K. Allen, J. Boschung, A. Nauels, Y. Xia, V. Bex \& P. M. Midgley (Eds.), Climate change 2013: the physical science basis. Contribution of working group I to the fifth assessment report of the intergovernmental panel on climate change. (pp. 1217-1308). Cambridge, United Kingdom and New York, USA: Cambridge University Press.

Clark, K. J., Hayward, B. W., Cochran, U. A., Wallace, L. M., Power, W. L., and Sabaa, A. T.. (2015). Evidence for past subduction earthquakes at a plate boundary with widespread upper plate faulting: southern Hikurangi Margin. New Zealand: Bulletin of the Seismological Society of America, 105(3), 1661-1690.

Cochran, U., Hannah, M., Harper, M., Van Dissen, R., Berryman, K., \& Begg, J. (2007). Detection of large, Holocene earthquakes using diatom analysis of coastal sedimentary sequences, Wellington, New Zealand. Quaternary Science Reviews, 26(7), 1129-1147. doi: 10.1016/j.quascirev.2007.01.008

Conley, D. J., \& Schelske, C. L. (2001). Biogenic Silica, Chapter 14. In J. P. Smol, H. J. B. Birks \& W. M. Last (Eds.), Tracking environmental change using lake 
sediments: terrestrial, algal, and siliceous indicators. (Volume 3, pp. 281-293).

Dordrecht: Klumer Academic Publishers.

Corella, J., Brauer, A., Mangili, C., Rull, V., Vegas-Vilarrúbia, T., Morellón, M., \& Valero-Garcés, B. (2012). The 1.5-ka varved record of Lake Montcortès (southern Pyrenees, NE Spain). Quaternary Research, 78, 323-332.

Crutzen, P., \& Stoemer, E. (2000). The "Anthropocene", global change. IGBP Newsletter, 41, 17-18.

Dakos, V., Carpenter, S. R., Brock, W. A., Ellison, A. M., Guttal, V., Ives, A. R., . . Scheffer, M. (2012). Methods for detecting early warnings of critical transitions in time series illustrated using simulated ecological data. PLOS ONE, 7(7), e41010. doi: 10.1371/journal.pone.0041010

Dakos, V., Scheffer, M., van Nes, E. H., Brovkin, V., Petoukhov, V., \& Held, H. (2008). Slowing down as an early warning signal for abrupt climate change. Proceedings of the National Academy of Sciences of the United States of America, 105(38), 14308. doi: 10.1073/pnas.0802430105

Davidson, W. (1993). Iron and manganese in lakes. Earth-Science Reviews, 34, 119163.

Davies, S. J., Lamb, H. F., \& Roberts, S. J. (2015). Micro-XRF core scanning in paleolimnology: recent developments, Chapter 7. In I. W. Croudace \& R. G. Rothwell (Eds.), Micro-XRF studies of sediment cores: applications of a nondestructive toll for the environmental sciences (pp. 189-226): Springer.

de Winton, M. (2016). LakeSPI results for four lakes in the Wellington Region. Prepared for Greater Wellington Regional Council. (pp. 1-41). Hamilton, New Zealand: NIWA.

de Winton, M., Champion, P., \& Wells, R. (2011). LakeSPI assessment of the Parangaruhu Lakes and Lake Pounui. Prepared for Greater Wellington Regional Council (pp. 1-32). Hamilton, New Zealand: NIWA.

Dean, S. M., \& Scott, P. A. (2009). The effect of local circulation variability on the detection and attribution of New Zealand temperature trends. Climate Dynamics, $35,565-589$.

Drake, D., Kelly, D., \& Schallenberg, M. (2011). Shallow coastal lakes in New Zealand: current conditions, catchment-scale human disturbance, and determination of ecological integrity. Hydrobiologia, 658(1), 87-101. doi: $10.1007 / \mathrm{s} 10750-010-0452-\mathrm{z}$ 
Enache, M. D., \& Cumming, B. F. (2007). Charcoal morphotypes in lake sediments from British Columbia (Canada): an assessment of their utility for the reconstruction of past fire and precipitation. Journal of Paleolimnology, 38(3), 347-363. doi: 10.1007/s10933-006-9084-8

European Union. (2000). Directive 2000/60/EC of the European Parliament and of the Council of 23 October 2000 establishing a framework for community action in the field of water policy. European Union.

Faegri, K., \& Iverson, J. (1989). Textbook of pollen analysis, 4th edition. Chichester: John Wiley \& Sons.

Fahey, B. D., \& Jackson, R. J. (1997). Environmental effects of forestry at Big Bush Forest, South Island, New Zealand: Changes in water chemistry. Journal of Hydrology: New Zealand, 36(1), 43-71.

Fogt, R. L., Bromwich, D. H., \& Hines, K. M. (2011). Understanding the SAM influence on the South Pacific ENSO teleconnection. Climate Dynamics, 36(1555-1576).

Gavin, D. G., Oswald, W. W., Wahl, E. R., \& Williams, J. W. (2003). A statistical approach to evaluating distance metrics and analog assignments for pollen records. Quaternary Research, 60(3), 356-367. doi: 10.1016/S00335894(03)00088-7

Grimm, E. (2015). Tilia Software Version 2.0.41. Springfield, Illinois State Museum. Guiry, M. D., \& Guiry, G. M. (2016). AlgalBase. Retrieved 02/11/2016, from http://www.algaebase.org

Guisan, A., Edwards, T. C., \& Hastie, T. (2002). Generalised linear and generalised additive models in studies of species distributions: setting the scene. Ecological Modelling, 157(2-3), 89-100.

Gupta, R. S., \& Sethi, M. (2014). Phylogeny and molecular signatures for the phylum Fusobacteria and its distinct subclades. Anaerobe, 28, 182-198. doi:

10.1016/j.anaerobe.2014.06.007

Haberzettl, T., Corbella, H., Fey, M., Janssen, S., Lücke, A., Mayr, C., . . Zolitschka, B. (2007). Lateglacial and Holocene wet-dry cycles in southern Patagonia: chronology, sedimentology and geochemistry of a lacustrine record from Laguna Potrok Aike, Argentina. The Holocene, 17(3), 297-310.

Harper, D. (1992). Eutrophication of freshwaters: principles, problems and restoration. 2-6 Boundary Row, London: Chapman \& Hall. 
Harper, M. A. (1994). Did Europeans introduce Asterionella formosa Hassall to New Zealand? In P. Kociolek (ed.) Proceedings of the 11th International Diatom Symposium. Memoirs of the Californian Academy of Sciences, 17, 479-484. Harper, M. A. (2015, 07/07/2015). [Processing for diatoms].

Harper, M. A., Mann, D. G., \& Patterson, J. E. (2009). Two unusual diatoms from New Zealand: Tabularia variostriata a new species and Eunophora berggrenii. Diatom Research, 24, 291-306.

Heath, M. W. (2015). Environmental drivers of phormidium blooms in New Zealand rivers. $\mathrm{PhD}$ thesis, Victoria University of Wellington.

Heron, D., Van Dissen, R., \& Sawa, M. (1998). Late Quaternary movement on the Ohariu Fault, Tongue Point to MacKays Crossing, North Island, New Zealand. New Zealand Journal of Geology and Geophysics, 41(4), 419-439.

Hill, R. D. (1963). The vegetation of the Wairarapa in mid-nineteenth century. Tuatara, 11(2), 83-89.

Hicks, B. J., Hamilton, D. P., Ling, N., \& Wood, S. A. (2007). Top down or bottom up? Feasibility of water clarity restoration in the lower Karori Reservoir by fish removal. CBER Contract Report 70, Prepared for the Karori Wildlife Sanctuary Trust. Centre for Biodiversity and Ecology Research, University of Waikato, Hamilton, New Zealand.

Hogg, A. G., Blackwell, P. G., Niu, M., Buck, C. E., Guilderson, T. P., Heaton, T. J., . . . Zimmerman, S. R. H. (2013). SHCal13 southern hemisphere calibration, 050,000 years cal BP. Radiocarbon, 55(4), 1889-1903.

Howarth, J. D., Fitzsimons, S. J., Norris, R. J., and Jacobsen, G. E. (2014). Lake sediments record high intensity shaking that provides insight into the location and rupture length of large earthquakes on the Alpine Fault. New Zealand: Earth and Planetary Science Letters, 403, 340-351.

Howarth, J. D., Fitzsimons, S. J., Jacobsen, G. E., Vandergoes, M. J., \& Norris, R. J. (2013). Identifying a reliable target fraction for radiocarbon dating sedimentary records from lakes. Quaternary Geochronology, 17, 68-80. doi:

10.1016/j.quageo.2013.02.001

Ivarsson, L. (2011). Cyclostephanos dubius. Diatoms of the United States. Retrieved 01.02.2017, from http://westerndiatoms.colorado.edu/taxa/species/cyclostephanos dubius

Jackson, D. A. (1993). Stopping rules in principal components analysis: a comparison of heuristical and statistical approaches. Ecology, 74, 2204-2214. 
Jellyman, D. J. (1980). Age, growth, and reproduction of perch, Perca fluviatilis L., in Lake Pounui. New Zealand Journal of Marine and Freshwater Research, 14(4), 391-400. doi: 10.1080/00288330.1980.9515881

Jellyman, D. J. (1989). Diet of two species of freshwater eel (Anguilla spp.) in Lake Pounui, New Zealand. New Zealand Journal of Marine and Freshwater Research, 23(1), 1-10. doi: 10.1080/00288330.1989.9516334

Jellyman, D. J. (1990). Meterology and limnology of Lake Pounui, Wairarapa. MAF Fisheries, Miscellaneous Report No. 56: NIWA.

Jellyman, D. J., \& Ryan, C. M. (1983). Seasonal migration of elvers (Anguilla spp.) into Lake Pounui, New Zealand, 1974-1978. New Zealand Journal of Marine and Freshwater Research, 17(1), 1-15. doi: 10.1080/00288330.1983.9515981

Johansen, J. R. (2010). Diatoms of aerial habitats. In J. P. Smol \& E. F. Stoermer (Eds.), The Diatoms: applications for the environmental and earth sciences (pp. 264274): Cambridge University Press.

John, J. (1983). The diatom flora of the Swan River Estuary Western Australia. Bibliotheca Phycologica, 64, 1-359.

Juggins, S. (2003). C2 software for ecological and palaeoecological data analysis and visualisation, User Guide Version 1.3. Department of Geography, Newcastle.

Kefi, S., Guttal, V., Brock, W. A., Carpenter, S. R., Ellison, A. M., Livina, V., . . . Dakos, V. (2014). Early warning signals of ecological transitions: methods for spatial patterns. PLOS ONE, 9(3), e92097.

Kelly, M. G., Bennion, H., Cox, E. J., Goldsmith, B., Jamieson, J., Juggins, S., . . . Telford, R. J. (2005). Common freshwater diatoms of Britain and Ireland: An interactive key. from Environmental Agency, Bristol http://craticula.ncl.ac.uk/EADiatomKey/html/taxa.html

Kilham, S. S., \& Kilham, P. (1975). Melosira granulata (Ehr). Ralfs: Morphology and ecology of a cosmopolitan freshwater diatom. International Association of Theoretical and Applied Limnology, 19, 2716-2721.

Kilham, S. S., Theriot, E. C., \& Fritz, S. C. (1996). Linking planktonic diatoms and climate change in the large lakes of the Yellowstone ecosystem using resource theory. Limnology and Oceanography, 41(5), 1052-1062. doi: 10.4319/1o.1996.41.5.1052

Kpodonu, A. T. N. K., Hamilton, D. P., Hartland, A., Laughlin, D. C., \& Lusk, C. H. (2016). Coupled use of sediment phosphorous speciation and pigment 
composition to infer phytoplankton phenology over 700 years in a deep oligotrophic lake. Biogeochemistry, 129, 181-196.

Krammer, K. (2002). Cymbella. In H. Lange-Bertalot (Ed.), Diatoms of the European inland waters and comparable habitats (Volume 3, pp. 1-584): Ruggell:

A.R.G.Gantner Verlag K.G.

Krammer, K., \& Lange-Bertalot, H. (1991). Bacillariophyceae: Parts 1-5. In H. Ettl, J. Gerloff, H. Heynig \& D. Mollenhauer (Eds.), Süsswasserflora von Mitteleuropa 2. Jena: VEB Gustav Fischer Verlag.

Langridge, R., Van Dissen, R., Rhoades, D., Villamor, P., Little, T., Litchfield, N., Clark, K., and Clark, D. (2011). Five thousand years of surface ruptures on the Wellington Fault, New Zealand: implications for recurrence and fault segmentation. Bulletin of the Seismological Society of America, 101, 2088-2107.

Lawless, P. F. (1983). Ecological studies on the zooplankton of Lake Pounui, Wairarapa. MSc thesis, Zoology, Victoria University of Wellington.

Leach, B. F. (1981). The prehistory of the Southern Wairarapa. Journal of the Royal Society of New Zealand, 11(1), 11-33. doi: 10.1080/03036758.1981.10419449

Legendre, P., \& Gallagher, E. D. (2001). Ecologically meaningful transformations for ordination of species data. Oecologia, 129, 271-280.

Li, Y., Liao, M., Chen, R., \& Shen, J. (2015). Diatom-based inference of variations in the strength of East Asian spring wind speeds since mid-Holocene. Paleogeography, Paleoclimatology, Paleoecology, 418, 65-74. doi: 10.1016/j.palaeo.2014.11.009

Little, T. A., Van Dissen, R., Schermer, E., \& Carne, R. (2009). Late Holocene surface ruptures on the southern Wairarapa Fault, New Zealand, link between earthquakes and the uplifting of beach ridges on a rocky coast. Lithosphere, 1, 428.

Livingstone, D. A. (1955). A lightweight piston sampler for lake deposits. Ecology, 36, 137-139.

Lowe, J. J., \& Walker, M. J. C. (2014). Reconstructing Quaternary environments. Retrieved from http://VUW.eblib.com/patron/FullRecord.aspx? $p=1783956$ Lund, J. W. G. (1946). Observations on soil algae. The ecology, size and taxonomy of british soil diatoms. The New Phytologist, 45(1), 56-110.

Matsumoto, D., Sawai, Y., Masaki, Y., Namegaya, Y., Shinozaki, T., Takeda, D., .. . Pilarczky, J. (2016). Erosion and sedimentation during the September 2015 flooding of the Kinu River, central Japan. Scientific Reports, 6, 34168. 
McFadgen, B. G. (1980). Maori Plaggen soils in New Zealand, their origin and properties. Journal of the Royal Society of New Zealand, 10(1), 3-18. doi: $10.1080 / 03036758.1980 .10426547$

McFadgen, B. G. (2003). Archeology of the Wellington Conservancy, Wairarapa: A study in tectonic archaeology. Wellington: Department of Conservation.

McGlone, M. S. (1989). The Polynesian settlement of New Zealand in relation to environmental and biotic changes. New Zealand Journal of Ecology, 12, 115129.

McGlone, M. S. (2002). A Holocene and latest Pleistocene pollen record from Lake Poukawa, Hawke's Bay, New Zealand. Global and Planetary Change, 33(3-4), 283-299. doi: 10.1016/S0921-8181(02)00083-8

McGlone, M. S., \& Wilmshurst, J. M. (1999). Dating initial Maori environmental impact in New Zealand. Quaternary International, 59(1), 5-16. doi: 10.1016/S1040-6182(98)00067-6

McQueen, D. R. (1969). Macroscopic plant remains in recent lake sediments. Tuatara, 17(1), 13-19.

McQueen, D. R. (1991). Plant succession and species diversity in vegetation around Lake Pounui, Southern North Island, New Zealand. Tuatara, 31(1), 43-65.

McSaveney, M., Graham, I., Begg, J., Beu, A., Hull, A., Kim, K., \& Zondervan, A. (2006). Late Holocene uplift of beach ridges at Turakirae Head, south Wellington coast, New Zealand. New Zealand Journal of Geology and Geophysics, 49(3), 337-358. doi: 10.1080/00288306.2006.9515172

McWethy, D. B., Higuera, P. E., Whitlock, C., Veblen, T. T., Bowman, D. M. J. S., Cary, G. J., . . Tepley, A. J. (2013). A conceptual framework for predicting temperate ecosystem sensitivity to human impacts on fire regimes. Global Ecology and Biogeography, 22(8), 900-912. doi: 10.1111/geb.12038

McWethy, D. B., Whitlock, C., Wilmshurst, J. M., McGlone, M. S., Fromont, M., Li, X., . . Cook, E. R. (2010). Rapid landscape transformation in South Island, New Zealand, following initial Polynesian settlement. Proceedings of the National Academy of Sciences of the United States of America, 107(50), 21343. doi: 10.1073/pnas.1011801107

McWethy, D. B., Whitlock, C., Wilmshurst, J. M., Wood, J. R., \& McGlone, M. S. (2014). A High- resolution chronology of rapid forest transitions following Polynesian arrival in New Zealand. PLOS ONE, 9(11). doi:

10.1371/journal.pone.0111328 
Mortlock, R. A., \& Froelich, P. N. (1989). A simple method for the rapid determination of biogenic opal in pelagic marine sediment. Deep-Sea Research, 36(9), 14151426.

Moss, B., Kosten, S., Meerhoff, M., Battarbee, R., Jeppesen, E., Mazzeo, N., . . . Scheffer, M. (2011). Allied attack: climate change and eutrophication. Inland Waters, 1(2), 101-205.

Mullan, B. A. (1989). Influence of Southern Oscillation on New Zealand weather. Paper presented at the Western Pacific International Meeting and Workshop on TOGA COARE.

. National Policy Statement for Freshwater Management. (2014). New Zealand: Ministry for the Environment.

Newnham, R. M., Lowe, D. J., McGlone, M. S., Wilmshurst, J. M., \& Higham, T. F. G. (1998). The Kaharoa tephra as a critical datum for earliest human impact in northern New Zealand. Journal of Archaeological Science, 25(6), 533-544. doi: 10.1006/jasc.1997.0217

NIWA. (2016). New Zealand's National Climate Database. from https://cliflo.niwa.co.nz/

Nobu, M. K., Dodsworth, J. A., Murugapiran, S. K., Rinke, C., Gies, E. A., Webster, G., ... Hedlund, B. P. (2016). Phylogeny and physiology of candidate phylum Atribacteria (OP9/JS1) inferred from cultivation-independent genomics. ISMEJ, 10(2), 273-286. doi: 10.1038/ismej.2015.97

Oksanen, J. F., Blanchet, G., Friendly, M., Kindt, R., Legendre, P., McGlinn, D., . . . Wagner, H. (2016). Vegan: Community Ecology Package. R package version 2.4-1.

Orpin, A. R., Carter, L., Page, M. J., Cochran, U. A., Trustrum, N. A., Gomez, B., . . . Northcote, L. (2009). Holocene sedimentary record from Lake Tutira: A template for upland watershed erosion proximal to the Waipaoa Sedimentary System, northeastern New Zealand. Marine Geology, 270, 11-29.

Overpeck, J. T., Webb, T., \& Prentice, I. C. (1985). Quantitative interpretation of fossil pollen spectra: Dissimilarity coefficients and the method of modern analogs. Quaternary Research, 23(1), 87-108. doi: 10.1016/0033-5894(85)90074-2

Page, M. J., Trustrum, N. A., \& DeRose, R. C. (1994). A high resolution record of storm-induced erosion from lake sediments, New Zealand. Journal of Paleolimnology, 11(3), 333-348. doi: 10.1007/bf00677993 
Page, M. J., Trustrum, N. A., Orpin, A. R., Carter, L., Gomez, B., Cochran, U. A., . . Northcote, L. (2010). Storm frequency and magnitude in response to Holocene climate variability, Lake Tutira, north-eastern New Zealand. Marine Geology, 270(1-4), 30-44. doi: 10.1016/j.margeo.2009.10.019

Palmer, A. S., Vucetich, C. G., McGlone, M., \& Harper, M. A. (1989). Last Glacial loess and early Last Glacial vegetation history of Wairarapa Valley, New Zealand. New Zealand Journal of Geology and Geophysics, 32(4), 499-513. doi: 10.1080/00288306.1989.10427557

Perrie, A., \& Milne, J. R. (2012). Lake water quality and ecology in the Wellington region: states and trends (pp. 1-116). Wellington, New Zealand: Greater Wellington Regional Council.

R Core Development Team. (2015). R: A language and environment for statistical computing. Vienna, Austria: R Foundation for Statistical Computing.

Rees, A. B. H., Cwynar, L. C., \& Fletcher, M. S. (2015). Southern Westerly Winds submit to the ENSO regime: A multiproxy paleohydrology record from Lake Dobson, Tasmania. Quaternary Science Reviews, 126, 254-263. doi: 10.1016/j.quascirev.2015.08.022

Reid, M. (2005). Diatom-based models for reconstructing past water quality and productivity in New Zealand lakes. Journal of Paleolimnology, 33(1), 13-38. doi: 10.1007/s10933-004-0424-2

Renwick, J. (2011). Kidson's synoptic weather types and surface climate variability over New Zealand. Weather and Climate, 31(3-23).

Renwick, J., \& Thompson, D. (2006). Climate variability: The Southern Annular Mode and New Zealand climate. Water and Atmosphere, 31, 3-23.

Rothwell, R. G., \& Croudace, I. W. (2015a). Micro-XRF studies of sediment cores: A perspective on capability and application in the environmental sciences, Chapter 1. In R. G. Rothwell \& I. W. Croudace (Eds.), Micro-XRF studies of sediment cores: Applications of a non-destructive toll for the environmental sciences (pp. 1-21): Springer.

Rothwell, R. G., \& Croudace, I. W. (2015b). Twenty years of XRF core scanning marine sediments: What do geochemical proxies tell us? Chapter 2. In R. G. Rothwell \& I. W. Croudace (Eds.), Micro-XRF studies of sediment cores: Applications of a non-destructive toll for the environmental sciences (pp. 25102): Springer. 
Round, F. E., Crawford, R. M., \& Mann, D. G. (1990). Diatoms: Biology and morphology of the genera: Cambridge University Press.

Ruhland, K. M., Paterson, A., \& Smol, J. P. (2015). Lake diatom responses to warming: Reviewing the evidence. Journal of Paleolimnology, 54(1), 1-35.

Ruhland, K. M., \& Smol, J. P. (2008). Hemispheric-scale patterns of climate-related shifts in palnktonic diatoms from North American and European lakes. Global Change Biology, 14, 2740-2754.

Schallenberg, M., Kelly, D., Clapcott, J., Death, R., MacNeil, C., Young, R., . . . Scarsbrook, M. (2011). Approaches to assessing ecological integrity of New Zealand freshwaters. Science for Conservation, 307, 1-86.

Scheffer, M., Carpenter, S. R., Lenton, T. M., Bascompte, J., Brock, W., Dakos, V., . . . Vandermeer, J. (2012). Anticipating critical transitions. Science, 338(6105), 344. doi: $10.1126 /$ science. 1225244

Scheffer, M., Hosper, S. H., Meijer, M. L., Moss, B., \& Jeppesen, E. (1993). Alternative equilibria in shallow lakes. Trends in Ecology \& Evolution, 8(8), 275-279. doi: 10.1016/0169-5347(93)90254-M

Scheffer, M., \& Nes, E. (2007). Shallow lakes theory revisited: Various alternative regimes driven by climate, nutrients, depth and lake size. Hydrobiologia, 584(1), 455-466. doi: 10.1007/s 10750-007-0616-7

Schneider, D., Arp, G., Reimer, A., Reitner, J., \& Daniel, R. (2013). Phylogenetic analysis of a microbialite-forming microbial mat from a hypersaline lake of the Kiritimati Atoll, Central Pacific. PLOS ONE, 8(6), e66662. doi: 10.1371/journal.pone.0066662

Schnurrenberger, D., Russell, J., \& Kelts, K. (2003). Classification of lacustrine sediments based on sedimentary components. Journal of Paleolimnology, 29, 141-154.

Shane, P., Froggatt, P., Smith, I., \& Gregory, M. (1998). Multiple sources for sea-rafted Loisels Pumice, New Zealand. Quaternary Research, 49(3), 271-279. doi: 10.1006/qres.1998.1968

Simpson, G. L. (2007). Analogue methods in paleoecology: Using the Analogue package. Journal of Statistical Software, 22(2).

Sims, P. A. (2006). Evolution of the diatoms: Insights from fossil, biological and molecular data. Phycologia., 45(4), 361.

Smith, K. F., \& Lester, P. J. (2007). Trophic interactions promote dominance by cyanobacteria (Anabaena spp.) in the pelagic zone of lower Karori reservoir, 
Wellington, New Zealand. New Zealand Journal of Marine and Freshwater Research, 41(2), 143-155. doi: 10.1080/00288330709509903

Smith, V. (2003). Eutrophication of freshwater and coastal marine ecosystems a global problem. Environmental Science \& Pollution Research, 10(2), 126-139. doi: 10.1065/espr2002.12.142

Smith, V. H., Wood, S. A., McBride, C. G., Atalah, J., Hamilton, D. P., \& Abell, J. (2016). Phosphorous and nitrogen loading restraints are essential for successful eutrophication control of Lake Rotorua, New Zealand. Inland Waters, 6, 273283.

Smol, J. P., \& Cumming, B. F. (2000). Tracking long-term change in climate using algal indicators in lake sediments. Journal of Phycology, 36, 986-1011.

Sondergaard, M., Jensen, J., \& Jeppesen, E. (2003). Role of sediment and internal loading of phosphorus in shallow lakes. Hydrobiologia, 506, 135-145.

Stepanek, J. (2011). Halamphora oligotraphenta. Diatoms of the United States. Retrieved 01.02.2017, from http://westerndiatoms.colorado.edu/taxa/species/halamphora oligotraphenta

Stephens, T., Atkin, D., Augustinus, P., Shane, P., Lorrey, A., Street-Perrott, A., . . Snowball, I. (2012). A late glacial Antarctic climate teleconnection and variable Holocene seasonality at Lake Pupuke, Auckland, New Zealand. J Paleolimnol, 48(4), 785-800. doi: 10.1007/s10933-012-9644-z

Stewart, G. H., \& Rose, A. B. (1990). The significance of life history strategies in the developmental history of mixed beech (Nothofagus) forests, New Zealand. Vegetatio, 87(2), 101-114.

Thompson, D. W. J., Solomon, S., Kushner, P. J., England, M. H., Grise, K. M., \& Karoly, D. J. (2011). Signatures of the Antarctic ozone hole in Southern Hemisphere surface climate change. Nature Geoscience, 4(741-749).

Tokinaga, H., Xie, S., Timmermann, A., McGregor, S., Ogata, T., Kubota, H., \& Okumura, Y. (2012). Regional patterns of tropical Indo-Pacific climate change: Evidence of the Walker Circulation weakening. Journal of Climate, 25(16891710).

Trodahl, M., Rees, A., Newnham, R., \& Vandergoes, M. (2016). Late Holocene geomorphic history of Lake Wairarapa, North Island, New Zealand. New Zealand Journal of Geology and Geophysics, 59(2), 330-340. doi: $10.1080 / 00288306.2015 .1133663$ 
Turner, G. M., \& Lillis, D. A. (1994). A palaeomagnetic secular variation record for New Zealand during the past 2500 years. Physics of the Earth and Planetary Interiors, 83(3), 265-282. doi: 10.1016/0031-9201(94)90093-0

van Dam, H., Merterns, A., \& Sinkeldam, J. (1994). A coded checklist and ecological indicator values of freshwater diatoms from The Netherlands. Netherlands Journal of Aquatic Ecology, 28(1), 117-133.

Verburg, P., Hamill, K., Unwin, M., \& Abell, J. (2010). Lake water quality in New Zealand 2010: Status and trends. Prepared for the Ministry for the Environment. Hamilton, New Zealand: NIWA.

Vos, P. C., \& de Wolf, H. (1988). Methodological aspects of paleo-ecological diatom research in coastal areas of the Netherlands. Netherlands Journal of Geosciences, 67, 31-40.

Wang, L., Lu, H., Liu, J., Gu, Z., Mingram, J., Chu, G., . . Liu, T. (2008). Diatombased inference of variations in the strength of Asian winter monsoon winds between 17,500 and 6000 calendar years B.P. Journal of Geophysical Research: Atmospheres, 113(D21). doi: 10.1029/2008JD010145

Wang, R., Dearing, J. A., Langdon, P. G., Zhang, E., Yang, X., Dakos, V., \& Scheffer, M. (2012). Flickering gives early warning signals of a critical transition to a eutrophic lake state. Nature, 492(7429), 419. doi: 10.1038/nature11655

Webster-Brown, J., Hawes, I., Jungblut, A., Wood, S. A., \& Christenson, H. (2015). The effects of entombment on water chemistry and bacterial assemblages in closed cryoconite holes on Antarctic glaciers. FEMS Microbiology Ecology, 91(12), fiv144.

Weller, D. I. (2011). Dectection, identification and toxigenicity of cyanobacteria in New Zealand lakes using PCR-based methods. New Zealand Journal of Marine and Freshwater Research, 45(4), 651-664.

Whitehead, S. J. (1976). Granulometric studies on selected tephra eruptions, North Island, New Zealand. BSc Hons thesis, Geography, Massey University, Palmerston North.

Whitlock, C., \& Larsen, C. (2001). Charcoal as a fire proxy, Chapter 5. In J. P. Smol, H. J. B. Birks \& W. M. Last (Eds.), Tracking environmental change using lake sediments: terrestrial, algal, and siliceous indicators (Voloume 3, pp. 75-97). Dordrecht, The Netherlands: Kluwer Academic Publishers.

Wilmshurst, J. M., Anderson, A. J., Higham, T. F. G., \& Worthy, T. H. (2008). Dating the late prehistoric dispersal of Polynesians to New Zealand using the 
commensal Pacific rat. Proceedings of the National Academy of Sciences of the United States of America, 105(22), 7676. doi: 10.1073/pnas.0801507105

Wilmshurst, J. M., \& McGlone, M. (2005). Corroded pollen and spores as indicators of changing lake sediment sources and catchment disturbance. Journal of Paleolimnology, 34, 503-517.

Wolfe, A.P., Hobbs, W.O., Birks, H.H., Briner, J.P., Holmgren., S.U., Ingolfsson O., . . . Vinebrooke, R.D. (2013). Stratigraphic expressions of the HoloceneAnthropocene transition revealed in sediment from remote lakes. Earth-Science Reviews, 116, 17-34.

Wood, S. (2011). Fast stable restricted maximum likelihood and marginal likelihood estimation of semiparametric generalized linear models. Journal of the Royal Statistical Society (B), 73, 3-36.

Wood, S. A., Smith, K. F., Banks, J. C., Tremblay, L. A., Rhodes, L., Mountfort, D., . . Pochon, X. (2013). Molecular genetic tools for environmental monitoring of New Zealand's aquatic habitats - past, present, and the future. New Zealand Journal of Marine and Freshwater Research, 47(1), 90-119.

Xhulaj, S. (2012). Diversity and floristic composition in diatom samples of a glacial lake. Journal of International Environmental Application \& Science, 7(1), 200.

Young, A. L. F. (2010). Using diatoms (class Bacillariophyceae) as a biological proxy for environmental change in the Canterbury High Country, Lake Hawdon, New Zealand. MSc thesis, Geology, University of Canterbury. Retrieved from http://ir.canterbury.ac.nz/bitstream/10092/5074/2/Thesis_fulltext.pdf 


\section{Appendices}

\section{A. List of submerged macrophytes recorded in Lake Pounui}

Submerged Macrophytes recorded in Lake Pounui from surveys conducted in 1976 (Jellyman, 1990), 2007 (Drake et al. 2011), 2011 (de Winton et al., 2011), 2016 (de Winton et al., 2016). Adapted from de Winton et al., 2016.

\begin{tabular}{|c|c|c|c|c|c|}
\hline $\begin{array}{c}\text { Plant } \\
\text { community }\end{array}$ & Species & 1976 & 2007 & 2011 & 2016 \\
\hline \multirow[t]{2}{*}{ Emergents } & $\begin{array}{l}\text { Schoenoplectus tabernaemontani (S. } \\
\text { validus) }\end{array}$ & & & $x$ & $x$ \\
\hline & Typha orientalis & $x$ & $x$ & $x$ & $x$ \\
\hline \multirow{7}{*}{ Turf plants } & Crassula sinclaririi & & & $x$ & \\
\hline & Glossostigma elatinoides & $x$ & & $x$ & \\
\hline & Glossostigma cleistanthum & & & $x$ & $x$ \\
\hline & $\begin{array}{l}\text { Glossostigma submersum } \\
\text { (G.diandrum) }\end{array}$ & $x$ & & & \\
\hline & Elatine gratioloides & & & $x$ & \\
\hline & Lilaeopsis novae-zelandiae & $x$ & & $x$ & $x$ \\
\hline & Limosella lineata & $x$ & & & \\
\hline Isoetes & Isoetes kirkii & $x$ & $x$ & $x$ & $x$ \\
\hline Milifoils & $\begin{array}{l}\text { Myriophyllum triphyllum } \\
\text { (M.elatinoides) }\end{array}$ & $x$ & $x$ & $x$ & $x$ \\
\hline \multirow[t]{2}{*}{ Pondweeds } & Potamogeton ochreatus & & & $x$ & $x$ \\
\hline & Potamogeton cheesemanii & & & $x$ & \\
\hline \multirow{7}{*}{ Charophytes } & Chara australis (C.corallina) & $x$ & & $x$ & $x$ \\
\hline & Chara fibrosa & & $x$ & & \\
\hline & Nitella sp. aff. cristata & & & $x$ & $x$ \\
\hline & Nitella pseudoflabellata & $x$ & & $x$ & \\
\hline & Nitella hookerii & & $x$ & & \\
\hline & Nitella stuartii & & & $x$ & \\
\hline & Nitella hyalina & & & & \\
\hline \multirow{3}{*}{$\begin{array}{l}\text { Invasive } \\
\text { species }\end{array}$} & Elodea canadensis & $x$ & $x$ & $\mathrm{x}$ & $x$ \\
\hline & Ranunculus trichophyllus & $x$ & & & $x$ \\
\hline & Potamogeton crispus & $x$ & & $x$ & $x$ \\
\hline \multirow[t]{2}{*}{ Other } & Lemna minor & $x$ & & & \\
\hline & Azolla filiculoides (A.rubra). & $x$ & & & \\
\hline
\end{tabular}




\section{B. Procedure for Radiocarbon Dating used by the Rafter National Isotope Centre, GNS Science}

Acid/Alkali/Acid Pretreatment

Acid/Alkali/Acid pretreatment was carried out on plant material to isolate the humin fraction. Samples were placed in $0.5 \mathrm{M} \mathrm{HCl}$ at $20^{\circ} \mathrm{C}$ for 30 minutes to remove foreign carbonates, then rinsed with de-ionised water until neutral. Samples were then placed in 1.0 $\mathrm{M} \mathrm{NaOH}$ at $20^{\circ} \mathrm{C}$ for 30 minutes to remove sap, lignite, and humic acids, then rinsed until neutral. The samples were then again placed in $0.5 \mathrm{M} \mathrm{HCl}$ at $20^{\circ} \mathrm{C}$ for 15 minutes, then rinse until neutral. Samples were then placed in a $50^{\circ} \mathrm{C}$ oven until dry, and weighed.

\section{Acid Etch Pretreatment}

Acid Etch pretreatment was carried out on freshwater mussel samples to remove foreign carbonates. Samples were placed in $0.5 \mathrm{M} \mathrm{HCl}$ for 1 minute, rinsed with de-ionised water until neutral, dried in a $50^{\circ} \mathrm{C}$ oven overnight, and weighed.

\section{Combustion}

Pretreated samples were combusted for 4 hours at $900^{\circ} \mathrm{C}$ in evacuated, sealed quartz tubes with cupric oxide which provides oxygen and silver wire which isolates sulphur and halogens. $\mathrm{CO}_{2}$ is then passed through ethanol/dry ice to purify, and collected in glass vessels.

\section{Graphitisation}

Purified $\mathrm{CO}_{2}$ is then converted to graphite. $\mathrm{CO}_{2}$ is mixed with hydrogen gas in a quartz reaction tube with iron powder as a catalyst. The tube is heated for 5 hours at $700^{\circ} \mathrm{C}$.

Accelerator Mass Spectrometry (AMS)

The samples are then sent for AMS radiocarbon dating. 


\section{Diatom Identification: Identifying photos from Lake Pounui, measurements, and references}

\section{ARAPHID}

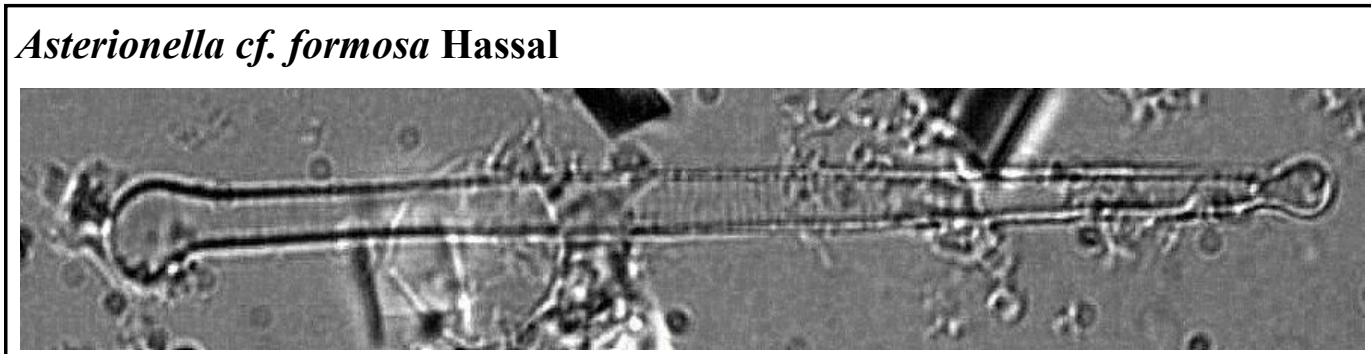

Measured dimensions from photo P2.1-4.0-4.5-05:

Length: $54.35 \mu \mathrm{m}$

Width: $3.8 \mu \mathrm{m}$

Dimensions in Krammer Lange-Bertalot (1991) Part 3 Page 103:

Length: $30-160 \mu \mathrm{m}$

Width: $1.3-6 \mu \mathrm{m}$

Identifying features: Asymmetric ends, very fine striae.

\section{Fragilaria capucina var. vaucheriae (Kuetzing) Lange-Bertalot}

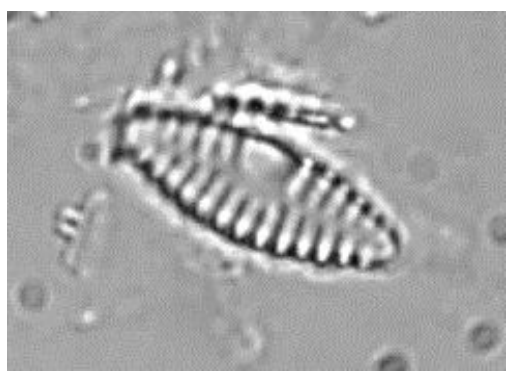

Measured dimensions from photo P3.1-45.0-45.5-72:

Length: $10.33 \mu \mathrm{m}$

Width: $3.26 \mu \mathrm{m}$

Striae in $10 \mu \mathrm{m}: 13$

Dimensions in Krammer Lange-Bertalot (1991) Part 3 Page 124:

Length: $5-150 \mu \mathrm{m}$

Width: $4-5 \mu \mathrm{m}$

Stiae in $10 \mu \mathrm{m}: 9-14$

Identifying features: Lanceolate, asymmetric valve, U-shaped gap in striae at central area. 


\section{Fragilaria cf. pseudoconstruens Marciniak}

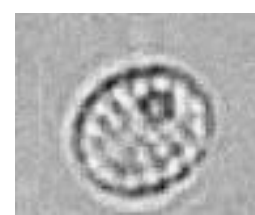

Measured dimensions from photo P3.1-45.0-45.5-72:

Length: $3.3 \mu \mathrm{m}$

Width: $3.3 \mu \mathrm{m}$

Striae in $10 \mu \mathrm{m}: 18$

Dimensions in Krammer Lange-Bertalot (1991) Part 3 Page 163:

Length: $3-22 \mu \mathrm{m}$

Width: $3-7 \mu \mathrm{m}$

Striae in $10 \mu \mathrm{m}: 15-18$

Identifying features: Round in shape, striae only on edges.

\section{Meridion circulare (Greville) Agardh}

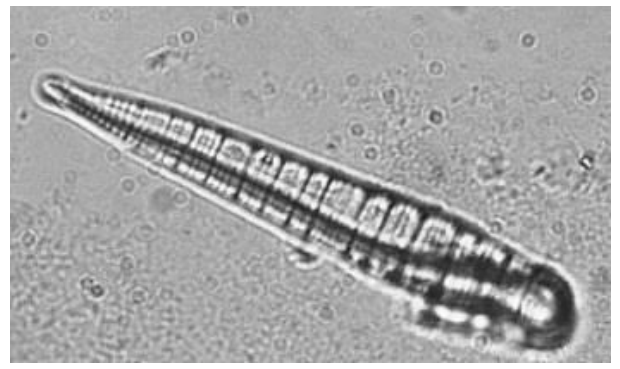

Measured dimensions from photo P3.2-85.0-85.5-10:

Length: $43.48 \mu \mathrm{m}$

Width: $6.5 \mu \mathrm{m}$

Striae in $10 \mu \mathrm{m}: 24$

Dimensions in Krammer Lange-Bertalot (1991) Part 3 Page 101:

Length: $12-400 \mu \mathrm{m}$

Width: $2-8 \mu \mathrm{m}$

Stiae in $10 \mu \mathrm{m}: 7.5-26$

Identifying features: Valves have a linear-clavate shape, with asymmetrical ends, and transverse costae. 


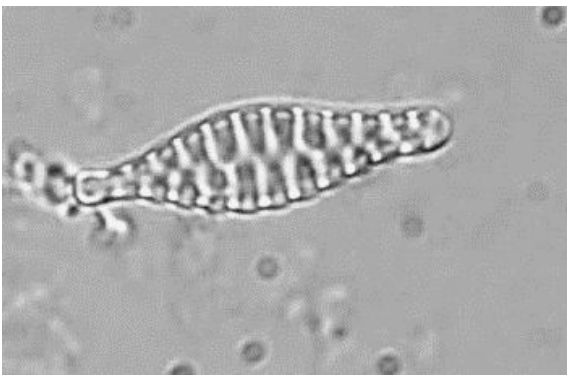

Dimensions in photo P3.1-45.0-45.5-66:

Length: $17.39 \mu \mathrm{m}$

Width: $4.35 \mu \mathrm{m}$

Striae in $10 \mu \mathrm{m}: 10$

Dimensions in Krammer Lange-Bertalot (1991) Part 3 Page 166 as Opephora olsenii:

Length: $7-60 \mu \mathrm{m}$

Width: $2.5-7 \mu \mathrm{m}$

Stiae in $10 \mu \mathrm{m}: 6-14$

Identifying features: U-shaped striae.

\section{Pseudostaurosira cf. brevistriata (Grunow) Williams \& Round}

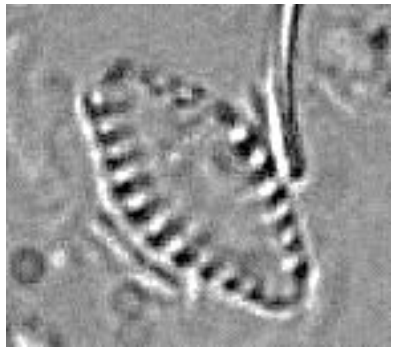

Dimensions in photo P3.1-5.5-5.5-50:

Length: $8.70 \mu \mathrm{m}$

Width: $4.4 \mu \mathrm{m}$

Striae in $10 \mu \mathrm{m}: 15$

Dimensions in Krammer Lange-Bertalot (1991) Part 3 Page 162 as Fragilaria brevistriata:

Length: $5-42 \mu \mathrm{m}$

Width: $3-7 \mu \mathrm{m}$

Striae in $10 \mu \mathrm{m}: 12-17$

Identifying features: Lanceolate to elliptical, striae restricted to valve margin. 


\section{Pseudostaurosira elliptica (Schumann) Edlund, Morales \& Spaulding}

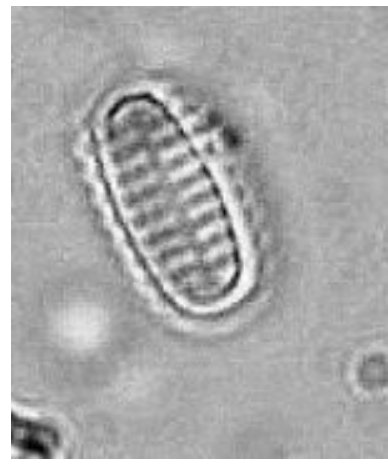

Dimensions in photo P3.1-45.0-45.5-23:

Length: $6.5 \mu \mathrm{m}$

Width: $3.7 \mu \mathrm{m}$

Striae in $10 \mu \mathrm{m}: 16$

Dimensions in Krammer Lange-Bertalot (1991) Part 3 Page 155 as Fragilaria elliptica:

Length: $3-10 \mu \mathrm{m}$

Width: $2.5-6 \mu \mathrm{m}$

Striae in $10 \mu \mathrm{m}: 11-16$

Identifying features: Elliptic shape.

\section{Stauroforma exiguiformis (Lange-Bertalot) Flower}

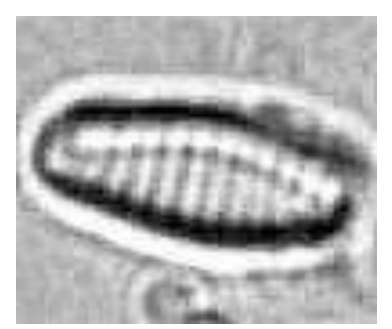

Dimensions in photo P3.1-55.0-55.5-03:

Length: $6.5 \mu \mathrm{m}$

Width: $2.7 \mu \mathrm{m}$

Striae in $10 \mu \mathrm{m}: 21$

Dimensions in Krammer Lange-Bertalot (1991) Part 3 Page 137 as Fragilaria exiguiformis:

Length: $5-25 \mu \mathrm{m}$

Width: $3-5 \mu \mathrm{m}$

Striae in $10 \mu \mathrm{m}$ : $18-21$

Identifying features: Striae meet in the middle. 


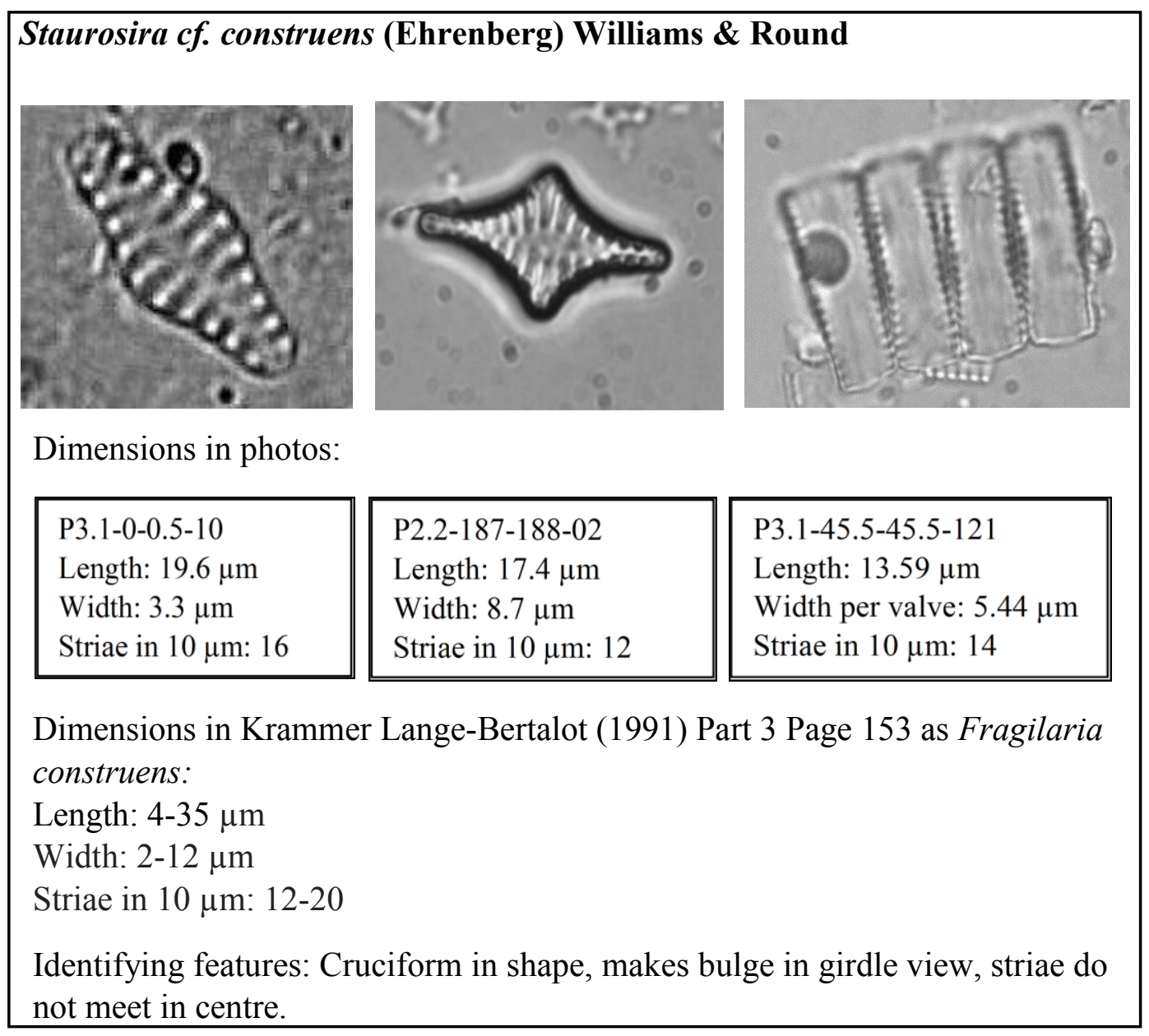

\section{Staurosira venter (Ehrenberg) Cleve \& Möller 1879}
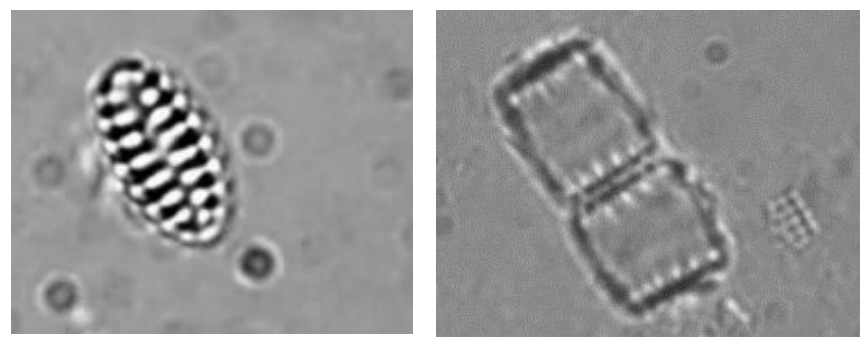

Dimensions in photos:

P2.2-186-187-01

Length: $6.52 \mu \mathrm{m}$

Width: $2.17 \mu \mathrm{m}$

Striae in $10 \mu \mathrm{m}: 14 \mu \mathrm{m}$

P3.1-45.0-45.5-50

Length per valve: $5.44,4.89 \mu \mathrm{m}$

Width: $4.35 \mu \mathrm{m}$

Striae in $10 \mu \mathrm{m}: \sim 16 \mu \mathrm{m}$

Dimensions in Krammer Lange-Bertalot (1991) Part 3 Page 153 as Fragilaria venter:

Length: 4-35 $\mu \mathrm{m}$

Width: $2-12 \mu \mathrm{m}$

Striae in $10 \mu \mathrm{m}: 14-18$

Identifying features: Valves are lanceolate, makes gentle bulge in girdle view. 


Staurosirella martyi (Héribaud) Morales
Dimensions in photo P3.1-5.0-5.5-51:
Length: $15.22 \mu \mathrm{m}$
Width: $5.44 \mu \mathrm{m}$
Striae in $10 \mu \mathrm{m}: 10$
Dimensions in Krammer Lange-Bertalot (1991) Part 3 Page 160 as Fragilaria
leptostauron var. martyii:
Length: $15-36 \mu \mathrm{m}$
Width: $10-23 \mu \mathrm{m}$
Striae in $10 \mu \mathrm{m}: 5-9$
Identifying features: U-shaped striae.

\section{Staurosirella pinnata (Ehrenberg) Williams \& Round}
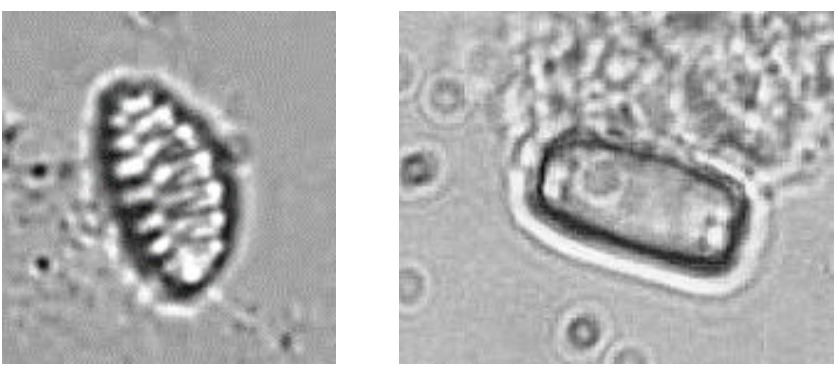

Dimensions in photos:

$$
\begin{aligned}
& \text { P3.1-45.0-45.5-76 } \\
& \text { Length: } 6.52 \mu \mathrm{m} \\
& \text { Width: } 3.26 \mu \mathrm{m} \\
& \text { Striae in } 10 \mu \mathrm{m}: 8
\end{aligned}
$$

\section{Girdle view}

P3.1-45.0-45.5-78

Length: $6 \mu \mathrm{m}$

Width: $2.2 \mu \mathrm{m}$

Dimensions in Krammer Lange-Bertalot (1991) Part 3 Page 156 as Fragilaria pinnata:

Length: $3-35 \mu \mathrm{m}$

Width: 2-8 $\mu \mathrm{m}$

Striae in $10 \mu \mathrm{m}: 6-12$

Identifying features: Valves are oval, wide striae. 

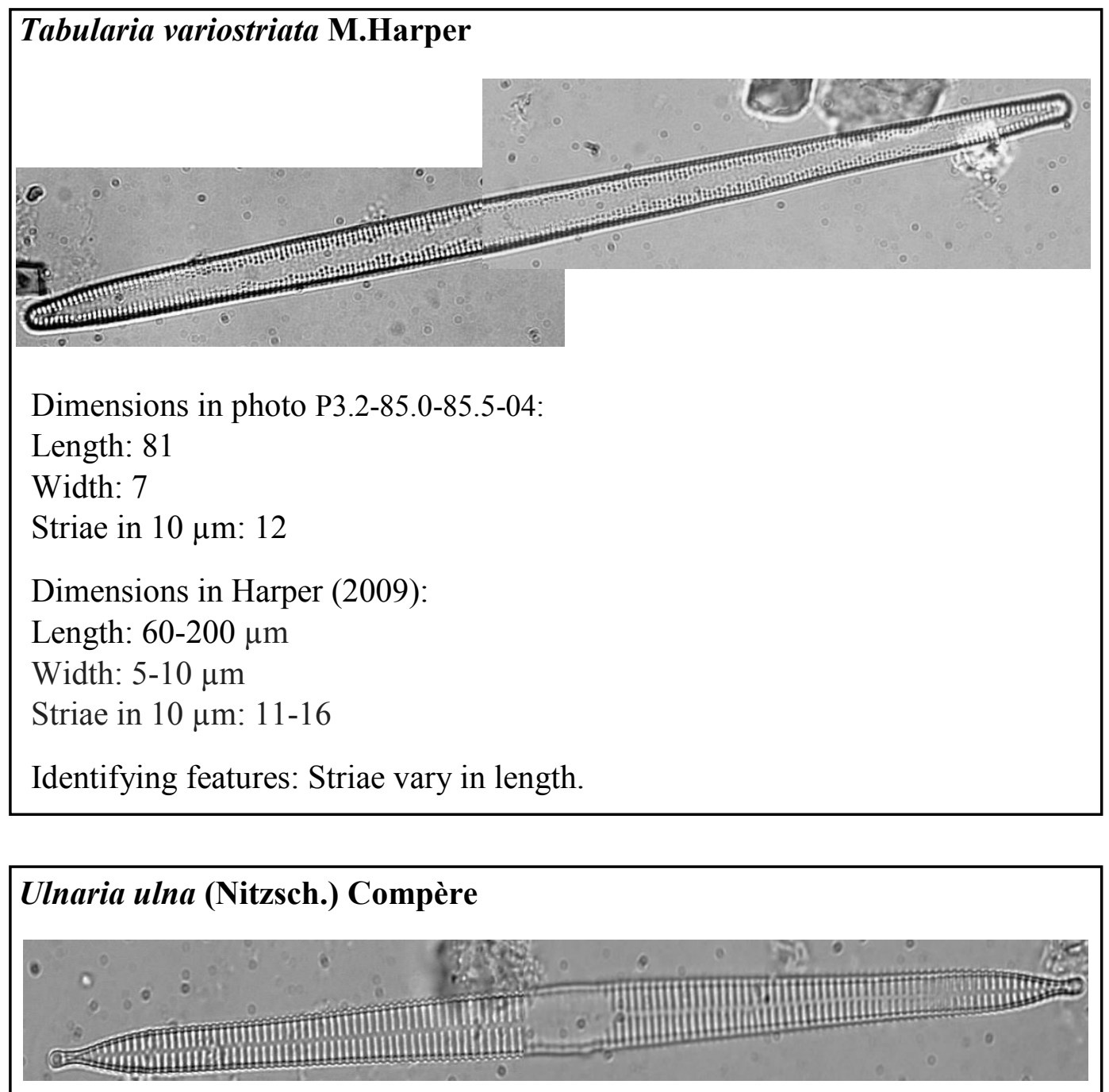

Dimensions in photo P3.1-35-35.5-10:

Length: $113 \mu \mathrm{m}$

Width: $6.52 \mu \mathrm{m}$

Striae in $10 \mu \mathrm{m}: 14$

Dimensions in Krammer Lange-Bertalot (1991) Part 3 Page 143 as Synedra ulna:

Length: $50-250 \mu \mathrm{m}$

Width: $2-9 \mu \mathrm{m}$

Stiae in $10 \mu \mathrm{m}: 7-15$

Identifying features: Gap in striae in centre. 


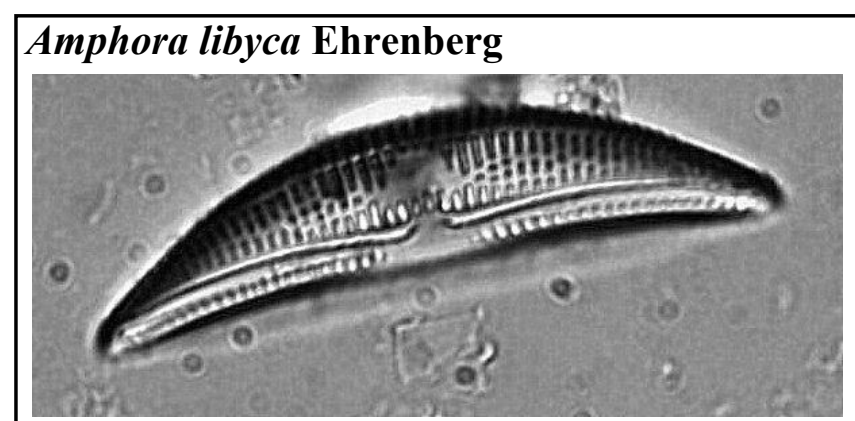

Dimensions in photo P2.1-5.0-5.5-07:

Length: $35.3 \mu \mathrm{m}$

Width: $7.6 \mu \mathrm{m}$

Striae in $10 \mu \mathrm{m}: 16$

Dimensions in Krammer Lange-Bertalot (1991) Part 1 Page 345:

Length: $20-80 \mu \mathrm{m}$

Width: $14-35 \mu \mathrm{m}$

Striae in $10 \mu \mathrm{m}: 3.5-12$

Identifying features: Valves lunate, raphe towards ventral margin, hyaline area in centre of dorsal side.

\section{Halamphora cf. oligotraphenta (Lange-Bertalot) Levkov}

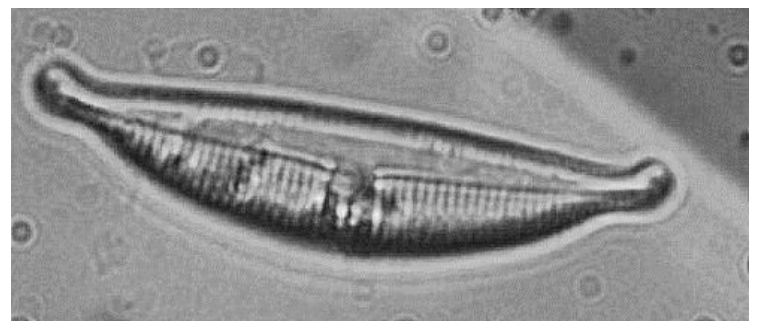

Dimensions from photo P3.1-5-5.5-078:

Length: $29.35 \mu \mathrm{m}$

Width: $6.52 \mu \mathrm{m}$

Striae in $10 \mu \mathrm{m}: 24$

Dimensions from Stepanek (2011):

Length: $22-33 \mu \mathrm{m}$

Width: 3.9-4.6 $\mu \mathrm{m}$

Striae in $10 \mu \mathrm{m}$ : $26-30$ centre, $32-34$ poles

Identifying features: Valves lanceolate, capitate ends. 
Cymbella aspera (Ehrenberg) Peragallo

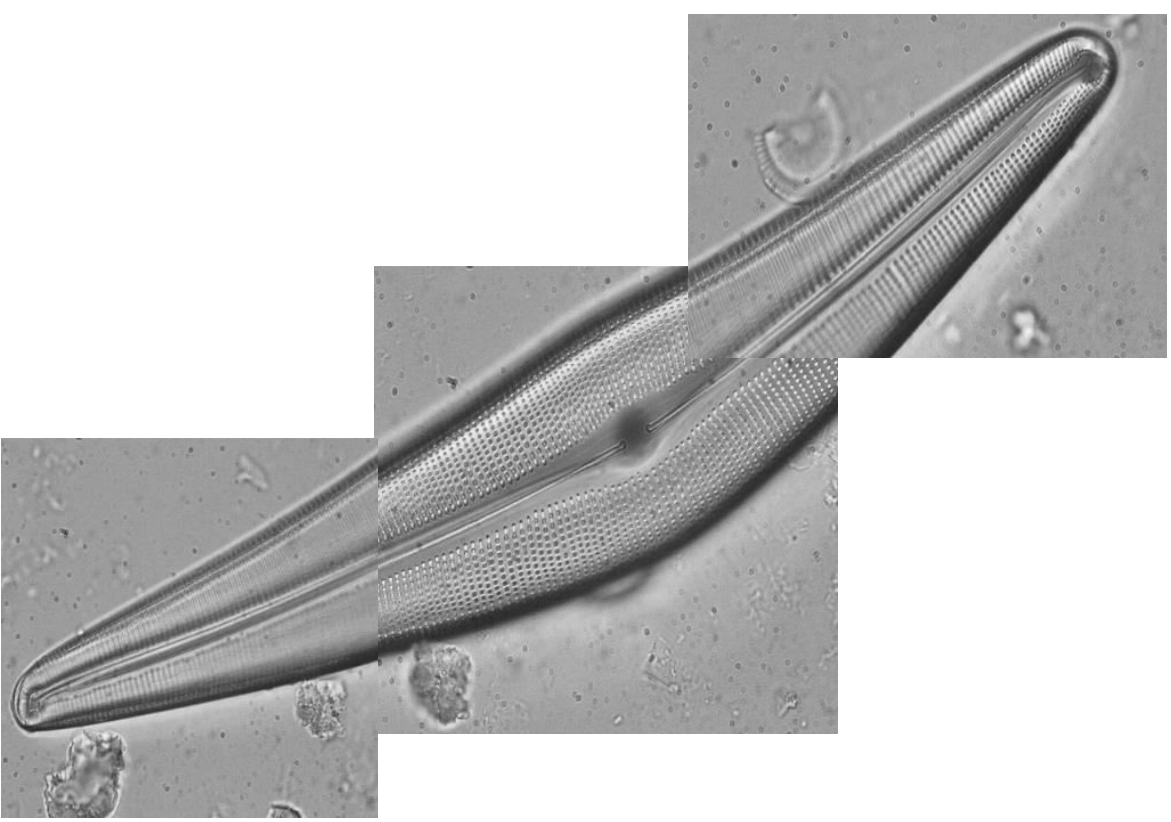

Dimensions from photo P3.1-5.0-5.5-25-28:

Length: $244 \mu \mathrm{m}$

Width: $37 \mu \mathrm{m}$

Striae in $10 \mu \mathrm{m}: 8$

Dimensions from Krammer Lange-Bertalot (1991) Part 1 Page 319:|

Length Range: 70-265 $\mu \mathrm{m}$

Width Range: $20-48 \mu \mathrm{m}$

Striae in $10 \mu \mathrm{m}: 7-10$ in middle, to $11-12$ at ends

Identifying features: no stigmata, very large. 

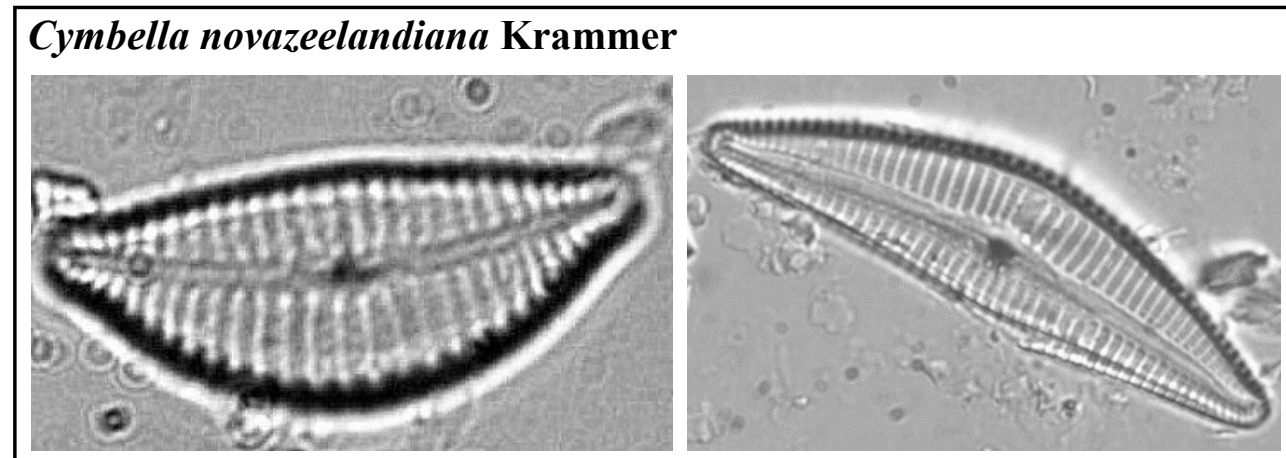

Dimensions from photos:

P3.1-45.0-45.5-05

Length: $22.8 \mu \mathrm{m}$

Width: $9.8 \mu \mathrm{m}$

Striae in $10 \mu \mathrm{m}: 12$

P3.1-45.0-45.5-123

Length: $44.57 \mu \mathrm{m}$

Width: $10.87 \mu \mathrm{m}$

Striae in $10 \mu \mathrm{m}: 12$

Dimensions from Krammer (2002):

Length Range: 24-57 $\mu \mathrm{m}$

Width Range: $10-12.8 \mu \mathrm{m}$

Striae in $10 \mu \mathrm{m}: 9-12$

Identifying features: 2 ventral stigmata.

\section{Cymbella cf. parva (W.Smith) Kirchner}

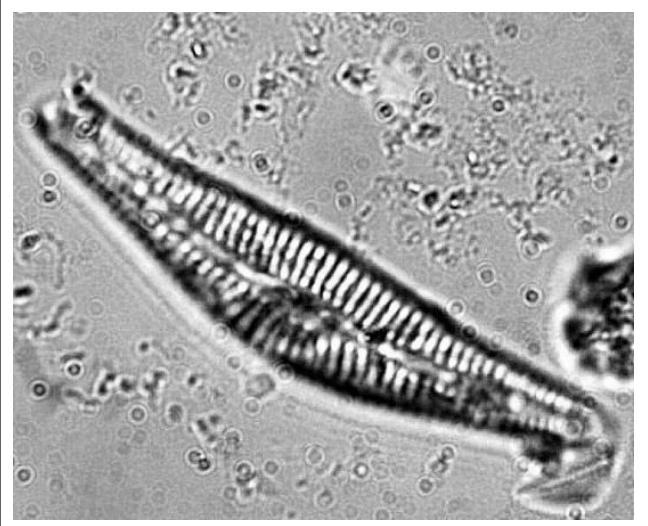

Dimensions from photo P3.3-25.0-25.5-01:

Length: $51.1 \mu \mathrm{m}$

Width: $10.3 \mu \mathrm{m}$

Striae in $10 \mu \mathrm{m}: 12$

Dimensions from Krammer Lange-Bertalot (1991) Part 1 Page 314 as

Cymbella affinis:

Length: $20-70 \mu \mathrm{m}$

Width: 7-16 $\mu \mathrm{m}$

Striae in $10 \mu \mathrm{m}$ : 9-11 middle, to $12-14$ at ends

Identifying features: Single ventral stigma. 

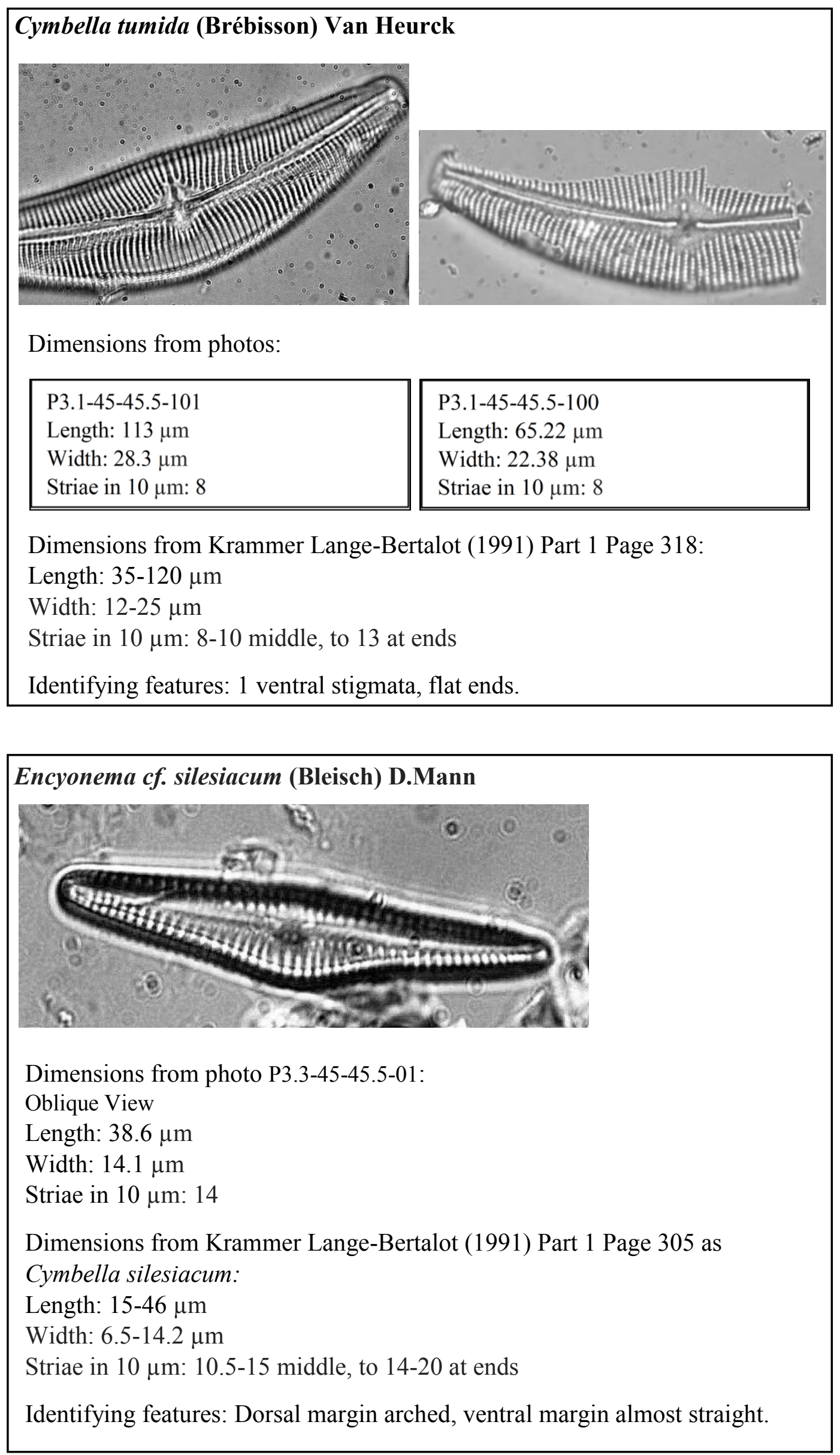


\section{Gomphonema affine Kuetzing}

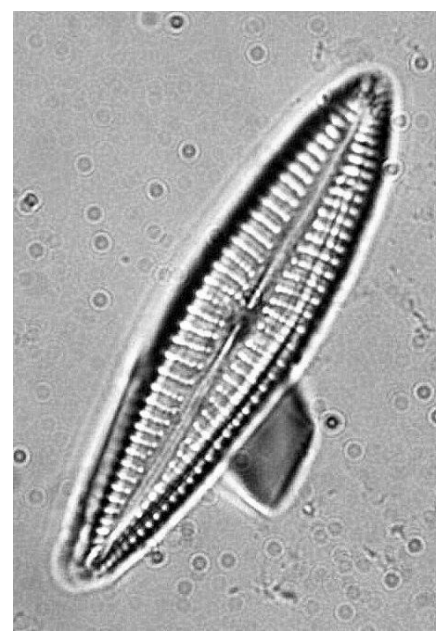

Dimensions from photo P3.3-45-45.5-02:

Length: $42.4 \mu \mathrm{m}$

Width: $9.7 \mu \mathrm{m}$

Striae in $10 \mu \mathrm{m}: 12$

Dimensions from Krammer Lange-Bertalot (1991) Part 1 Page 366:

Length: $30-100 \mu \mathrm{m}$

Width: $7-12 \mu \mathrm{m}$

Striae in $10 \mu \mathrm{m}: 9-12$

Identifying features: Valves linear to elliptic lanceolate.

\section{Gomphonema augur Ehrenberg}

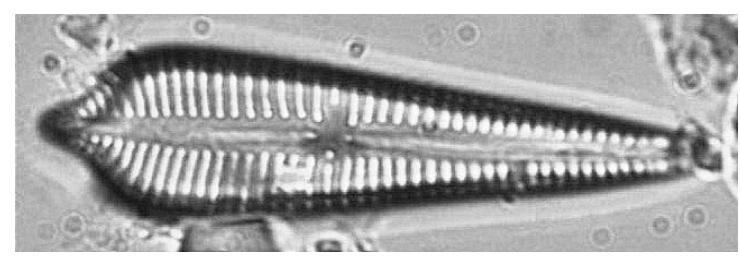

Dimensions from photo P3.1-95.0-95.5-09:

Length: $40.2 \mu \mathrm{m}$

Width: $10.87 \mu \mathrm{m}$

Striae in $10 \mu \mathrm{m}: 14$

Dimensions from Krammer Lange-Bertalot (1991) Part 1 Page 363:

Length: $17-130 \mu \mathrm{m}$

Width: 8-20 $\mu \mathrm{m}$

Striae in $10 \mu \mathrm{m}: 7-15$

Identifying features: Asymmetrical to transapical axis, head much wider than tail, single stigma with one shorter striae in central area. 
Gomphonema cf. angustatum (Kuetzing) Rabenhorst

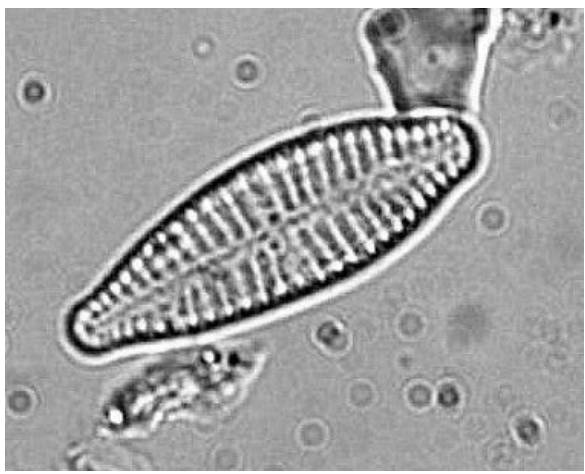

Dimensions from photo P3.3-15.0-15.5-32:

Length: $19.6 \mu \mathrm{m}$

Width: $6.5 \mu \mathrm{m}$

Striae in $10 \mu \mathrm{m}: 14$

Dimensions from Krammer Lange-Bertalot (1991) Part 1 Page 360:

Length: $12-45 \mu \mathrm{m}$

Width: $5-9.5 \mu \mathrm{m}$

Striae in $10 \mu \mathrm{m}: 7-14$

Identifying features: no stigmata.

\section{Gomphonema truncatum Ehrenberg}

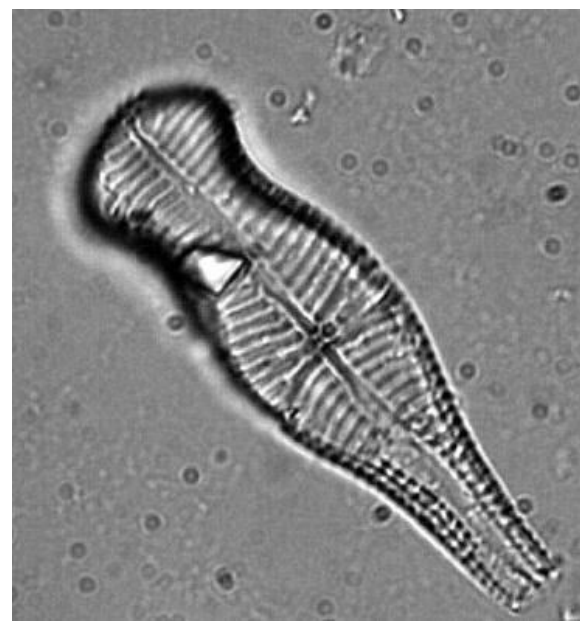

Dimensions from photo P3.3-15.0-15.5-32:

Length: $38 \mu \mathrm{m}$

Width: $10.87 \mu \mathrm{m}$

Striae in $10 \mu \mathrm{m}: 12$

Dimensions from Krammer Lange-Bertalot (1991) Part 1 Page 369:

Length: $13-75 \mu \mathrm{m}$

Width: $7-17 \mu \mathrm{m}$

Striae in $10 \mu \mathrm{m}$ : 9-12

Identifying features: Headpole capitate, single stigma, radiate striae. 

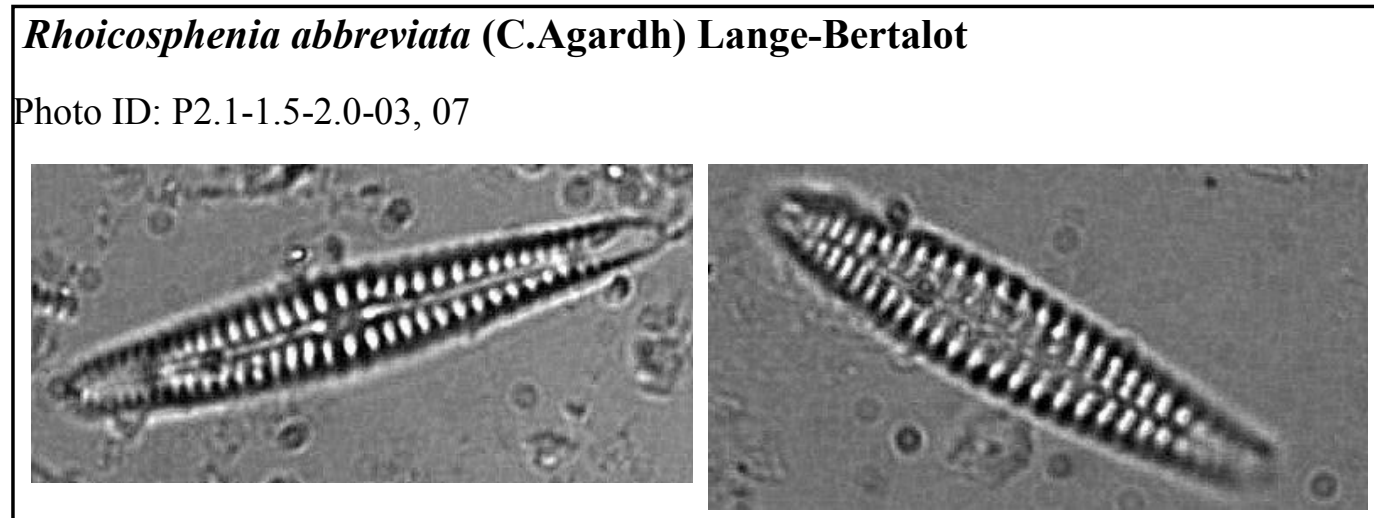

Dimensions from photos:
P2.1-1.5-2.0-03
Concave valve
Length: $23.9 \mu \mathrm{m}$
Width: $3.7 \mu \mathrm{m}$
Striae in $10 \mu \mathrm{m}: 16$

P2.1-1.5-2.0-07

Convex valve

Length: $21.7 \mu \mathrm{m}$

Width: $4.3 \mu \mathrm{m}$

Striae in $10 \mu \mathrm{m}: 14$

Dimensions from Krammer Lange-Bertalot (1991) Part 1 Page 381:

Length: $10-75 \mu \mathrm{m}$

Width: $3-8 \mu \mathrm{m}$

Striae in $10 \mu \mathrm{m}: 15-20$

Identifying features: Pseudosepta present, heterovalvar.

\section{CENTRICS}

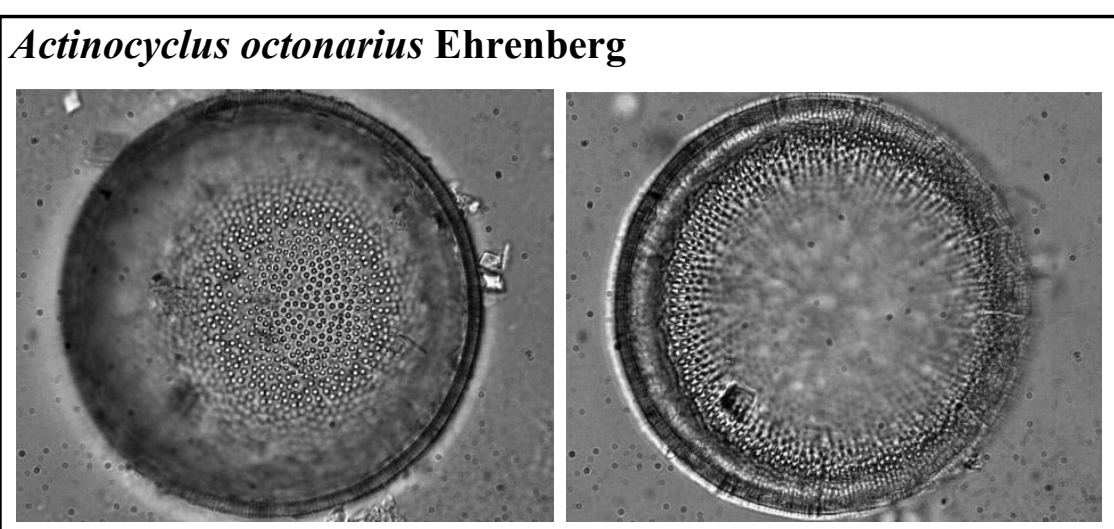

Dimensions from photo P2.1-2.0-2.5-02, 03:

Diameter: $67.4 \mu \mathrm{m}$

Areolae in $10 \mu \mathrm{m}: 8$

Dimensions from Krammer Lange-Bertalot (1991) Part 3 Page 88:

Diameter: 50-300 $\mu \mathrm{m}$

Dimensions from Witkowski et al. (2000):

Areolae in $10 \mu \mathrm{m}: 6-8$

Identifying features: very large, dome shaped. 

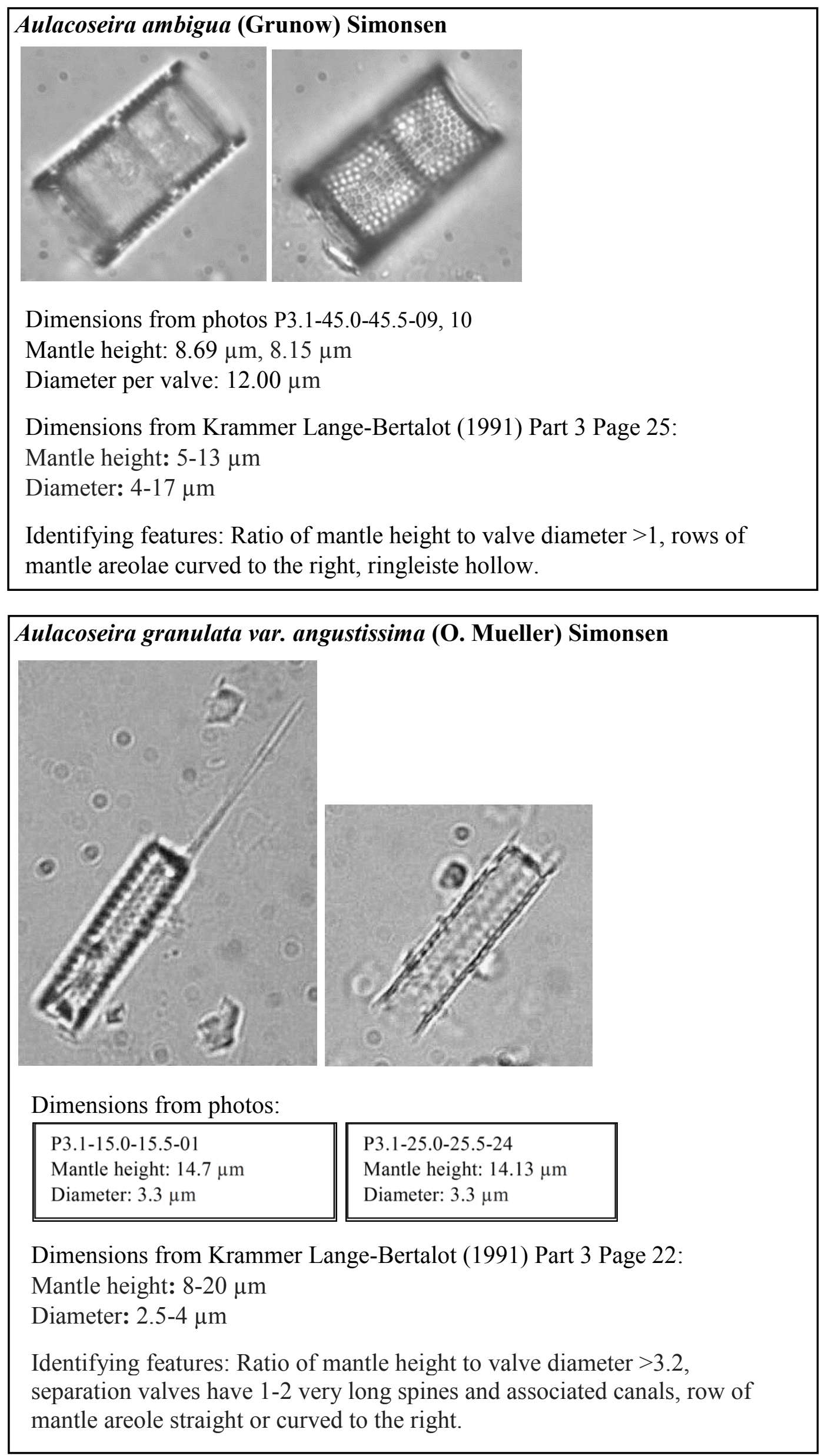

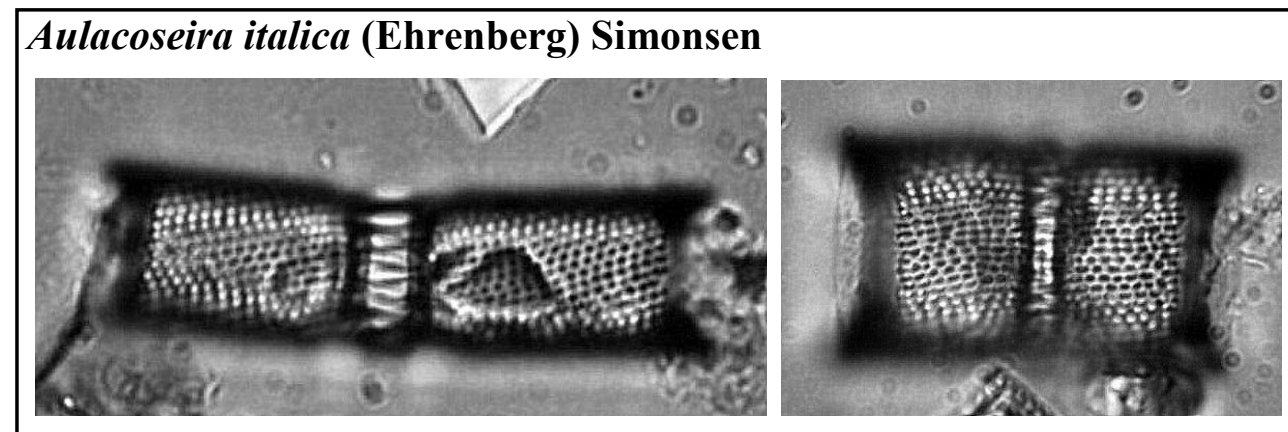

Dimensions from photos:

P2.1-1.0-1.5-26

Mantle height per valve: $10.87 \mu \mathrm{m}$, $13.0 \mu \mathrm{m}$

Diameter per valve: $7.6 \mu \mathrm{m}$

P2.1-5.5-6.0-06

Mantle height per valve: $10.87 \mu \mathrm{m}$, $9.8 \mu \mathrm{m}$

Diameter per valve: $14.1 \mu \mathrm{m}$

Dimensions from Krammer Lange-Bertalot (1991) Part 3 Page 30:

Mantle height: 8-20 $\mu \mathrm{m}$

Diameter: 3- $23 \mu \mathrm{m}$

Identifying features: Linking spines large, mantle areolae slit shaped and straight or curved to the left.

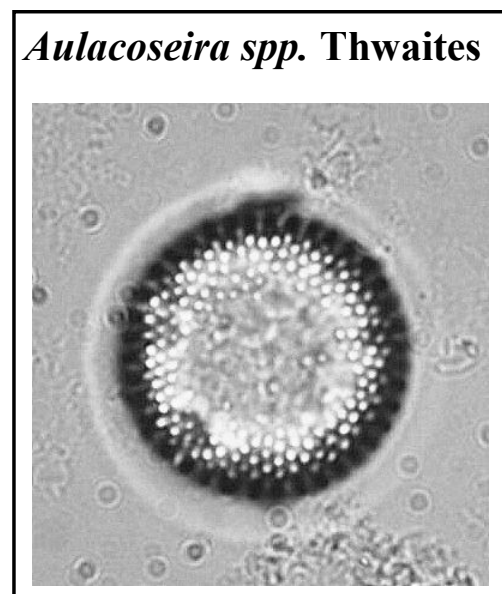

Diameter from photo: $16.3 \mu \mathrm{m}$ 


\section{Discostella stelligera (Cleve \& Grunow) Houk \& Klee}

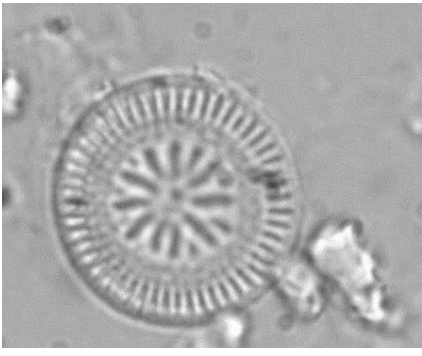

Dimensions from photo P2.1-1.0-1.5-26:

Diameter: $13.04 \mu \mathrm{m}$

Striae in $10 \mu \mathrm{m}: 13$

Dimensions from Krammer Lange-Bertalot (1991) Part 3 Page 50 as

Cyclotella stelligera:

Diameter: 5-40 $\mu \mathrm{m}$

Striae in $10 \mu \mathrm{m}: 10-14 \mu \mathrm{m}$

Identifying features: Stellate center, marginal striae form ring.
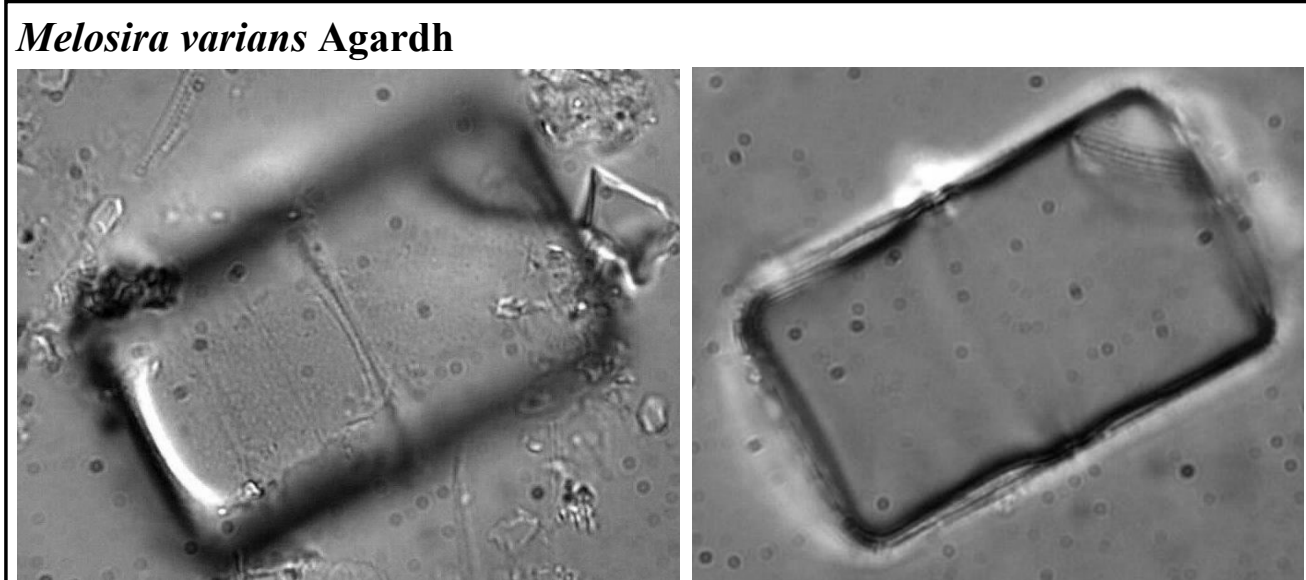

Dimensions from photo P2.1-1.0-1.5-26, 27:

Mantle height per valve: $17.9 \mu \mathrm{m}$

Diameter per valve: $21.7 \mu \mathrm{m}$

Dimensions from Krammer Lange-Bertalot (1991) Part 3 Page 7:

Mantle height: $4-14 \mu \mathrm{m}$

Diameter: 8-35 $\mu \mathrm{m}$

Identifying features: Valves lack areolae 


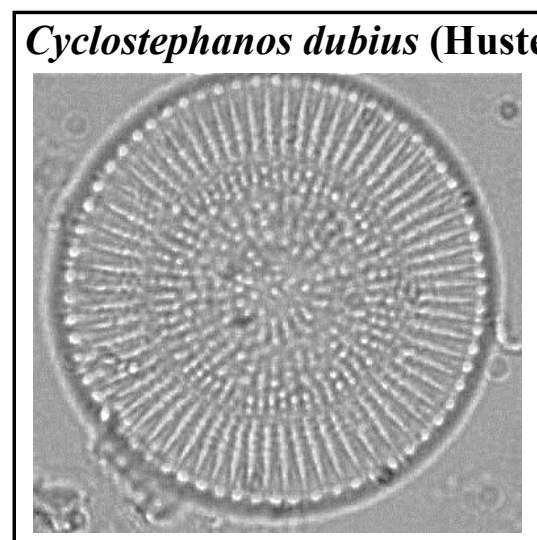

Dimensions from photo P3.1-35.0-35.5-15:

Diameter: $22.8 \mu \mathrm{m}$

Costae in $10 \mu \mathrm{m}: 18 \mu \mathrm{m}$

Dimensions from Ivarsson (2011) \& Krammer Lange-Bertalot (1991) Part 3 Page 64:

Diameter: $4.5-35 \mu \mathrm{m}$

Costae in $10 \mu \mathrm{m}: 12-18$

Identifying features: Marginal costae distinct, central areolae organised into striae in larger valves, while central areolae are more irregular in smaller valves.

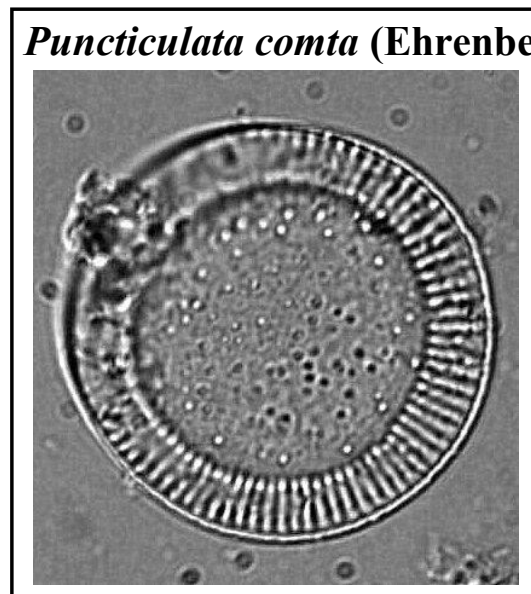

Dimensions from photo P3.1-35.0-35.5-15

Diameter: $23.9 \mu \mathrm{m}$

Striae in $10 \mu \mathrm{m}: 16 \mu \mathrm{m}$

Dimensions from Krammer Lange-Bertalot (1991) Part 3 Page 57 as Cyclotella radiosa:

Diameter: $8-50 \mu \mathrm{m}$

Striae in $10 \mu \mathrm{m}: 13-16$

Identifying features: Marginal striae form ring, sparse variable areolae in centre. 


\section{EPITHEMIOID}

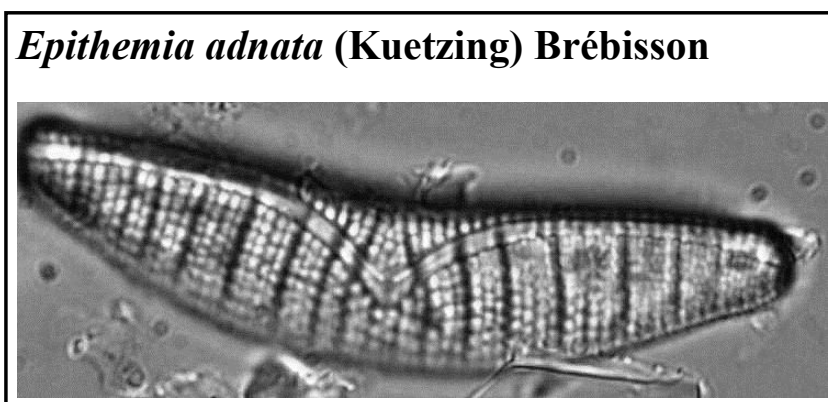

Dimensions from photo P3.1-0-0.5-20:

Length: $47.83 \mu \mathrm{m}$

Width: $11.96 \mu \mathrm{m}$

Striae in $10 \mu \mathrm{m}: 15$

Dimensions in Krammer Lange-Bertalot (1991) Part 2 Page 152:

Length: $20-150 \mu \mathrm{m}$

Width: 7-14 $\mu \mathrm{m}$

Striae in $10 \mu \mathrm{m}: 11-14$

Identifying features: Valves dorsiventral, with rostrate ends. Dorsal side convex, ventral side slightly concave. In the centre of the value the raphe canal arches towards the dorsal margin, reaching half way.

\section{Epithemia sorex Kuetzing}

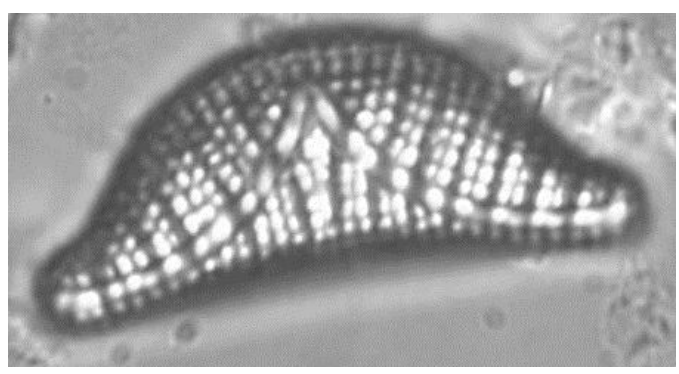

Dimensions from photo P3.1-0-0.5-01:

Length: $28.26 \mu \mathrm{m}$

Width: $11.96 \mu \mathrm{m}$

Striae in $10 \mu \mathrm{m}: 16$

Dimensions from Krammer Lange-Bertalot (1991) Part 2 Page 154:

Length: $8-70 \mu \mathrm{m}$

Width: $6.5-16 \mu \mathrm{m}$

Striae in $10 \mu \mathrm{m}: 10-15$

Identifying features: Valves strongly dorsiventral. In the centre of the value the raphe canal arches almost touching the dorsal margin. 


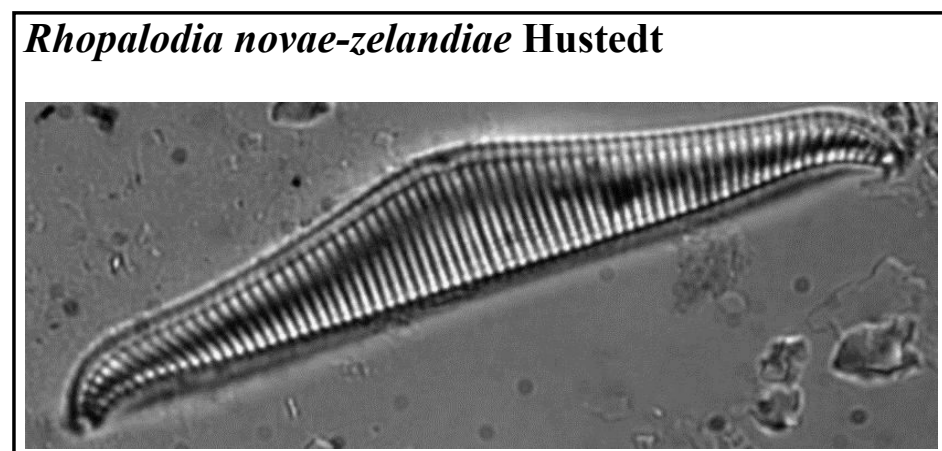

Dimensions from photo P3.1-45-45.5-41:

Length: $53.26 \mu \mathrm{m}$

Width: $8.70 \mu \mathrm{m}$

Striae in $10 \mu \mathrm{m}: 16$

Dimensions from Cassie (1989):

Length: $100-200 \mu \mathrm{m}$

Width: 9-12 $\mu \mathrm{m}$

Striae in $10 \mu \mathrm{m}: 12-14$

Identifying features: Ends bent towards ventral margin, centre arching slightly towards dorsal margin. Notch visible in centre dorsal margin, no evident costae amongst striae.

\section{Rhopalodia brebissonii Krammer}

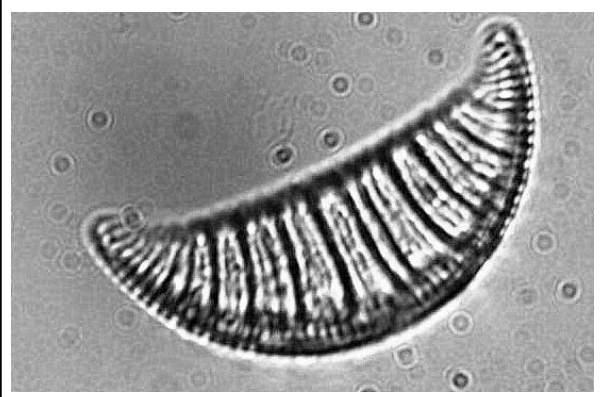

Dimensions from photo P3.3-35-35.5-09:

Length: $29.4 \mu \mathrm{m}$

Width: $10.87 \mu \mathrm{m}$

Fibulae in $100 \mu \mathrm{m}: 60$

Dimensions from Krammer Lange-Bertalot (1991) Part 2 Page 164:

Length: $15-40 \mu \mathrm{m}$

Width: $12-20 \mu \mathrm{m}$

Fibulae in $100 \mu \mathrm{m}: 35-60$

Identifying features: Valves semi-circular, strongly convex dorsal margin. 


\section{Rhopalodia cf. rupestis (W. Smith) Krammer}

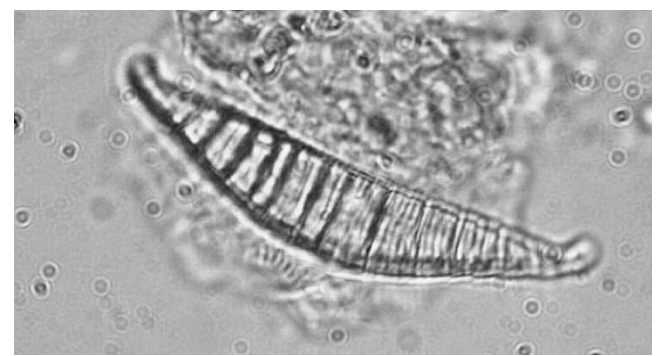

Dimensions from photo P3.3-55-55.5-14:

Length: $>30 \mu \mathrm{m}$

Width: $18 \mu \mathrm{m}$

Fibulae in $100 \mu \mathrm{m}: 30$

Dimensions from Krammer Lange-Bertalot (1991) Part 2 Page 165:

Length: $20-74 \mu \mathrm{m}$

Width: 5-8 $\mu \mathrm{m}$

Fibulae in $100 \mu \mathrm{m}: 30-50$

Identifying features: Valves lunate, with ventral margin slightly concave or straight, ends slightly bent ventrally.

\section{EUNOTIOID}

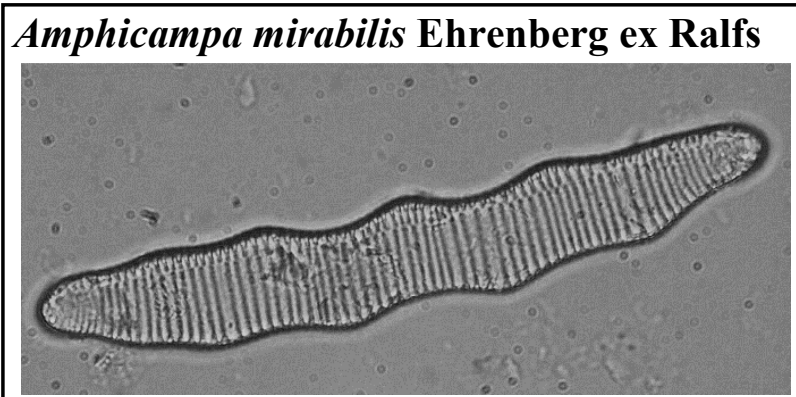

Dimensions from photo P3.1-5-5.5-16:

Length: $83.7 \mu \mathrm{m}$

Width: $11.96 \mu \mathrm{m}$

Striae in $10 \mu \mathrm{m}: 10$

Cassie (1989) \& Krammer Lange-Bertalot (1991) Part 1 Page 195:

Length: $80-120 \mu \mathrm{m}$

Width: $8-11 \mu \mathrm{m}$

Striae in $10 \mu \mathrm{m}: 8-12$

Identifying features: Undulating dorsal and ventral margins, striae are asymmetric. 


\section{MONORAPHID}

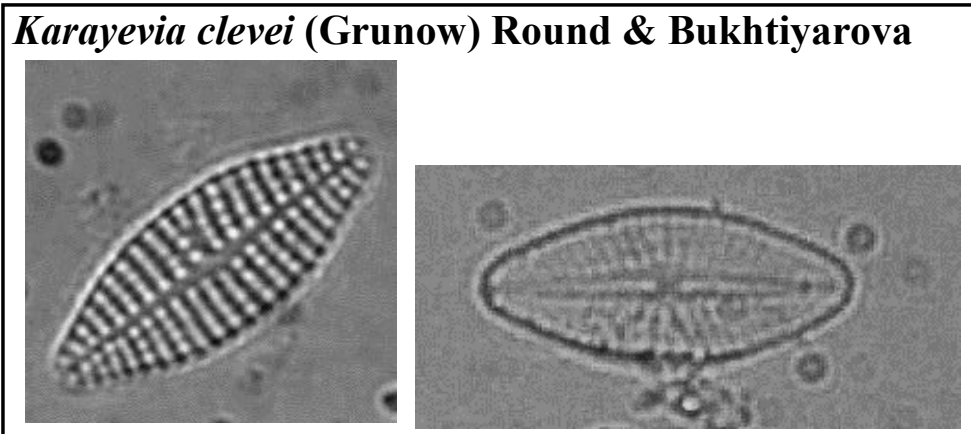

Dimensions from photos:

P3.1-45-45.5-31

Rapheless valve

Length: $16.31 \mu \mathrm{m}$

Width: $5.44 \mu \mathrm{m}$

Striae in $10 \mu \mathrm{m}: 16$
P3.1-45-45.5-20

Raphe valve

Length: $11.96 \mu \mathrm{m}$

Width: $4.89 \mu \mathrm{m}$

Striae in $10 \mu \mathrm{m}: 28$

Dimensions from Krammer Lange-Bertalot (1991) Part 4 Page 35:

Length: $8-32 \mu \mathrm{m}$

Width: $4.5-10 \mu \mathrm{m}$

Striae in $10 \mu \mathrm{m}$ : 9-16 on raphless valve, $16-26$ on raphe valve

Identifying features: Valves lanceolate, areolae visible in striae in rapheless valve, striae on raphe valve fine and radiate.

\section{Karayevia oblongella (Oestrup) Aboal}

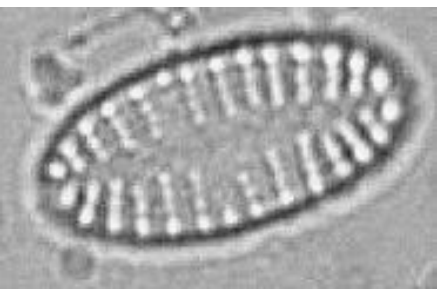

Dimensions from photo P3.3-15-15.5-10:

Rapheless valve

Length: $10.87 \mu \mathrm{m}$

Width: $4.9 \mu \mathrm{m}$

Striae in $10 \mu \mathrm{m}: 13$

Dimensions from Krammer Lange-Bertalot (1991) Part 4 Page 29:

Length: 7-20 $\mu \mathrm{m}$

Width: $4-8 \mu \mathrm{m}$

Striae in $10 \mu \mathrm{m}$ : $10-14$ on rapheless valve, $23-27$ on raphe valve

Identifying features: Valves elliptic to linear elliptic, striae very coarse on rapheless valve, striae much denser on raphe valve. 

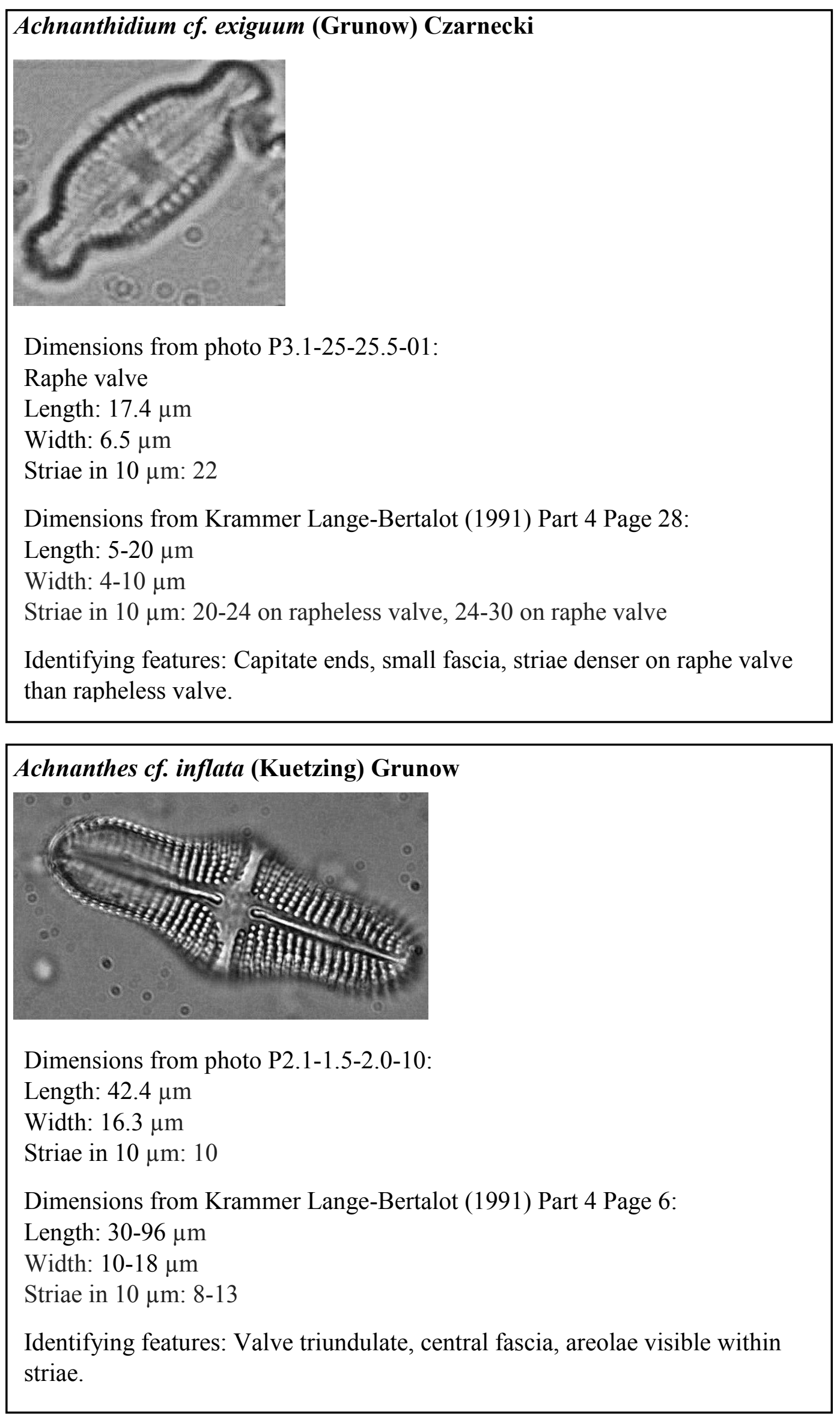

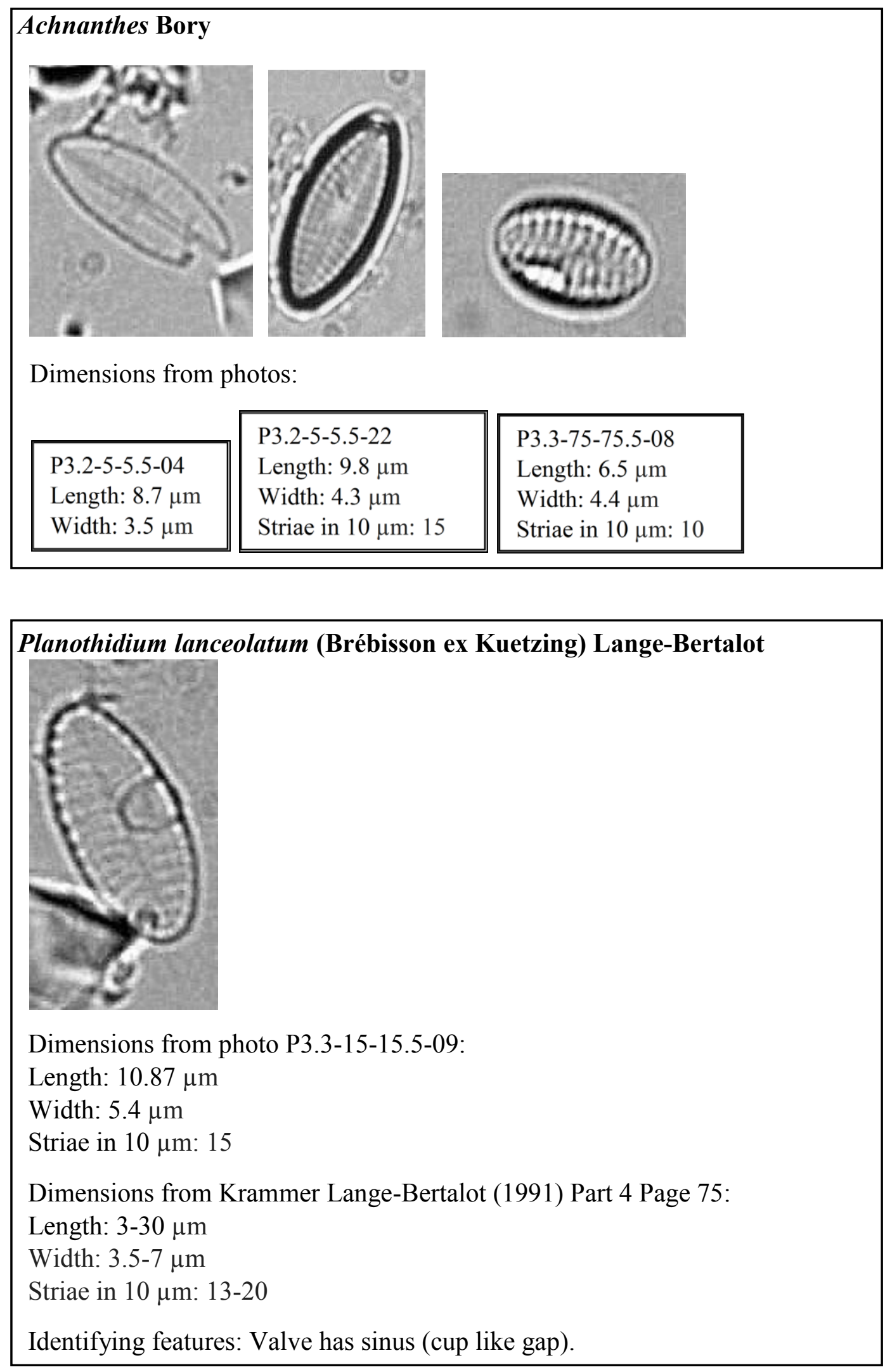


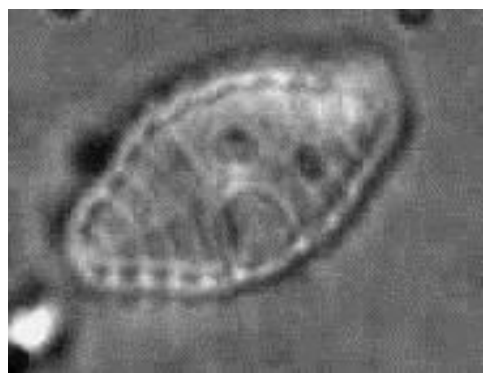

Dimensions from photo P3.1-45-45.4-39:

Length: $10.87 \mu \mathrm{m}$

Width: $5.44 \mu \mathrm{m}$

Striae in $10 \mu \mathrm{m}: 11$

Dimensions from Krammer Lange-Bertalot (1991) Part 4 Page 79 as Achnanthes lanceolatum subsp. Robusta:

Length: $11-24 \mu \mathrm{m}$

Width: 6-9 $\mu \mathrm{m}$

Striae in $10 \mu \mathrm{m}: 8-12$

Identifying features: Valve has sinus (cup like gap), fewer striae than Planothidium lanceolatum.

\section{Cocconeis placentula Ehrenberg}

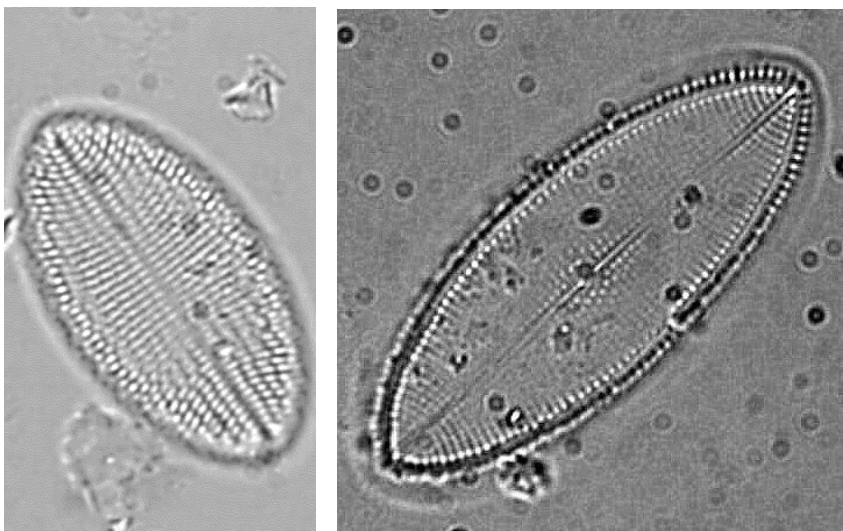

Dimensions from photos:

P3.1-45-45.5-06

Rapheless valve

Length: $22.83 \mu \mathrm{m}$

Width: $11.96 \mu \mathrm{m}$

Striae in 10 um: 22
P3.1-45-45.5-61

Raphe valve

Length: $32.61 \mu \mathrm{m}$

Width: $17.4 \mu \mathrm{m}$

Striae in 10 um: 21

Dimensions from Krammer Lange-Bertalot (1991) Part 4 Page 86:

Length: $7.5-98 \mu \mathrm{m}$

Width: $8-40 \mu \mathrm{m}$

Striae in $10 \mu \mathrm{m}$ : 14-23 on raphe valve, 13-36 on rapheless valve

Identifying features: Valve elliptic to linear elliptic, areolae visible in striae, striae interrupted on raphe valve by hyaline ring. 
Dimensions from photo P3.1-55-55.5-02:

Length: $9.8 \mu \mathrm{m}$

Width: $6 \mu \mathrm{m}$

Striae in $10 \mu \mathrm{m}: 24$

Dimensions from Krammer Lange-Bertalot (1991) Part 4 Page 91:

Length: $6.5-13 \mu \mathrm{m}$

Width: $4-8.3 \mu \mathrm{m}$

Striae in $10 \mu \mathrm{m}: 16-25$

Identifying features: Valve elliptic to linear elliptic, gap in striae in centre of valve.

\section{NITZCHIOID}

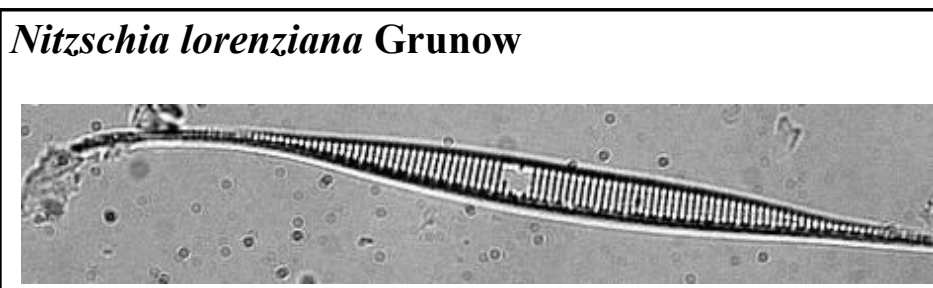

Dimensions from photo P3.1-25-25.5-44:

Length: $>77 \mu \mathrm{m}$

Width: $4.4 \mu \mathrm{m}$

Striae in $10 \mu \mathrm{m}: 18$

Fibulae in $10 \mu \mathrm{m}: 8$

Dimensions from Krammer Lange-Bertalot (1991) Part 2 Page 125:

Length: $37-190 \mu \mathrm{m}$

Width: $3-7 \mu \mathrm{m}$

Striae in $10 \mu \mathrm{m}: 13-19$

Fibulae in $10 \mu \mathrm{m}: 6-10$

Identifying features: Valves linear to lanceolate, long rostrate ends, visible striae. 


\section{Nitzchia amphibia Grunow}

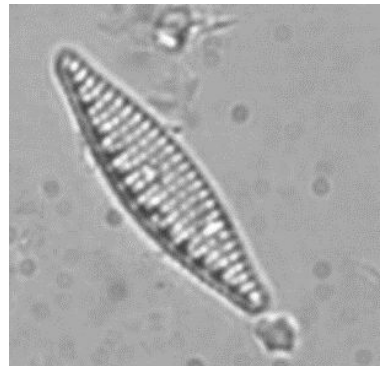

Dimensions from photo P3.1-45-45.5-88:

Length: $17.94 \mu \mathrm{m}$

Width: $4.35 \mu \mathrm{m}$

Striae in $10 \mu \mathrm{m}: 19$

Fibulae in $10 \mu \mathrm{m}: 9$

Dimensions from Krammer Lange-Bertalot (1991) Part 2 Page 108:

Length: 6-50 $\mu \mathrm{m}$

Width: 4-6 $\mu \mathrm{m}$

Striae in $10 \mu \mathrm{m}: 14-18$

Fibulae in $10 \mu \mathrm{m}: 7-9$

Identifying features: Valves linear to lanceolate, areolae visible in striae.

\section{Nitzschia Hassall (hyaline small)}

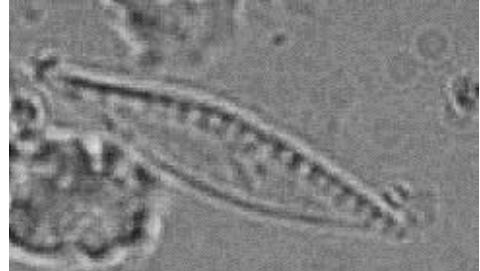

Dimension from photo P3.1-45-45.5-02:

Length: $15.2 \mu \mathrm{m}$

Width: $2.7 \mu \mathrm{m}$

Fibulae in $10 \mu \mathrm{m}: 16$

\section{Nitzchia Hassall (hyaline elongate)}

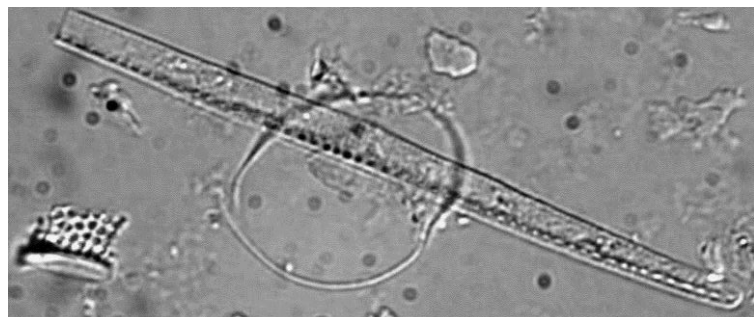

Dimension from photo P3.1-45-45.5-21:

Length: $52 \mu \mathrm{m}$

Width: $2.7 \mu \mathrm{m}$ 


\section{Nitzschia valdestriata Aleem \& Hustedt}

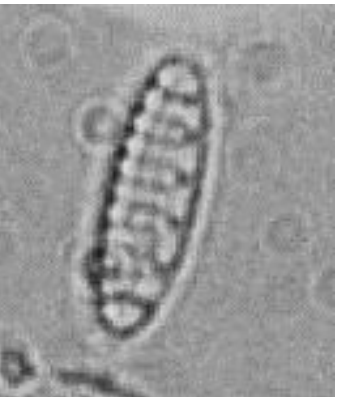

Dimensions from photo P3.1-5-5.5-24:

Length: $7.6 \mu \mathrm{m}$

Width: $2.2 \mu \mathrm{m}$

Fibulae in $10 \mu \mathrm{m}: 8$

Dimensions from Krammer Lange-Bertalot (1991) Part 2 Page 121:

Length: $5-13 \mu \mathrm{m}$

Width: $2.5-3 \mu \mathrm{m}$

Striae in $10 \mu \mathrm{m}: 16-19$

Fibulae in $10 \mu \mathrm{m}: 6-14$

Identifying features: Valves linear to elliptic, small, with large fibulae.

\section{SURIRELLIOD}

\section{Tryblionella levidensis W.Smith}

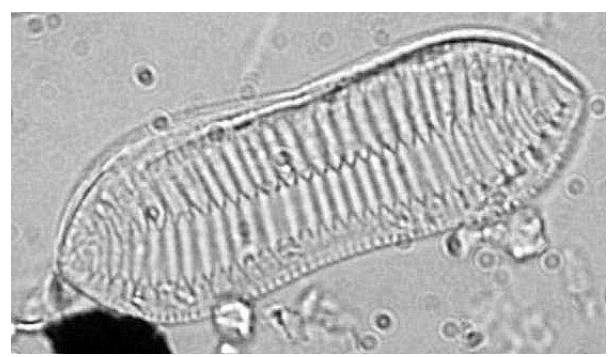

Dimensions from photo P3.1-45-45.4-86:

Length: $34.8 \mu \mathrm{m}$

Width: $10.87 \mu \mathrm{m}$

Fibulae in $10 \mu \mathrm{m}: 14$

Dimensions from Krammer Lange-Bertalot (1991) Part 2 Page 37 as Nitzschia tryblionella var. levidensis:

Length: $18-65 \mu \mathrm{m}$

Width: $8-23 \mu \mathrm{m}$

Striae in $10 \mu \mathrm{m}: 35-36$

Fibulae in $10 \mu \mathrm{m}: 6-12$

Identifying features: Valves constricted at centre, fibulae asymmetric. 


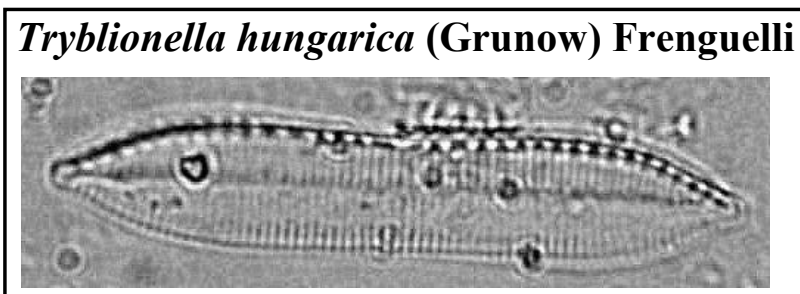

Dimensions from photo P3.1-45-45.4-07:

Length: $33.7 \mu \mathrm{m}$

Width: $5.4 \mu \mathrm{m}$

Striae in $10 \mu \mathrm{m}: 24$

Fibulae in $10 \mu \mathrm{m}: 11$

Dimensions from Krammer Lange-Bertalot (1991) Part 2 Page 42 as Nitzschia hungarica:

Length: $20-130 \mu \mathrm{m}$

Width: 4.5-9 $\mu \mathrm{m}$

Striae in $10 \mu \mathrm{m}: 16-22$

Fibulae in $10 \mu \mathrm{m}: 7-12$

Identifying features: Valves linear, slightly concave in centre, longitudinal fold present.

\section{Surirella cf. bohemica (Maly) Maly ex Schoenfeldt}

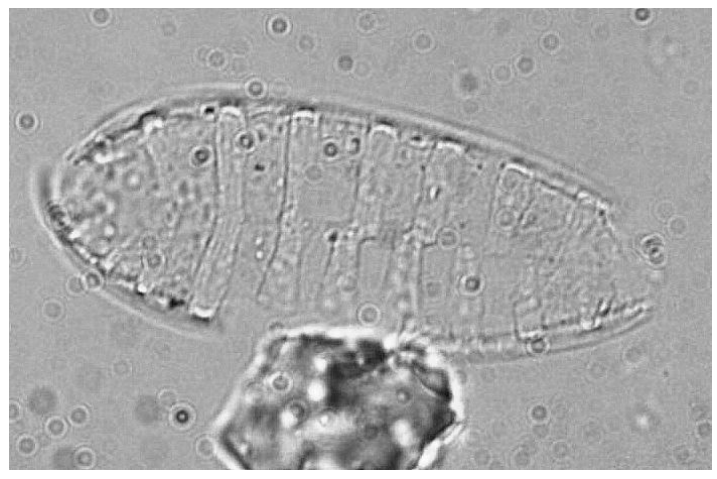

Dimensions from photo P3.1-15-15.5-39:

Length: $42.4 \mu \mathrm{m}$

Width: $15.2 \mu \mathrm{m}$

Fibulae in $100 \mu \mathrm{m}: 30$

Dimensions from Krammer Lange-Bertalot (1991) Part 2 Page 204:

Length: $33-80 \mu \mathrm{m}$

Width: $13-19 \mu \mathrm{m}$

Fibulae in $100 \mu \mathrm{m}: 22-35$

Identifying features: Valves slightly heteropolar, cuneate ends. 


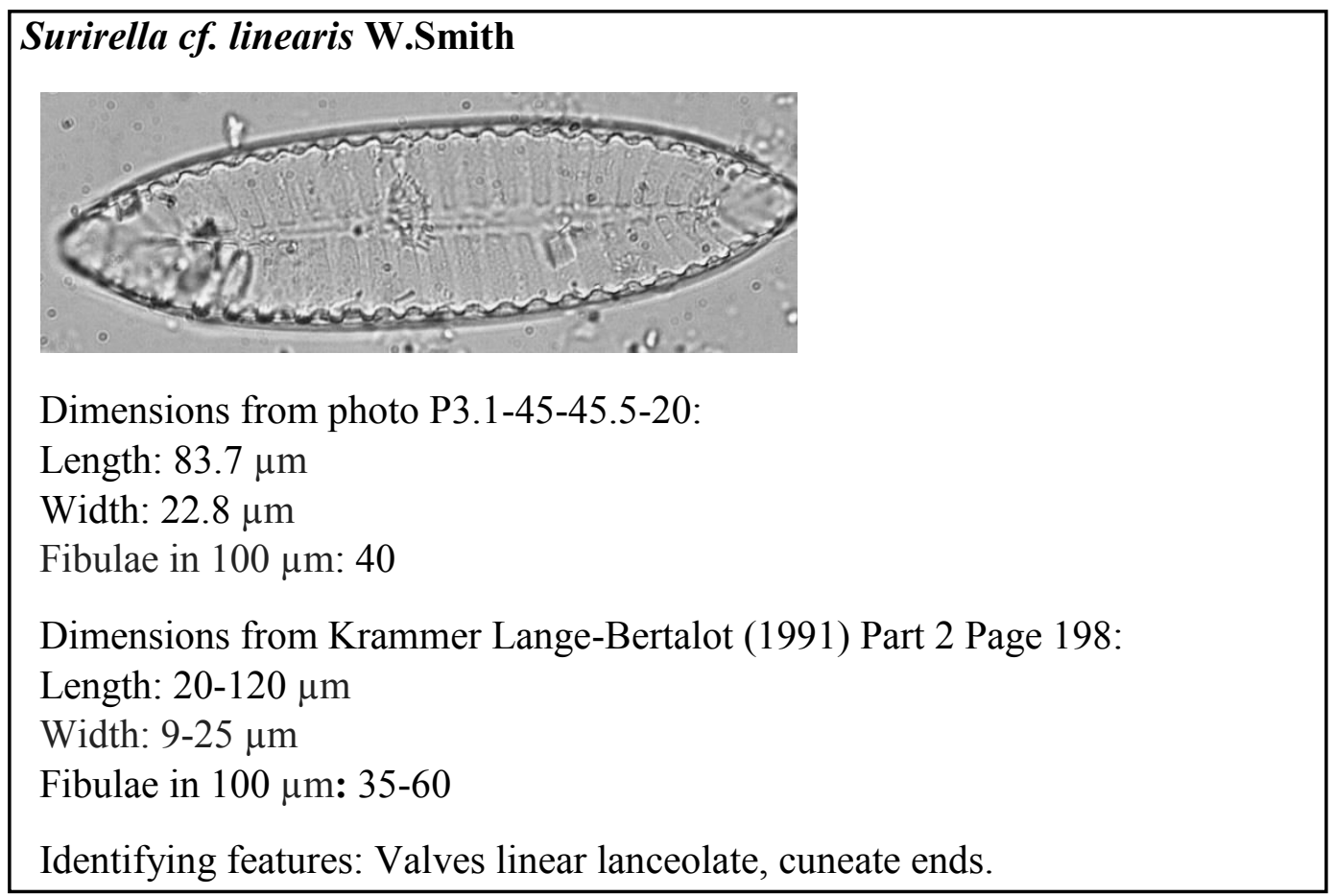

\section{Surirella cf. linearis var. helvetica (Brun) Meister}

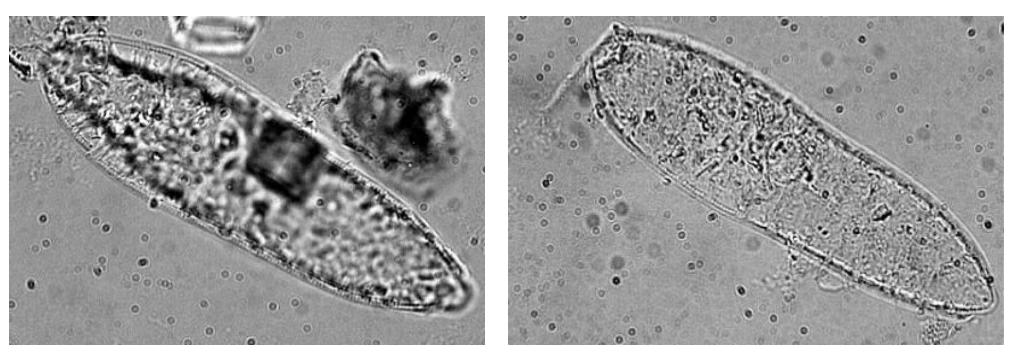

Dimensions from photos:

\begin{tabular}{|l|l|}
\hline P3.2-45-45.5-23 & $\begin{array}{l}\text { P3.2-45-45.5-13 } \\
\text { Length: } 64.1 \mu \mathrm{m} \\
\text { Width: } 17.4 \mu \mathrm{m}\end{array}$ \\
Fibulae in $100 \mu \mathrm{m}: 30$ & $\begin{array}{l}\text { Width: } 64.1 \mu \mathrm{m} \\
\text { Fibulae in } 100 \mu \mathrm{m}: 30\end{array}$ \\
\hline
\end{tabular}

Dimensions from Krammer Lange-Bertalot (1991) Part 2 Page 198:

Length: $20-120 \mu \mathrm{m}$

Width: 9-25 $\mu \mathrm{m}$

Fibulae in $100 \mu \mathrm{m}: 35-60$

Identifying features: Valves heteropolar, slightly concave in centre. 

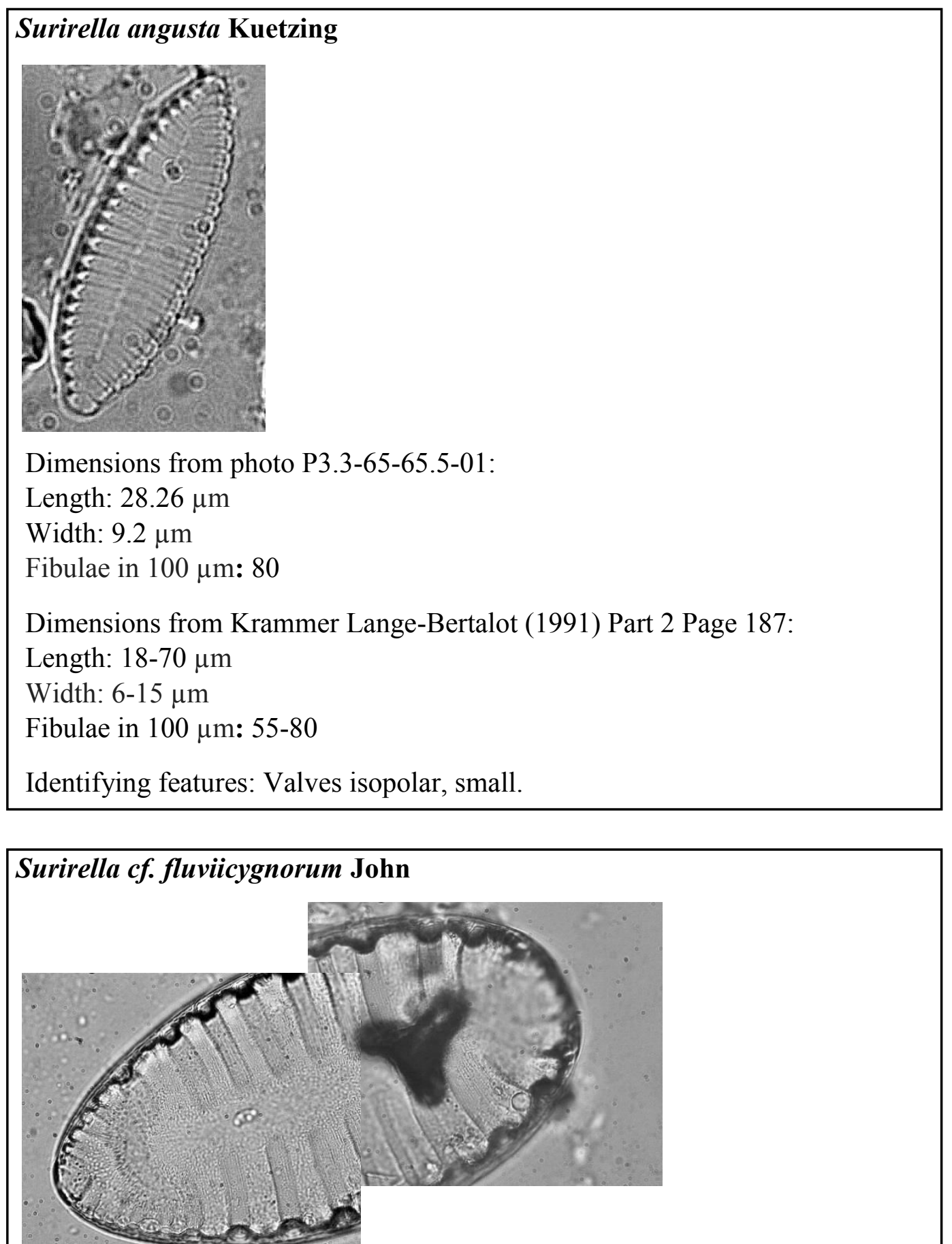

Dimensions from photo P3.2-75-75.5-33:

Length: $135.9 \mu \mathrm{m}$

Width: $>65 \mu \mathrm{m}$

Fibulae in $100 \mu \mathrm{m}: 10$

Dimensions from John (1983):

Length: $60-140 \mu \mathrm{m}$

Width: $34-60 \mu \mathrm{m}$

Fibulae in $100 \mu \mathrm{m}: 12-16$

Identifying features: Valves very large, sparse fibulae. 


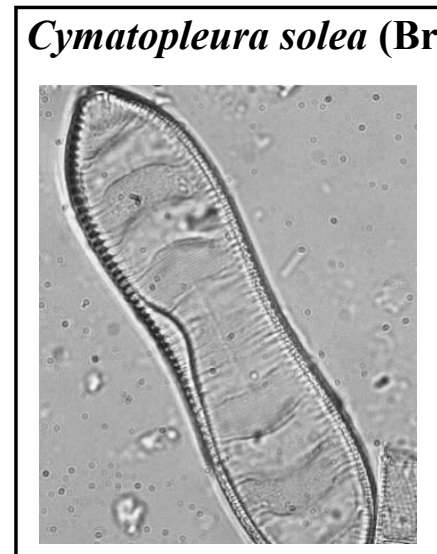

Dimensions from photo P3.3-15-15.5-20:

Length: $>75 \mu \mathrm{m}$

Width: $21.24 \mu \mathrm{m}$

Fibulae in $100 \mu \mathrm{m}: 90$

Dimensions from Krammer Lange-Bertalot (1991) Part 2 Page 168:

Length: $30-300 \mu \mathrm{m}$

Width: $10-45 \mu \mathrm{m}$

Fibulae in $100 \mu \mathrm{m}: 60-90$

Identifying features: Valves linear, constricted in centre, undulation on face.

\section{SYMMETRICAL BIRAPHID}

\section{Brachysira brebissonii R.Ross}

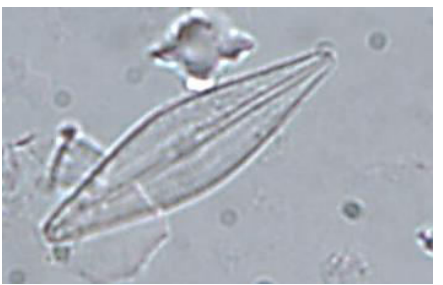

Dimensions from photo P3.1-45-45.5-06:

Length: $18.48 \mu \mathrm{m}$

Width: $4.35 \mu \mathrm{m}$

Striae in $10 \mu \mathrm{m}: 30$

Krammer Lange-Bertalot (1991) Part 1 Page 254 as Anonmoneis brachysira:

Length: $14-47 \mu \mathrm{m}$

Width: 4-10 $\mu \mathrm{m}$

Striae in $10 \mu \mathrm{m}: 26-30$

Identifying features: Very fine 'patchy' looking striae, raphe between two longitudinal ribs, central area oval or circular. 


\section{Caloneis bacillum (Gunrow) Cleve}

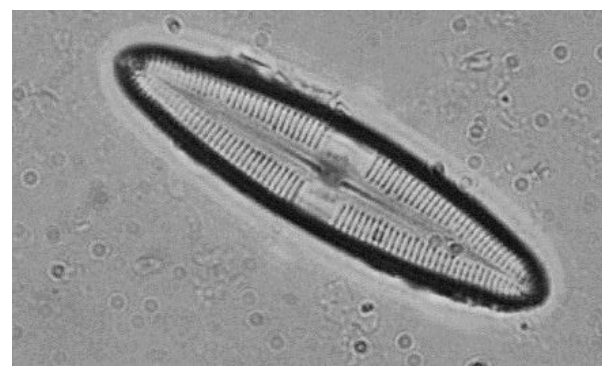

Dimensions from photo P3.1-25-25.5-30:

Length: $35.9 \mu \mathrm{m}$

Width: $8.7 \mu \mathrm{m}$

Striae in $10 \mu \mathrm{m}: 28$

Dimensions from Krammer Lange-Bertalot (1991) Part 1 Page 390:

Length: $15-48 \mu \mathrm{m}$

Width: $4-9 \mu \mathrm{m}$

Striae in $10 \mu \mathrm{m}: 20-30$

Identifying features: Valves linear to lanceolate with central fascia which is usually asymmetric.

\section{Caloneis $c f$. ventricosa (Ehrenberg) F.Meister}

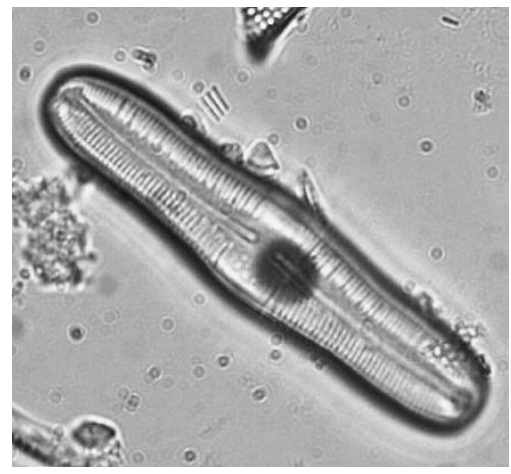

Dimensions from photo P3.1-35-35.5-26:

Length: $47.8 \mu \mathrm{m}$

Width: $10.87 \mu \mathrm{m}$

Striae in $10 \mu \mathrm{m}: 20$

Dimensions from Krammer Lange-Bertalot (1991) Part 1 Page 388 as

Caloneis silicula:

Length: $13-120 \mu \mathrm{m}$

Width: $5-20 \mu \mathrm{m}$

Striae in $10 \mu \mathrm{m}: 15-20$

Identifying features: Valves biconstricted with central fascia which is usually asymmetric. 


\section{Craticula cuspidata (Kuetzing) D.Mann}

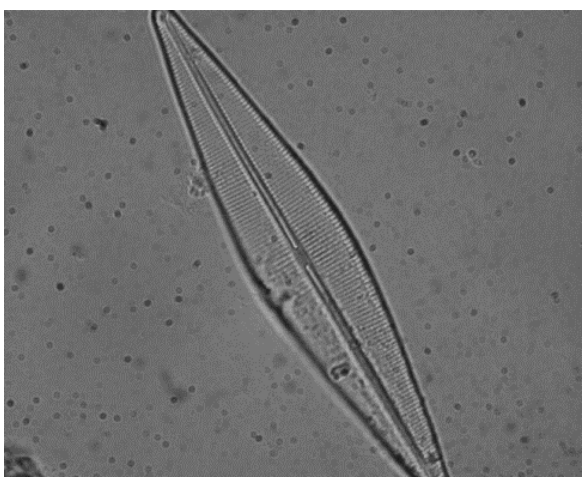

Dimensions from photo P3.2-35-35.5-14:

Length: $150 \mu \mathrm{m}$

Width: $31 \mu \mathrm{m}$

Striae in $10 \mu \mathrm{m}: 14$

Dimensions from Krammer Lange-Bertalot (1991) Part 1 Page 126:

Length: $30-250 \mu \mathrm{m}$

Width: $13-44 \mu \mathrm{m}$

Striae in $10 \mu \mathrm{m}: 11-24$

Identifying features: Valve rhombic to lanceolate with narrow ends. Striae form cross-hatched pattern.

\section{Diploneis subovalis Cleve}

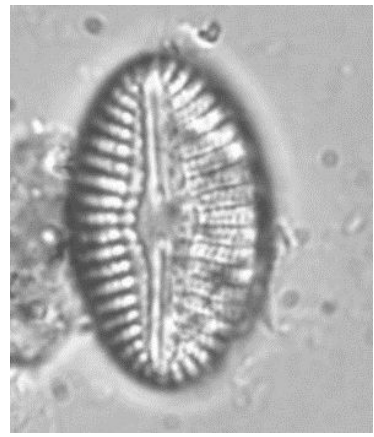

Dimensions from photo P3.1-45-45.5-91:

Length: $18.48 \mu \mathrm{m}$

Width: $10.87 \mu \mathrm{m}$

Striae in $10 \mu \mathrm{m}: 13$

Dimensions from Krammer Lange-Bertalot (1991) Part 1 Page 288:

Length: $10-50 \mu \mathrm{m}$

Width: $8-20 \mu \mathrm{m}$

Striae in $10 \mu \mathrm{m}: 10-12$

Identifying features: Valves elliptic to oval, large circular central area, biseriate except in canals. 

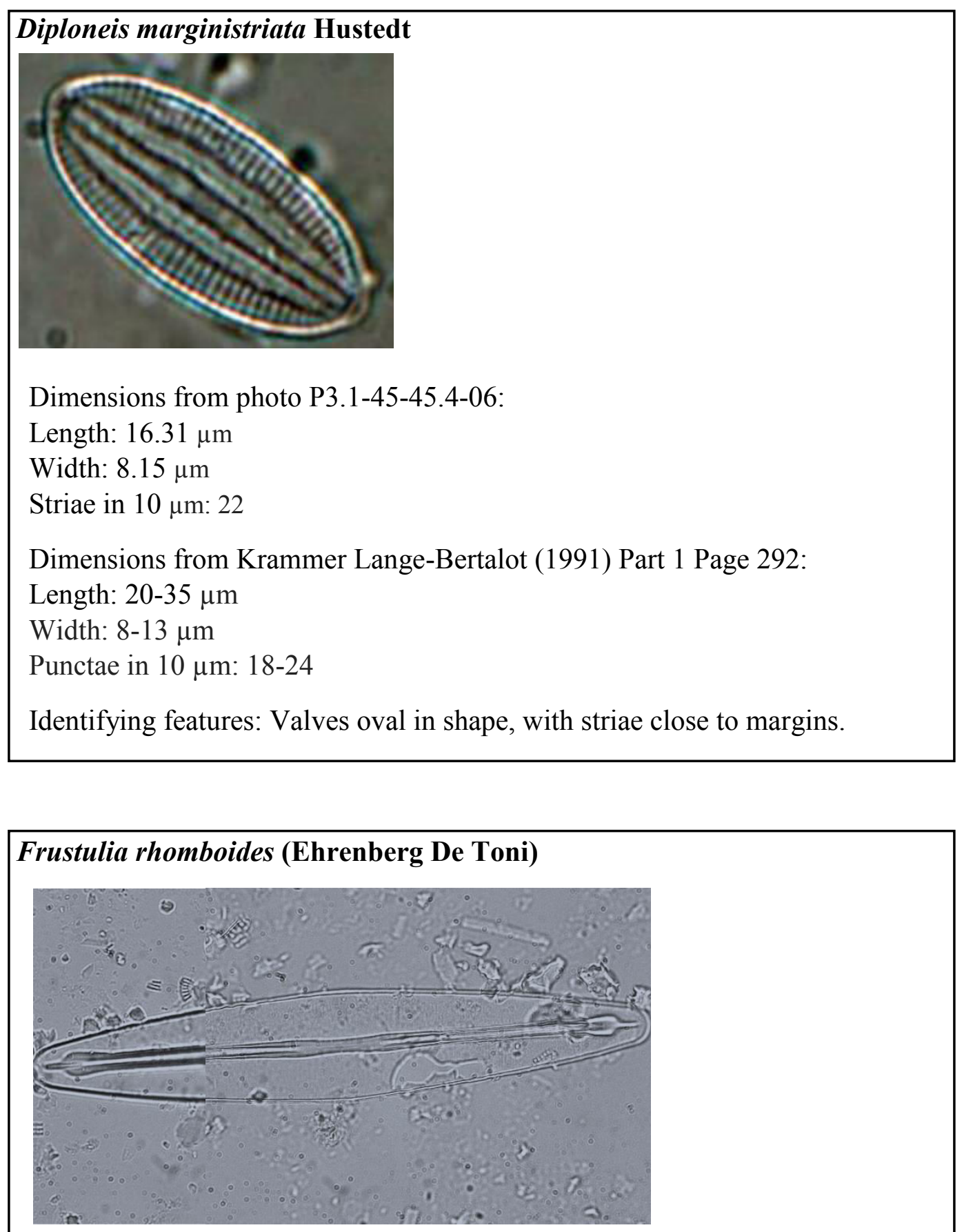

Dimensions from photo P3.1-25-25.5-02:

Length: $119.57 \mu \mathrm{m}$

Width: $21.7 \mu \mathrm{m}$

Dimensions from Krammer Lange-Bertalot (1991) Part 1 Page 259:

Length: $40-160 \mu \mathrm{m}$

Width: 10-30 $\mu \mathrm{m}$

Punctae in $10 \mu \mathrm{m}: 20-28$

Identifying features: Porte-crayon endings, very fine striae. 


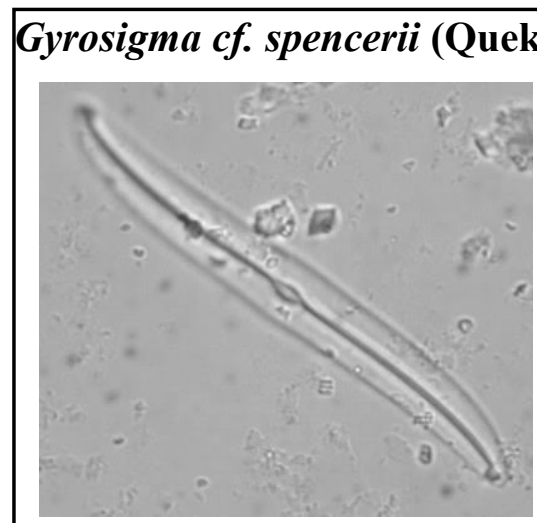

Dimensions from photo P3.1-45-45.5-115:

Length: $110 \mu \mathrm{m}$

Width: $12.5 \mu \mathrm{m}$

Dimensions from Krammer Lange-Bertalot (1991) Part 1 Page 298:

Length: $70-220 \mu \mathrm{m}$

Width: $12-25 \mu \mathrm{m}$

Striae in $10 \mu \mathrm{m}: 17-23$

Identifying features: Very fine striae, ends curving in opposite directions.

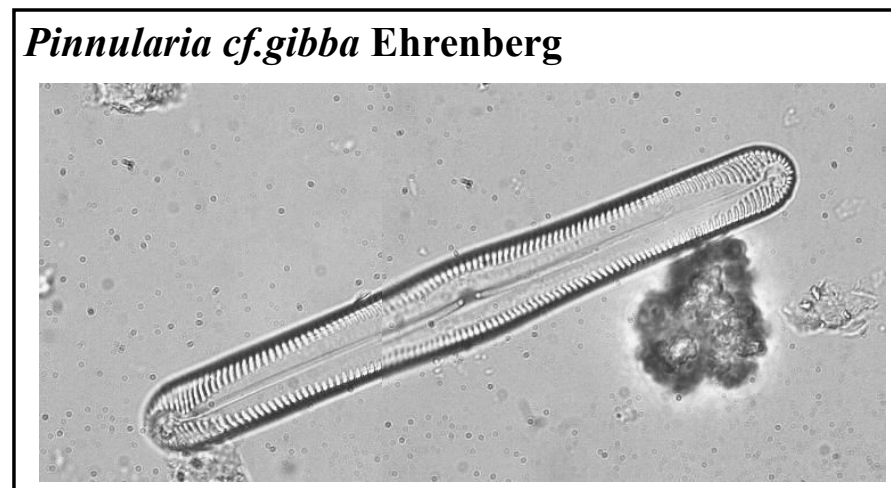

Dimensions from photo P3.3-45-45.5-38:

Length: $120 \mu \mathrm{m}$

Width: $15 \mu \mathrm{m}$

Striae in $10 \mu \mathrm{m}: 12$

Dimensions from Krammer Lange-Bertalot (1991) Part 1 Page 423

Length: $50-140 \mu \mathrm{m}$

Width: $7-13 \mu \mathrm{m}$

Striae in $10 \mu \mathrm{m}: 9-12$

Identifying features: Striae radiate to convergent and restricted to margin. 


\section{Pinnularia divergens W.Smith}

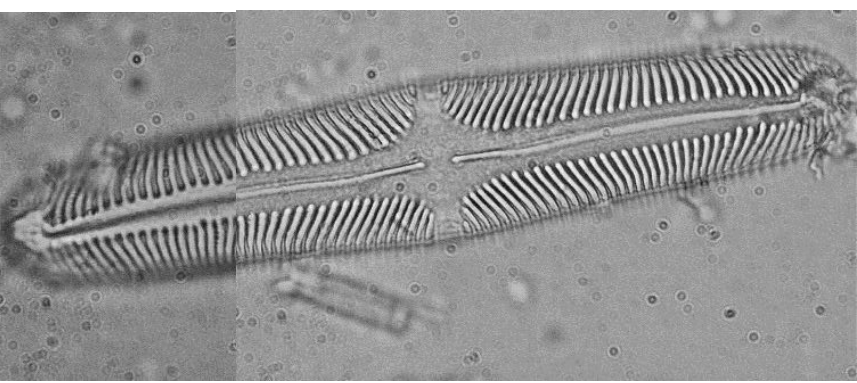

Dimensions from photo P3.1-35-35.5-34:

Length: $94.6 \mu \mathrm{m}$

Width: $18.5 \mu \mathrm{m}$

Striae in $10 \mu \mathrm{m}: 9$

Dimensions from Krammer Lange-Bertalot (1991) Part 1 Page 407:

Length: $50-160 \mu \mathrm{m}$

Width: $13-30 \mu \mathrm{m}$

Striae in $10 \mu \mathrm{m}: 8-12$

Identifying features: Costae radiate to convergent, bayonet raphe ends, lunate thickening in central edges.

\section{Pinnularia cf. interrupta W.Smith}

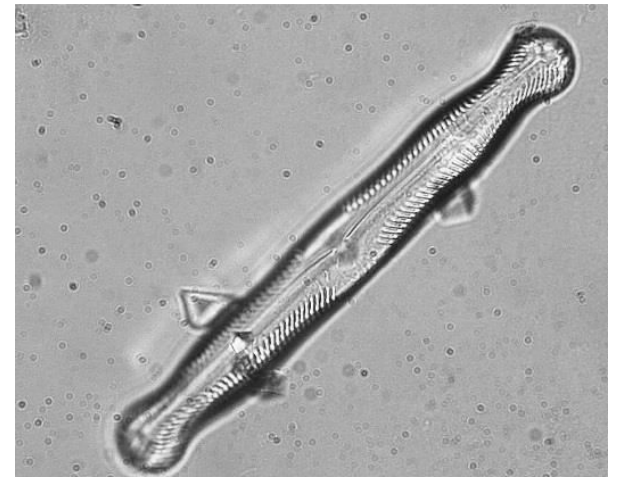

Dimensions from photo P3.2-75-75.5-28:

Length: $89.1 \mu \mathrm{m}$

Width: $12 \mu \mathrm{m}$

Striae in $10 \mu \mathrm{m}: 12$

Dimensions from Krammer Lange-Bertalot (1991) Part 1 Page 424:

Length: $26-80 \mu \mathrm{m}$

Width: 7-11 $\mu \mathrm{m}$

Striae in $10 \mu \mathrm{m}: 9-15$

Identifying features: Valve has undulating margins with capitate ends and space in central area. 


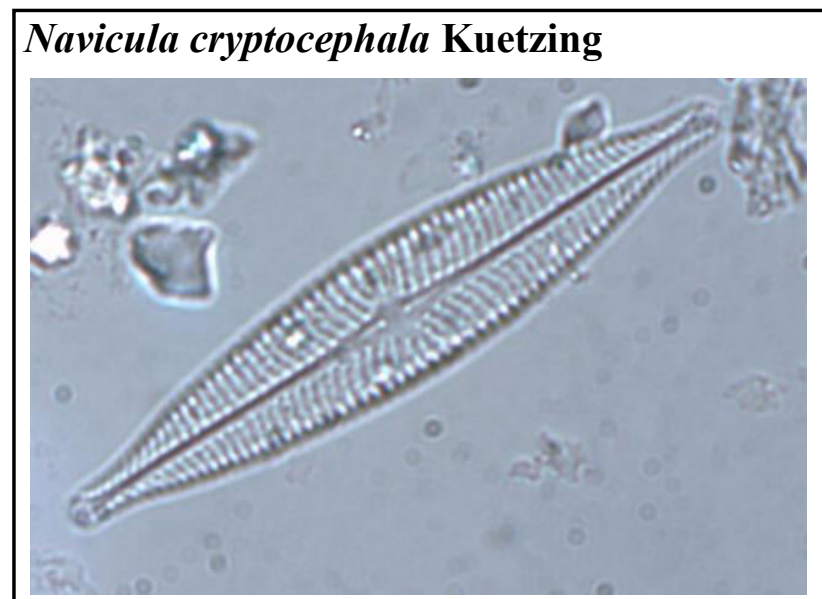

Dimensions from photo P3.1-45-45.5-48:

Length: $41 \mu \mathrm{m}$

Width: $8 \mu \mathrm{m}$

Striae in $10 \mu \mathrm{m}: 14$

Dimensions from Krammer Lange-Bertalot (1991) Part 1 Page 102:

Length: $20-40 \mu \mathrm{m}$

Width: $5.2-7 \mu \mathrm{m}$

Striae in $10 \mu \mathrm{m}: 14-17$

Identifying features: Valves lanceolate with protracted ends. Central area circular.

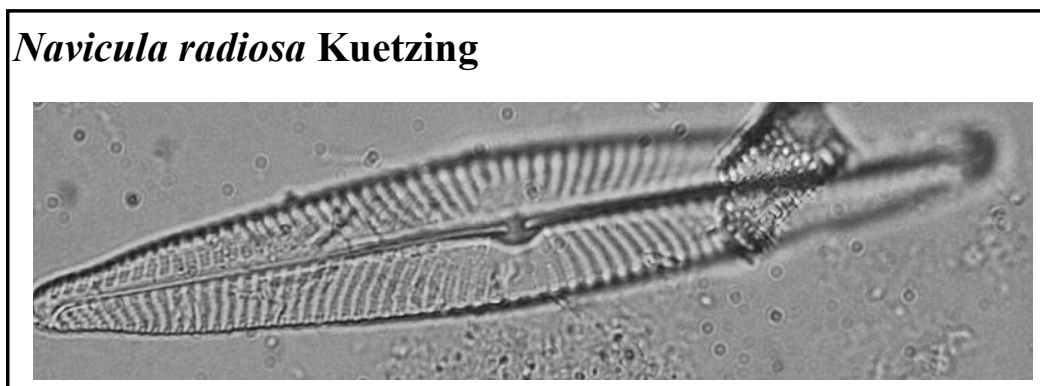

Dimensions from photo P3.1-25-25.5-21:

Length: $83 \mu \mathrm{m}$

Width: $13 \mu \mathrm{m}$

Striae in $10 \mu \mathrm{m}: 10$

Dimensions from Krammer Lange-Bertalot (1991) Part 1 Page 99:

Length: $40-120 \mu \mathrm{m}$

Width: $7.5-19 \mu \mathrm{m}$

Striae in $10 \mu \mathrm{m}: 10-12$

Identifying features: Valves lanceolate with radiate striae near centre and convergent striae near pole, circular central area. 


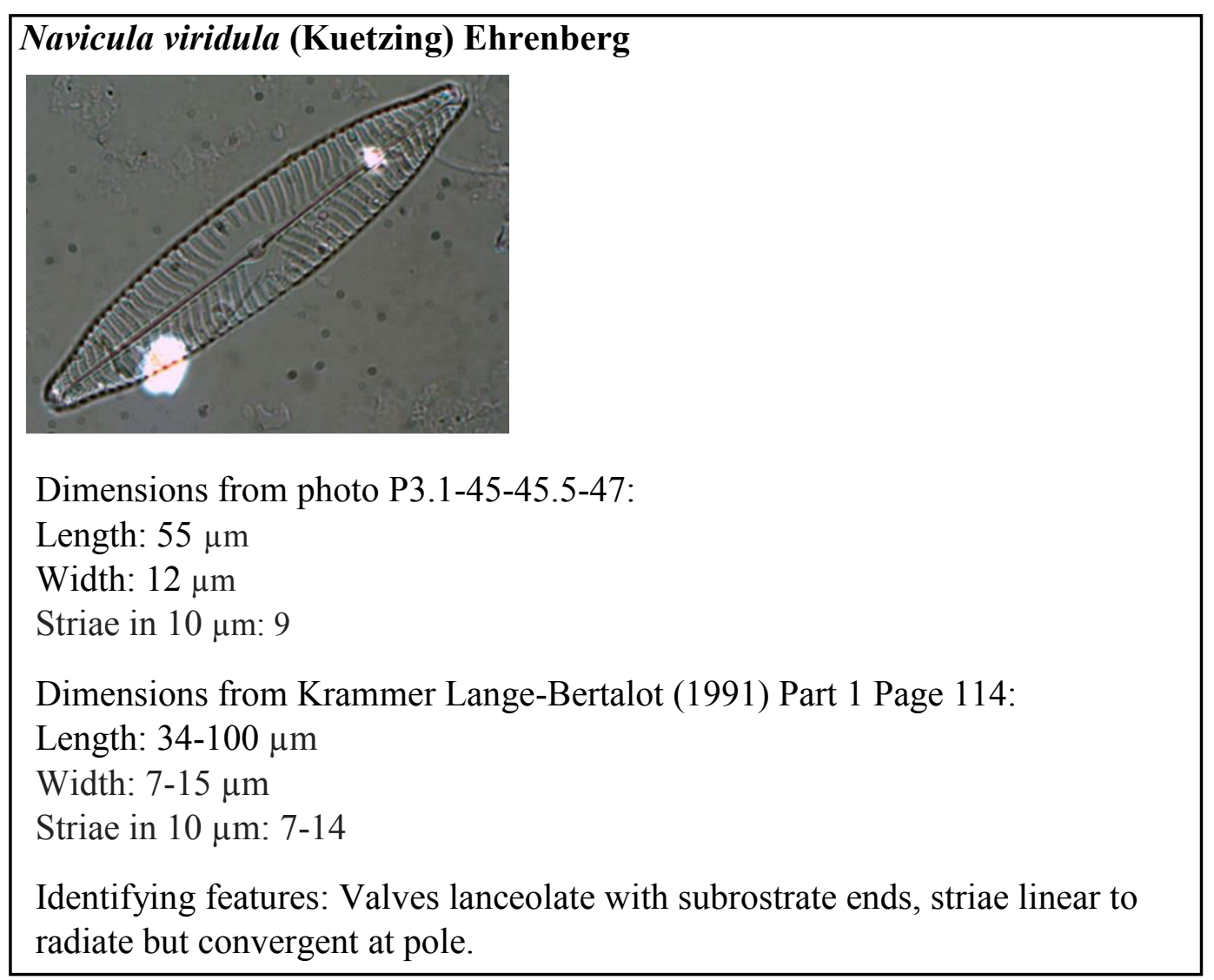

\section{Cavinula pseudoscutiformis (Hustedt) Mann \& Stickle}

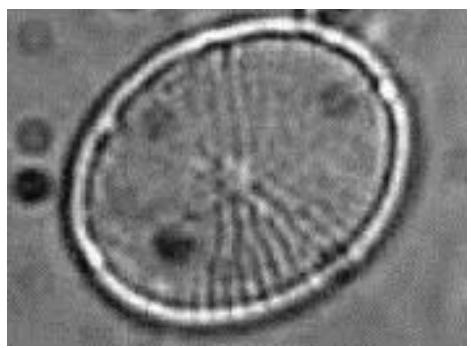

Dimensions from photo P3.1-45-45.5-36:

Length: $10 \mu \mathrm{m}$

Width: $8 \mu \mathrm{m}$

Striae in $10 \mu \mathrm{m}: 24$

Dimensions from Krammer Lange-Bertalot (1991) Part 1 Page 159 as

Navicula pseudoscutiformis:

Length: $3.5-25 \mu \mathrm{m}$

Width: $3-17 \mu \mathrm{m}$

Striae in $10 \mu \mathrm{m}: 20-26$

Identifying features: Valve round, radiate striae. 


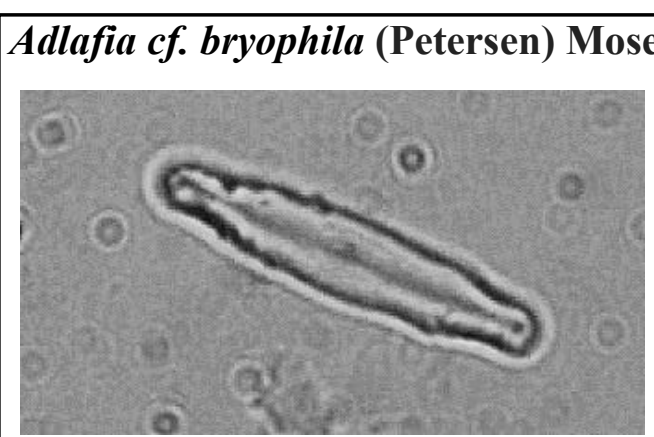

Dimensions from photo P3.1-35-35.5-29:

Length: $15.2 \mu \mathrm{m}$

Width: $3.3 \mu \mathrm{m}$

Dimensions from Krammer Lange-Bertalot (1991) Part 1 Page 181 as Navicula bryophila:

Length: $10-25 \mu \mathrm{m}$

Width: $2.5-4 \mu \mathrm{m}$

Striae in $10 \mu \mathrm{m}: 24-36$

Identifying features: Small valve, very fine striae.

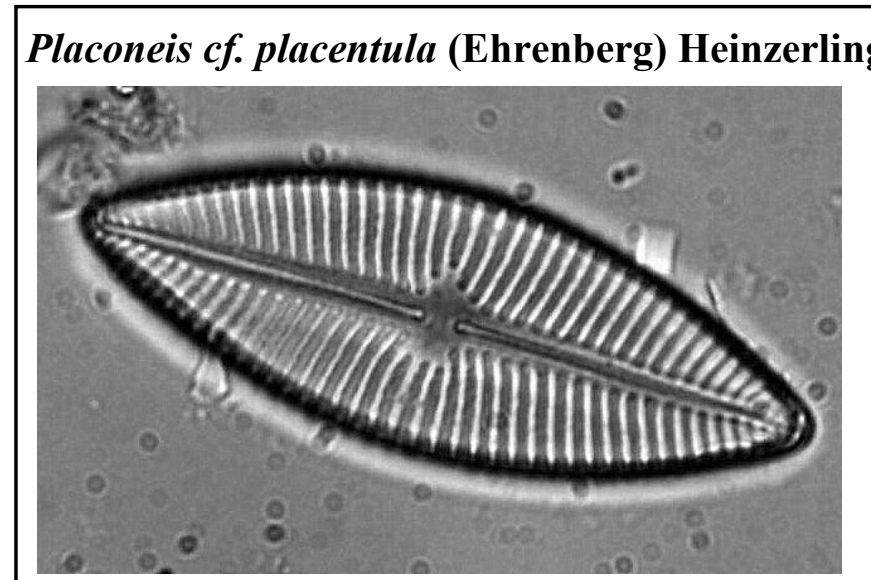

Dimensions from photo P2.1-0-0.5-14:

Length: $40 \mu \mathrm{m}$

Width: $14 \mu \mathrm{m}$

Striae in $10 \mu \mathrm{m}: 12$

Dimensions from Krammer Lange-Bertalot (1991) Part 1 Page 145 as Navicula placentula:

Length: $30-70 \mu \mathrm{m}$

Width: $12-28 \mu \mathrm{m}$

Striae in $10 \mu \mathrm{m}: 9-12$

Identifying features: Valve lanceolate, striae biseriate, thick edge. 
Humidophila contenta (Gunrow) Lowe et al.
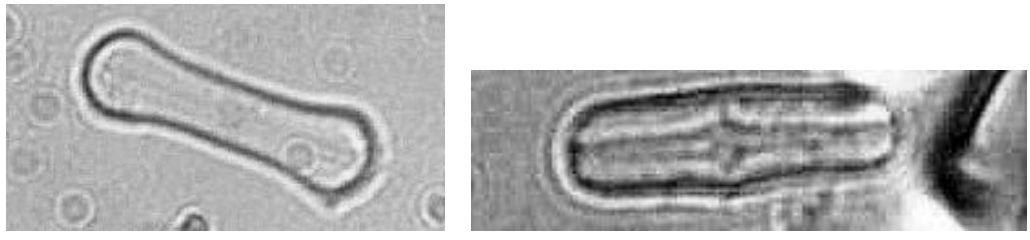

Dimensions from photos:

P3.1-75-75.5-03

Length: $12 \mu \mathrm{m}$

P3.1-75-75.5-05

Width: $2 \mu \mathrm{m}$ Length: $8 \mu \mathrm{m}$

Width: $2 \mu \mathrm{m}$

Dimensions from Krammer Lange-Bertalot (1991) Part 1 Page 219 as

Navicula contenta:

Length: $4-30 \mu \mathrm{m}$

Width: $2-6 \mu \mathrm{m}$

Striae in $10 \mu \mathrm{m}: 25-40$

Identifying features: Bow-tie shape.

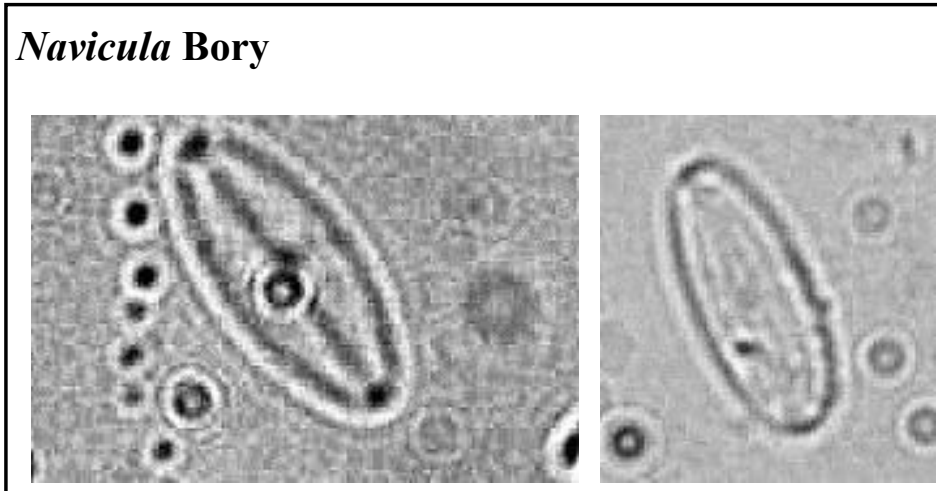

Dimensions from photos:

P3.3-85-75.5-13

Length: $8 \mu \mathrm{m}$

P3.1-75-75.5-10

Width: $2 \mu \mathrm{m}$

Length: $8 \mu \mathrm{m}$

Width: $3 \mu \mathrm{m}$ 


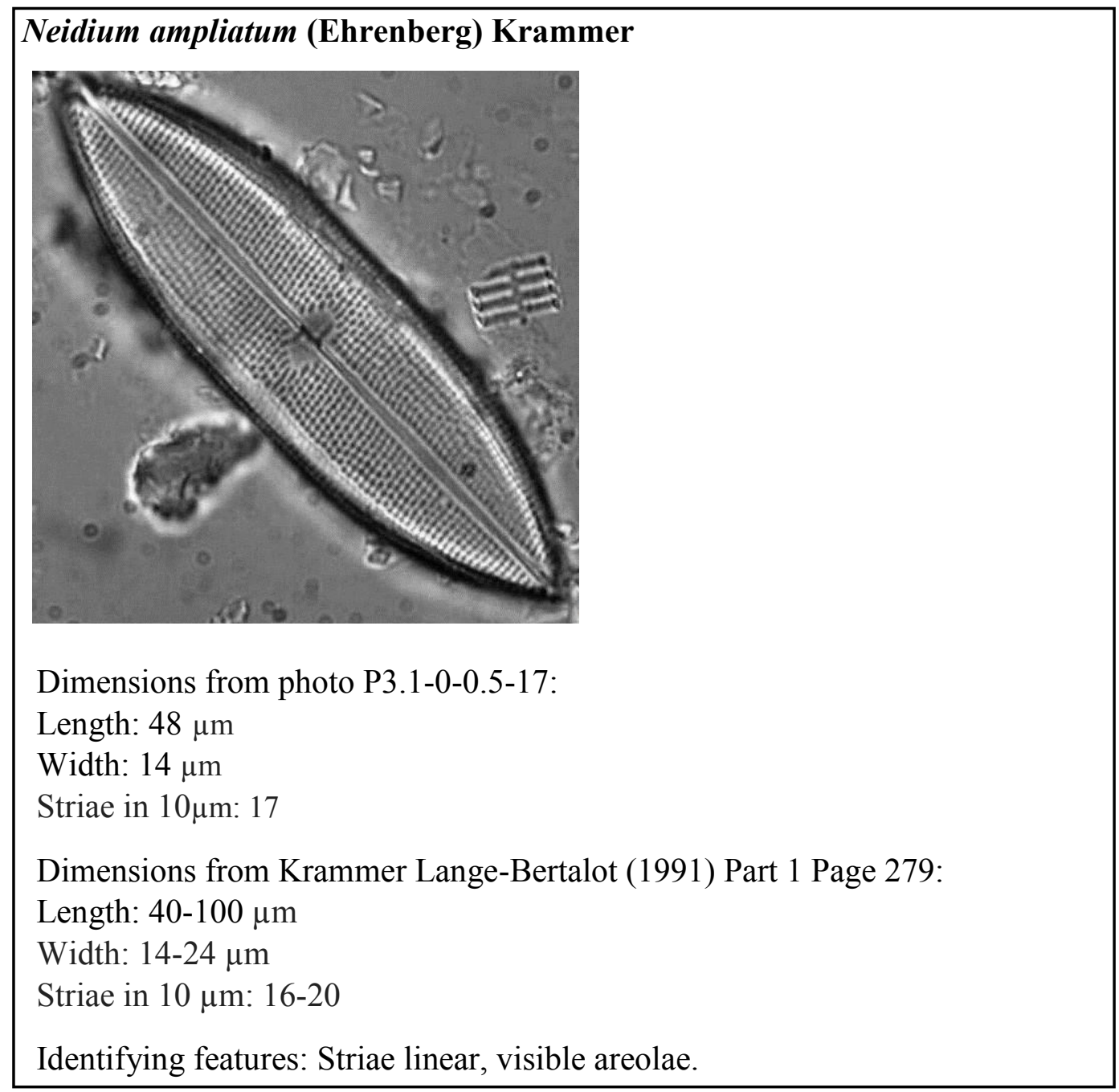

Sellaphora cf. seminulum (Grunrow) D.G.Mann

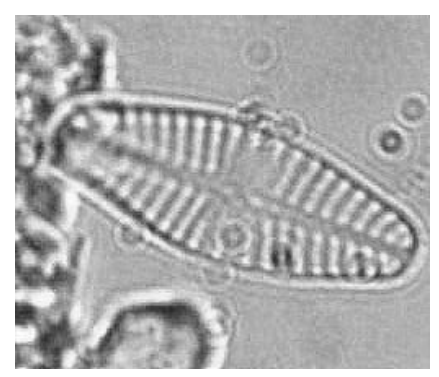

Dimensions from photo P3.3-65-65.5-05:

Length: $8 \mu \mathrm{m}$

Width: $3 \mu \mathrm{m}$

Striae in $10 \mu \mathrm{m}: 22$

Dimensions from Krammer Lange-Bertalot (1991) Part 1 Page 230 as Navicula seminulum:

Length: 3-21 $\mu \mathrm{m}$

Width: $2-5 \mu \mathrm{m}$

Striae in $10 \mu \mathrm{m}: 18-22$

Identifying features: Central area bow-tie shape. 

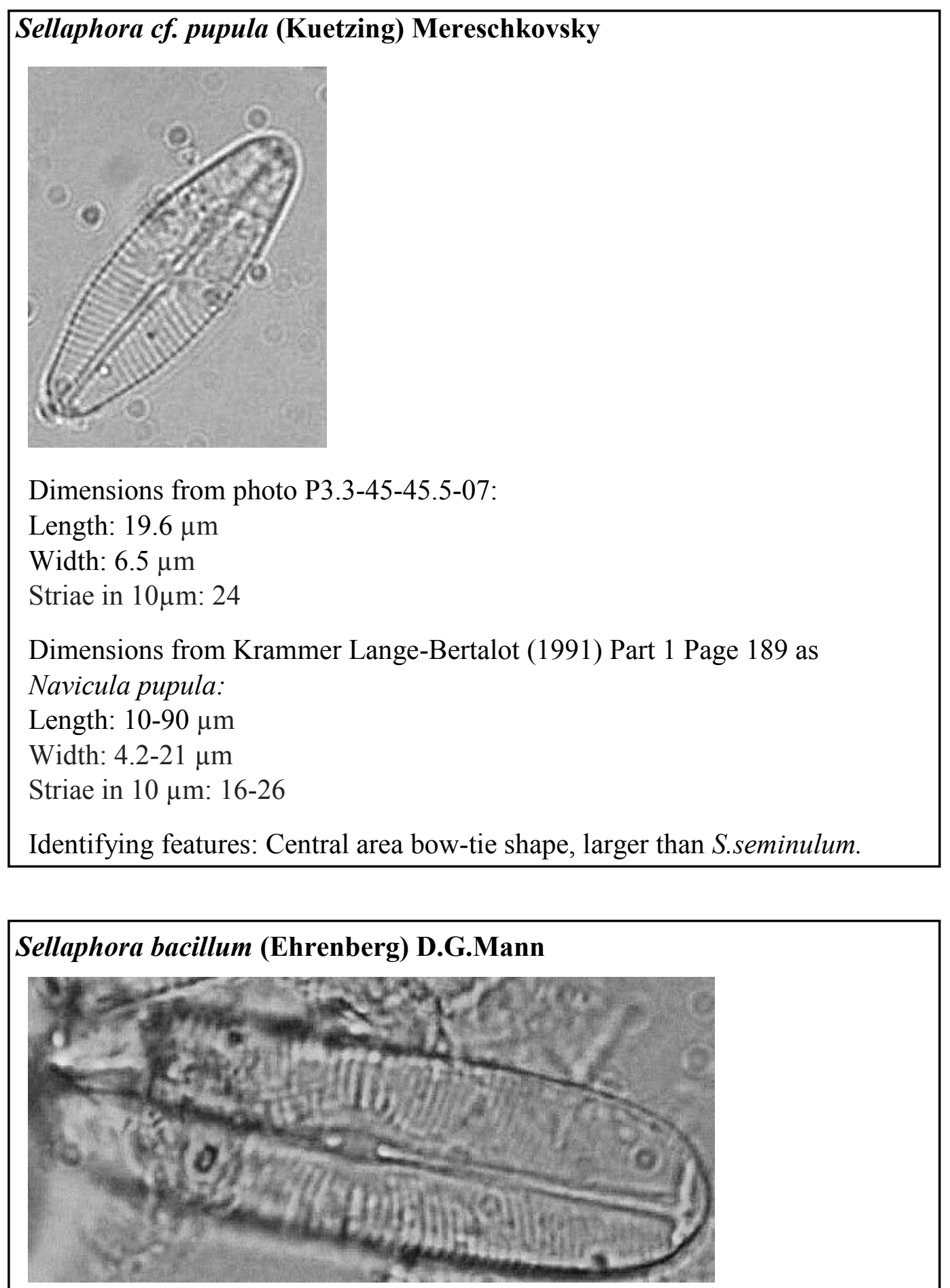

Dimensions from photo P3.1-35-35.5-09:

Length: $30 \mu \mathrm{m}$

Width: $9 \mu \mathrm{m}$

Striae in $10 \mu \mathrm{m}: 24$

Dimensions from Krammer Lange-Bertalot (1991) Part 1 Page 187 as

Navicula bacillum:

Length: $30-45 \mu \mathrm{m}$

Width: $10-20 \mu \mathrm{m}$

Striae in $10 \mu \mathrm{m}$ : 12-16 in centre, 22-24 distal

Identifying features: Linear valve, broadly rounded ends, elliptical centre. 
Sellaphora aff. pseudoventralis (Hustedt) Chudaev \& Gololobova

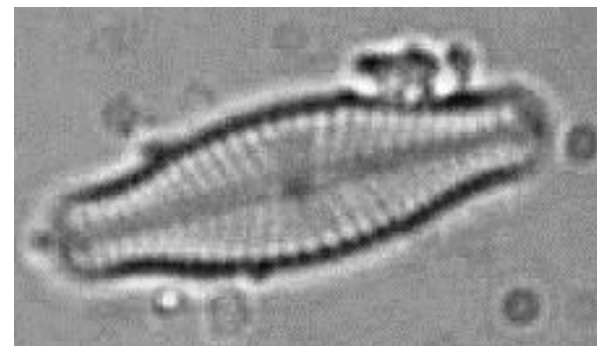

Dimensions from photo P3.1-0-0.5-10:

Length: $14 \mu \mathrm{m}$

Width: $5 \mu \mathrm{m}$

Striae in $10 \mu \mathrm{m}: 19$

Dimensions from Krammer Lange-Bertalot (1991) Part 1 Page 198 as Navicula pseudoventralis:

Length: $8-15 \mu \mathrm{m}$

Width: $4-5 \mu \mathrm{m}$

Striae in $10 \mu \mathrm{m}: 18-20$

Identifying features: Broad rostrate ends.

\section{Stauroneis phoenicenteron (Nitzsch) Ehrenberg}

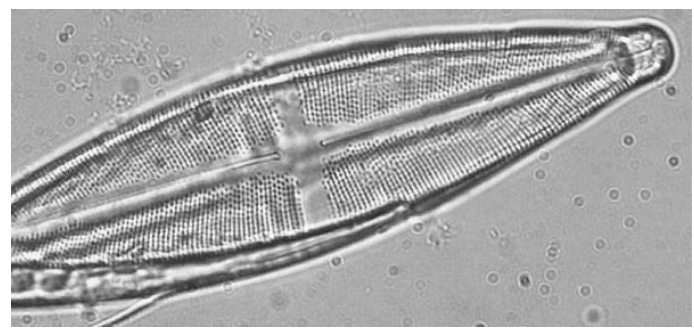

Dimensions from photo P3.3-55-55.5-03:

Length: $80 \mu \mathrm{m}$

Width: $20 \mu \mathrm{m}$

Striae in $10 \mu \mathrm{m}: 11$

Punctae in $10 \mu \mathrm{m}: 20$

Dimensions from Krammer Lange-Bertalot (1991) Part 1 Page 239:

Length: $70-360 \mu \mathrm{m}$

Width: $16-53 \mu \mathrm{m}$

Striae in $10 \mu \mathrm{m}: 12-20$

Punctae in $10 \mu \mathrm{m}: 12-21$

Identifying features: Cross in central area, visible punctae. 


Stauroneis cf. anceps Ehrenberg
Dimensions from photo P3.3-55-55.5-03:
Length: $55 \mu \mathrm{m}$
Width: $10 \mu \mathrm{m}$
Striae in $10 \mu \mathrm{m}: 20$
Dimensions from Krammer Lange-Bertalot (1991) Part 1 Page 240:
Length: $20-130 \mu \mathrm{m}$
Width: $6-18 \mu \mathrm{m}$
Striae in $10 \mu \mathrm{m}: 20-33$
Punctae in $10 \mu \mathrm{m}: 23-35$
Identifying features: Cross in central area.




\section{Diatom ecological and habitat preferences}

\section{Diatom ecological preferences (van Dam et al., 1994)}

\begin{tabular}{|r|l|l|}
\hline \multicolumn{2}{|c|}{$\mathrm{pH}$} \\
\hline 1 & acidobionitic & optimal occurrence at $\mathrm{pH}<5.5$ \\
\hline 2 & acidophilous & mainly occurring at $\mathrm{pH}<7$ \\
\hline 3 & circumneutral & mainly occurring at $\mathrm{pH}$-values about 7 \\
\hline 4 & alkaliphilious & mainly occurring at $\mathrm{pH}>7$ \\
\hline 5 & alkalibiontic & exclusively occurring at $\mathrm{pH}>7$ \\
\hline 6 & indifferent & no apparent optimum \\
\hline 7 & unknown & \\
\hline
\end{tabular}

\begin{tabular}{|r|l|r|r|}
\hline \multicolumn{3}{|c|}{ Salinity } \\
\hline 1 & fresh & \multicolumn{1}{|c|}{$\mathrm{Cl}^{-}\left(\mathrm{mg} \mathrm{l}^{-1}\right)$} & Salinity (\%o) \\
\hline 2 & fresh brackish & $<100$ & $<0.2$ \\
\hline 3 & brackish fresh & $500-1000$ & $<0.9$ \\
\hline 4 & brackish fresh & $1000-5000$ & $1.8-9.0$ \\
\hline 5 & unknown & & \\
\hline
\end{tabular}

\begin{tabular}{|r|l|}
\hline \multicolumn{2}{|c|}{ Nitrogen uptake metabolism } \\
\hline 1 & $\begin{array}{l}\text { nitrogen-autotrohic taxa, tolerating very small concentration of organically } \\
\text { bound nitrogen }\end{array}$ \\
\hline 2 & $\begin{array}{l}\text { nitrogen-autotrophic taxa, tolerating elevated concentrations of organically } \\
\text { bound nitrogen }\end{array}$ \\
\hline 3 & $\begin{array}{l}\text { facultatively nitrogen-heterotrophic taxa, needing periodically elevated } \\
\text { concentrations of organically bound nitrogen }\end{array}$ \\
\hline 4 & $\begin{array}{l}\text { obligatory nitrogen-heterotrphic taxa, needing continuously elevated } \\
\text { concentrations of organically bound nitrogen }\end{array}$ \\
\hline 5 & unknown \\
\hline
\end{tabular}

\section{Oxygen Requirements}

\begin{tabular}{|r|l|}
\hline 1 & continuously high (about 100\% saturation) \\
\hline 2 & fairly high (above $75 \%$ saturation) \\
\hline 3 & moderate (above $50 \%$ saturation) \\
\hline 4 & low (above $30 \%$ saturation) \\
\hline 5 & very low (about 10\% saturation) \\
\hline 6 & unknown \\
\hline
\end{tabular}

\begin{tabular}{|r|l|r|r|}
\hline \multicolumn{3}{|c|}{ Saprobity (S) } \\
\hline 1 & oligosaprobous & Oxygen saturation (\%) & BOD $^{20}\left(\mathrm{mg} \mathrm{I}^{-1}\right)$ \\
\hline 2 & $\beta$-mesosaprobous & $70-85$ & $<2$ \\
\hline 3 & $\alpha$-mesosaprobous & $25-70$ & $2-4$ \\
\hline 4 & $\begin{array}{l}\alpha \text {-meso- } \\
\text { /polysaprobous }\end{array}$ & $10-25$ & $4-13$ \\
\hline
\end{tabular}




\begin{tabular}{|l|l|r|r|}
5 & polysaprobous & $<10$ & $>22$ \\
\hline 6 & unknown & & \\
\hline
\end{tabular}

\section{Trophic State (T)}

\begin{tabular}{|r|l|}
\hline 1 & oligotraphentic \\
\hline 2 & oligo-mesotraphentic \\
\hline 3 & mesotraphentic \\
\hline 4 & meso-eutraphentic \\
\hline 5 & eutraphentic \\
\hline 6 & hypereutraphentic \\
\hline 7 & oligo- to eutraphentic (hypereutraphentic) \\
\hline 8 & unknown \\
\hline
\end{tabular}

\section{Moisture (M)}

1 never, or only very rarely, occurring outside water bodies

2 mainly occurring in water bodies, sometimes on wet places

3 mainly occurring in water bodies, also regularly on wet and moist places

4 mainly occurring on wet and moist or temporarily dry places

5 near exclusively occurring outside water bodies

6 unknown 
Diatom taxa and ecological preferences from van Dam et al (1994) (numbers relate to table above)

\begin{tabular}{|c|c|c|c|c|c|c|c|}
\hline & $\begin{array}{l}\widetilde{I} \\
\underline{I} \\
\varrho\end{array}$ & 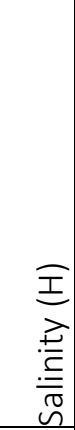 & 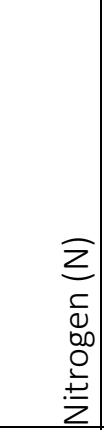 & 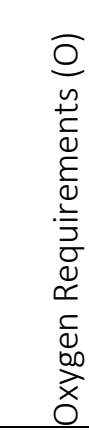 & $\begin{array}{l}\bar{n} \\
\frac{\pi}{0} \\
0 \\
0 \\
\frac{0}{0} \\
0 \\
\\
\end{array}$ & 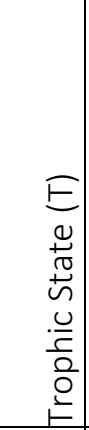 & 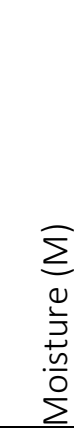 \\
\hline $\begin{array}{l}\text { Aulacoseira ambigua (Grunow) } \\
\text { Simonsen }\end{array}$ & 4 & 2 & 2 & 3 & 2 & 5 & 1 \\
\hline Aulacoseira Thwaites & $\mathrm{n} / \mathrm{a}$ & $n / a$ & $n / a$ & $\mathrm{n} / \mathrm{a}$ & $\mathrm{n} / \mathrm{a}$ & $\mathrm{n} / \mathrm{a}$ & $\mathrm{n} / \mathrm{a}$ \\
\hline $\begin{array}{l}\text { Aulacoseira italica (Ehrenberg) } \\
\text { Simonsen }\end{array}$ & 3 & 2 & 2 & 2 & 2 & 4 & 3 \\
\hline $\begin{array}{l}\text { Aulacoseira granulata var. } \\
\text { angustissima (O. Mueller) Simonsen }\end{array}$ & 4 & 2 & 2 & 3 & 2 & 5 & 1 \\
\hline Actinocyclus octonarius Ehrenberg & $\mathrm{n} / \mathrm{a}$ & 4 & $\mathrm{n} / \mathrm{a}$ & $\mathrm{n} / \mathrm{a}$ & $\mathrm{n} / \mathrm{a}$ & $\mathrm{n} / \mathrm{a}$ & $\mathrm{n} / \mathrm{a}$ \\
\hline $\begin{array}{l}\text { Puncticulata comta (Ehrenberg) } \\
\text { Hakasson D Res }\end{array}$ & 4 & 2 & 1 & 2 & 2 & 5 & 1 \\
\hline $\begin{array}{l}\text { Cyclostephanos dubius (Hustedt) } \\
\text { Round }\end{array}$ & 5 & 3 & 2 & 2 & 3 & 5 & 1 \\
\hline $\begin{array}{l}\text { Discostella stelligera (Cleve \& } \\
\text { Grunow) Houk \& Klee }\end{array}$ & 4 & 2 & $\mathrm{n} / \mathrm{a}$ & $\mathrm{n} / \mathrm{a}$ & $\mathrm{n} / \mathrm{a}$ & 2 & 1 \\
\hline Melosira varians Agardh & 4 & 2 & 3 & 3 & 3 & 5 & 2 \\
\hline Asterionella formosa Hassal & 4 & 2 & 2 & 2 & 2 & 4 & 1 \\
\hline $\begin{array}{l}\text { Pseudostaurosira brevistriata } \\
\text { (Grunow) Williams \& Round }\end{array}$ & 4 & 2 & 1 & 1 & 1 & 7 & 2 \\
\hline $\begin{array}{l}\text { Fragilaria capucina var. vaucheriae } \\
\text { (Kuetzing) Lange-Bertalot }\end{array}$ & 4 & 2 & 2 & 3 & 3 & 5 & 3 \\
\hline $\begin{array}{l}\text { Staurosira construens (Ehrenberg) } \\
\text { Williams \& Round }\end{array}$ & 4 & 2 & 1 & 1 & 2 & 4 & 1 \\
\hline $\begin{array}{l}\text { Staurosira venter (Ehrenberg) Cleve } \\
\text { \& Möller } 1879\end{array}$ & 4 & 2 & 2 & 1 & 2 & 4 & 1 \\
\hline $\begin{array}{l}\text { Pseudostaurosira elliptica } \\
\text { (Schumann) Edlund, Morales \& } \\
\text { Spaulding }\end{array}$ & 4 & 2 & 1 & 1 & 2 & 4 & 1 \\
\hline $\begin{array}{l}\text { Staurosirella pinnata (Ehrenberg) } \\
\text { Williams \& Round }\end{array}$ & 4 & 2 & 2 & 1 & 2 & 7 & 3 \\
\hline $\begin{array}{l}\text { Fragilaria pseudoconstruens } \\
\text { Marciniak }\end{array}$ & 4 & 2 & $\mathrm{n} / \mathrm{a}$ & $\mathrm{n} / \mathrm{a}$ & $\mathrm{n} / \mathrm{a}$ & $\mathrm{n} / \mathrm{a}$ & $\mathrm{n} / \mathrm{a}$ \\
\hline Ulnaria ulna (Nitzsch.) Compère & 4 & 2 & 2 & 3 & 4 & 7 & 2 \\
\hline $\begin{array}{l}\text { Stauroforma exiguiformis (Lange- } \\
\text { Bertalot) Flower }\end{array}$ & 3 & 1 & 1 & 1 & 1 & 2 & 3 \\
\hline Fragilaria Lyngbye & $\mathrm{n} / \mathrm{a}$ & 2 & $\mathrm{n} / \mathrm{a}$ & $\mathrm{n} / \mathrm{a}$ & $\mathrm{n} / \mathrm{a}$ & $\mathrm{n} / \mathrm{a}$ & $\mathrm{n} / \mathrm{a}$ \\
\hline
\end{tabular}




\begin{tabular}{|c|c|c|c|c|c|c|c|}
\hline Meridion circulare (Greville) Agardh & 4 & 2 & 2 & 2 & 2 & 7 & 1 \\
\hline $\begin{array}{l}\text { Staurosirella martyi (Héribaud) } \\
\text { Morales }\end{array}$ & 4 & 2 & n/a & n/a & $\mathrm{n} / \mathrm{a}$ & $\mathrm{n} / \mathrm{a}$ & 2 \\
\hline $\begin{array}{l}\text { Opephora mutabilis (Grunow) Sabbe } \\
\text { \& Vyverman }\end{array}$ & 4 & 3 & $\mathrm{n} / \mathrm{a}$ & $\mathrm{n} / \mathrm{a}$ & $\mathrm{n} / \mathrm{a}$ & $\mathrm{n} / \mathrm{a}$ & 2 \\
\hline Tabularia variostriata M.Harper & 4 & 3 & $\mathrm{n} / \mathrm{a}$ & $\mathrm{n} / \mathrm{a}$ & $\mathrm{n} / \mathrm{a}$ & $\mathrm{n} / \mathrm{a}$ & $\mathrm{n} / \mathrm{a}$ \\
\hline $\begin{array}{l}\text { Amphicampa mirabilis Ehrenberg ex } \\
\text { Ralfs }\end{array}$ & 2 & 2 & $\mathrm{n} / \mathrm{a}$ & $\mathrm{n} / \mathrm{a}$ & $\mathrm{n} / \mathrm{a}$ & 1 & $\mathrm{n} / \mathrm{a}$ \\
\hline Brachysira brebissonii R.Ross & 2 & 1 & 1 & 2 & 1 & 1 & 3 \\
\hline Caloneis bacillum (Grunow) Cleve & 4 & 2 & 1 & 2 & 2 & 4 & 2 \\
\hline $\begin{array}{l}\text { Caloneis ventricosa (Ehrenberg) } \\
\text { F.Meister }\end{array}$ & 4 & 2 & 1 & 2 & 1 & 4 & 1 \\
\hline Craticula cuspidata (Kützing) D.Mann & 4 & 2 & 2 & 3 & 3 & 5 & 1 \\
\hline Diploneis marginistriata Hustedt & 4 & 1 & $\mathrm{n} / \mathrm{a}$ & $\mathrm{n} / \mathrm{a}$ & 1 & $\mathrm{n} / \mathrm{a}$ & $\mathrm{n} / \mathrm{a}$ \\
\hline Diploneis subovalis Cleve & 4 & 2 & $\mathrm{n} / \mathrm{a}$ & $\mathrm{n} / \mathrm{a}$ & $\mathrm{n} / \mathrm{a}$ & $\mathrm{n} / \mathrm{a}$ & $\mathrm{n} / \mathrm{a}$ \\
\hline $\begin{array}{l}\text { Frustulia rhomboides (Ehrenberg) De } \\
\text { Toni }\end{array}$ & 2 & 1 & 1 & 1 & 1 & 1 & 2 \\
\hline $\begin{array}{l}\text { Gyrosigma spencerii (Quekett) } \\
\text { Griffith \& Henfrey }\end{array}$ & 4 & 3 & $\mathrm{n} / \mathrm{a}$ & $\mathrm{n} / \mathrm{a}$ & $\mathrm{n} / \mathrm{a}$ & $\mathrm{n} / \mathrm{a}$ & $\mathrm{n} / \mathrm{a}$ \\
\hline $\begin{array}{l}\text { Adlafia bryophila (Petersen) Moser } \\
\text { Lange-Bertalot \& Metzeltin }\end{array}$ & 3 & 1 & 1 & 1 & 1 & 3 & 5 \\
\hline $\begin{array}{l}\text { Humidophila contenta (Grunow) } \\
\text { Lowe et al. }\end{array}$ & 4 & 2 & 2 & 1 & 2 & 7 & 4 \\
\hline Navicula cryptocephala Kuetzing & 3 & 2 & 2 & 3 & 3 & 7 & 2 \\
\hline $\begin{array}{l}\text { Cavinula pseudoscutiformis (Hustedt) } \\
\text { Mann \& Stickle }\end{array}$ & 4 & 2 & 1 & 2 & 2 & 4 & 3 \\
\hline Navicula radiosa Kuetzing & 3 & 2 & 2 & 2 & 2 & 4 & 3 \\
\hline $\begin{array}{l}\text { Navicula viridula (Kuetzing) } \\
\text { Ehrenberg }\end{array}$ & 4 & 2 & 2 & 2 & 3 & 5 & 1 \\
\hline $\begin{array}{l}\text { Placoneis placentula (Ehrenberg) } \\
\text { Heinzerling }\end{array}$ & 4 & 2 & 2 & 2 & 2 & 5 & 1 \\
\hline Navicula Bory & $\mathrm{n} / \mathrm{a}$ & $\mathrm{n} / \mathrm{a}$ & $\mathrm{n} / \mathrm{a}$ & $\mathrm{n} / \mathrm{a}$ & $\mathrm{n} / \mathrm{a}$ & $\mathrm{n} / \mathrm{a}$ & $\mathrm{n} / \mathrm{a}$ \\
\hline $\begin{array}{l}\text { Neidium ampliatum (Ehrenberg) } \\
\text { Krammer }\end{array}$ & 2 & 1 & $\mathrm{n} / \mathrm{a}$ & $\mathrm{n} / \mathrm{a}$ & 1 & 1 & 3 \\
\hline Pinnularia divergens W.Smith & 3 & 1 & $\mathrm{n} / \mathrm{a}$ & $\mathrm{n} / \mathrm{a}$ & 1 & 1 & 3 \\
\hline Pinnularia gibba Ehrenberg & 3 & 2 & 2 & 3 & 3 & 7 & 2 \\
\hline Pinnularia interrupta W.Smith & 3 & 1 & 1 & 1 & 1 & 2 & 3 \\
\hline $\begin{array}{l}\text { Sellaphora bacillum (Ehrenberg) } \\
\text { D.G.Mann }\end{array}$ & 4 & 2 & 1 & 2 & 2 & 4 & 2 \\
\hline $\begin{array}{l}\text { Sellaphora pseudoventralis (Hustedt) } \\
\text { Chudaev \& Gololobova }\end{array}$ & 4 & 2 & 1 & 1 & 1 & 2 & 3 \\
\hline $\begin{array}{l}\text { Sellaphora pupula (Kuetzing) } \\
\text { Mereschkovsky }\end{array}$ & 3 & 2 & 2 & 3 & 3 & 4 & 2 \\
\hline $\begin{array}{l}\text { Sellaphora seminulum (Grunow) D.G. } \\
\text { Mann }\end{array}$ & 3 & 2 & 3 & 4 & 4 & 5 & 3 \\
\hline Stauroneis anceps Ehrenberg & $\mathrm{n} / \mathrm{a}$ & $\mathrm{n} / \mathrm{a}$ & $\mathrm{n} / \mathrm{a}$ & $\mathrm{n} / \mathrm{a}$ & $\mathrm{n} / \mathrm{a}$ & $\mathrm{n} / \mathrm{a}$ & $\mathrm{n} / \mathrm{a}$ \\
\hline Stauroneis phoenicenteron (Nitzsch) & 3 & 2 & 2 & 3 & 2 & 4 & 2 \\
\hline
\end{tabular}




\begin{tabular}{|c|c|c|c|c|c|c|c|}
\hline Ehrenberg & & & & & & & \\
\hline $\begin{array}{l}\text { Karayevia clevei (Grunow) Round \& } \\
\text { Bukhtiyarova }\end{array}$ & 4 & 2 & 2 & 2 & 2 & 4 & 1 \\
\hline $\begin{array}{l}\text { Karayevia nitidiformis (Lange- } \\
\text { Bertalot) Bukhtiyarova }\end{array}$ & $\mathrm{n} / \mathrm{a}$ & $\mathrm{n} / \mathrm{a}$ & $\mathrm{n} / \mathrm{a}$ & $\mathrm{n} / \mathrm{a}$ & $\mathrm{n} / \mathrm{a}$ & $\mathrm{n} / \mathrm{a}$ & $\mathrm{n} / \mathrm{a}$ \\
\hline $\begin{array}{l}\text { Achnanthidium exiguum (Grunow) } \\
\text { Czarnecki }\end{array}$ & 4 & 2 & 2 & 1 & 2 & 7 & 3 \\
\hline Karayevia oblongella (Oestrup) Aboal & 3 & 2 & 1 & 1 & 1 & 1 & 3 \\
\hline $\begin{array}{l}\text { Achnanthes inflata (Kuetzing) } \\
\text { Grunow }\end{array}$ & $\mathrm{n} / \mathrm{a}$ & 2 & $\mathrm{n} / \mathrm{a}$ & $\mathrm{n} / \mathrm{a}$ & $\mathrm{n} / \mathrm{a}$ & $\mathrm{n} / \mathrm{a}$ & $\mathrm{n} / \mathrm{a}$ \\
\hline Achnanthes Bory & $\mathrm{n} / \mathrm{a}$ & $\mathrm{n} / \mathrm{a}$ & $\mathrm{n} / \mathrm{a}$ & $\mathrm{n} / \mathrm{a}$ & $n / a$ & $\mathrm{n} / \mathrm{a}$ & $\mathrm{n} / \mathrm{a}$ \\
\hline Cocconeis neothumensis Krammer & 5 & 1 & $\mathrm{n} / \mathrm{a}$ & $\mathrm{n} / \mathrm{a}$ & 1 & $\mathrm{n} / \mathrm{a}$ & $\mathrm{n} / \mathrm{a}$ \\
\hline Cocconeis placentula Ehrenberg & 4 & 2 & 2 & 3 & 2 & 5 & 2 \\
\hline $\begin{array}{l}\text { Planothidium } \\
\text { lanceolatum subsp. robusta (Hustedt) } \\
\text { Lange-Bertalot }\end{array}$ & 4 & 2 & 2 & 3 & 4 & 7 & $\mathrm{n} / \mathrm{a}$ \\
\hline $\begin{array}{l}\text { Planothidium lanceolatum (Brébisson } \\
\text { ex Kuetzing) Lange-Bertalot }\end{array}$ & 4 & 2 & $\mathrm{n} / \mathrm{a}$ & $\mathrm{n} / \mathrm{a}$ & $\mathrm{n} / \mathrm{a}$ & 1 & $\mathrm{n} / \mathrm{a}$ \\
\hline Amphora libyca Ehrenberg & 4 & 2 & $\mathrm{n} / \mathrm{a}$ & $\mathrm{n} / \mathrm{a}$ & $n / a$ & $\mathrm{n} / \mathrm{a}$ & $\mathrm{n} / \mathrm{a}$ \\
\hline $\begin{array}{l}\text { Halamphora cf. oligotraphenta } \\
\text { (Lange-Bertalot) Levkov }\end{array}$ & $\mathrm{n} / \mathrm{a}$ & $\mathrm{n} / \mathrm{a}$ & $\mathrm{n} / \mathrm{a}$ & $\mathrm{n} / \mathrm{a}$ & $\mathrm{n} / \mathrm{a}$ & $\mathrm{n} / \mathrm{a}$ & $\mathrm{n} / \mathrm{a}$ \\
\hline $\begin{array}{l}\text { Cymbella aspera (Ehrenberg) } \\
\text { Peragallo }\end{array}$ & 4 & 2 & 1 & 1 & 1 & 7 & $\mathrm{n} / \mathrm{a}$ \\
\hline Cymbella novazeelandiana Krammer & 4 & 2 & $\mathrm{n} / \mathrm{a}$ & $\mathrm{n} / \mathrm{a}$ & $n / a$ & $\mathrm{n} / \mathrm{a}$ & $\mathrm{n} / \mathrm{a}$ \\
\hline Cymbella parva (W.Smith) Kirchner & 3 & 2 & 1 & 1 & 1 & 2 & 2 \\
\hline $\begin{array}{l}\text { Encyonema silesiacum (Bleisch) } \\
\text { D.Mann }\end{array}$ & 3 & 2 & 2 & 3 & 3 & 7 & 1 \\
\hline $\begin{array}{l}\text { Cymbella tumida (Brébisson) Van } \\
\text { Heurck }\end{array}$ & 4 & 2 & 1 & 1 & 1 & 4 & 1 \\
\hline $\begin{array}{l}\text { Epithemia adnata (Kuetzing) } \\
\text { Brébisson }\end{array}$ & 5 & 2 & 1 & 2 & 2 & 4 & 2 \\
\hline Epithemia sorex Kuetzing & 5 & 2 & 1 & 2 & 2 & 5 & 2 \\
\hline Gomphonema affine Kuetzing & 4 & 2 & 1 & 1 & 2 & 3 & 3 \\
\hline $\begin{array}{l}\text { Gomphonema angustatum } \\
\text { (Kuetzing) Rabenhorst }\end{array}$ & $\mathrm{n} / \mathrm{a}$ & $\mathrm{n} / \mathrm{a}$ & $\mathrm{n} / \mathrm{a}$ & $\mathrm{n} / \mathrm{a}$ & $\mathrm{n} / \mathrm{a}$ & $\mathrm{n} / \mathrm{a}$ & $\mathrm{n} / \mathrm{a}$ \\
\hline Gomphonema augur Ehrenberg & 4 & 2 & 1 & 1 & 2 & 4 & 1 \\
\hline Gomphonema truncatum Ehrenberg & 4 & 2 & 1 & 2 & 2 & 4 & 2 \\
\hline $\begin{array}{l}\text { Rhoicosphenia abbreviata (C.Agardh) } \\
\text { Lange-Bertalot }\end{array}$ & 4 & 2 & 2 & 2 & 2 & 5 & 2 \\
\hline Rhopalodia brebissonii Krammer & 4 & 3 & $\mathrm{n} / \mathrm{a}$ & $\mathrm{n} / \mathrm{a}$ & $\mathrm{n} / \mathrm{a}$ & $\mathrm{n} / \mathrm{a}$ & $\mathrm{n} / \mathrm{a}$ \\
\hline Rhopalodia novae-zelandiae Hustedt & 4 & 2 & $n / a$ & $\mathrm{n} / \mathrm{a}$ & $n / a$ & $\mathrm{n} / \mathrm{a}$ & $\mathrm{n} / \mathrm{a}$ \\
\hline $\begin{array}{l}\text { Rhopalodia rupestris (W.Smith) } \\
\text { Krammer }\end{array}$ & 4 & 2 & $\mathrm{n} / \mathrm{a}$ & $\mathrm{n} / \mathrm{a}$ & $n / a$ & $\mathrm{n} / \mathrm{a}$ & $\mathrm{n} / \mathrm{a}$ \\
\hline Nitzschia amphibia Grunow & 4 & 2 & 3 & 3 & 3 & 5 & 3 \\
\hline $\begin{array}{l}\text { Nitzschia vadestriata Aleem \& } \\
\text { Hustedt }\end{array}$ & 4 & $\mathrm{n} / \mathrm{a}$ & $\mathrm{n} / \mathrm{a}$ & 1 & $\mathrm{n} / \mathrm{a}$ & $\mathrm{n} / \mathrm{a}$ & 4 \\
\hline Tryblionella levidensis W.Smith & 4 & 3 & 2 & 3 & 3 & 5 & 1 \\
\hline
\end{tabular}




\begin{tabular}{|l|r|r|r|r|r|r|r|} 
Nitzschia lorenziana Grunow & 4 & 4 & $\mathrm{n} / \mathrm{a}$ & $\mathrm{n} / \mathrm{a}$ & $\mathrm{n} / \mathrm{a}$ & $\mathrm{n} / \mathrm{a}$ & $\mathrm{n} / \mathrm{a}$ \\
\hline Nitzschia Hassall (hyaline small) & $\mathrm{n} / \mathrm{a}$ & $\mathrm{n} / \mathrm{a}$ & $\mathrm{n} / \mathrm{a}$ & $\mathrm{n} / \mathrm{a}$ & $\mathrm{n} / \mathrm{a}$ & $\mathrm{n} / \mathrm{a}$ & $\mathrm{n} / \mathrm{a}$ \\
\hline Nitzchia Hassall (hyaline elongate) & $\mathrm{n} / \mathrm{a}$ & $\mathrm{n} / \mathrm{a}$ & $\mathrm{n} / \mathrm{a}$ & $\mathrm{n} / \mathrm{a}$ & $\mathrm{n} / \mathrm{a}$ & $\mathrm{n} / \mathrm{a}$ & $\mathrm{n} / \mathrm{a}$ \\
\hline $\begin{array}{l}\text { Tryblionella hungarica (Grunow) } \\
\text { Frenguelli }\end{array}$ & 4 & 3 & 2 & 4 & 3 & 5 & 1 \\
\hline $\begin{array}{l}\text { Cymatopleura solea (Brebisson) } \\
\text { W.Smith }\end{array}$ & 4 & 2 & 2 & 3 & 2 & 5 & 1 \\
\hline Surirella angusta Kuetzing & 4 & 2 & 2 & 2 & 2 & 5 & 3 \\
\hline Surirella fluvicygnorum John & $\mathrm{n} / \mathrm{a}$ & 3 & $\mathrm{n} / \mathrm{a}$ & $\mathrm{n} / \mathrm{a}$ & $\mathrm{n} / \mathrm{a}$ & $\mathrm{n} / \mathrm{a}$ & $\mathrm{n} / \mathrm{a}$ \\
\hline $\begin{array}{l}\text { Surirella cf. bohemica (Maly) Maly ex } \\
\text { Schoenfeldt }\end{array}$ & $\mathrm{n} / \mathrm{a}$ & $\mathrm{n} / \mathrm{a}$ & $\mathrm{n} / \mathrm{a}$ & $\mathrm{n} / \mathrm{a}$ & $\mathrm{n} / \mathrm{a}$ & $\mathrm{n} / \mathrm{a}$ & $\mathrm{n} / \mathrm{a}$ \\
\hline Surirella linearis W.Smith & 3 & 2 & $\mathrm{n} / \mathrm{a}$ & $\mathrm{n} / \mathrm{a}$ & 2 & 2 & 3 \\
\hline $\begin{array}{l}\text { Surirella linearis var. helvetica (Brun) } \\
\text { Meister }\end{array}$ & 3 & 2 & $\mathrm{n} / \mathrm{a}$ & $\mathrm{n} / \mathrm{a}$ & 1 & 1 & 3 \\
\hline
\end{tabular}


Diatom habitat preferences

\begin{tabular}{|c|c|c|}
\hline Species & Habitat & Reference \\
\hline $\begin{array}{l}\text { Adlafia bryophila (Petersen) Moser Lange- } \\
\text { Bertalot \& Metzeltin }\end{array}$ & Soil & van Dam et al. (1994) \\
\hline Caloneis bacillum (Grunow) Cleve & Soil & Johansen (2010) \\
\hline Stauroneis anceps Ehrenberg & Soil & Lund (1946) \\
\hline Sellaphora seminulum (Grunow) D.G.Mann & Soil & Lund (1946) \\
\hline Amphicampa mirabilis Ehrenberg ex Ralfs & Soil & Guiry and Guiry (2016) \\
\hline Caloneis ventricosa (Ehrenberg) F.Meister & Epipelic & Round et al. (1990) \\
\hline $\begin{array}{l}\text { Cavinula pseudoscutiformis (Hustedt) Mann } \\
\text { \& Stickle }\end{array}$ & Epipelic & Round et al. (1990) \\
\hline Craticula cuspidata (Kützing) D.Mann & Epipelic & Round et al. (1990) \\
\hline Cymatopleura solea (Brebisson) W.Smith & Epipelic & Round et al. (1990) \\
\hline Brachysira brebissonii R. Ross & Epipelic & Round et al. (1990) \\
\hline Diploneis marginistriata Hustedt & Epipelic & Round et al. (1990) \\
\hline Diploneis subovalis Cleve & Epipelic & Round et al. (1990) \\
\hline Frustulia rhomboides (Ehrenberg) De Toni & Epipelic & Round et al. (1990) \\
\hline $\begin{array}{l}\text { Gyrosigma spencerii (Quekett) Griffith \& } \\
\text { Henfrey }\end{array}$ & Epipelic & Round et al. (1990) \\
\hline Humidophila contenta (Grunow) Lowe et al. & Epipelic & Round et al. (1990) \\
\hline Navicula Bory & Epipelic & Round et al. (1990) \\
\hline Navicula cryptocephala Kuetzing & Epipelic & Round et al. (1990) \\
\hline Navicula radiosa Kuetzing & Epipelic & Round et al. (1990) \\
\hline $\begin{array}{l}\text { Placoneis placentula (Ehrenberg) } \\
\text { Heinzerling }\end{array}$ & Epipelic & Round et al. (1990) \\
\hline Navicula viridula (Kuetzing) Ehrenberg & Epipelic & Round et al. (1990) \\
\hline Neidium ampliatum (Ehrenberg) Krammer & Epipelic & Round et al. (1990) \\
\hline Nitzchia Hassall (hyaline elongate) & Epipelic & Round et al. (1990) \\
\hline Nitzschia amphibia Grunow & Epipelic & Round et al. (1990) \\
\hline Nitzschia Hassall (hyaline small) & Epipelic & Round et al. (1990) \\
\hline Nitzschia vadestriata Aleem \& Hustedt & Epipelic & Round et al. (1990) \\
\hline Nitzschia lorenziana Grunow & Epipelic & Round et al. (1990) \\
\hline Pinnularia divergens W.Smith & Epipelic & Round et al. (1990) \\
\hline Pinnularia gibba Ehrenberg & Epipelic & Round et al. (1990) \\
\hline Pinnularia interrupta W.Smith & Epipelic & Round et al. (1990) \\
\hline Sellaphora bacillum (Ehrenberg) D.G.Mann & Epipelic & Round et al. (1990) \\
\hline $\begin{array}{l}\text { Sellaphora pseudoventralis (Hustedt) } \\
\text { Chudaev \& Gololobova }\end{array}$ & Epipelic & Round et al. (1990) \\
\hline $\begin{array}{l}\text { Sellaphora pupula (Kuetzing) } \\
\text { Mereschkovsky }\end{array}$ & Epipelic & Round et al. (1990) \\
\hline $\begin{array}{l}\text { Stauroneis phoenicenteron (Nitzsch) } \\
\text { Ehrenberg }\end{array}$ & Epipelic & Round et al. (1990) \\
\hline Surirella angusta Kuetzing & Epipelic & Round et al. (1990) \\
\hline Surirella fluvicygnorum John & Epipelic & Round et al. (1990) \\
\hline
\end{tabular}




\begin{tabular}{|c|c|c|}
\hline $\begin{array}{l}\text { Surirella linearis var. helvetica (Brun) } \\
\text { Meister }\end{array}$ & Epipelic & Round et al. (1990) \\
\hline Surirella linearis W.Smith & Epipelic & Round et al. (1990) \\
\hline $\begin{array}{l}\text { Surirella cf. bohemica (Maly) Maly ex } \\
\text { Schoenfeldt }\end{array}$ & Epipelic & Round et al. (1990) \\
\hline Tryblionella hungarica (Grunow) Frenguelli & Epipelic & Round et al. (1990) \\
\hline Tryblionella levidensis W.Smith & Epipelic & Round et al. (1990) \\
\hline Achnanthes Bory & Epiphytic & Round et al. (1990) \\
\hline Achnanthes inflata (Kuetzing) Grunow & Epiphytic & Round et al. (1990) \\
\hline $\begin{array}{l}\text { Achnanthidium exiguum (Grunow) } \\
\text { Czarnecki }\end{array}$ & Epiphytic & Round et al. (1990) \\
\hline Amphora libyca Ehrenberg & Epiphytic & Round et al. (1990) \\
\hline $\begin{array}{l}\text { Halamphora cf. oligotraphenta (Lange- } \\
\text { Bertalot) Levkov }\end{array}$ & Epiphytic & Round et al. (1990) \\
\hline Cocconeis neothumensis Krammer & Epiphytic & Round et al. (1990) \\
\hline Cocconeis placentula Ehrenberg & Epiphytic & Round et al. (1990) \\
\hline Cymbella aspera (Ehrenberg) Peragallo & Epiphytic & Round et al. (1990) \\
\hline Cymbella novazeelandiana Krammer & Epiphytic & Round et al. (1990) \\
\hline Cymbella parva (W.Smith) Kirchner & Epiphytic & Round et al. (1990) \\
\hline Cymbella tumida (Brébisson) Van Heurck & Epiphytic & Round et al. (1990) \\
\hline Encyonema silesiacum (Bleisch) D.Mann & Epiphytic & Round et al. (1990) \\
\hline Epithemia adnata (Kuetzing) Brébisson & Epiphytic & Round et al. (1990) \\
\hline Epithemia sorex Kuetzing & Epiphytic & Round et al. (1990) \\
\hline Gomphonema affine Kuetzing & Epiphytic & Round et al. (1990) \\
\hline Gomphonema augur Ehrenberg & Epiphytic & Round et al. (1990) \\
\hline $\begin{array}{l}\text { Gomphonema angustatum (Kuetzing) } \\
\text { Rabenhorst }\end{array}$ & Epiphytic & Round et al. (1990) \\
\hline Gomphonema truncatum Ehrenberg & Epiphytic & Round et al. (1990) \\
\hline $\begin{array}{l}\text { Karayevia clevei (Grunow) Round \& } \\
\text { Bukhtiyarova }\end{array}$ & Epiphytic & Round et al. (1990) \\
\hline Meridion circulare (Greville) Agardh & Epiphytic & Round et al. (1990) \\
\hline $\begin{array}{l}\text { Opephora mutabilis (Grunow) Sabbe \& } \\
\text { Vyverman }\end{array}$ & Epiphytic & Round et al. (1990) \\
\hline $\begin{array}{l}\text { Tabularia fasciculata (Agardh)Williams et } \\
\text { Round }\end{array}$ & Epiphytic & Round et al. (1990) \\
\hline Tabularia variostriata M.Harper & Epiphytic & Round et al. (1990) \\
\hline $\begin{array}{l}\text { Planothidium lanceolatum (Brébisson ex } \\
\text { Kuetzing) Lange-Bertalot }\end{array}$ & Epiphytic & Round et al. (1990) \\
\hline $\begin{array}{l}\text { Planothidium } \\
\text { lanceolatum subsp. robusta (Hustedt) } \\
\text { Lange-Bertalot }\end{array}$ & Epiphytic & Round et al. (1990) \\
\hline Karayevia oblongella (Oestrup) Aboal & Epiphytic & Round et al. (1990) \\
\hline $\begin{array}{l}\text { Rhoicosphenia abbreviata (C.Agardh) Lange- } \\
\text { Bertalot }\end{array}$ & Epiphytic & Round et al. (1990) \\
\hline Rhopalodia brebissonii Krammer & Epiphytic & Round et al. (1990) \\
\hline
\end{tabular}




\begin{tabular}{|c|c|c|}
\hline Rhopalodia novae-zelandiae Hustedt & Epiphytic & Round et al. (1990) \\
\hline Rhopalodia rupestris (W.Smith) Krammer & Epiphytic & Round et al. (1990) \\
\hline Staurosirella martyi (Héribaud) Morales & Epiphytic & Round et al. (1990) \\
\hline Actinocyclus octonarius Ehrenberg & Planktic & Round et al. (1990) \\
\hline Aulacoseira italica (Ehrenberg) Simonsen & Planktic & Round et al. (1990) \\
\hline Aulacoseira Thwaites & Planktic & Round et al. (1990) \\
\hline $\begin{array}{l}\text { Discostella stelligera (Cleve \& Grunow) } \\
\text { Houk \& Klee }\end{array}$ & Planktic & Round et al. (1990) \\
\hline $\begin{array}{l}\text { Fragilaria capucina var. vaucheriae } \\
\text { (Kuetzing) Lange-Bertalot }\end{array}$ & Planktic & Round et al. (1990) \\
\hline Fragilaria pseudoconstruens Marciniak & Planktic & Round et al. (1990) \\
\hline Fragilaria Lyngbye & Planktic & Round et al. (1990) \\
\hline $\begin{array}{l}\text { Pseudostaurosira elliptica (Schumann) } \\
\text { Edlund, Morales \& Spaulding }\end{array}$ & Planktic & Round et al. (1990) \\
\hline $\begin{array}{l}\text { Puncticulata comta (Ehrenberg) Hakasson D } \\
\text { Res }\end{array}$ & Planktic & Round et al. (1990) \\
\hline $\begin{array}{l}\text { Stauroforma exiguiformis (Lange-Bertalot) } \\
\text { Flower }\end{array}$ & Planktic & Round et al. (1990) \\
\hline Ulnaria ulna (Nitzsch.) Compère & Planktic & Round et al. (1990) \\
\hline Aulacoseira ambigua (Grunow) Simonsen & Tychoplanktic & $\begin{array}{l}\text { Li et al. (2015), Kilham } \\
\text { and Kilham (1975), } \\
\text { Ruhland et al. (2015) }\end{array}$ \\
\hline $\begin{array}{l}\text { Aulacoseira granulata var. angustissima } \\
\text { (O.Mueller) Simonsen }\end{array}$ & Tychoplanktic & $\begin{array}{l}\text { Li et al. (2015), Kilham } \\
\text { and Kilham (1975), } \\
\text { Ruhland et al. (2015) }\end{array}$ \\
\hline Cyclostephanos dubius (Hustedt) Round & Tychoplanktic & Li et al. (2015) \\
\hline Asterionella formosa Hassal & Tychoplanktic & Li et al. (2015) \\
\hline Melosira varians Agardh & Tychoplanktic & Vos and de Wolf (1988) \\
\hline $\begin{array}{l}\text { Staurosira construens (Ehrenberg) Williams } \\
\text { \& Round }\end{array}$ & Tychoplanktic & Vos and de Wolf (1988) \\
\hline $\begin{array}{l}\text { Staurosira venter (Ehrenberg) Cleve \& } \\
\text { Möller } 1879\end{array}$ & Tychoplanktic & Vos and de Wolf (1988) \\
\hline $\begin{array}{l}\text { Staurosirella pinnata (Ehrenberg) Williams } \\
\text { \& Round }\end{array}$ & Tychoplanktic & Vos and de Wolf (1988) \\
\hline $\begin{array}{l}\text { Pseudostaurosira brevistriata (Grunow) } \\
\text { Williams \& Round }\end{array}$ & Tychoplanktic & Vos and de Wolf (1988) \\
\hline
\end{tabular}




\section{E. Diatom supplementary results}

Diatom stratigraphy - diatoms making up $>2 \%$ of $>2$ samples

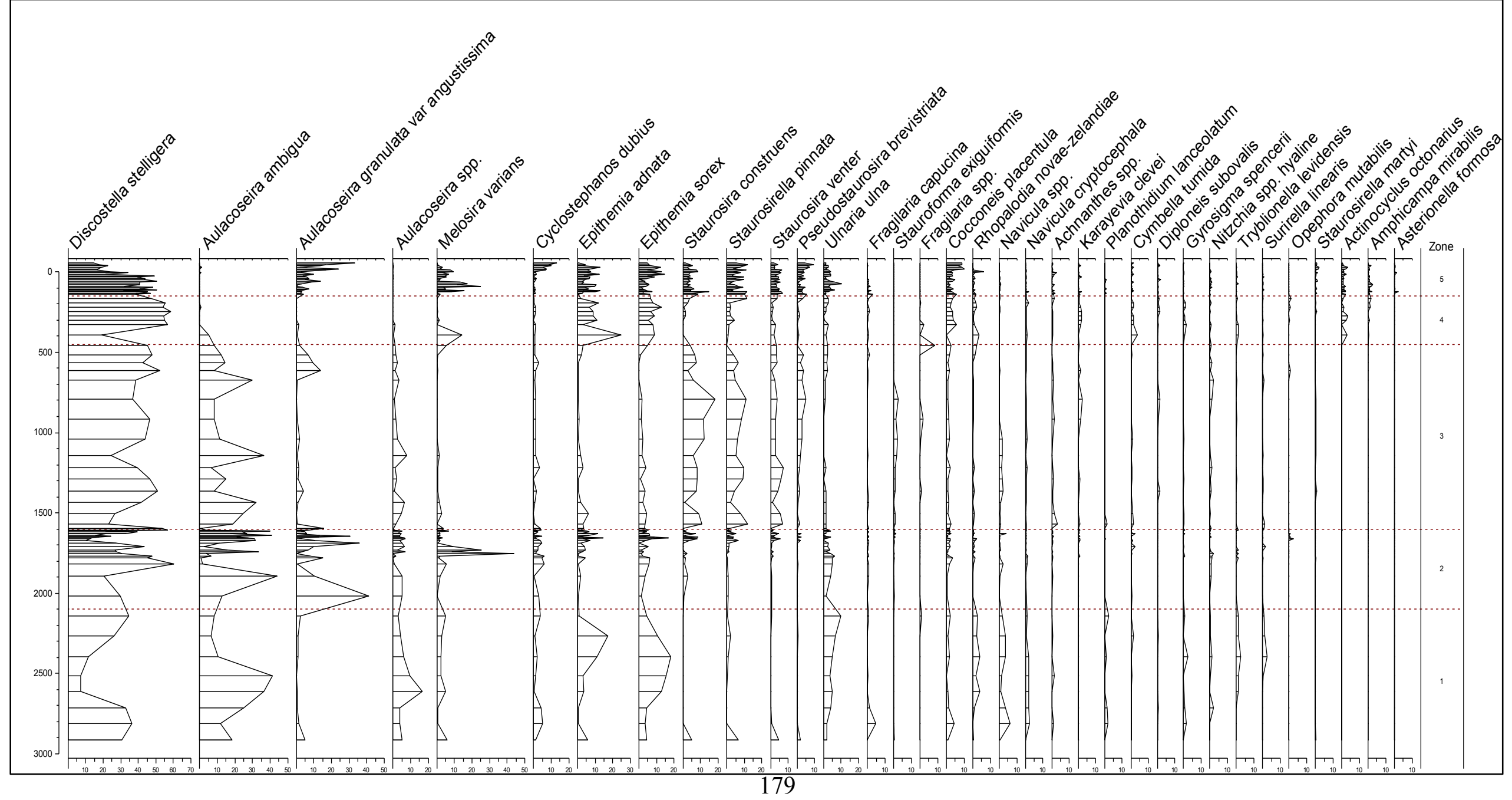




\section{Summary Statistics for Diatom Species Abundance}

\begin{tabular}{|c|c|c|c|c|c|c|}
\hline Species & Hills N2 & Min & Max & Mean & Median & St.dev \\
\hline $\begin{array}{l}\text { Aulacoseira ambigua } \\
\text { (Grunow) Simonsen }\end{array}$ & 31.27 & 0 & 132 & 33.19 & 19 & 39.25 \\
\hline Aulacoseira Thwaites & 28.68 & 0 & 50 & 6.97 & 4 & 8.86 \\
\hline $\begin{array}{l}\text { Aulacoseira italica } \\
\text { (Ehrenberg) Simonsen }\end{array}$ & 10.29 & 0 & 4 & 0.32 & 0 & 0.80 \\
\hline $\begin{array}{l}\text { Aulacoseira granulata var } \\
\text { angustissima (O.Mueller) } \\
\text { Simonsen }\end{array}$ & 26.45 & 0 & 123 & 19.16 & 9 & 25.96 \\
\hline $\begin{array}{l}\text { Actinocyclus octonarius } \\
\text { Ehrenberg }\end{array}$ & 20.97 & 0 & 11 & 1.69 & 0 & 2.72 \\
\hline $\begin{array}{l}\text { Puncticulata comta } \\
\text { (Ehrenberg) Hakasson D } \\
\text { Res }\end{array}$ & 16.95 & 0 & 5 & 0.72 & 0 & 1.33 \\
\hline $\begin{array}{l}\text { Cyclostephanos dubius (Hus } \\
\text { tedt) Round }\end{array}$ & 31.86 & 0 & 39 & 6.44 & 3 & 7.49 \\
\hline $\begin{array}{l}\text { Discostella stelligera (Cleve } \\
\text { \& Grunow) Houk \& Klee }\end{array}$ & 64.38 & 22 & 181 & 105.11 & 113 & 42.68 \\
\hline Unidentified centric & 3.20 & 0 & 4 & 0.11 & 0 & 0.51 \\
\hline Melosira varians Agardh & 19.98 & 0 & 132 & 12.40 & 5 & 20.57 \\
\hline Asterionella formosa Hassal & 2.58 & 0 & 4 & 0.09 & 0 & 0.49 \\
\hline $\begin{array}{l}\text { Pseudostaurosira } \\
\text { brevistriata (Grunow) } \\
\text { Williams \& Round } \\
\end{array}$ & 33.97 & 0 & 28 & 5.15 & 3 & 5.66 \\
\hline $\begin{array}{l}\text { Fragilaria capucina var. } \\
\text { vaucheriae (Kuetzing) } \\
\text { Lange-Bertalot }\end{array}$ & 19.36 & 0 & 14 & 1.28 & 0 & 2.17 \\
\hline $\begin{array}{l}\text { Staurosira construens } \\
\text { (Ehrenberg) Williams \& } \\
\text { Round }\end{array}$ & 38.66 & 0 & 56 & 11.16 & 9 & 10.82 \\
\hline $\begin{array}{l}\text { Staurosira venter } \\
\text { (Ehrenberg) Cleve \& Möller } \\
1879\end{array}$ & 46.32 & 0 & 21 & 7.15 & 6 & 5.62 \\
\hline $\begin{array}{l}\text { Pseudostaurosira elliptica } \\
\text { (Schumann) Edlund, } \\
\text { Morales \& Spauldin }\end{array}$ & 11.08 & 0 & 4 & 0.32 & 0 & 0.77 \\
\hline $\begin{array}{l}\text { Tabularia fasciculata } \\
\text { (Agardh)Williams et Round }\end{array}$ & 1.00 & 0 & 1 & 0.01 & 0 & 0.11 \\
\hline $\begin{array}{l}\text { Staurosirella pinnata } \\
\text { (Ehrenberg) Williams \& } \\
\text { Round }\end{array}$ & 43.32 & 0 & 35 & 12.23 & 10 & 10.45 \\
\hline $\begin{array}{l}\text { Fragilaria } \\
\text { pseudoconstruens } \\
\text { Marciniak }\end{array}$ & 19.17 & 0 & 4 & 0.56 & 0 & 0.96 \\
\hline $\begin{array}{l}\text { Ulnaria ulna (Nitzsch) } \\
\text { Compère }\end{array}$ & 48.34 & 0 & 31 & 8.21 & 7 & 6.10 \\
\hline $\begin{array}{l}\text { Stauroforma exiguiformis } \\
\text { (Lange-Bertalot) Flower }\end{array}$ & 14.88 & 0 & 8 & 0.80 & 0 & 1.61 \\
\hline Fragilaria Lyngbye & 2.61 & 0 & 25 & 0.57 & 0 & 3.02 \\
\hline Meridion circulare (Greville) & 1.00 & 0 & 1 & 0.01 & 0 & 0.11 \\
\hline
\end{tabular}




\begin{tabular}{|c|c|c|c|c|c|c|}
\hline Agardh & & & & & & \\
\hline $\begin{array}{l}\text { Staurosirella martyi } \\
\text { (Héribaud) Morales }\end{array}$ & 13.08 & 0 & 7 & 0.59 & 0 & 1.28 \\
\hline $\begin{array}{l}\text { Opephora mutabilis } \\
\text { (Grunow) Sabbe \& } \\
\text { Vyverman }\end{array}$ & 5.26 & 0 & 8 & 0.29 & 0 & 1.07 \\
\hline Opephora P.Petit & 5.45 & 0 & 4 & 0.17 & 0 & 0.62 \\
\hline $\begin{array}{l}\text { Tabularia variostriata } \\
\text { M.Harper }\end{array}$ & 11.21 & 0 & 4 & 0.39 & 0 & 0.92 \\
\hline $\begin{array}{l}\text { Amphicampa mirabilis } \\
\text { Ehrenberg ex Ralfs }\end{array}$ & 17.44 & 0 & 8 & 0.99 & 0 & 1.79 \\
\hline $\begin{array}{l}\text { Amphicampa (Ehrenberg) R } \\
\text { alfs }\end{array}$ & 1.00 & 0 & 2 & 0.03 & 0 & 0.23 \\
\hline $\begin{array}{l}\text { Brachysira brebissonii } \\
\text { R.Ross }\end{array}$ & 6.40 & 0 & 2 & 0.11 & 0 & 0.35 \\
\hline $\begin{array}{l}\text { Caloneis bacillum (Grunow) } \\
\text { Cleve }\end{array}$ & 10.67 & 0 & 3 & 0.21 & 0 & 0.52 \\
\hline $\begin{array}{l}\text { Caloneis ventricosa } \\
\text { (Ehrenberg) F.Meister }\end{array}$ & 1.80 & 0 & 2 & 0.04 & 0 & 0.26 \\
\hline Caloneis Cleve & 1.00 & 0 & 1 & 0.01 & 0 & 0.11 \\
\hline $\begin{array}{l}\text { Craticula cuspidata } \\
\text { (Kuetzing) D.Mann }\end{array}$ & 11.00 & 0 & 1 & 0.15 & 0 & 0.35 \\
\hline $\begin{array}{l}\text { Craticula } \\
\text { halophila (Grunow) } \\
\text { D.G.Mann }\end{array}$ & 1.00 & 0 & 1 & 0.01 & 0 & 0.11 \\
\hline $\begin{array}{l}\text { Diploneis marginistriata } \\
\text { Hustedt }\end{array}$ & 14.30 & 0 & 3 & 0.31 & 0 & 0.63 \\
\hline Diploneis subovalis Cleve & 31.04 & 0 & 6 & 1.04 & 1 & 1.24 \\
\hline $\begin{array}{l}\text { Frustulia rhomboides } \\
\text { (Ehrenberg) De Toni }\end{array}$ & 6.25 & 0 & 2 & 0.13 & 0 & 0.44 \\
\hline $\begin{array}{l}\text { Gyrosigma spencerii } \\
\text { (Quekett) Griffith \& } \\
\text { Henfrey }\end{array}$ & 16.82 & 0 & 8 & 0.71 & 0 & 1.31 \\
\hline $\begin{array}{l}\text { Adlafia bryophila (Petersen) } \\
\text { Moser Lange-Bertalot \& } \\
\text { Metzeltin }\end{array}$ & 5.00 & 0 & 1 & 0.07 & 0 & 0.25 \\
\hline $\begin{array}{l}\text { Humidophila contenta } \\
\text { (Grunow) Lowe et al }\end{array}$ & 11.11 & 0 & 4 & 0.27 & 0 & 0.64 \\
\hline $\begin{array}{l}\text { Navicula cryptocephala } \\
\text { Kuetzing }\end{array}$ & 35.57 & 0 & 7 & 1.51 & 1 & 1.59 \\
\hline $\begin{array}{l}\text { Cavinula pseudoscutiformis } \\
\text { (Hustedt) Mann \& Stickle }\end{array}$ & 6.40 & 0 & 2 & 0.11 & 0 & 0.35 \\
\hline Navicula radiosa Kuetzing & 27.59 & 0 & 4 & 0.69 & 0 & 0.91 \\
\hline $\begin{array}{l}\text { Navicula viridula (Kuetzing) } \\
\text { Ehrenberg }\end{array}$ & 2.00 & 0 & 1 & 0.03 & 0 & 0.16 \\
\hline $\begin{array}{l}\text { Placoneis placentula } \\
\text { (Ehrenberg) Heinzerling }\end{array}$ & 2.00 & 0 & 1 & 0.03 & 0 & 0.16 \\
\hline Navicula Bory & 20.42 & 0 & 19 & 2.09 & 1 & 3.42 \\
\hline $\begin{array}{l}\text { Neidium ampliatum } \\
\text { (Ehrenberg) Krammer }\end{array}$ & 1.00 & 0 & 2 & 0.03 & 0 & 0.23 \\
\hline $\begin{array}{l}\text { Pinnularia divergens } \\
\text { W.Smith }\end{array}$ & 5.44 & 0 & 2 & 0.09 & 0 & 0.33 \\
\hline
\end{tabular}




\begin{tabular}{|c|c|c|c|c|c|c|}
\hline Pinnularia gibba Ehrenberg & 7.00 & 0 & 1 & 0.09 & 0 & 0.29 \\
\hline $\begin{array}{l}\text { Pinnularia interrupta } \\
\text { W.Smith }\end{array}$ & 1.00 & 0 & 1 & 0.01 & 0 & 0.11 \\
\hline Pinnularia Ehrenberg & 13.89 & 0 & 3 & 0.33 & 0 & 0.70 \\
\hline $\begin{array}{l}\text { Sellaphora bacillum } \\
\text { (Ehrenberg) D.G.Mann }\end{array}$ & 1.00 & 0 & 1 & 0.01 & 0 & 0.11 \\
\hline $\begin{array}{l}\text { Sellaphora pseudoventralis } \\
\text { (Hustedt) Chudaev \& } \\
\text { Gololobova }\end{array}$ & 5.00 & 0 & 1 & 0.07 & 0 & 0.25 \\
\hline $\begin{array}{l}\text { Sellaphora pupula (Kuetzing } \\
\text { ) Mereschkovsky }\end{array}$ & 7.36 & 0 & 5 & 0.24 & 0 & 0.73 \\
\hline $\begin{array}{l}\text { Sellaphora seminulum } \\
\text { (Grunow) D.G.Mann }\end{array}$ & 12.52 & 0 & 3 & 0.32 & 0 & 0.71 \\
\hline $\begin{array}{l}\text { Stauroneis anceps } \\
\text { Ehrenberg }\end{array}$ & 2.00 & 0 & 1 & 0.03 & 0 & 0.16 \\
\hline $\begin{array}{l}\text { Stauroneis phoenicenteron } \\
\text { (Nitzsch) Ehrenberg }\end{array}$ & 9.00 & 0 & 2 & 0.16 & 0 & 0.43 \\
\hline Stauroneis Ehrenberg & 3.00 & 0 & 1 & 0.04 & 0 & 0.20 \\
\hline $\begin{array}{l}\text { Karayevia clevei (Grunow) } \\
\text { Round \& Bukhtiyarova }\end{array}$ & 31.04 & 0 & 7 & 1.48 & 1 & 1.76 \\
\hline $\begin{array}{l}\text { Achnanthidium exiguum } \\
\text { (Grunow) Czarnecki }\end{array}$ & 5.14 & 0 & 4 & 0.16 & 0 & 0.59 \\
\hline $\begin{array}{l}\text { Karayevia oblongella } \\
\text { (Oestrup) Aboal }\end{array}$ & 9.14 & 0 & 3 & 0.21 & 0 & 0.57 \\
\hline $\begin{array}{l}\text { Achnanthes } \\
\text { inflata (Kuetzing) Grunow }\end{array}$ & 1.00 & 0 & 1 & 0.01 & 0 & 0.11 \\
\hline Achnanthes Bory & 29.07 & 0 & 9 & 1.37 & 1 & 1.73 \\
\hline $\begin{array}{l}\text { Cocconeis neothumensis } \\
\text { Krammer }\end{array}$ & 7.12 & 0 & 3 & 0.15 & 0 & 0.45 \\
\hline $\begin{array}{l}\text { Cocconeis placentula } \\
\text { Ehrenberg }\end{array}$ & 40.75 & 0 & 30 & 7.08 & 5 & 6.49 \\
\hline Cocconeis Ehrenberg & 1.00 & 0 & 1 & 0.01 & 0 & 0.11 \\
\hline $\begin{array}{l}\text { Planothidium } \\
\text { lanceolatum subsp robusta } \\
\text { (Hustedt) Lange-Bertalot }\end{array}$ & 12.13 & 0 & 7 & 0.60 & 0 & 1.37 \\
\hline $\begin{array}{l}\text { Planothidium lanceolatum } \\
\text { (Brébisson ex Kuetzing) } \\
\text { Lange-Bertalot }\end{array}$ & 12.60 & 0 & 3 & 0.28 & 0 & 0.62 \\
\hline $\begin{array}{l}\text { Planothidium Round \& } \\
\text { LBukhtiyarova }\end{array}$ & 1.00 & 0 & 5 & 0.07 & 0 & 0.57 \\
\hline Amphora libyca Ehrenberg & 6.37 & 0 & 3 & 0.15 & 0 & 0.48 \\
\hline $\begin{array}{l}\text { Halamphora cf. } \\
\text { oligotraphenta (Lange- } \\
\text { Bertalot) Levkov }\end{array}$ & 1.00 & 0 & 1 & 0.01 & 0 & 0.11 \\
\hline $\begin{array}{l}\text { Cymbella aspera } \\
\text { (Ehrenberg) Peragallo }\end{array}$ & 18.66 & 0 & 5 & 0.67 & 0 & 1.16 \\
\hline $\begin{array}{l}\text { Cymbella novazeelandiana } \\
\text { Krammer }\end{array}$ & 22.23 & 0 & 4 & 0.68 & 0 & 1.05 \\
\hline $\begin{array}{l}\text { Cymbella parva (W.Smith) } \\
\text { Kirchner }\end{array}$ & 1.00 & 0 & 2 & 0.03 & 0 & 0.23 \\
\hline $\begin{array}{l}\text { Encyonema silesiacum } \\
\text { (Bleisch) D.Mann }\end{array}$ & 2.00 & 0 & 1 & 0.03 & 0 & 0.16 \\
\hline
\end{tabular}




\begin{tabular}{|c|c|c|c|c|c|c|}
\hline $\begin{array}{l}\text { Cymbella tumida } \\
\text { (Brébisson) Van Heurck }\end{array}$ & 31.15 & 0 & 11 & 1.75 & 1 & 2.07 \\
\hline Cymbella C.Agardh & 7.20 & 0 & 3 & 0.16 & 0 & 0.49 \\
\hline $\begin{array}{l}\text { Epithemia adnata } \\
\text { (Kuetzing) Brébisson }\end{array}$ & 40.02 & 1 & 74 & 14.63 & 11 & 13.67 \\
\hline Epithemia sorex Kuetzing & 47.07 & 0 & 55 & 15.97 & 13 & 12.30 \\
\hline $\begin{array}{l}\text { Gomphonema affine } \\
\text { Kuetzing }\end{array}$ & 3.00 & 0 & 1 & 0.04 & 0 & 0.20 \\
\hline $\begin{array}{l}\text { Gomphonema angustatum } \\
\text { (Kuetzing) Rabenhorst }\end{array}$ & 6.74 & 0 & 4 & 0.21 & 0 & 0.68 \\
\hline $\begin{array}{l}\text { Gomphonema augur } \\
\text { Ehrenberg }\end{array}$ & 9.00 & 0 & 2 & 0.16 & 0 & 0.43 \\
\hline $\begin{array}{l}\text { Gomphonema truncatum } \\
\text { Ehrenberg }\end{array}$ & 2.67 & 0 & 2 & 0.05 & 0 & 0.28 \\
\hline Gomphonema Ehrenberg & 2.00 & 0 & 2 & 0.05 & 0 & 0.32 \\
\hline $\begin{array}{l}\text { Rhoicosphenia } \\
\text { abbreviata (C.Agardh) } \\
\text { Lange-Bertalot }\end{array}$ & 1.00 & 0 & 1 & 0.01 & 0 & 0.11 \\
\hline $\begin{array}{l}\text { Rhopalodia brebissonii } \\
\text { Krammer }\end{array}$ & 5.40 & 0 & 3 & 0.12 & 0 & 0.43 \\
\hline $\begin{array}{l}\text { Rhopalodia novae- } \\
\text { zelandiae Hustedt }\end{array}$ & 30.59 & 0 & 18 & 2.69 & 2 & 3.25 \\
\hline $\begin{array}{l}\text { Rhopalodia rupestris } \\
\text { (W.Smith) Krammer }\end{array}$ & 1.00 & 0 & 1 & 0.01 & 0 & 0.11 \\
\hline Nitzschia amphibia Grunow & 17.31 & 0 & 3 & 0.40 & 0 & 0.73 \\
\hline $\begin{array}{l}\text { Nitzschia vadestriata Aleem } \\
\text { \& Hustedt }\end{array}$ & 6.40 & 0 & 2 & 0.11 & 0 & 0.35 \\
\hline $\begin{array}{l}\text { Tryblionella levidensis } \\
\text { W.Smith }\end{array}$ & 18.45 & 0 & 8 & 0.87 & 0 & 1.52 \\
\hline $\begin{array}{l}\text { Nitzschia lorenziana } \\
\text { Grunow }\end{array}$ & 11.76 & 0 & 3 & 0.31 & 0 & 0.71 \\
\hline $\begin{array}{l}\text { Nitzschia Hassall (hyaline } \\
\text { small) }\end{array}$ & 27.57 & 0 & 5 & 0.96 & 0 & 1.26 \\
\hline $\begin{array}{l}\text { Nitzchia Hassall (hyaline } \\
\text { elongate) }\end{array}$ & 29.45 & 0 & 6 & 1.16 & 1 & 1.44 \\
\hline $\begin{array}{l}\text { Tryblionella hungarica } \\
\text { (Grunow) Frenguelli }\end{array}$ & 10.71 & 0 & 2 & 0.20 & 0 & 0.49 \\
\hline Tryblionella W.Smith & 3.57 & 0 & 2 & 0.07 & 0 & 0.30 \\
\hline $\begin{array}{l}\text { Cymatopleura solea } \\
\text { (Brebisson) W.Smith }\end{array}$ & 6.23 & 0 & 2 & 0.12 & 0 & 0.40 \\
\hline Surirella angusta Kuetzing & 1.00 & 0 & 1 & 0.01 & 0 & 0.11 \\
\hline $\begin{array}{l}\text { Surirella fluvicygnorum } \\
\text { John }\end{array}$ & 8.33 & 0 & 5 & 0.27 & 0 & 0.75 \\
\hline $\begin{array}{l}\text { Surirella cf. bohemica } \\
\text { (Maly) Maly ex Schoenfeldt }\end{array}$ & 2.27 & 0 & 3 & 0.07 & 0 & 0.38 \\
\hline Surirella linearis W.Smith & 14.11 & 0 & 8 & 0.61 & 0 & 1.27 \\
\hline $\begin{array}{l}\text { Surirella linearis var } \\
\text { helvetica (Brun) Meister }\end{array}$ & 6.00 & 0 & 3 & 0.16 & 0 & 0.54 \\
\hline Surirella Turpin & 20.17 & 0 & 4 & 0.59 & 0 & 0.97 \\
\hline
\end{tabular}




\section{F. Core Descriptions}

\section{P1.1-0.40-1.23m}

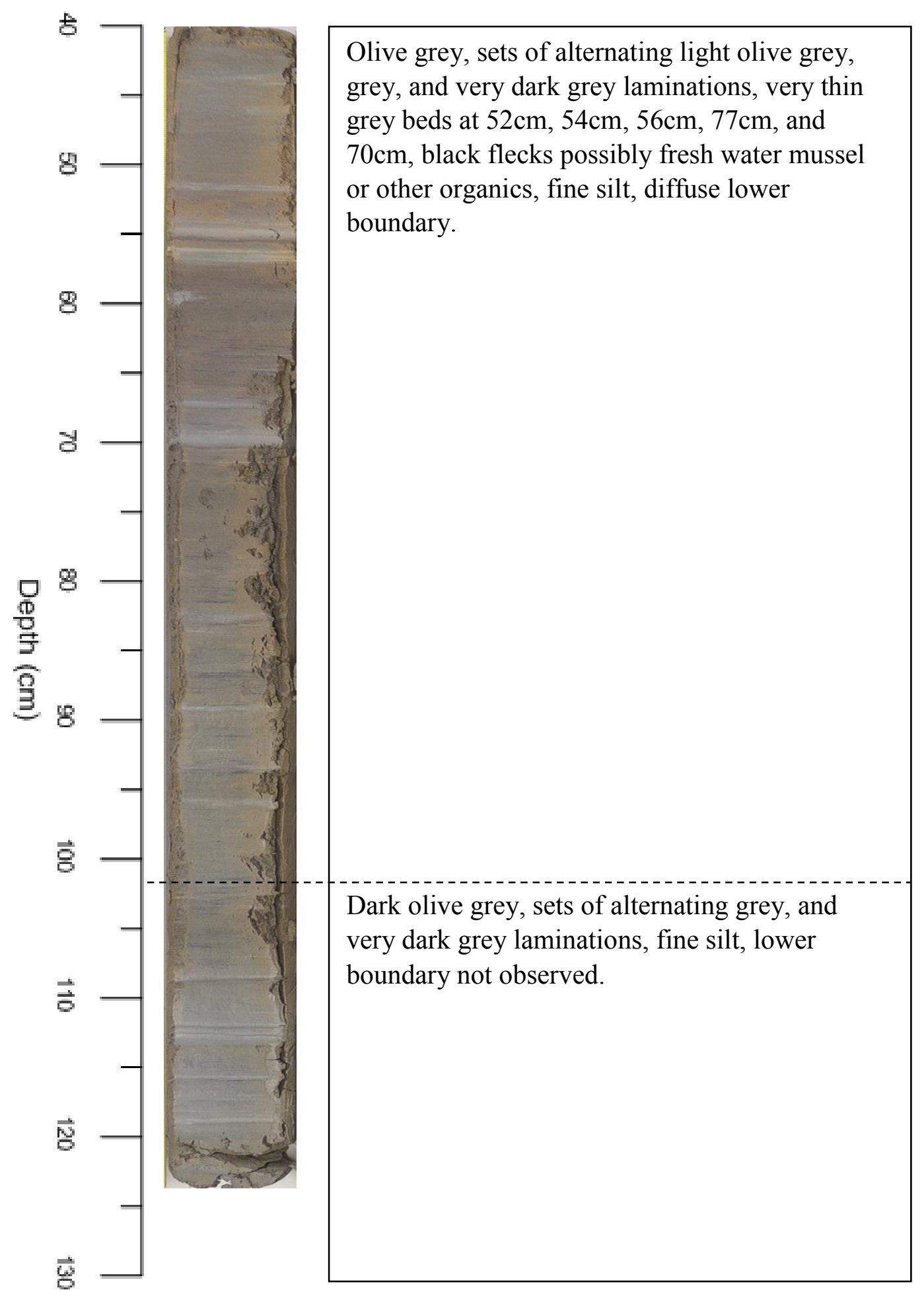




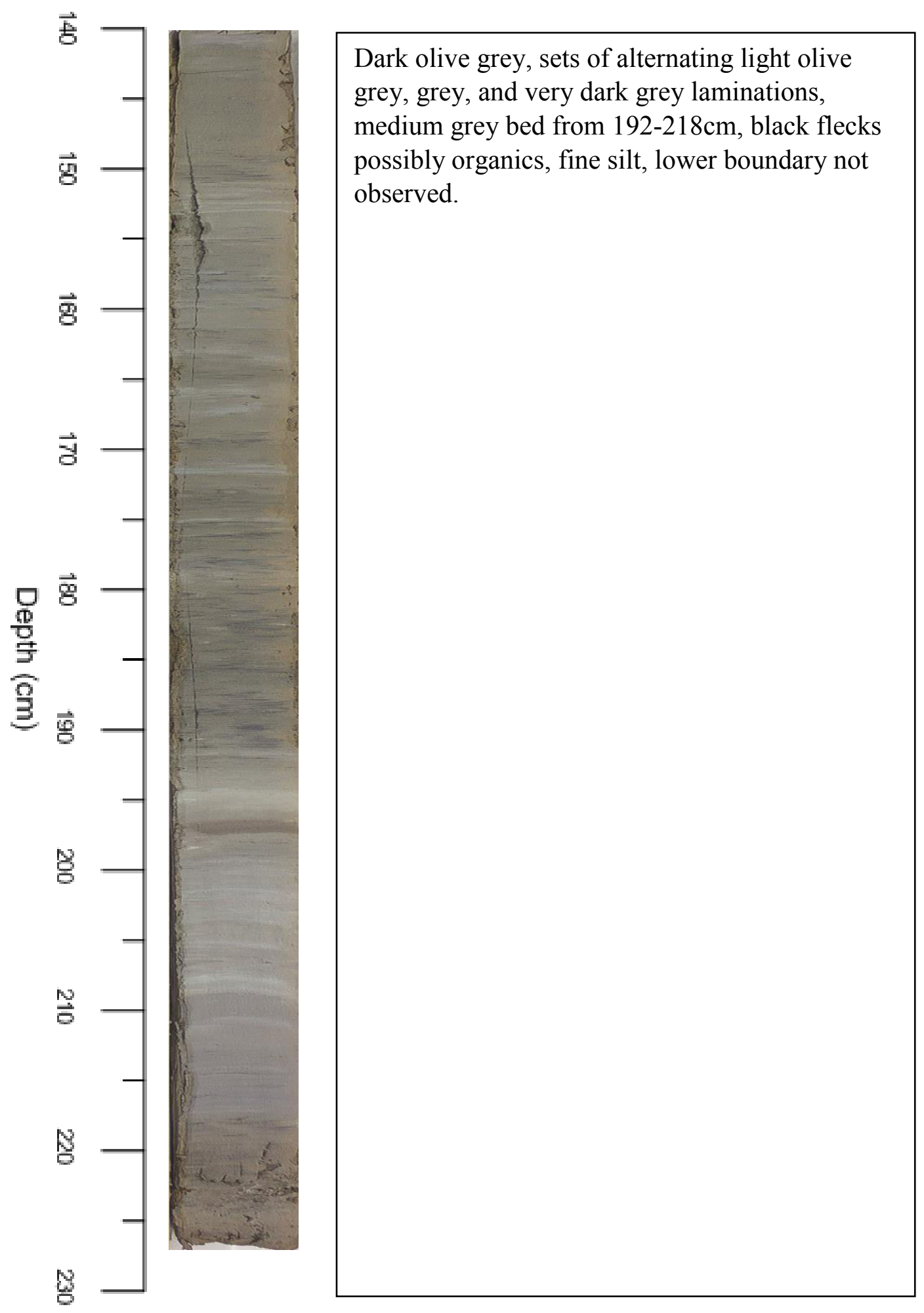




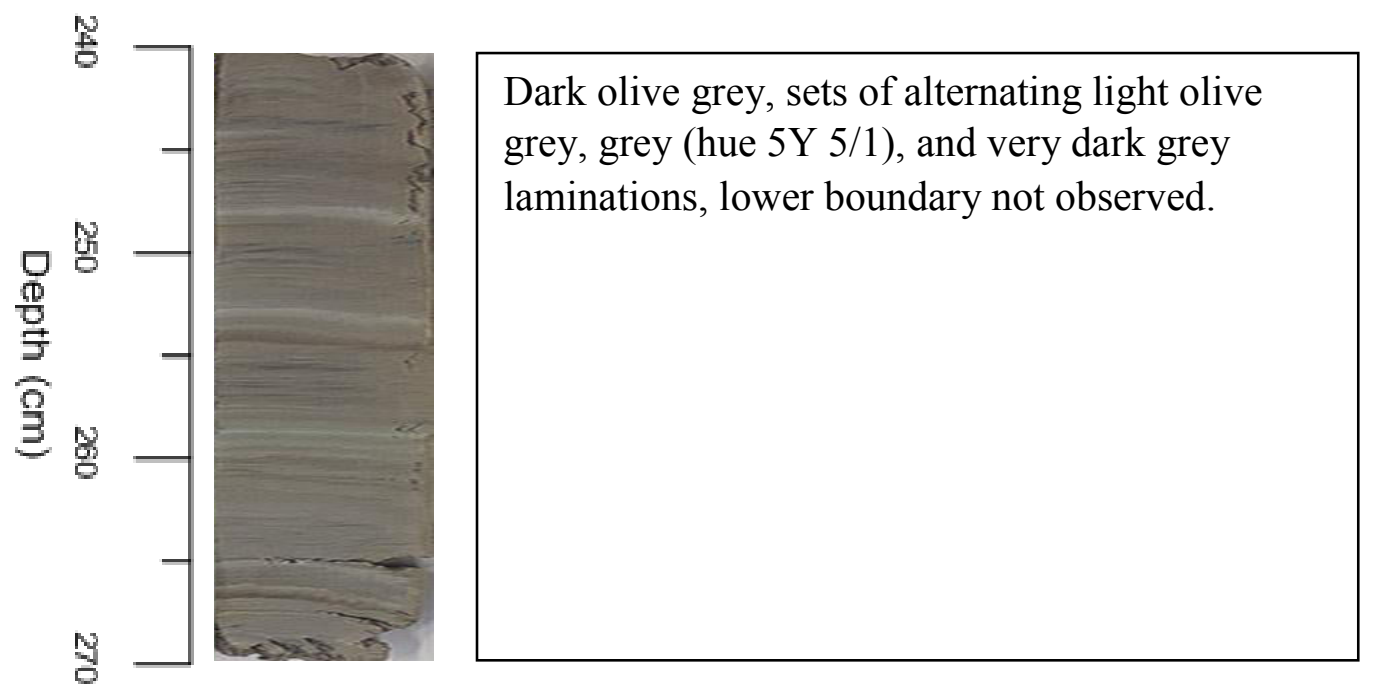

\section{Colours from Munsell Soil Colour Chart (1994 revised edition:}

- Olive grey hue 5 Y 5/2

- Light olive grey hue 5 Y $5 / 2$

- Dark olive grey hue 5Y 3/2

- Grey hue 5Y 5/1

- Light grey hue $5 Y$ 7/1

- Dark grey hue 5Y 4/1

- Very dark grey 5 Y 3/1 


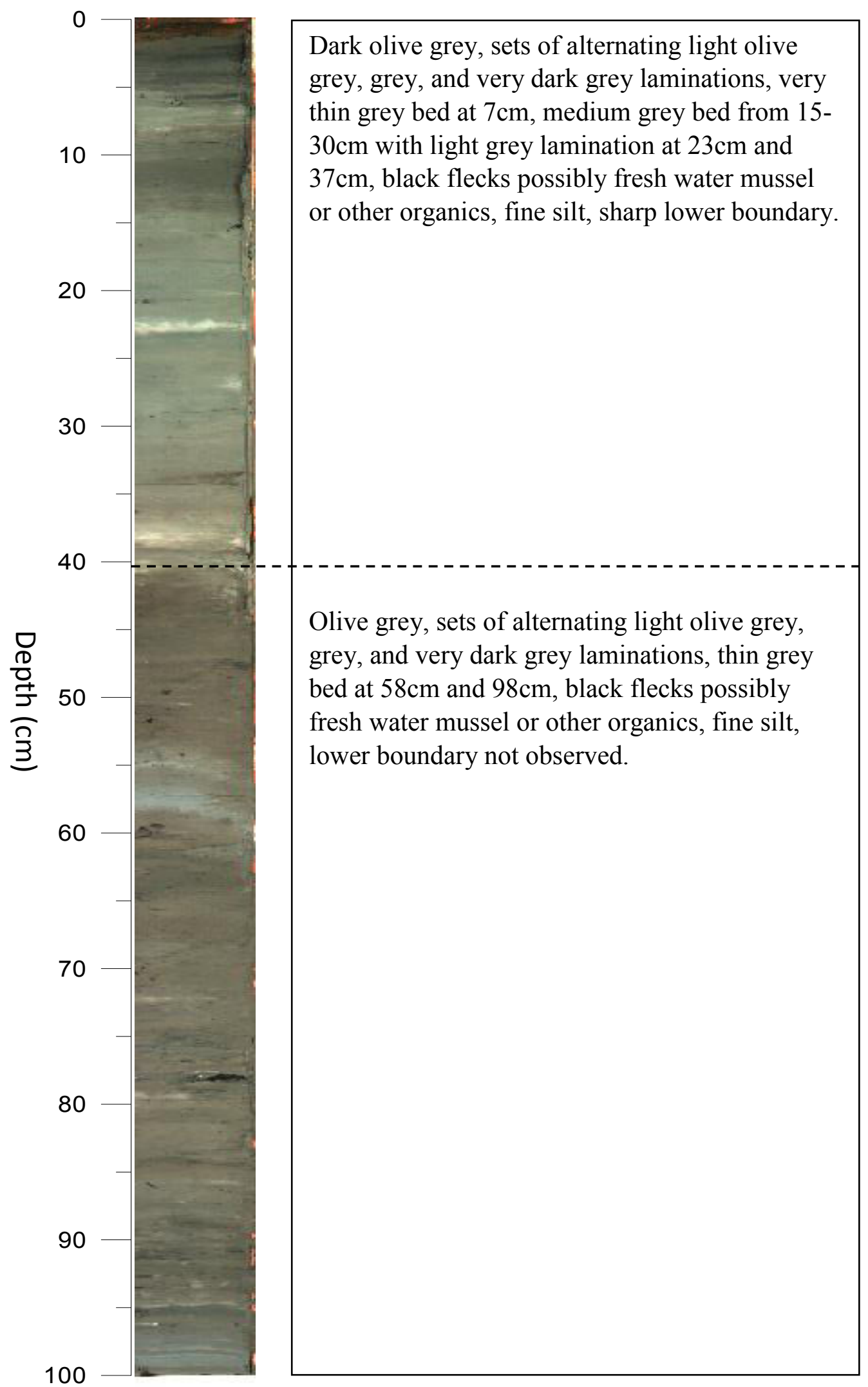




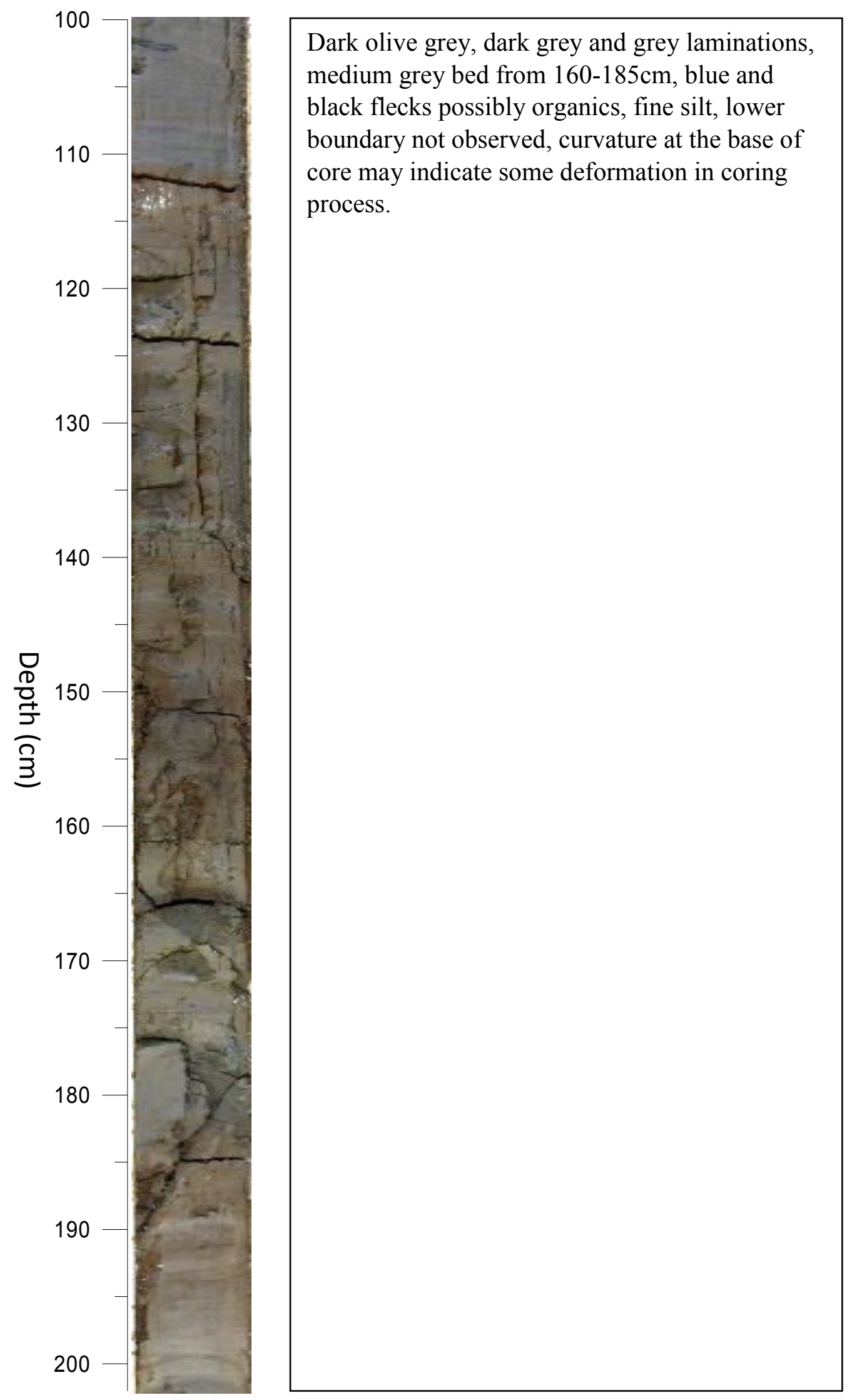




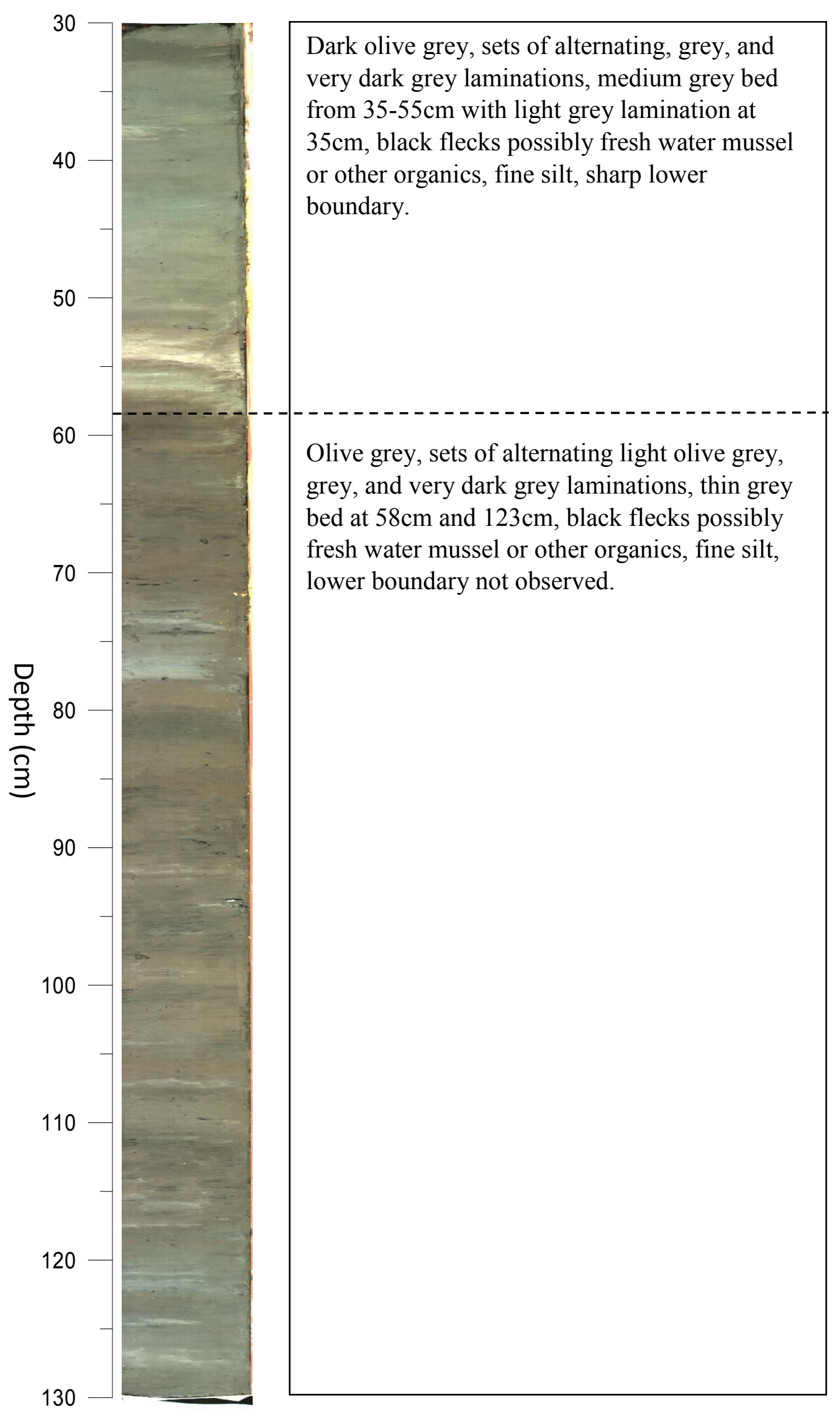




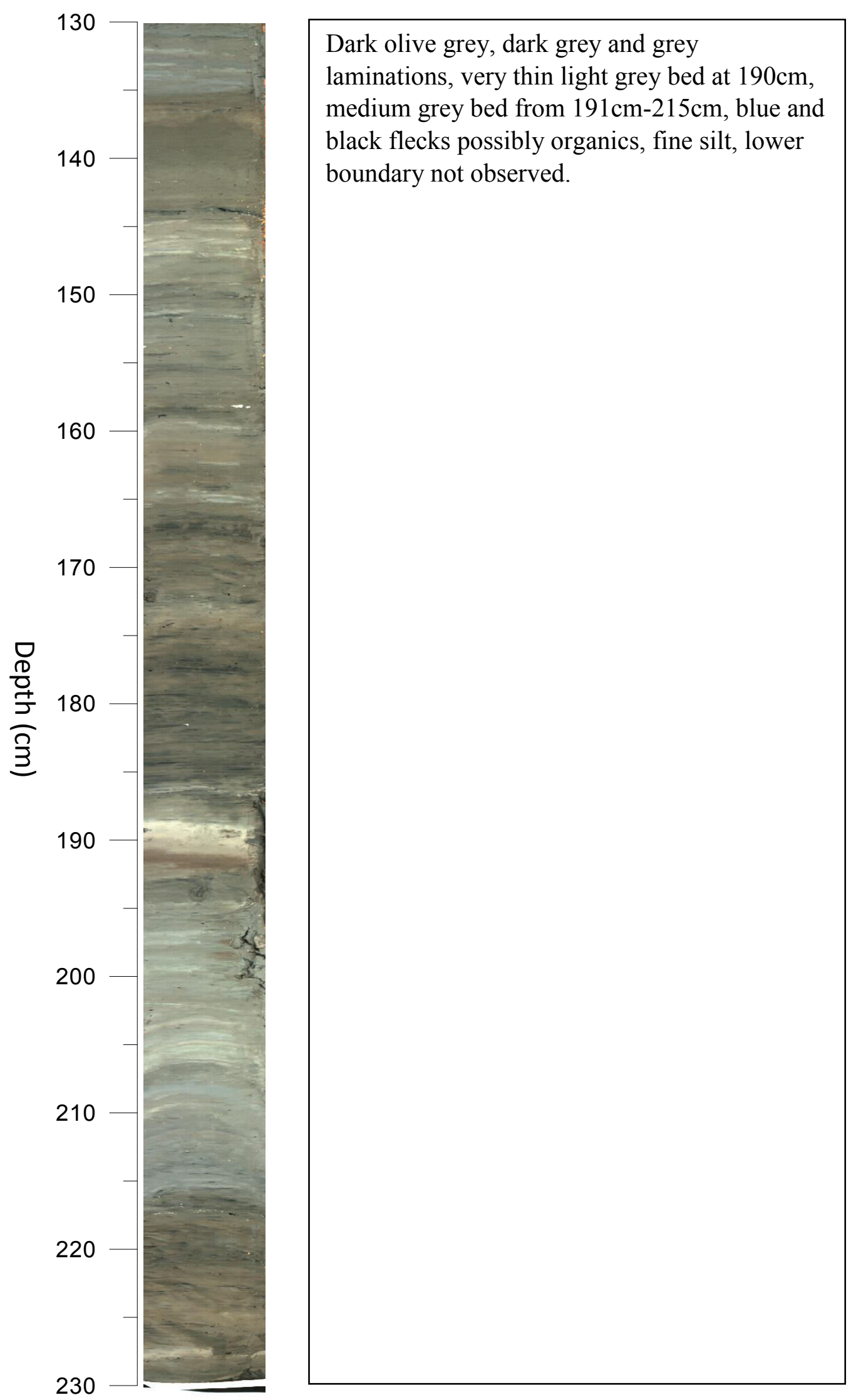




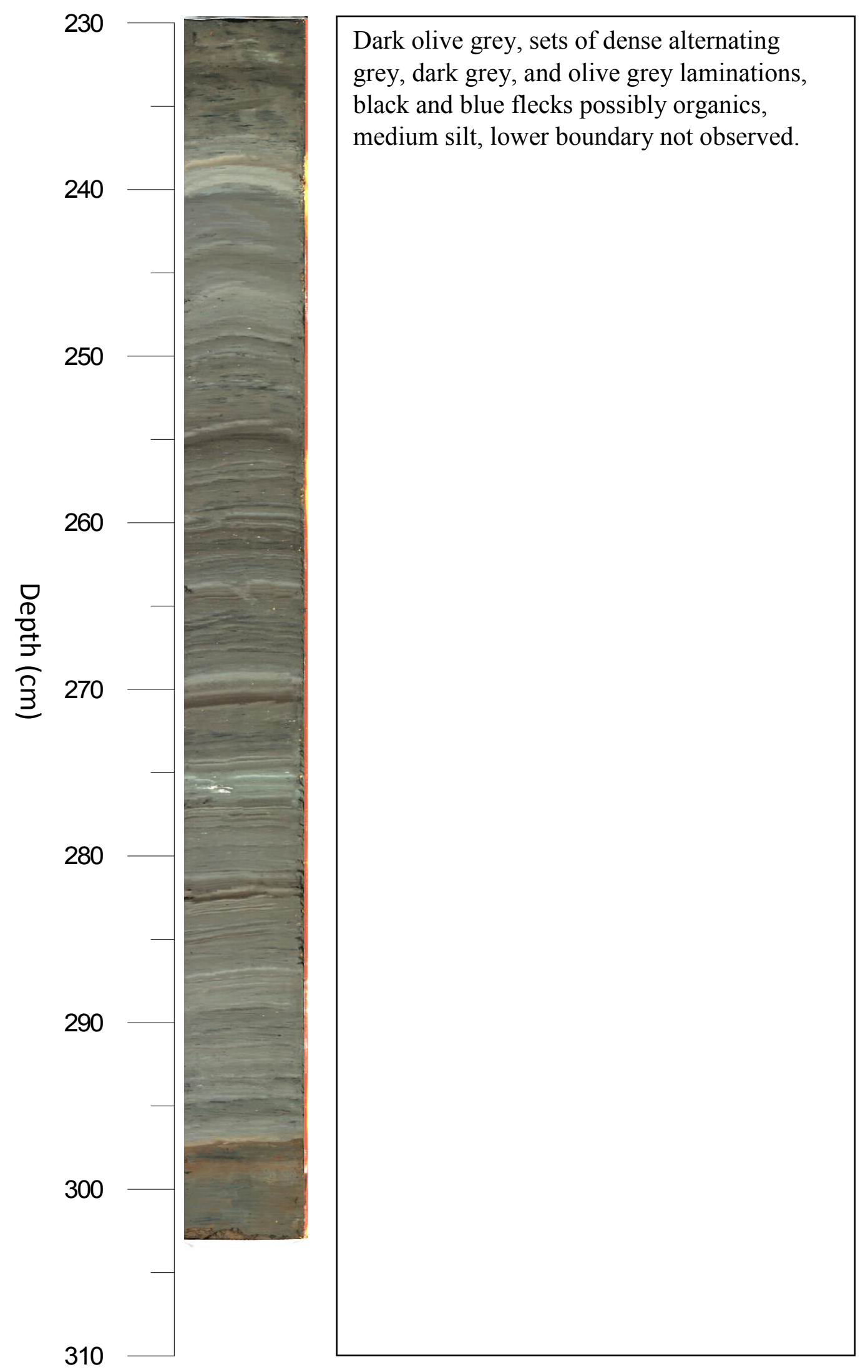




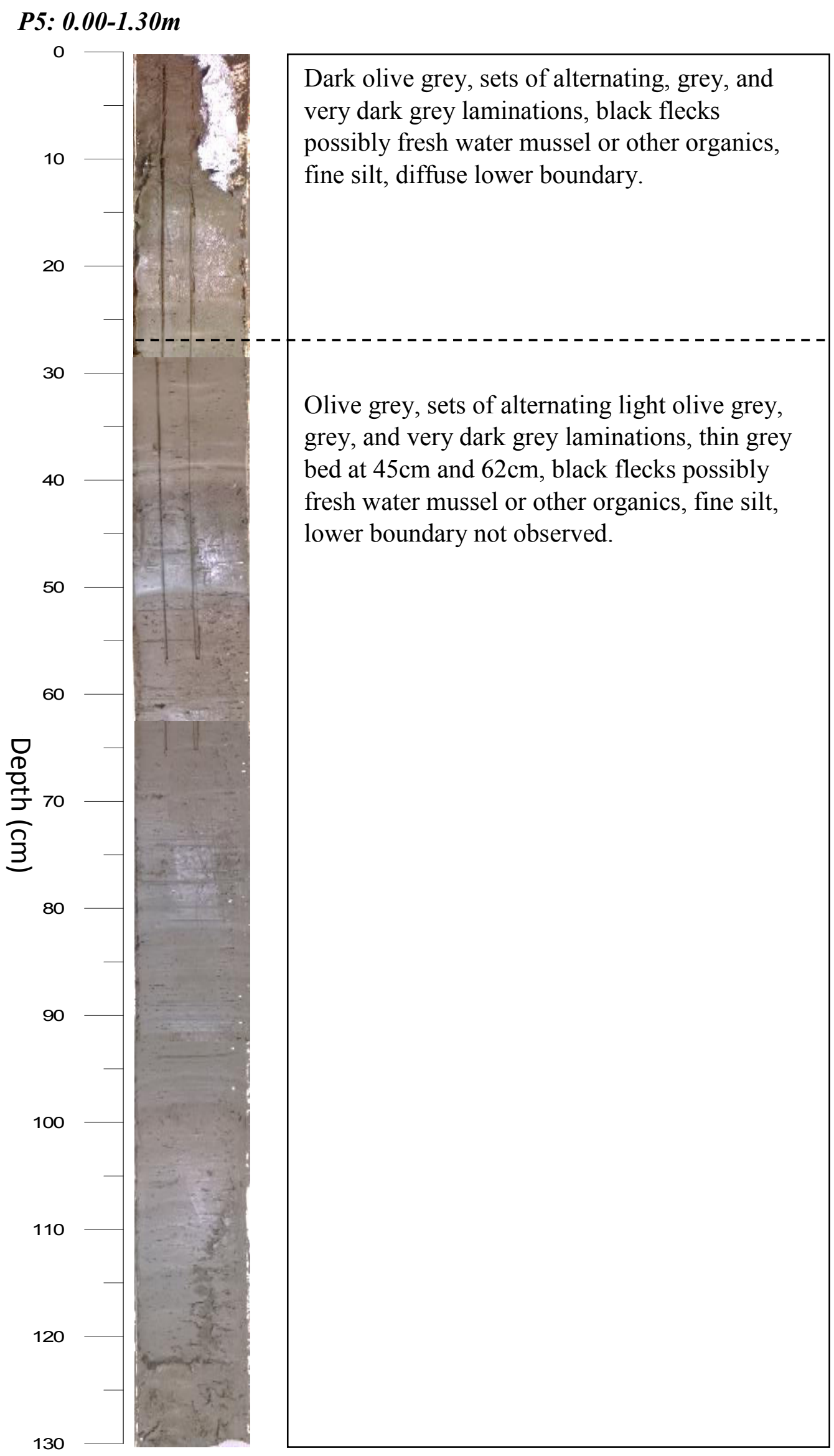



